\title{
UC-NRLF
}

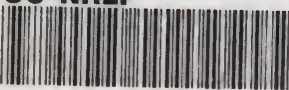

क $3 \quad 34 \quad 718$

\section{WVE ITORSEWOMAN}




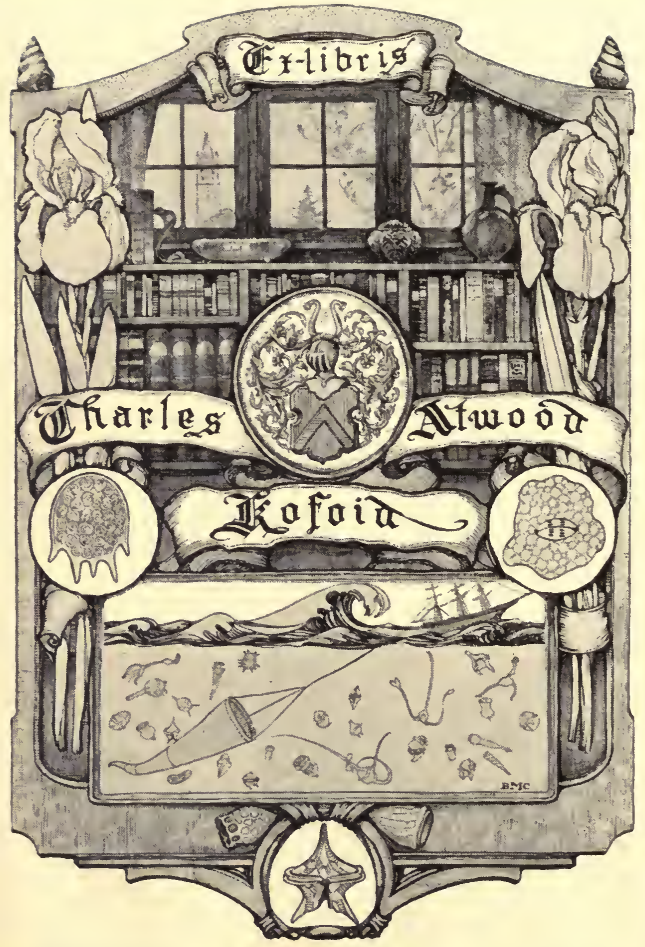




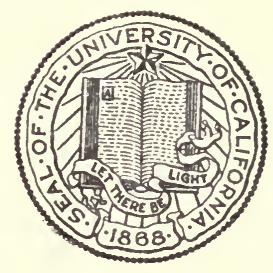

\title{
THE LIBRARY OF
}

\section{THE UNIVERSITY OF CALIFORNIA}

\author{
PRESENTED BY \\ PROF. CHARLES A. KOFOID AND \\ MRS. PRUDENCE W. KOFOID
}




$$
n^{2}-\omega^{k}
$$




\section{THE \\ HORSEWOMAN}






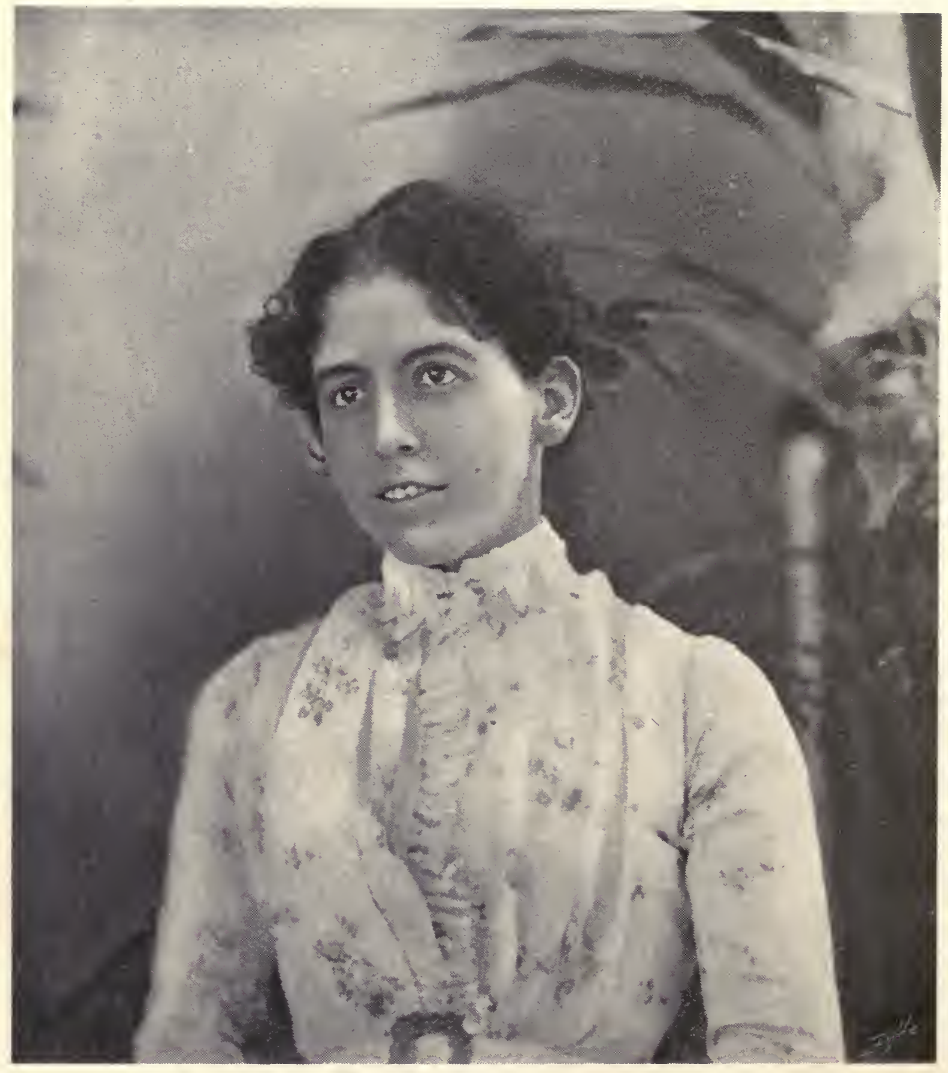

$$
\text { Alice In. Trayes }
$$




\section{THE HORSEWOMAN}

A Practical Guide to Side-Saddle Riding

BY

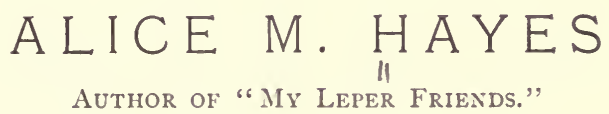

EDITED BY

M. HORACE HAYES, F.R.C.V.S.

(Late Captain "The Buff")

AUTHOR OF

"Points of the Horse," “Veterinary Notes for Horse-Owners," "Riding aNd Hunting," etc.

Second Edition, revised, enlarged and 133 photographic illustrations added.

LONDON

HURST AND BLACKETT, LIMITED

I3 GREAT MARLBOROUGH STREET

1903

All rights reserved 
PRINTED BY KELLY'S DIRECTORIES LTD., I.ONDON AND KINGSTON. 


\section{$S^{\prime} F 309$ \\ $1+29$ \\ 1903}

PREFACE.

THE first edition of this book was the result of seven years' experience of riding hundreds of horses in India, Ceylon, Egypt, China and South Africa; the most trying animals being those of which I was the rough-rider at my husband's horse-breaking classes. Since that edition came out, I have hunted a good deal, chiefly, in Leicestershire and Cheshire, and have taught many pupils, both of which experiences were of special advantage to me in preparing this new edition; because English ladies regard riding, principally, from a hunting point of view, and the best way to supplement one's education, is to try to teach.

The directions about side-saddles and seat are the outcome of practical work and fortunate opportunities; and I hope they will be as useful to my readers as they have been to my pupils. Although I have ridden, when abroad, some of the worst buckjumpers that could be found in any country, I have never "cut a voluntary," thanks to the adoption of a seat and saddle which gave the necessary grip. Of course I have had "purls," when horses have "come down" with me out hunting; and on one occasion 
in China, when a horse which I mounted for the first time, reared and came over.

I have taken Figs. 32 to 5I, 7I to 78 and Fig. 90 from Riding and Hunting, and Figs. 147 and 148 from Points of the Horse. My husband has written Chapter XXII.

I have omitted the chapter on my Riding Experiences, as I thought it out of place in a purely teaching book.

Knowing the immense value of photographs in explaining technical subjects, I have gladly availed myself of the expert help of my husband and son in that form of illustration.

I am greatly obliged to Miss Harding, Miss Burnaby, Miss Neil, the Rev. G. Broke, the Rev. R. J. Gornall, Mr. Clarence Hailey of Newmarket, the Editor of Country Life and the Editor of The Queen, for the admirable photographs and blocks they most kindly lent me. I regret that I inadvertently omitted to place the names of $\mathrm{Mr}$. Clarence Hailey and the Gresham Studio, Adelaide, South Australia, under the excellent photographs which are respectively reproduced in Figs. 2 and 3.

This edition is practically a new book.

Yew Tree House,

Crick, Rugby, $25^{\text {th } M a r c h,}$ I903. 


\section{O N T E N T S.}

CHAPTER I.

Beginning to Ride.

CHAPTER II.

HORSES FOR LADIES.

CHAPTER III.

\section{Side-SADDLES}

CHAPTER IV.

BRIDLES

Riding DREsS .

CHAPTER V.

\section{- CHAPTER VI.}

Mounting And Dismounting .

CHAPTER VII.

How to Hold the Reins

CHAPTER VIII.

The Seat .

CHAPTER IX.

Hands, Voice, Whip and Spur

CHAPTER X.

First Lessons in Riding 
CHAPTER XIII.

Riding without Reins . . . . . . 233 to 243

CHAPTER XIV.

NeRVE . . . . . . . . . 244 to 247

CHAPTER XV.

Fences, Country and Gates . . . . . 248 to 303

CHAPTER XVI.

HunTing .

CHAPTER XVII.

Riding And Hunting Abroad. . . . . 38r to 393

CHAPTER XVIII.

Walking Foxhound Puppies . . . . . 394 to $4 \mathrm{I} 3$

CHAPTER XIX.

KindNESS TO HoRses

CHAPTER XX.

Cross-Saddle Riding for Ladies . . . . 426 to 430

CHAPTER XXI.

Riding Difficult Horses

43 I to 464

CHAPTER XXII.

Names of External Parts of the Horse . . 465 to 473 


\section{I S T OF I L L USTRATIONS.}

Frontispiece.--Alice M. Hayes.

FIG.

PAGE

I. Man riding a horse over a fence in a side-saddle . 3

2. Miss Burnaby's Butterfly . . . . . . 9

3. Miss Neil's Jackeroo . . . . . . . I I

4. Mr. Vansittart's Romance . . . . . . . . $I_{3}$

5. Irish mare, Salary . . . . . . .

6. Polo pony, Pat . . . . . . . . .

7. Arab pony, Freddie . . . . . . . . . 19

8. Side view of saddle tree . . . . . . 26

9. Underneath view of saddle tree . . . . . 27

ro. Front view of saddle tree . . . . . . 29

I r. Underneath view of saddle tree and its webs . . $3^{\text {I }}$

I 2. Grip with improved leaping head , . . . 35

I3. $\quad$ ordinary $\quad, \quad$. . . . $\quad . \quad 37$

14. Hook for stirrup leather . . . . . . 39

15. Leaping head too low down . . . . 40

r6. Side view of a properly made saddle . . . . 4 I

I 7. Champion and Wilton's extra stirrup case . . . 43

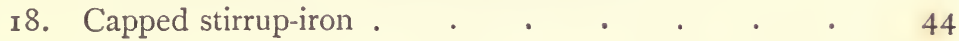

I9. Slipper stirrup . . . . . . . . 44

20. The Christie stirrup . . . . . . . 44

2r. Foot caught . . $\quad . \quad$. $\quad . \quad$. 45

22. Latchford stirrup . . . . . . . 46

23. Scott's stirrup . . . . . . . . 46

24. $"$ " open . . . . . . . . . . 47

25. Cope's stirrup . . . . . . . . 48 
FIG.

26. Foot released by Cope's stirrup . . . . . 49

27. Scott's stirrup . . . . . . . . 50

28. Foot caught on off side . . . . . . 5 I

29. Child mounted. . . . . . . . . 6I

30. Child jumping without reins . . . . . 63

3r. Foot caught, on account of its having been put into the stirrup from the wrong side.

32. "Head" of a single bridle : $a$, crown-piece; $b, b$, cheek-pieces ; $c$, throat-latch ; $d$, front or brow-band

33. Unjointed snaffle

34. Chain snaffle . . . . . . . . 72

35. Ordinary snaffle with cheeks . . , . . 72

36. Nutcracker action of jointed snaffle on horse's mouth 73

37. Action of unjointed snaffle on horse's mouth . . 73

38. Action of a curb as a lever . . . . . 73

39. Properly constructed curb for ordinary hunter. Side view.

40. Ward Union curb bridle with half-moon snaffle . $\quad 75$

41. Curb chain covered with india-rubber tube . . 76

42. Chin-strap unbuckled . . . . . . 76

43. Chin-strap buckled . . . . . . . 76

44. Curb reversed by horse throwing up his head, in the absence of a chin-strap . . . . . 77

45. Cavasson nose-band . . . . . . . . $\quad$. 79

46. Standing martingale attached to rings of the snaffle . 80

47. Lord Lonsdale's registered running martingale . . $8 \mathrm{r}$

48. Maximum length of standing martingale . . . 83

49. Side view of horse's lower jaw . . . . . 85

50. Angle made by the cheeks of a curb, when the reins are taken up . . . . . . . . . . . 86

5I. View of under-surface of lower jaw . . . . 87

52. The Hayes' Safety Skirt open for mounting . . 9I

53. Off side of the Hayes' Safety Skirt • • • • 93

54. The Hayes' Safety Skirt closed for walking . • 95 
FIG.

PAGE

55. Apron skirt open for mounting . . . . . . 97

56. The apron skirt closed for walking . . . . . 99

57. Riding dress for child . . . . . . IOI

58. Loose riding coat, too long . . . . . 103

59. Front view of good riding coat . . . . . 105

6. Back view of good riding coat . . . . . 507

6r. Terai hat and Norfolk jacket . . . . . rog

62. Pith hat and drill jacket . . . . . . Iо9

63. Good driving coat . . . . . . . I I I

64. Top of boot catching on safety bar, flap . . . I I

65. Front view of riding under-bodice . . . . 12 I

66. Back view of riding under-bodice . . . . 123

67. Foot raised for mounting . . . . 127

68 Ready to mount . . . . . . . . 129

69. Dismounting without help . . . . . 133

70., with help . . . . . 135

7 I. A rein in each hand . . . . . . . 137

72. Single reins crossed in one hand . . . 138

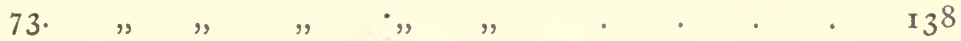

74. Double reins held separately in two hands . . 139

75 Holding double reins crossed in one hand . . 140

76. Double reins in left hand: one crossed, the other hooked up on middle finger. . . . . ' I4I

77. Reins held in one hand in military fashion . $\quad \mathbf{I}_{42}$

78. Off rein taken up by right hand from position shown in Fig 77 . $\quad . \quad$. $\quad . \quad$. $\quad . \quad$. 143

79. Position of rider's legs at the walk . : . . 147

8o. Hooked back leg, the direction of the pressure of which is shown by the fore finger of the left hand .

8r. Seat at the walk . . . . . . . $\mathrm{I}_{53}$

82. Length of stirrup . . . . . . . $\mathrm{I} 55$

83. Correct position of legs . . . . . . . $\quad$ I 57

84. Leaning back . . . . . . . 158

8.5. Hunting whip . . . . . . . . $\quad$ I 7 I 
FIG.

86. Thong properly put on . . . . . . . 173

87. $, \quad, \quad$, . . . . . . . $\quad$ I73

88.,$\quad$ incorrectly put on . . . . . . $\quad$ r 75

89. $"$ not quite right . . . . . . . 175

90. A practical bullfinch . . . . . . $\quad$ I77

9r. Spur-carrying whip used for high school riding . . I8r

92. Thorough-bred mare at a walk . . . . . 187

93. Preparing to rise at the trot, with stirrup at correct length . . . . . . . . . r I I

94. Rising at the trot, with stirrup at correct length . . $\quad$ r93

95. Preparing to rise at the trot, with stirrup too long . $\quad$ I 95

96. Rising at the trot, with stirrup too long . . . $\quad$ I97

97. Canter, with right leg hooked back, and stirrup too long $\quad$ I99

98. Good seat at canter or gallop . . . . . 201

99. $" \quad, \quad, \quad$ " . . . . . . . 203

ro०. " " " . . . . . . . 205

ıо . Bad seat; right leg hooked back, stirrup too long, and foot "home" . . . . . . . 207

I02. Miss Emmie Harding jumping wire . . . . 2 II

103. Maximum amount of pressure on leaping head .. . 2 I 3

ro4. Position of legs in jumping . . . . 2 I 5

105. Driving horse over jumps . . . . . . 235

ı०6. A cut-and-laid fence . . . . . . $25 \mathrm{I}$

r०7. " " " during construction . . . 253

ro8. A stake and bound fence . . . . . . 255

ro9. Post and rails to close gap in hedge . . . . 257

I I0. Posts and rails . . . . . . . . 259

III. $", "$, with ditch . . . . . 26 r

I 2. Midland stile . . . . . . . 263

II3. An oxer . . . . . . . . . ${ }_{26}$

II 4. Wire in front of bullfinch . . . . . . ${ }_{267}$

II5 Galway bank . . . . . . . . 27 I

Ir6. Side view of bank shown in Fig. 115 . . . 273

II7. Galway bank . . . . . . . . 275 
FIG.

PAGE

I 18. "Cope and dash" wall . . . . . . 277

Ir9. Loose stone wall . . . . . . . 279

r20. Low bank with ditch on both sides . . . . 28 I

I 2 I. View of country between Yelvertoft and Crick . . $\quad{ }_{28}$

122. Grass on each side of the road . . . . . 285

I23. Ordinary five-barred gate . $\quad$ • . . . $\quad 289$

I24. Bridle gate . . . . . . . . 29 r

I25. Gate with wooden latch . . . . . . 293

I 26. ", , spring , which has to be drawn back . 295

r27. , , , , , , , , , pushed forward 297

r28. Double gate . • . • • • • . 299

129. A puzzle in gate-opening . . . . . . 30 I

I30. Ridge and furrow . . . . . . . 317

r 3 . , , , . . . . $\quad 3^{2 r}$

132. Haystack and gate . . . . . . 329

133. Brook . . . . . . . . 337

134. Pollard willows in the next field . . . . 339

35. The Cottesmore drawing a covert . . . . 355

136. Wire board . . . . . . . 359

137. Red flag . . . . . . . . . 363

138. "Ware wire" . . . . . . . . . . . 365

139. Iron hurdle. . . . . . . . 367

I40. Wire on top of gate . . . . . . . 369

I4 r. Pytchley puppy, Mottley . . . . . . 40 I

142. Front view of kennel coat . . . . . 403

143. Back view of kennel coat . . . . . . 405

144. Puppies with bicycle . . . . . 407

145. Pytchley puppy, Monarch . . . . . 409

r46. Riding mountain zebra . • . • . . 457

I47. External parts of horse . . . . ' . . 467

148. Measurements of horse . . . . . . 471 



\title{
THE HORSEWOMAN.
}

\author{
$\rightarrow$ \\ CHAPTER I. \\ BEGINNING TO RIDE.
}

Instruction based on experience assists us in the attainment of all arts, and hastens the process of learning. Although a specially.gifted individual who has not been taught, may be able to sing in a pleasing style, no one has ever become an accomplished pianist without competent instruction; the former being somewhat in the position of a man, the latter in that of a lady, as regards riding. In all countries we find good untaught horsemen who have got "shaken into their seats" by constant practice, with or without a saddle, which in most cases is chiefly a protection to the animal's back. A side-saddle, on the contrary, is as artificial a production as a musical instrument, and a full knowledge of its peculiarities often cannot be acquired during a lifetime. Here the great difference between men and women is that the former ride the horse ; the latter, the saddle. The tyranny of the side- 
saddle would not be so marked as it is, if this article of gear were of a uniform pattern of the best possible kind. Unfortunately it is generally built according to the fantastic ideas of fashionable makers who have no practical experience of side-saddle riding. Unaided learners have such difficulty in acquiring security and grace of seat and good hands, that many ladies who have ridden all their lives, and have lots of pluck, are poor performers, particularly in the huntingfield. A beginner who is put on a properly made saddle and suitable horse, and is taught the right principles of riding, will make more progress in a month than, she would otherwise do in, say, five years. The artificiality of side-saddle riding extends even to the horse, which must be free from certain faults, such as unsteadiness in mounting, that would not render him unsuitable to carry a male rider.

Competency in the instructor is of the first importance. Nothing is more absurd than for a man who cannot ride well in a side-saddle, to try to unfold to a lady the mysteries of seat. Such men, instead of getting into a side-saddle and showing their pupils "how to do it," generally attempt to conceal their ignorance by the use of stock phrases. If asked "Why?" they invariably reply, "Because it's the right thing to do," or words to that effect. I have never heard of women venturing to teach men how to ride.

Davis, a young groom we had, was a rare instance of a man who was thoroughly competent to teach 
ladies how to ride, because he had lots of practice in side saddles, and had ample opportunities of learning the theory of the art, while I was teaching pupils in a riding school, where I rode and jumped horses without a skirt. Fig. I shows Davis riding in a side saddle over a gate, on my grey horse Gustave. The

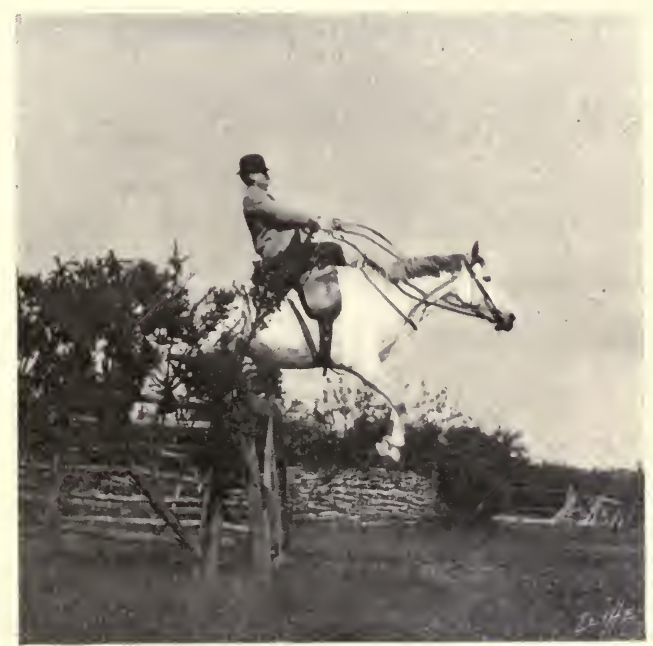

Fig. 1.-Man riding a horse over a fence in a side-saddle.

fact of his not hanging on to the horse's head is a good proof that he had a strong seat.

The first lessons in balance and grip should be given by a competent horsewoman, and the ridingskirt should either be taken off or pinned back (for instance, with a safety-pin), in order that the lady instructor may be able to see and at once correct faults in the position of the legs, which is hardly a task fit for a man, even were he competent to per- 
form it. After the pupil has acquired a good seat at the various paces and over small fences, her further education in the guidance and control of her mount might be entrusted to a competent horseman, preferably to a good cross-country rider, and not, as is frequently the case, to an ex-military riding-master, who, having been taught that a cavalryman's right hand has to be occupied with a sword or lance, considers that ladies should 'also adopt the one-handed system of riding! As a rule, the services of a good horseman are desirable when the pupil is fit to ride in the open, because he is more helpful than a lady rider in rendering prompt assistance on an emergency. Besides, riding men usually know more about the bitting and handling of horses than women, and are therefore better able to impart instruction in this branch of equitation.

It is as impossible to lay down a hard-and-fast rule as to the age at which a girl may be allowed to mount a pony or donkey, as it is to control the spirits and daring of a foxhound puppy. Those who possess the sporting instinct and the desire to emulate the example of their hunting parents or friends, should certainly be encouraged and taught to ride as soon as they manifest their wish to do so. Many hunting women allow their children to occasionally attend meets in a governess car or other suitable conveyance, and the budding sportsmen and sportswomen in the vehicle keenly follow the hounds, as far as they can do so, by the roads. On non-hunting days during the season, it 
is no uncommon sight in hunting districts to see ladies walking by the side of their tiny daughters who are mounted on ponies, and giving them instruction in riding. In cub-hunting time we may often see the good results of such lessons, when parent and daughter appear together, and the little girl on her pony follows the lead over small fences which "mother" knows can be negotiated by both with safety.

Twenty years ago, infants were often carried in panniers or baskets, one on each side of a led pony or donkey, with the supposed object of initiating them to horse exercise. The pannier training was followed by the little girls being placed on a pilch, and conducted about by a mounted groom with a leading-rein. This leading-rein system is absolutely worthless as a means for teaching horse-control to children, and should be used only as a safeguard with an animal which the young rider may be unable to hold.

At whatever age a child is taught to ride, we should bear in mind that the exercise always entails a certain amount of fatigue, and should be taken in moderation. The many lamentable accidents which have occurred to young girls from being "dragged," show the vital necessity of supplying the small horsewoman with the most reliable safety appliances in saddlery and dress. The parent or guardian often overlooks this allimportant point, and devotes his or her entire attention to securing a quiet animal.

Girls who do not possess any aptitude or desire to 
ride should not be compelled to practise this art, for, apart from the cruelty of subjecting a highly nervous girl to the torture of riding lessons, such unwilling pupils never become accomplished horsewomen. In the same way, a child who has no ear for music, and who is forced against her wish to learn the piano, never develops into a good player.

The same remark applies to older ladies, who, with the usual angelic resignation of my sex, try their best to obey the command of their lords and masters by learning to ride. I fear that success in this art is seldom attained by ladies over thirty years of age, for by that time they have generally lost the dashing pluck of their youth; their figures have become set and matronly; and, as a rule, they find great difficulty in mastering the subtleties of balance and grip. Also, a state of nervous anxiety is apt to add to the general stiffness of their appearance, and to suggest discomfort and irritability.

We read from time to time alarming rumours of "spinal curvature" as a result of side-saddle riding, but I have never known a case of this to occur, either to old or young, although the near-side position of the leaping-head has a tendency to develop the muscles of the left leg more than those of the right leg, a fact which I discovered as soon as I began to ride a bicycle, after having had many years' experience on horses. Riding alternately on a saddle with the leaping-head on the near side and on one with the leaping-head on the off side, would help 
to save the back and legs of a lady's horse. In cantering or galloping, the animal puts more weight on the leading fore leg, which is consequently more liable to suffer from the injurious effects of work than the non-leading leg; and, as we all know, to canter or gallop comfortably, a lady's horse has to lead with his off fore when the leaping-head is on the near side; and vice versâ. Also, the vulnerable side of the back and withers of an animal which carries a sidesaddle, is the one which is opposite to that on which the leaping-head is fixed. I am afraid that these practical considerations would not outweigh the dictates of fashion and the expense of having two saddles for one horse. The Young Lady's Equestrian Manual, which was published in ${ }_{1} 838$, tells us that in the early part of the last century, a plan which was similar to the one in question was adopted of having movable crutches, "in order to afford a lady, by merely changing their relative positions, the means of riding, as she might please, on either side of her horse," and that this change of crutches was found advantageous. I do not think that a side-saddle built on this principle would look neat enough for modern requirements. 


\section{CHAPTER II. \\ HORSES FOR LADIES.}

A IIUNTER suitable for a lady should be temperate, sound, strong, safe and clever over fences, and fast enough for his country. As extra fatigue is entailed on a lady's mount by the side position of his rider, he should be quite-2 I lbs. above the weight he has to carry. As a rule, he should not be younger than seven, and should have had, at least, two seasons' hunting in which to learn his business. Fig. 2 shows us a typical high-class Leicestershire hunter; and Fig. 3, a good Australian hunter.

Mr. Vansittart's Romance (Fig. 4) was one. of the nicest of the many Australian horses I rode, during my sojourns in India, between the years 1885 and I89I. He was thoroughbred and was the winner of several races on the flat and across country. In those days, the idiotic custom of docking horses had not found favour in Australia.

The requirements of the various hunting countries differ greatly. For the Shires, a lady would want a well-bred galloper which can "spread himself out" 
over his fences, because there is almost always a ditch or a rail on one side or the other of the Midland hedges. Temperate he must be, because the fields in Leicester-

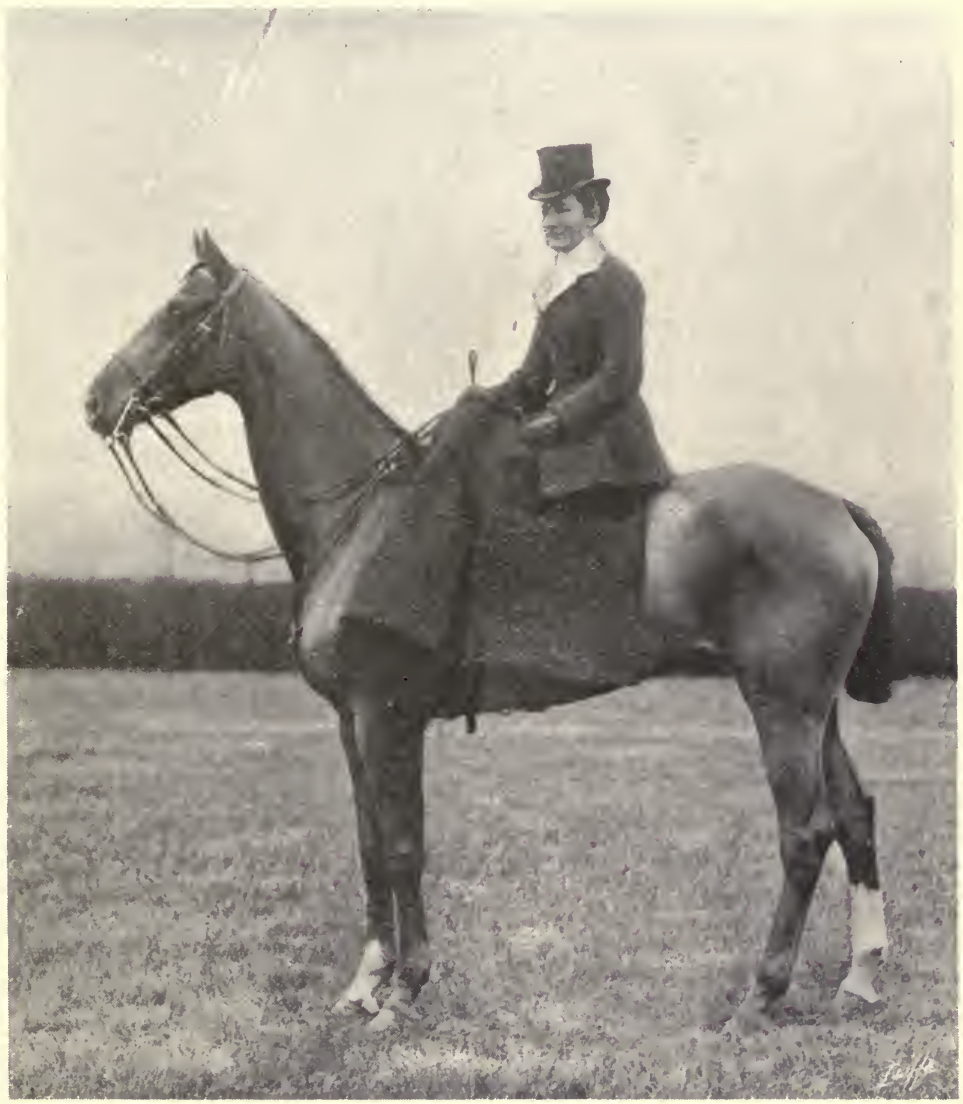

Fig. 2.-Miss Burnaby's Butterfly.

shire, for instance, are so large that there is often a crowd of riders waiting their turn at the only practicable place in a jump, filing through a gate, or waiting 
en masse in a cramped space at the covert side, and a horse who displays temper on such occasions is naturally regarded as a nuisance and danger by the rest of the field. Besides, it must be remembered that nothing tends to spoil the nerves of any rider, man or woman, more than attempting to hunt in a big country like Leicestershire on a bad-tempered horse, and especially on a refuser which has a tendency to rear. On no account should a lady ride a roarer, although the artful dealer may assure her that the "whistle" which the animal makes, will be a secret unknown to any one except herself and the horse. In the large majority of cases, roaring is a disease which increases with time, and the accompanying noise is distressing to all lovers of horses who hear it. Kickers, even with red bows on their tails, should on no account be ridden; for they are a danger to man, woman, horse, and hound, and are the cause of many accidents every hunting season. It would appear that ladies-not those of the present day, let us hope-were not sufficiently careful in insisting on this last-mentioned requirement in their hunters; for Captain Elmhirst, writing in $\mathbf{1} 88_{3}$, says, "Horse dealers, farmers, andwe are sorry to add-ladies must especially be avoided; for who ever saw a vicious kicker that was not ridden by one of these three?"

Apart from the danger to others, it is obvious that no sane woman would ride a horse which would be likely to kick her in the event of a fall. When I was in India, I had to get rid of a horse because of his 
vicious tendency in this respect. He was a goodlooking Australian, a clever fencer, and had a nice mouth, but so vicious that when we first got him, he

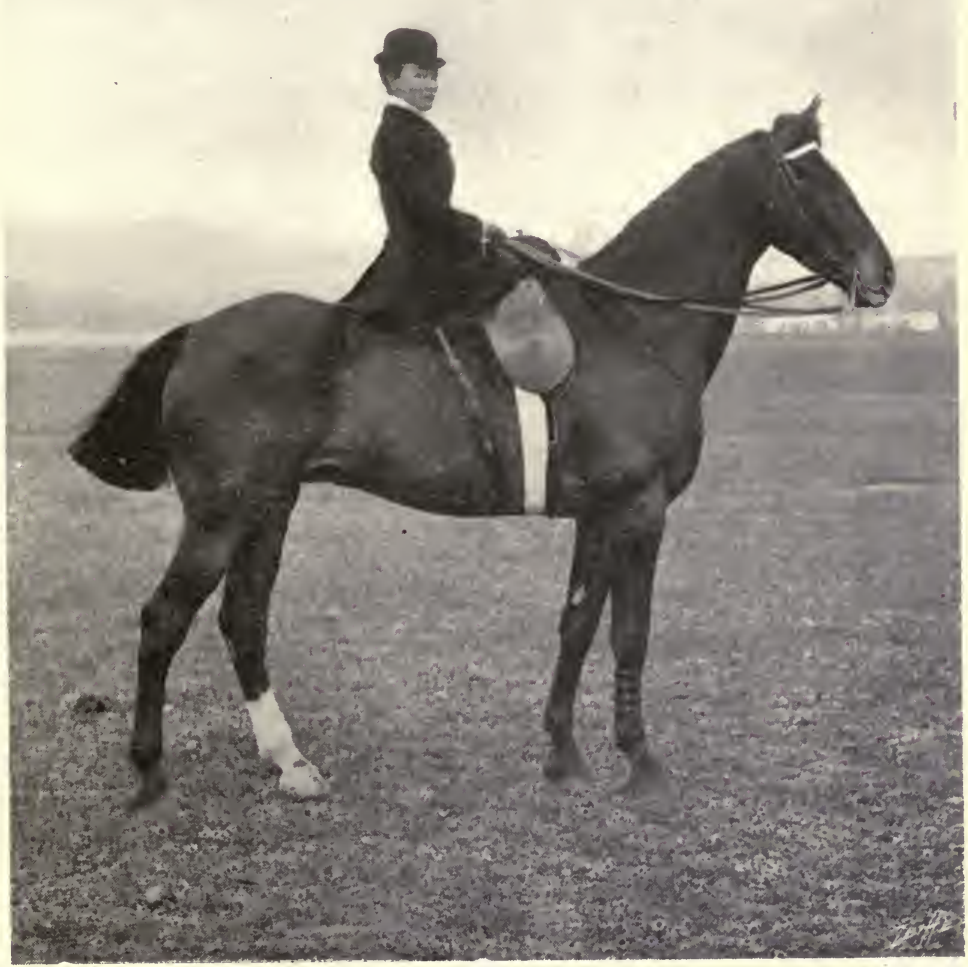

Fig. 3.-Miss Neil's Jackeroo.

used to rush open-mouthed at any one who went near him, except his syce. My husband took him in hand, and he became sufficiently civilised to take carrots 
from me. When I rode him, I found he was always looking out for an excuse to "play up," or to lash out at other horses. In order to test his jumping, a lightweight gentleman rider one day rode him over a made course. The animal blundered badly at one of the fences, threw his rider, and while the man was lying on his back on the ground the horse deliberately put a fore foot on him, and would have doubtless broken his back, if my husband, who was standing near the fence, had not pulled the vicious brute off. We got rid of him, and I heard shortly afterwards that he had killed his jockey, a native, in a hurdle race at Calcutta, by the adoption of similar vicious tactics. It would have been criminâl to have taken such a horse as that into any hunting-field.

A hunter should have good shoulders (long, flat, and oblique) and a comparatively high forehand; for horses which are lower in front than at the croup are uncomfortable to ride, and there is generally some difficulty in retaining the side saddle in its place on their backs. The height of a hunter will depend greatly on that of his rider. For instance, a tail woman with a "comfortable" figure would be suitably mounted on a horse 16 hands or more high, whereas a light girl of medium height would find an animal of say $\mathrm{I}^{-2}$ as much as she could comfortably manage; for we must remember that big horses, as a rule, take a good deal of "collecting." A small horse generally stays better, can come out oftener, is handier, and not so likely to hurt one if he falls. For the Shires I do 
not think a lady's hunter should be much under I 5-2, and he must be a big jumper and well bred. Hunting women, as a rule, do not pay much attention to the good looks of their horses, for hunting is not a church

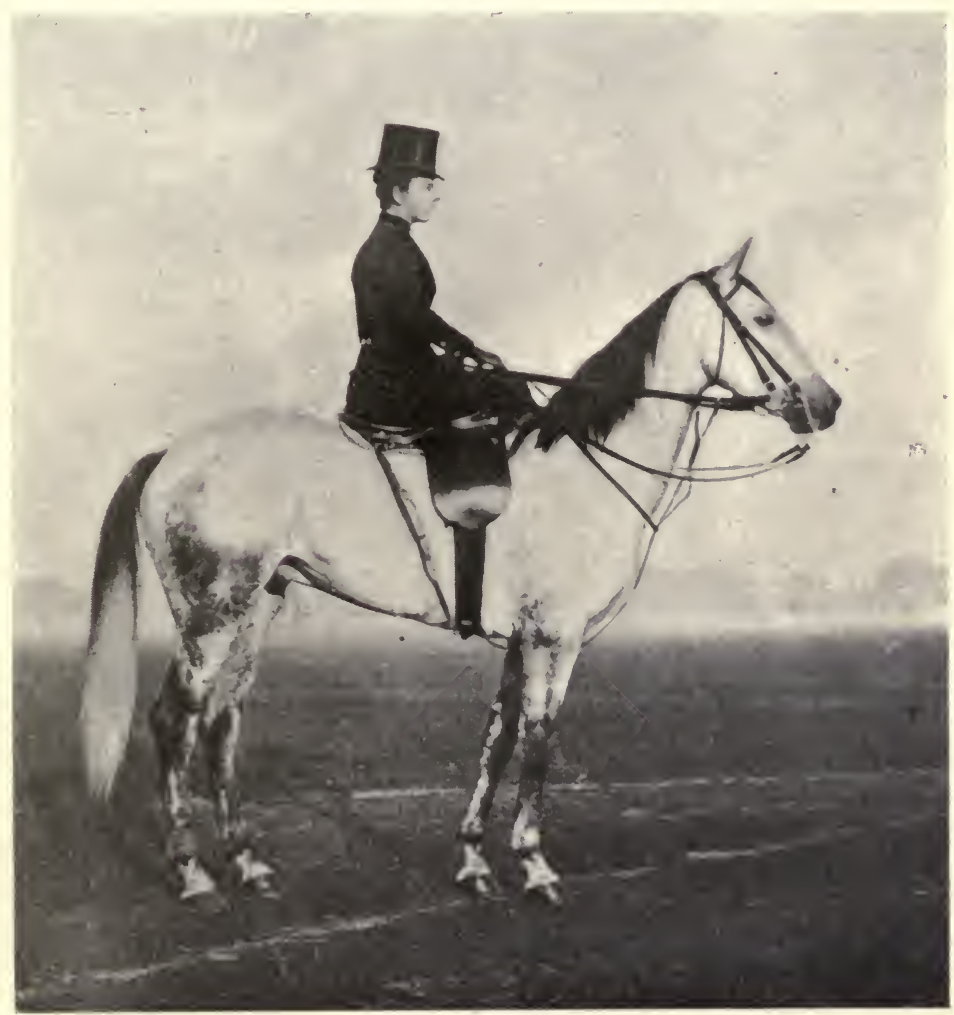

Fig. 4.-Mr. Vansittart's Romance.

parade, and the finest performer over a country is always admired and coveted whatever his appearance may be. The same may be said about colour; although, as a grey horse is conspicuous enough to be 
singled out of a crowd of bays and browns, a lady who is at all "impartial" in her seat would do well to select a horse wearing a less noticeable tint of coat. As rearing is the worst vice a lady's mount can possess, no horse who has a tendency to rear should be ridden by a woman, as from her position in the side-saddle she is far more helpless than a man on such an animal. A lady's hunter should not have too light a mouth, but should go nicely up to his bridle, and not resent the use of the curb, which is sometimes necessary in avoiding danger. He should on no account be inclined to pull. A perfect hunter is like a thorough good sportsman, who regards his share of bangs and blows as all in the day's work. As the majority of hunters have their own likes and dislikes about jumping certain kinds of fences, a lady should know precisely what to expect from her mount and what his jumping capabilities are, before taking. him into the hunting-field, which is not the place for experiments. I had many pleasant days out hunting with the Quorn, Belvoir, Cottesmore, and North Cheshire on the Irish mare, Salary (Fig. 5).

In summing up the requirements of a hunter for either man or woman; I cannot do better than to quote the following sound advice from Whyte Melville: "People talk about size and shape, shoulders, quarters, blood, bone and muscle, but for my part, give me a hunter with brains. He has to take care of the biggest fool of the two, and think for both." 
To be capable of safely crossing a stiff country, a horse requires at least a few falls-which had best be shared by a man-and much experience, which cannot

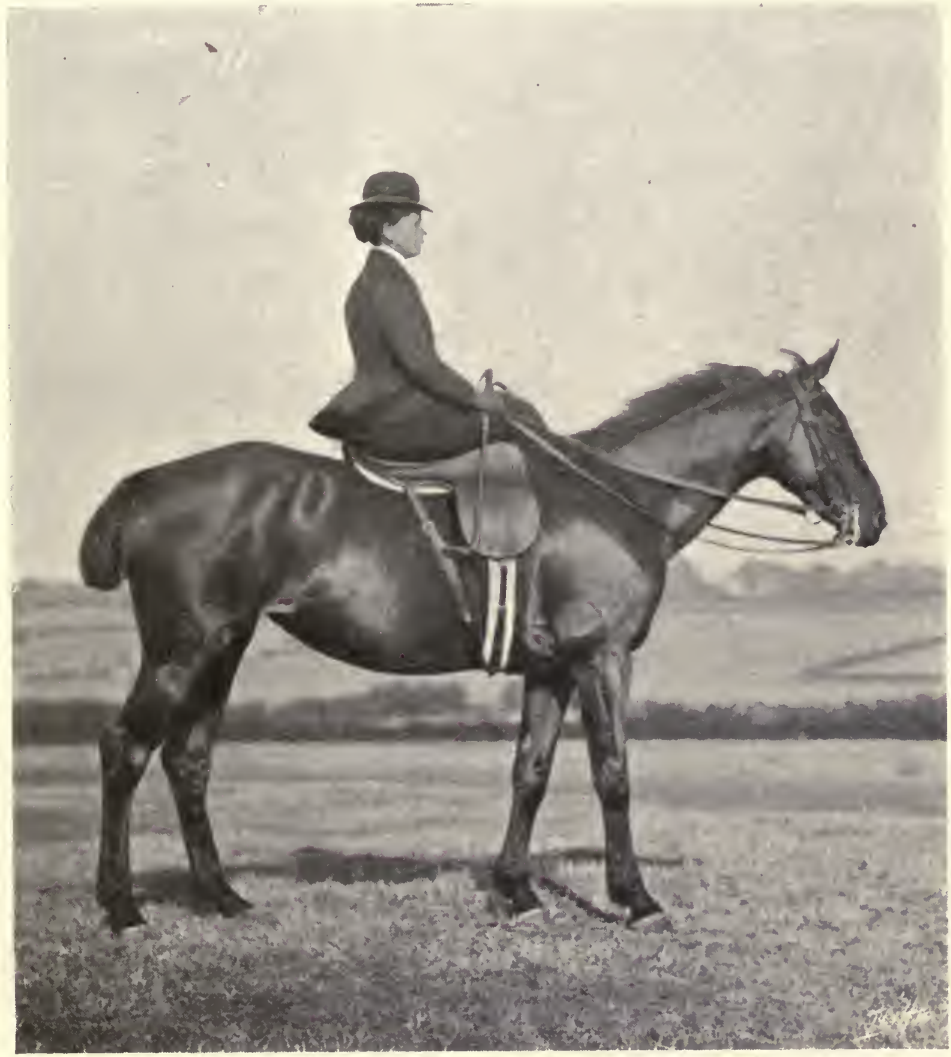

Fig. 5.-Irish mare, Salary.

be obtained without time. Hence, I would advise no lady, however well she may ride, to hunt on a young horse, who will always require a good deal of time in which to learn his business. It is certainly no pleasure 
to be on the back of a horse who is inclined to drop his hind legs in the ditch on the other side, or to "chance" a post and rails. Many young horses are so reluctant in going at a fence, and in "spreading themselves out," that they are no good except when ridden by a man who can use his legs, which is a feat that a woman is unable to accomplish.

A perfect hack, whether for man or woman, is far more difficult to find at the present time than a good hunter, and when found will command a fancy price. The ideal hack is a showy, well-bred animal of the officer's charger type, which has been thoroughly well "made" in all his paces. Such an animal appears at his best when executing a slow, collected canter, with arched neck and looking full of fire and gaiety, though ridden with an almost slack rein, and intent only on rendering prompt obedience to the slightest indication of his rider. In Germany and France the hacks ridden in the Tiergarten and Bois, for instance, are thoroughly " made," and compare very favourably with the pulling, half-broken brutes on which many ladies appear in the Row. In former times, before the introduction of the leaping-head made hunting possible for women, more attention was paid to the breaking and training of hacks than at present, on account of the great demand for "complete ladies' horses." The advent of the bicycle for ladies has almost abolished hacking as a pastime and means of exercise, and hence the difficulty in finding a well-broken animal for this work. The best substitute is, I think, a good polo pony, because 
the requirements of that game demand that the animal should be temperate, handy, and capable of being ridden with a slack rein. The polo pony Pat (Fig. 6) is a perfect hack, with a snaffe-bridle mouth, and so steady and clever that he can canter round the pro-

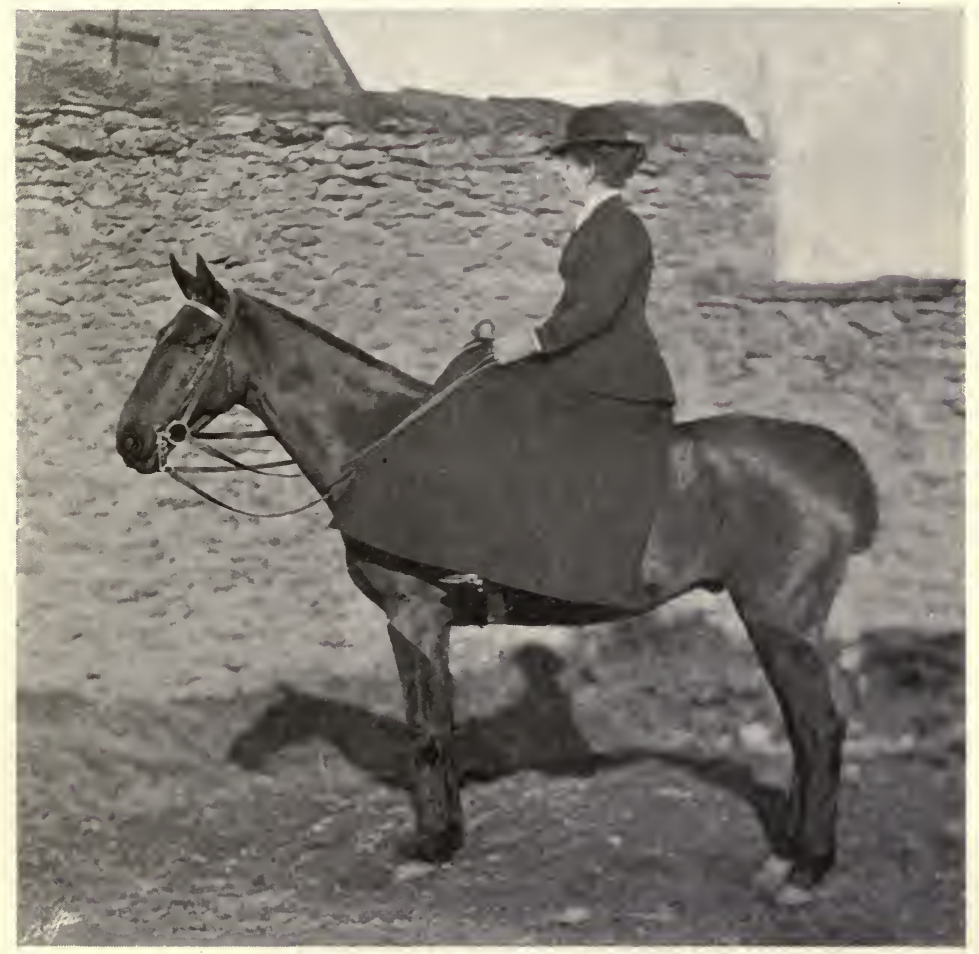

Fig. 6.-Polo pony, Pat.

verbial sixpence. He has played well in several polo matches.

Although many ladies in this country have never enjoyed the luxury of riding a high-caste Arab, we occasionally see these animals in the Row and hunting- 
field. The sight of an "Arabi tattoo" to an old Indian like myself, revives many pleasant memories of delightful equine friends in the East. The Arab is par excellence the most perfect hack for a lady, and I think it would be ungrateful of me in this new edition to omit the portrait of my Arab pony Freddie (Fig. 7), even though the cut of the riding-habit is out of date.

Although a good horsewoman may be satisfied with any animal which is fit for a man, provided he is steady to mount and does not require an unusual amount of collecting; it is not safe to put an inexperienced or nervous rider on a horse that has not been taught to carry a habit, which a groom can do by riding the animal with a rug or dark overcoat on the near side, and letting it flop about. Horses rarely object to the presence of a skirt, though I have known cases in which the animal went almost wild with terror when the right leg was put over the crutch. It is, therefore, wise to accustom a horse to the skirt and leg by means of a groom.

The fact of a lady having to ride in a side-saddle, puts her under the following three disadvantages as compared to a man in a "cross-saddle" : she is, as a rule, unable to mount without assistance; she cannot apply the pressure of the right leg to the side of the horse; and it is difficult for her "to drop her hands" in order to pull him together. The judicious application of a crop or ash-plant (my husband, though an Irishman, swears by a Neilgherry cane) may partly make up for the absence of a leg on the off side; but, however well a woman may ride, she should not have a 
horse which "plays up" when he is being mounted, or sprawls about and requires constant pulling together when she is in the saddle.

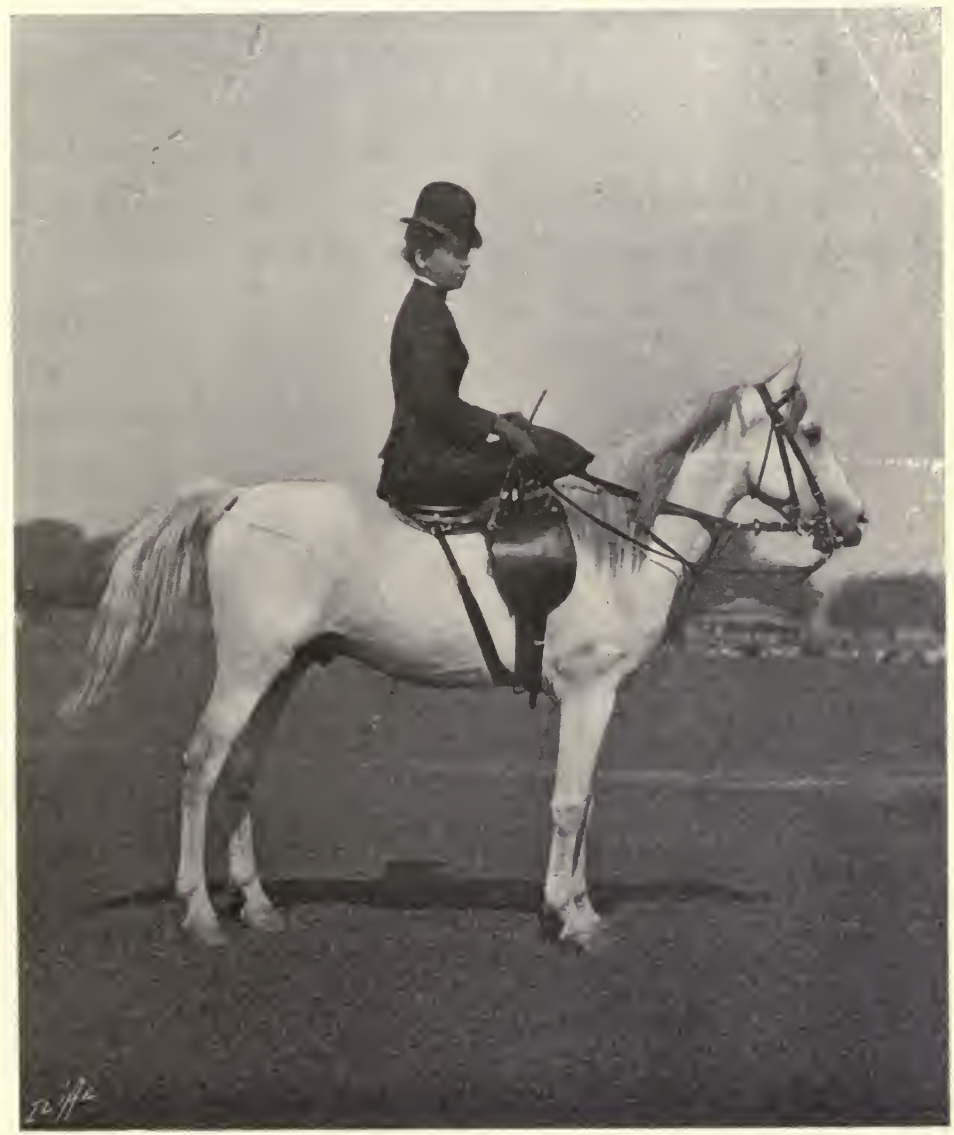

Fig. 7.-Ȧrab pony, Freddie

The style of hack should be lin thorough keeping with that of the rider. :A slight lady has a greater range of choice in horseflesh than a portly dame, 
who would be best suited with a weight-carrying hunter or compact cob. The height might vary from I 4-2 to I 5-3. I hardly think that even a small woman would look well on a pony which is less than $\mathrm{I} 3-3$.

A beginner should be put on a lazy animal, whether horse or pony, that will condescend to trot or canter for only a short distance, which will be quite far enough for its inexperienced rider. Many parents who are supervising the riding instruction of their children, look too far ahead when selecting a mount. Instead of purchasing a steady, plodding; though not unwilling slave, they invest in a second- or third-stage animal, which is absolutely useless to a beginner, because it wants more riding than she can give it. Such a young lady needs a thoroughly steady animal, no matter how old or ugly it may be, and she will probably learn more about riding on it in a month, than she would in a year on a horse which would have to be led by a groom, on account of its unsteadiness. A good donkey is a most useful conveyance for young girls, as he can generally be trusted to take things quietly, and will not unduly exert himself without being called upon to do so.

For the benefit of inexperienced riders, I must not omit to mention that the measurement of horses is taken from the highest point of the withers to the ground. A horse is measured by hands and inches, not, as in humans, by feet and inches. A hand is 4 in., therefore an animal of $I_{5}$ hands is $5 \mathrm{ft}$. in height ; I 6 hands, 5 ft. 4 in. ; I 7 hands, 5 ft. 8 in. ; and one of $17-2$-which would be a gigantic height 
in a saddle horse, but not in a cart horse - would be $5 \mathrm{ft}$. Io in. high. A woman of medium height, like myself, who stands $5 \mathrm{ft}$. 3 in. in "stocking feet" - a height, by-the-bye, which is accorded to the Venus de Medici (we might make use of that fact on being termed "little") — would find a horse of I5-I or I 5-2 a very nice, useful height; though she need by no means limit herself to height with any horse which is springy and active, does not require a great amount of collecting, is easy in his paces, and has a good mouth. The bigger a horse is, the more fatiguing do we find him to ride, if his mouth, manners, and paces are not thoroughly "made." The late Esa bin Curtis, a celebrated Arab horse dealer, in speaking of big buck-jumping Walers, said, "God hath not made man equal unto them," and, however well a woman may ride, it is no pleasure to find herself breathless and exhausted in her efforts to control such animals. On the other hand, many small horses which play, up are most difficult to sit, for, although they may not take their rider's breath away by their display of physical power, they are like quicksilver on a frying-pan, and highly test our agility in the matter of balance and grip.

I cannot conclude this chapter on ladies' horses without expressing my strong condemnation of the senseless and cruel practice of docking riding horses; which has nothing in its favour except its conformance to fashion, and which in this case is disgusting cruelty. 'Thoroughbred horses are never docked, whether they 
be used for racing, steeplechasing or hunting, and it is a monstrous thing to mutilate unfortunate half-breds, especially mares, and condemn them to be tortured by flies, and to have the most sensitive parts of their bodies turned into a safe camping ground for insects, simply because these poor animals have a stain in their pedigree. In summer time, when flies are troublesome, we may often see a long-tailed brood mare at grass protecting both herself and her suckling foal from these irritating pests by the free use of her tail ; but docked mares are deprived of this means of driving away insects, and have been known to unwittingly injure their young by kicking and plunging violently in their efforts to rid themselves of attacking flies. The unfortunate foal is unable to take its natural nourishment in peace, and consequently does not thrive so well as does the offspring of an unmutilated mother. One of the feeble arguments set forth in favour of docking is, that it prevents a hunter from soiling the coat of his rider by his tail; but, as my husband truly says in his new edition of Veterinary Notes for Horse Owners, "This idea is an absurdity, because an undocked horse cannot reach his rider with his tail, if it is banged short, which is a fact known to all military men. Besides, mud on a hunting coat is 'clean dirt.'" The actual pain caused by the operation is trivial as compared with the life-long misery to which tailless horses are subjected, for we deprive them for ever of their caudal appendage, and the ridiculous stump sticking up where the tail ought 
to be, is as ungraceful as it is indecent, especially in the case of mares. Our friend, the late Dr. George Fleming, says in The Wanton Mutilation of Animals, " nothing can be more painful and disgusting to the real horseman and admirer of this most symmetrically formed and graceful animal than the existence of this most detestable and torturing fashion; and those who perform the operation or sanction it are not humane, nor are they horsemen, but rather are they horsemaimers and promoters of the worst form of cruelty to animals. Let anyone go to Rotten Row during the season, and satisfy himself as to the extent to which the fashion prevails, and the repulsive appearance which otherwise beautiful horses present. The astonishing and most saddening feature of the equestrian promenade is the presence of ladies riding mares which are almost tailless. Surely a plea might be entered here for the use of a fig-leaf to clothe the nude." I feel sure that if my sex had a voice in the matter, this wholesale mutilation of mares would soon cease. Dr. Fleming, writing in the Nineteenth Century over twenty years ago, said: "I hope and believe that when the horse-loving public and the friends of animals begin to realise how cruel and degrading some of these mutilations are, they will not be long in having them suppressed "; but the horselovers do not appear to have done much in this matter so far. This writer tells us that "the ancient Welsh laws protected it" (the horse's tail) "from harm at the hands of man," and that "an ecclesiastical canon was 
issued in order to prevent it from being damaged in the eighth century." Cannot our laws do something to protect mares, at any rate, from the cruelty of docking in the twentieth century? Dr. Fleming, in reviewing the history of docking from its earliest times, tells us that he saw an old print " which represented a very emaciated horse, with a fashionable tail, standing in a luxuriant meadow, his body covered with flies, which prevented him from grazing, and from which he could not free himself; ; a notice board in the field announced that horses were taken in to graze, those with undocked tails at six shillings a week and docked ones at eighteenpence."

When Voltaire visited this country in the first quarter of the eighteenth century, he was so impressed with our barbarity, especially in the cutting off the tails of our horses, that he could not refrain from giving vent to one of his pungent sarcasms in the following epigram :-

"Vous fiers Anglois

Barbares que vous êtes

Coupez la tête aux rois

Et la queue à vos bêtes;

Mais les François,

Polis et droits,

Aiment les lois,

Laissent la queue aux bêtes

Et la tête à leurs rois." 


\section{H A P T E R I I .}

SIDE-SADDLES.

Description of a.Side-Saddle-Saddle Tree-Covering of a Side-SaddlePanel--The Leaping Head-Stirrup Leather-Safety Bars-Safety Stirrups -Girths-Balance Strap-Breast-plate-Weight of a Side-Saddle-Shape of the Seat of a Side-Saddle-The Saddle must Fit the Rider-Crupper-

Numdahs and Saddle Cloths-Side-Saddles for Children-Saddling a Horse -Prevention of Sore Backs-Cleaning a Side-Saddle.

DESCRIPTION OF A SIDE-SADDLE.

A properly made side-saddle consists of the following parts :-

I. A tree, which is a wooden frame that is strengthened with steel and iron, and is provided with an upper crutch (near head) and webs.

2. A leather covering, which comprises the seat, off flap, and safe, which is the trade term for the near flap.

3. A panel (or cushion), which is placed underneath the tree, so as to protect the animal's back from the hurtful pressure of the unprotected tree.

4. A leaping head, which helps the lady to obtain security of seat.

5. A stirrup leather.

6. A stirrup iron. 
7. A stirrup bar for the stirrup leather.

8. Girths.

9. Balance strap.

To these ordinary components of a side-saddle, a

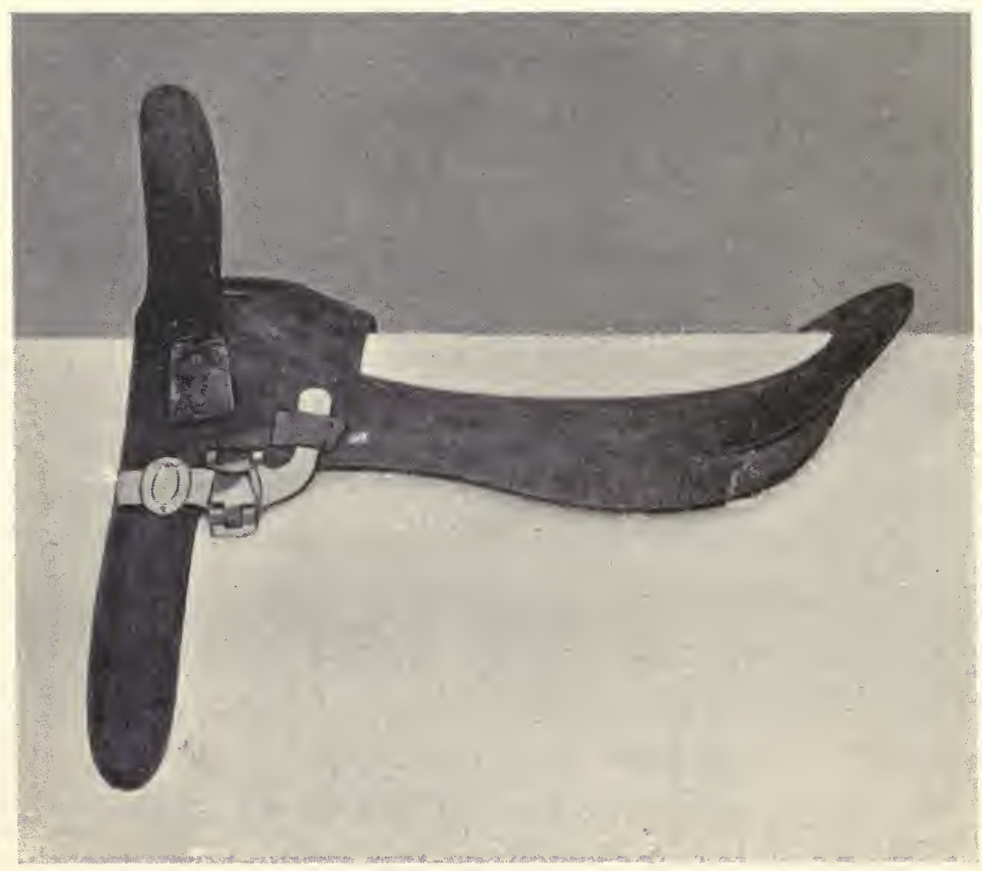

Fig. 8.--Side view of saddle tree.

breast-plate and saddle cloth or numdah are sometimes added. On rare occasions a crupper is used.

SADDLE TREE.

The tree (Figs. 8, 9, ro, and I I) consists of two bars (side boards), which are connected together in front 
by the pommel, and behind by the cantle. The pommel is made up of a gullet plate, which is a steel arch that goes over the withers, and its coverings. The points of the tree are connected, one on

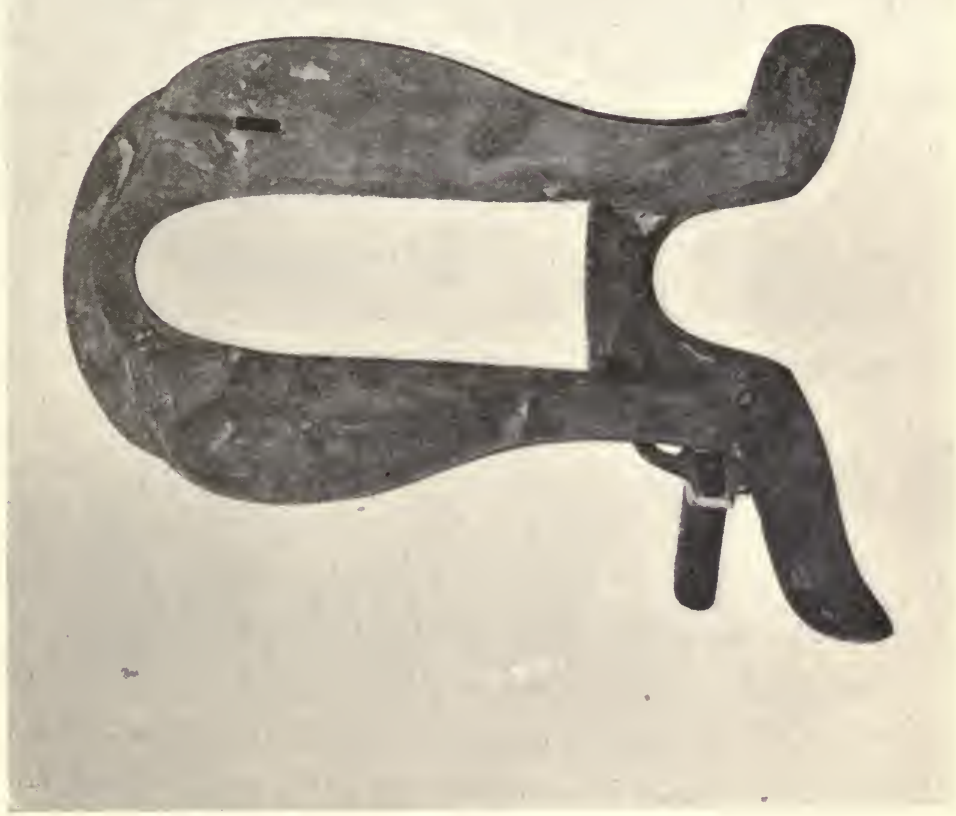

Fig. 9. - Underneath view of saddle tree.

each side, to the front ends of the bars and to the gullet plate, and they point downwards. The stirrup bar, which should be of a safety pattern, is attached to the near bar, a little lower down than the leaping head. 
The webs (Fig. I I) of a tree are strong hempen bands which cover the open space down the centre of the tree, and are nailed, at one end, to the pommel, and at the other end to the cantle. They are tightly stretched, in order to give the rider a comfortable seat; and to keep her weight off the horse's backbone.

The office of the bars of the tree is to evenly distribute the rider's weight, by means of the panel, over the muscles which run along each side of the horse's backbone, and which form the only suitable bearing surfaces for the purpose in question. No weight should fall on the animal's backbone, because it is very sensitive to pressure, even when the pressure is well distributed. In order to obtain this indispensable condition of evenly-distributed pressure, the bars of the tree of a saddle which is to be made for a particular horse, should accurately fit the bearing surfaces of the back upon which they rest, and should be well away from the backbone; in fact, the distance between the bars should not be less than four inches. When the rider is in the saddle, a fair amount of space should exist between the gullet plate and the withers, so that no injurious pressure may fall on the top or sides of the withers, which are particularly susceptible to inflammation from this cause.

In order to avoid giving an undue height to the pommel, with the object of keeping it off the withers, it should be "cut back" (Fig. II), although this cutting back need not be carried to the excessive 
extent that is sometimes practised. In a man's saddle, the pommel is generally straight.

The points of the tree should accurately fit the parts upon which they rest, so as to prevent any "wobbling" of the saddle. The near point of the tree (Fig. IO) is usually made long, with the idea of

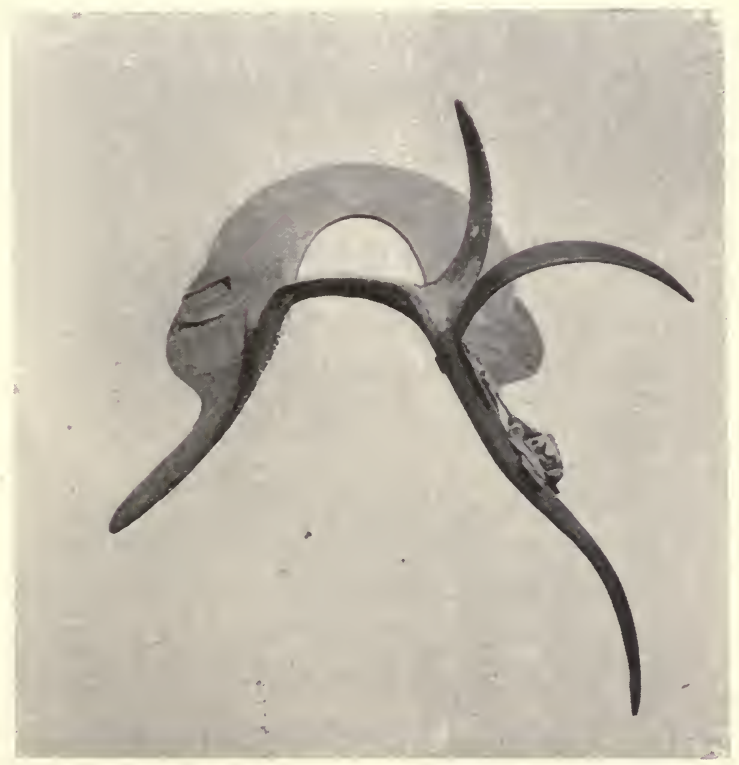

Fig. I0.-Front view of saddle tree.

helping the saddle to keep in its place; but if this is done, the oft point should be comparatively short, because, if both points be long, they will be apt to become pulled further apart in the event of the horse turning round sharply, as he would have to do in a narrow stall, or even when refusing a jump.

The upper crutch, or, as it is called by saddlers, the 
near head, is a more or less upright projection which is placed on the near side of the pommel, in order to give support to the rider's right leg. The slope and bearing surface of this near head should be regulated, so that (as we shall see further on) the lower part of the rider's right leg may extend downwards along the shoulder of the horse, and that the lady may be able to exert full pressure against the near head, by the inward rotation of her thigh (p. r 57). The height of the near head depends on the thickness of the rider's thigh, because a fat leg will require a higher crutch than a thin one. If the upper crutch be unduly long, it will push the skirt up and give it a bad appearance. We must, however, bear in mind that if it is too short for its legitimate purpose, it will afford an insecure grip to the right leg, which is a consideration that must not be neglected.

Before the leaping head (p. 33) was invented, sidesaddles were provided with an off crutch, which was placed on the off side of the pommel. In a very old saddle which I saw, it took the form of an upright handle, which was placed parallel to the direction of the withers, and which apparently was intended to be grasped by the right hand of the rider in case of emergency. In a saddle of mine, which is about roo years old, the off crutch projects horizontally to the right. Fifty years ago, the off crutch was almost always upright, and was often placed so close to the near crutch that the rider was able to get a fairly firm support for her right leg by jamming it between these 
two crutches. As the great utility of the leaping head received increasingly wide recognition, the off crutch underwent a gradual process of decadence, because it is of no benefit to a rider who understands the use of a

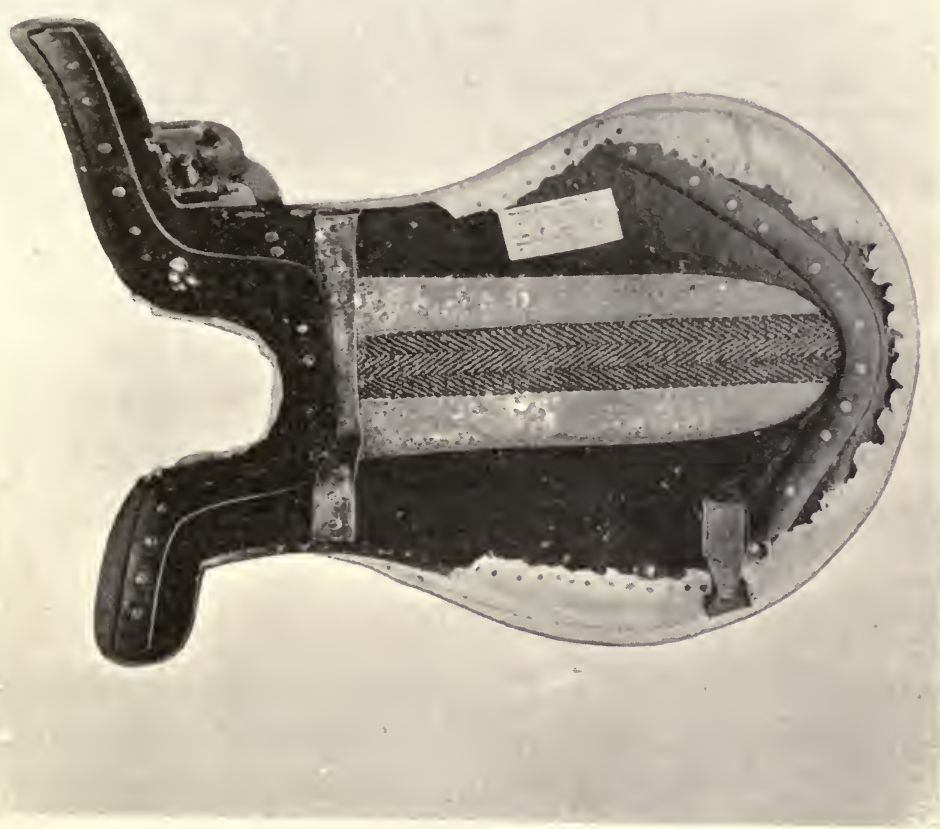

Fig. II.-Underneath_view of saddle tree and its webs.

leaping head. Indications of its previous existence may occasionally be seen, especially abroad, in the form of an entirely useless thickening of the off side of the pommel. 
COVERING OF A SIDE-SADDLE.

The seats of good saddles are generally of pigskin, and the flaps of cow-hide. The fact of the seat being of buckskin or other rough leather will increase the lady's security in the saddle, but may somewhat detract from the smartness of her appearance, especially if the leather is white. I can see no objection to the seat of the saddle being of rough brown leather. Formerly, all side-saddles had a "stuffed safe," in which the front part of the near flap is padded, but nowadays it is rarely, if ever, used by smart hunting people. It is evidently the surviving remains of the voluminous pad, upon which ladies used to rest the lower part of their right leg in the days before the leaping head was invented. Ornamental stitching about the seat and safe of a saddle is equally out of date.

\section{PANEL.}

It is all important that the panel should be so carefully stuffed, that the rider's weight will be evenly distributed over the bearing surfaces of her animal's back. Even if this is done to perfection, the desirable arrangement will last for only a short time, if the stuffing is of the wrong kind of material. Instead of using fine wool (best flock), incompetent or unduly economical saddlers often employ flock which is largely composed of cotton waste, and, consequently, when they stuff or re-stuff a saddle, lumps, from the absorption of perspiration, are 
apt to form in the panel, with the frequent result of a sore back. Although the stuffing of side-saddles is too technical a subject to attack in these pages, I would fail in my duty to my readers if I omitted to advise them always to go to a first-class saddler for a new saddle, or to get an old one re-stuffed, which should be done as may be required, preferably, before the beginning of the hunting season, supposing that the saddle has seen a good deal of service. It is often thought that expert saddlers are to be found only in London; but if a saddler is clever at his trade, the fact of his having a shop in a good hunting district, must be a great advantage to him in studying the requirements of riding people.

was invented about 1830 by M. Pellier, who was well known in Paris as a riding master. Its object is to help the rider to obtain security of seat by a fixed surface against which she can press the front and lower part of her left thigh. Before the invention of the leaping head, ladies had to rely entirely on the right leg for grip, and consequently few, if any of them, were able to hunt. Mr. John Allen, who wrote Modern Riding, in I 825 , tells us that "the left leg is nearly, if not wholly useless; for though a stirrup is placed on the foot, the only use of it is to ease the leg a little, which, for want of practice, might ache by dangling and suspension." 
The following are the chief points to be considered about a leaping head :-

I. Its curve should be so arranged that the harder a lady presses against it, the more will her left leg be carried inwards, so that the flat (inside) of her knee may be brought in contact with the flap of the saddle (Fig. I2). An ordinary leaping head is curved, as a rule, in such a manner that when a rider seeks to obtain support from it by the pressure of her left leg, this limb is carried outwards, and she is able to get a point d'appui only at the extreme end of this projection (Fig. I3). It is evident that the closer the left leg is to the saddle, the firmer will be the seat. Besides, the more the left leg is brought outwards, the more weight will be put on the near side, which, as we shall see further on, is the very thing a rider ought to avoid.

2. The leaping head should be close to the upper crutch (Figs. I 2 and I6). The usual plan of putting it much lower down (Fig. 15) tends to bring the weight to the near side, a fact which can be easily tested, especially in trotting, by trying the improvement in question, which was suggested to me by Mr. Ford of Rugby, who is a very competent and experienced saddler.

3. Usually, the leaping head is attached to the tree by means of a screw, which is an arrangement that has the disadvantage of not allowing the leaping head to be placed close to the upper crutch. If the leaping 
head is riveted on to the tree (as in Figs. Io and I6), which is the better plan, it can be placed as near as we like to the upper crutch, and it will have no

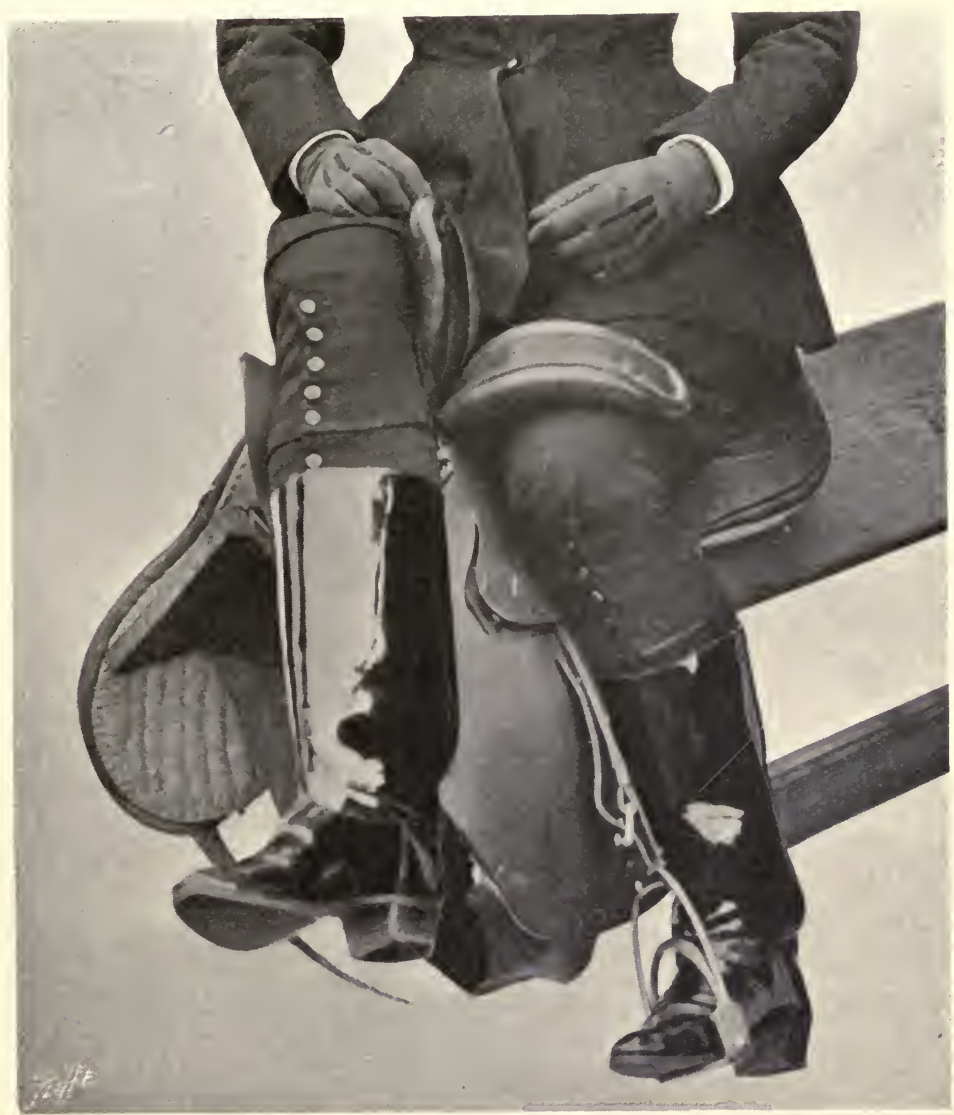

Fig. 12.-Grip with improved leaping head.

tendency to wobble about, as it would be apt to do, if it was fixed by a screw. As the screws of the leaping heads of cheap saddles are almost always made of 
annealed iron, which is a form of cast-iron, it is not an uncommon occurrence for the screw of one of these saddles to break, which is more apt to occur at a critical moment, as for instance when the horse is jumping or "playing up," than when he is going quietly. On the only occasion I ever rode over a fence in one of these cheap Walsall saddles, the screw broke, but luckily I "remained."

4. When the leaping head is a fixture, the bearing surface which it presents to the rider's left leg should be in the same direction as the upper part of that limb, so that the pressure on it may be evenly distributed. By placing a straight stick under the leaping head, and holding it in the direction which the left thigh would occupy, when the rider is mounted, we can easily see if the bearing surface is in the proper position.

5. As an aid to security of seat, it is well to have the under surface of the leaping head and the off side of the upper crutch covered with rough brown leather, which, we should bear in mind, is concealed from view, when the lady is in the saddle, and consequently it will not detract from the smartness of her appearance.

STIRRUP-LEATHER.

The stirrup-leather, which is on the near side, should always be attached to a bar, and not, as is sometimes done, to the balance strap (p. 53); 
because, in this case, its length will be subject to frequent variation, not only when the saddle is put

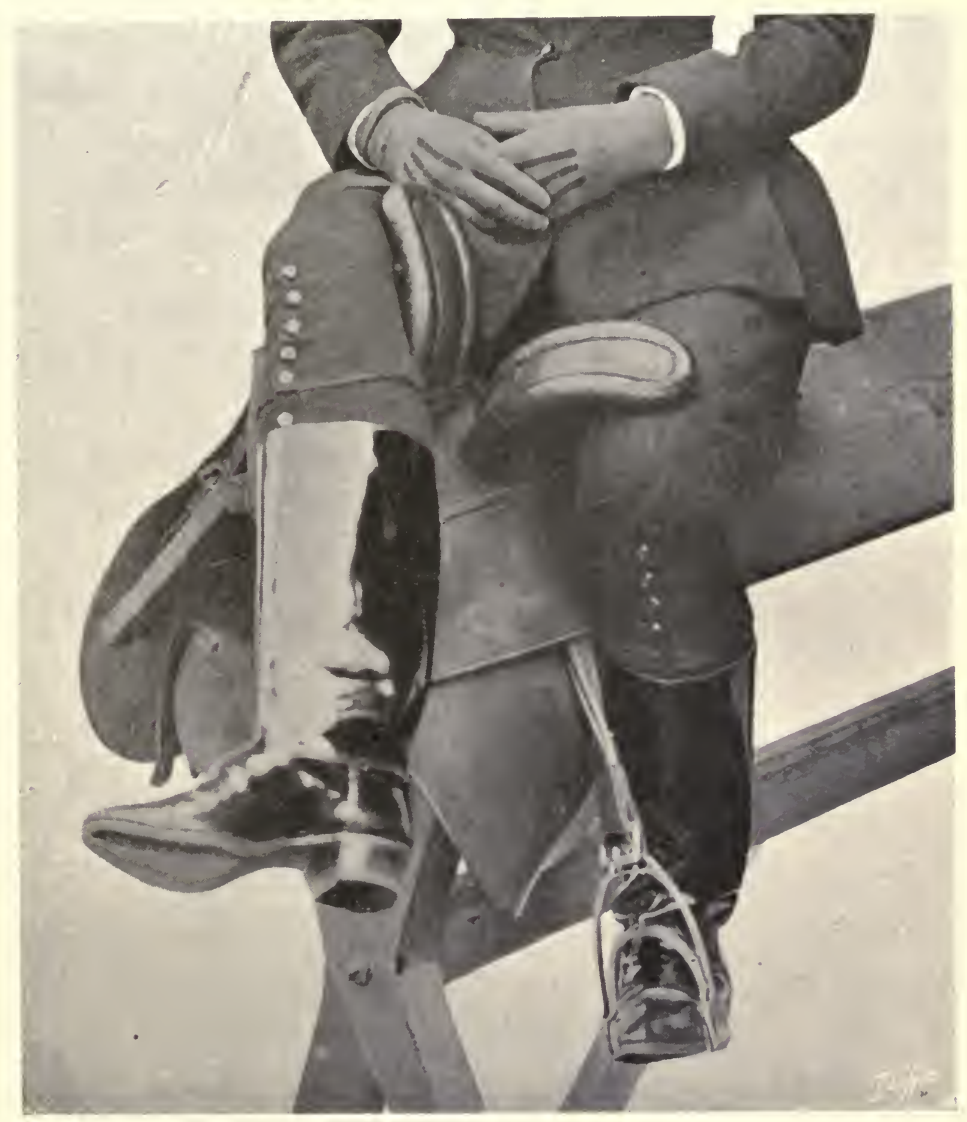

Fig. I3--Grip with ordinary leaping head.

on different animals, but also when the horse gets slack in his girth from work. When it is fixed to a bar, which should always be of the safety kind, no 
alteration in the correct length of the leather will take place.

The arrangement for undoing the stirrup-leather is in the most convenient position when it is close to the iron, and not in proximity to the stirrup-bar, as is the case in a man's hunting saddle. If the leather is used in the latter manner, the buckle will be apt to hurt the inside of the lady's left leg, when she brings the knee close to the flap of the saddle; and it will be more inconvenient to alter the length of the leather; when the lady is mounted, than if the buckle or hook was low down. The hook (Fig. I4) is better than a buckle, because it lies flatter and is easier to arrange.

\section{SAFETY RARS.}

A safety bar is a bar which will release the leather, in the event of the rider falling from the saddle, and at the same time getting her foot caught in the stirrup-iron. To be reliable, it should do this, whether the lady falls on the near side, or on the off side. The best safety bar which has. up to the present been put before the public, is undoubtedly Champion and Wilton's latest pattern. It releases with absolute certainty on both sides, and can be fitted in such a manner that it will allow the flat of the left leg to be brought close to the saddle. As safety bars and safety stirrups are the only means for ensuring a lady from being dragged 
by her stirrup, and as Champion and Wilton's safety bar is more reliable in this respect than any safety

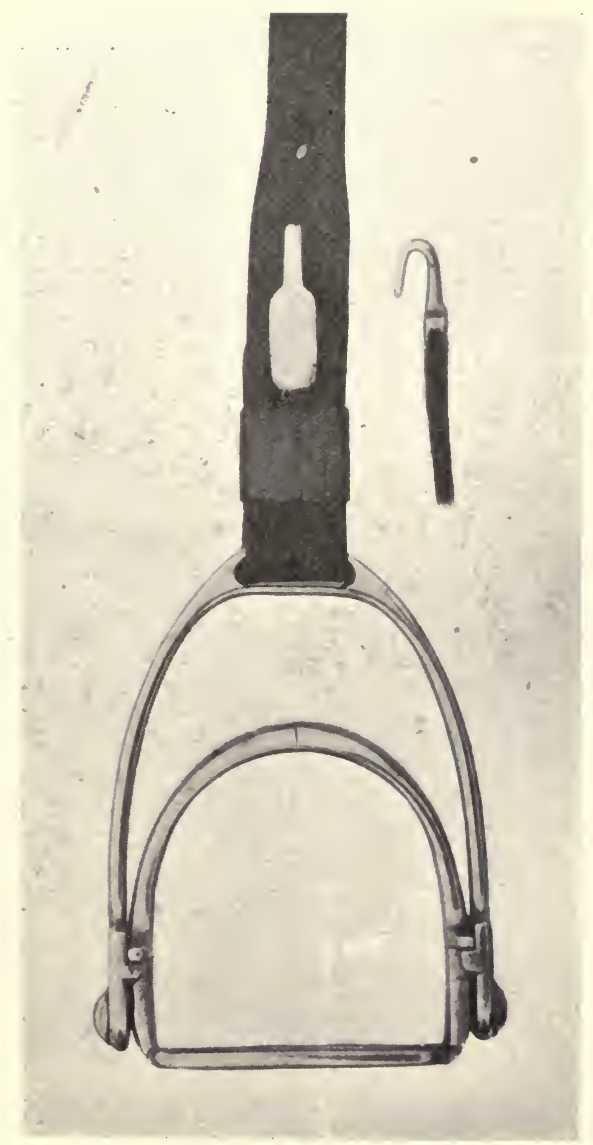

Fig. I4. - Hook for stirrup leather.

stirrup, it stands to reason that it should be used with every side-saddle. With this bar on a saddle, there is of course no objection to the use of a 
safety stirrup, in order to make "doubly sure." It is usually fitted with a thick flap (Fig. I 5), which prevents the left leg from being brought close to the saddle; but this objection can be removed by the adoption of Mr. Ford's plan of greatly reducing the

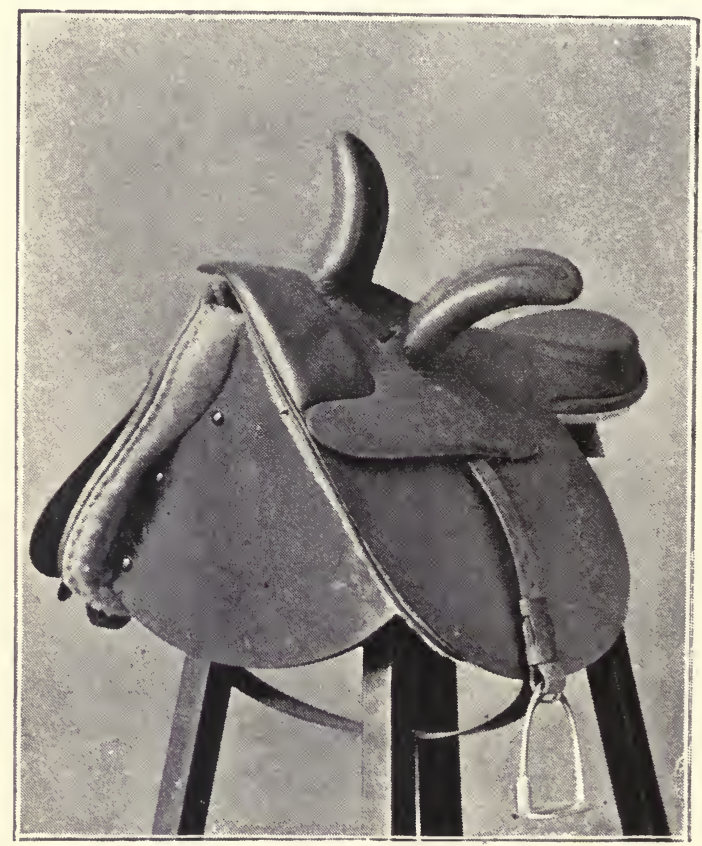

Fig. 15.-Leaping head too low down.

size of the flap of the bar, and making it fit into an opening cut out of the near flap of the saddle (Fig. I6). I have found this arrangement a great improvement on the old clumsy flap, the lower edge of which is unpleasantly apt to catch on the rider's boot, especially when trotting. I shall discuss the failings of safety stirrups further on. 
Owing to the position which a lady occupies in a side-saddle, she is often inclined to draw her foot back to such an extent that she would pull the leather out of the bar, if the action of the bar was

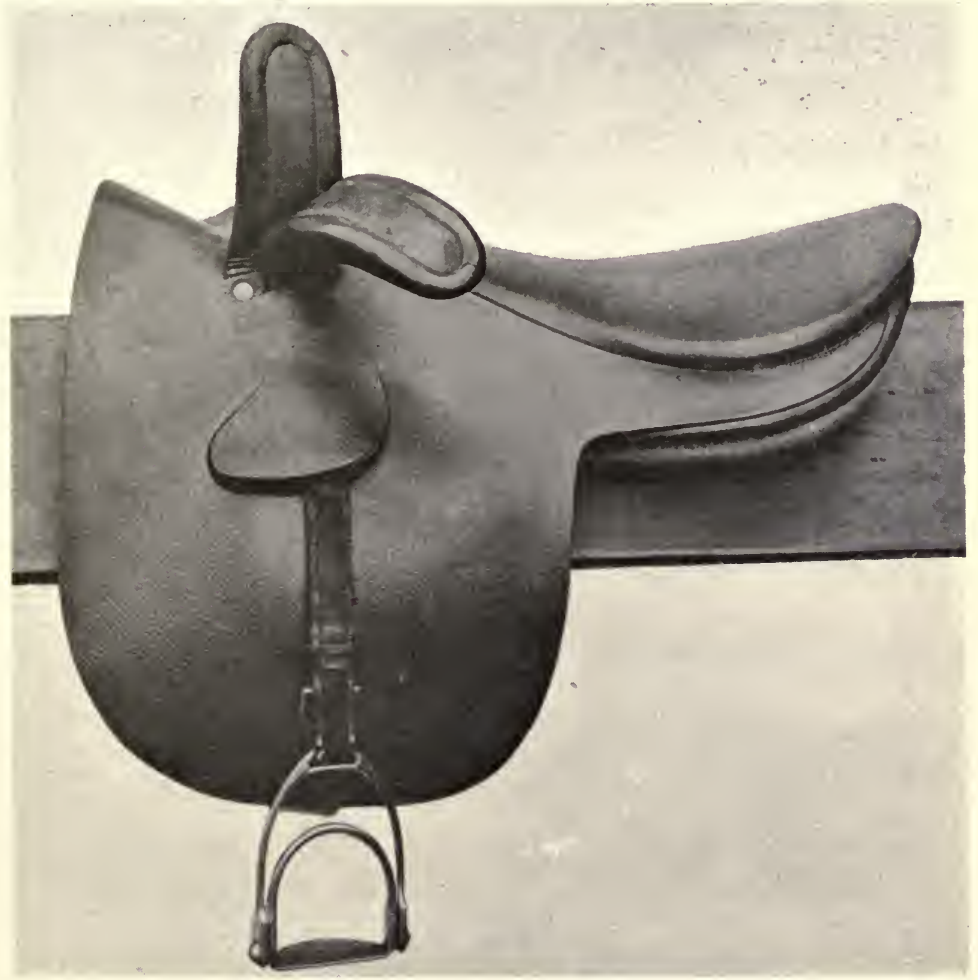

Fig. I6. - Side view of a properly made saddle.

similar to that of a man's saddle; but a Champion and Wilton's bar is so devised that it will free the leather, only when the pressure of the left leg is removed from the flap of the bar, in which case the lady will have quitted the saddle. Hence, as 
long as she, keeps her seat, she cannot pull the leather out of the bar by drawing back her left leg. The only thing which prevents this safety arrangement from being absolutely perfect; is the liability the leather has of falling out of the bar and becoming lost, in the event of the rider severing her connection with the saddle, in which case the retaining action of the flap on the bar will cease.

For this emergency, Messrs. Champion and Wilton provide side saddles with a small leather case which contains an extra stirrup, and which is attached to the near side of the saddle, so that it is concealed from view, when the lady is mounted (Fig. I7): The weight of the stirrup and case is only half a pound.

\section{SAFETY STIRRUPS,}

both for men and ladies, have been in existence for hundreds of years. Apparently the first variety of this contrivance was the capped stirrup-iron, either simple (Fig. I 8 ) or in the form of a slipper (Fig. 19), which was provided with an arrangement on its sole that prevented the toe of the slipper from yielding to downward pressure, but allowed it to revolve upwards, and thus to facilitate the release of the foot, in the event of a fall. The simple capped stirrup was used by ancient Spanish Cavaliers, and is still employed by many of their descendants in America. In apparent oblivion of these facts, the Christie stirrup (Fig. 20), made on the same prin- 
ciple, was patented about four years ago. Besides its undue weight ( $\mathrm{I} / 4 \mathrm{lb}$. as compared to the $\mathrm{I} / 2 \mathrm{lb}$.

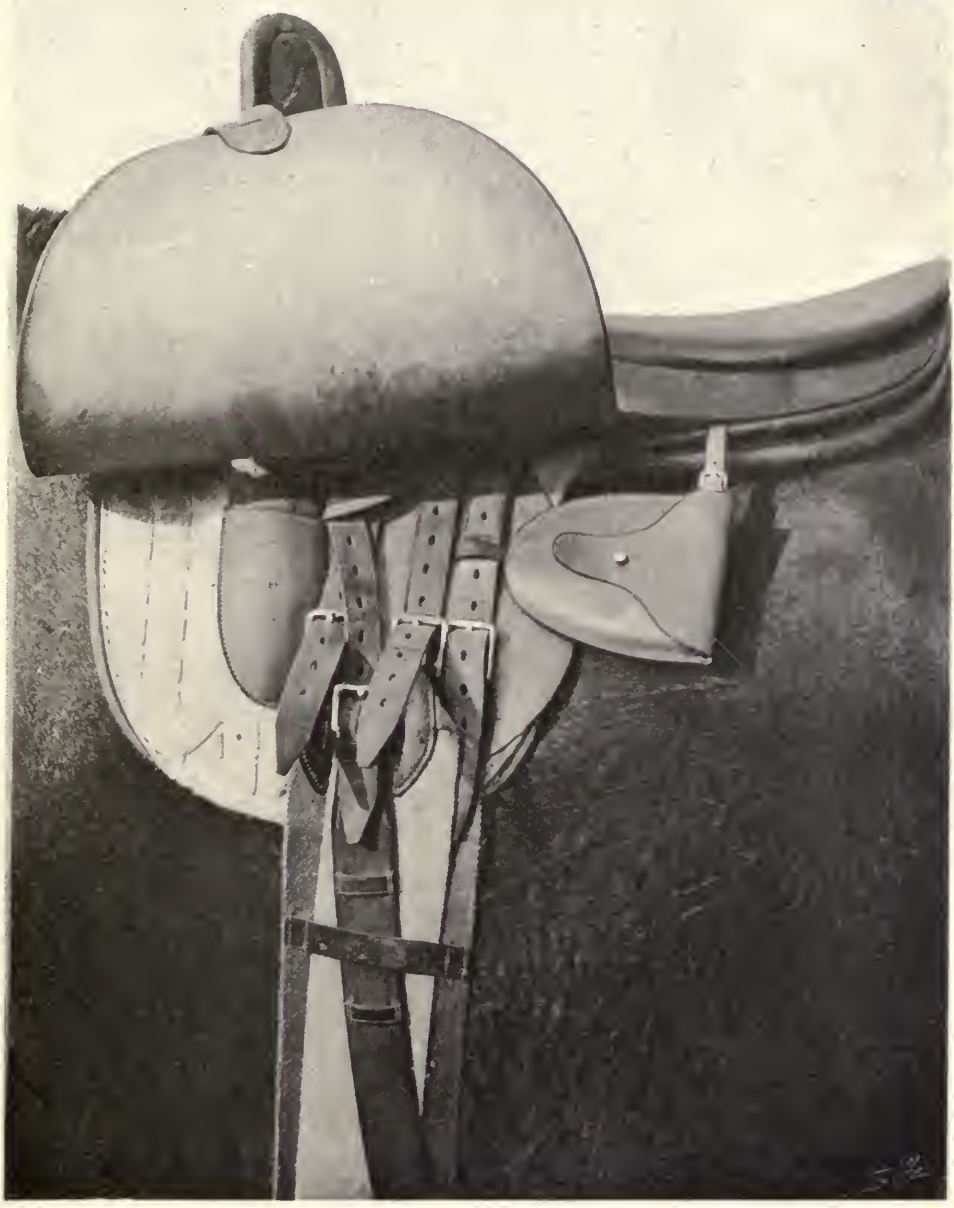

Fig. 17.-Champion and Wilton's extra stirrup case.

of the slipper stirrup), it has the further disadvantage of allowing the possibility of the toe being caught 
between its bars (Fig. 21). Want of neatness appears to have been the only cause of the abandon-

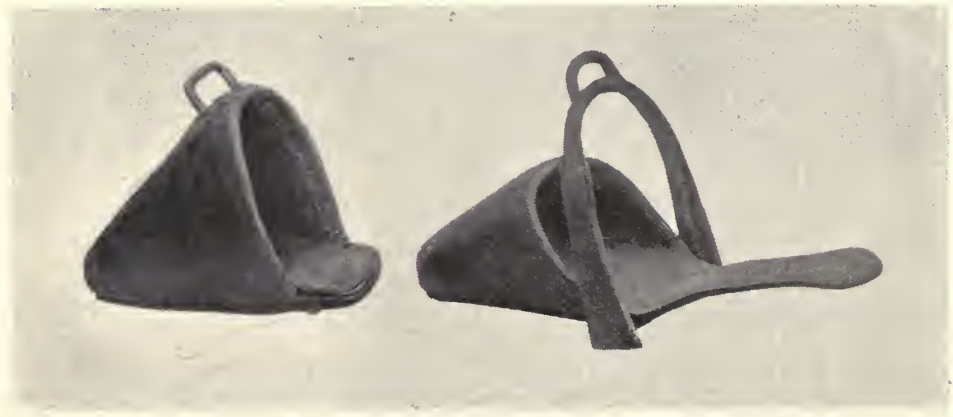

Fig. 18.-Capped stirrup-iron.

Fig. 19.--Slipper stirrup.

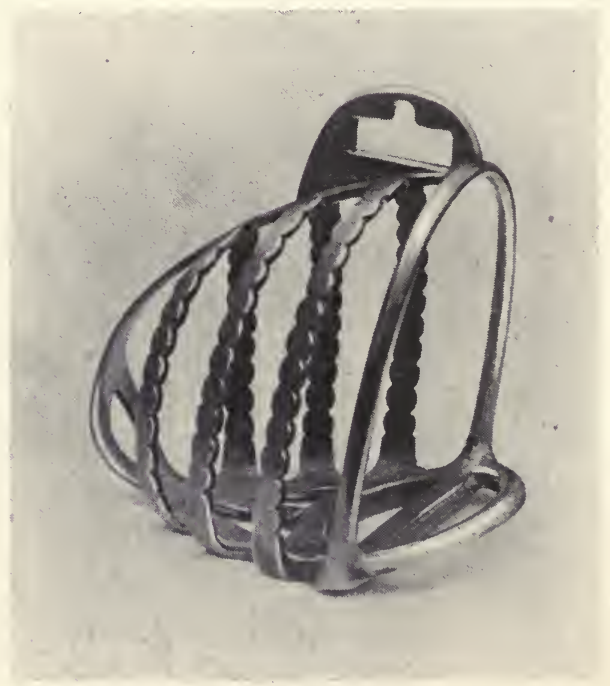

Fig. 20.-The Christie stirrup.

ment of the capped stirrup, which is certainly safer than any of its successors, the first ${ }^{-}$English one of 
which appears to have been the Latchford safety stirrup (Fig. 22). It consists of two irons; the small one, which is placed within the large one,

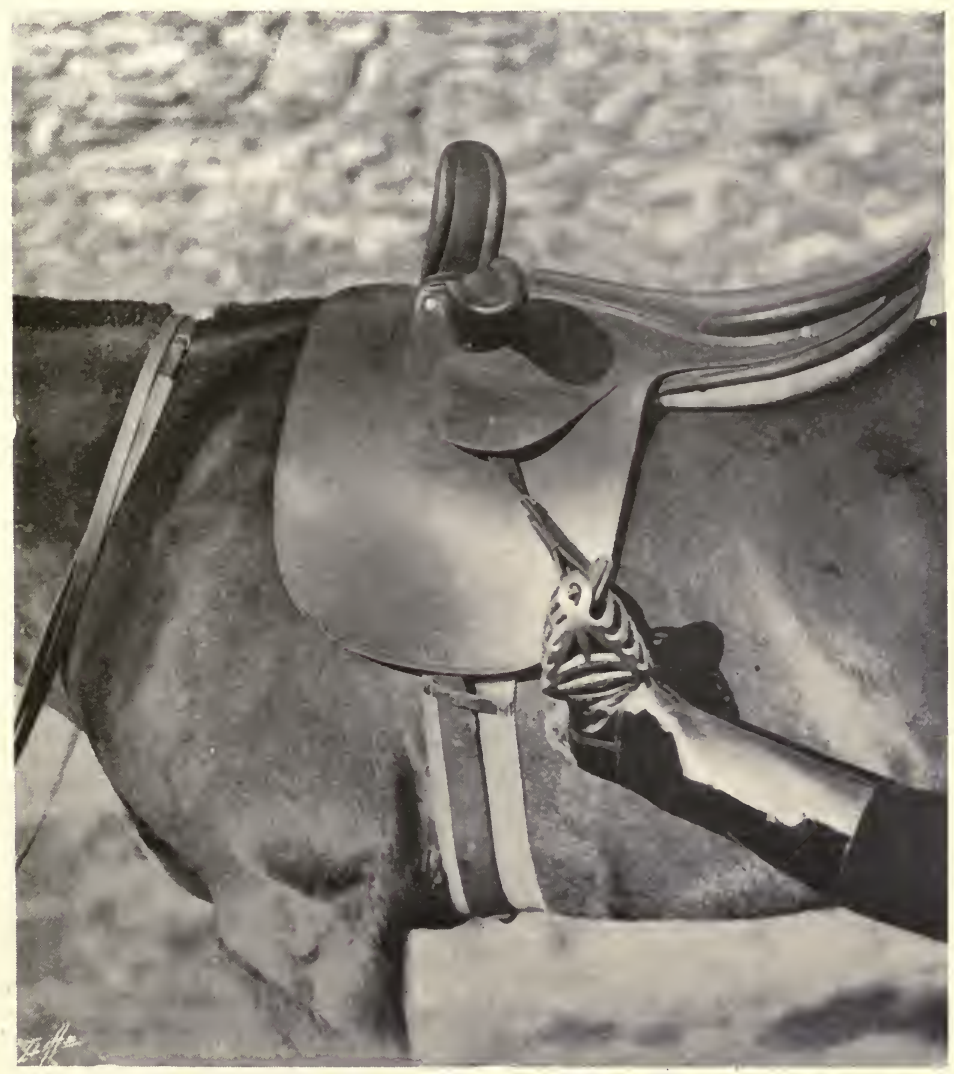

Fig. 21,-Foot caught.

being made to come out the moment the foot gets dragged in it, in which case it parts company with its fellow, and is then liable to get lost. The Scott safety stirrup (Figs. 23 and 24) has not this fault, 
for its inner iron always retains its connection with the outer one, and can be replaced without delay, if the lady after her tumble desires to remount. The Latchford, Scott ordinary, and Cope safety stirrup (Figs. 25 and 26) open only one way, so that the foot, when correctly placed in any of them, may not be liable, as in the event of a fall, to be

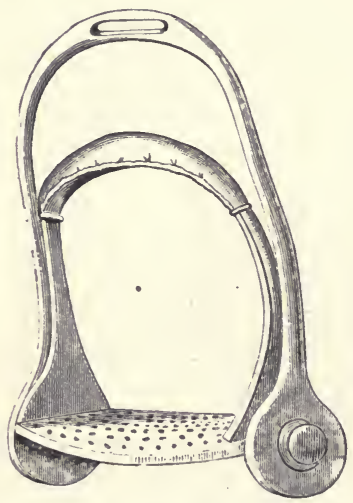

Fig. 22.-Latchford stirrup.

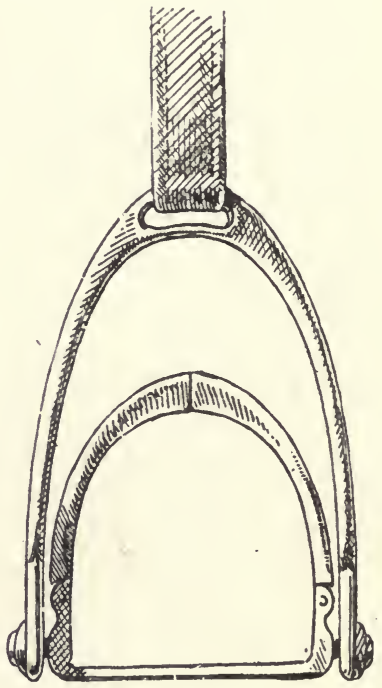

Fig. 23. -Scott's stirrup.

forced through the outer iron, in which case the lady. would almost to a certainty get hung up if her saddle was not provided with a safety bar. In these stirrups, the side of the "tread,"* which ought to be to the rear, is generally indicated by the fact of its being straight, while the other

* The "tread" is the part of the stirrup-iron on which the sole of the rider's boot rests. 
side is curved (Fig. 24). This is done in Fig. 27, by the word "heel."

The chief faults of so-called safety stirrups are as follows:-

r. They may catch on the foot, on account of getting crushed by coming in violent contact with a tree,

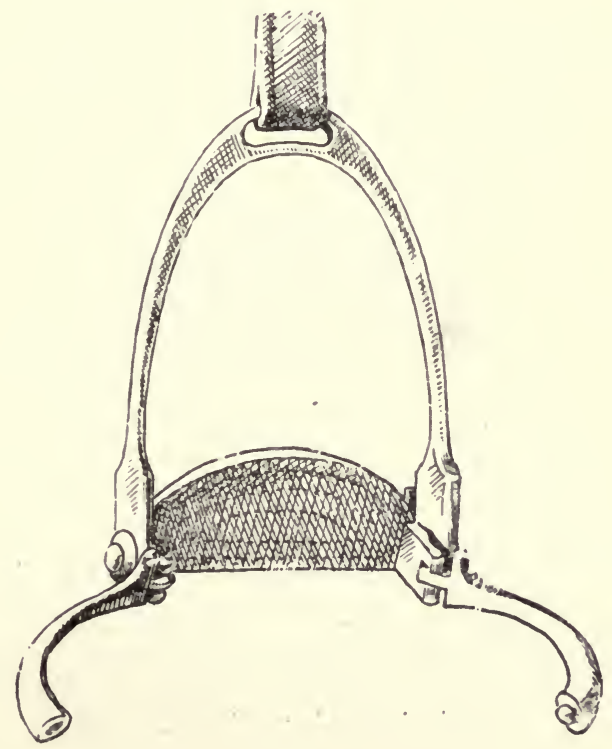

Fig. 24.-Scott's stirrup open.

wall or other hard object, or by the horse falling on his near side. When I was living in India, I had a Scott safety stirrup jammed on my foot in this manner, by a horse which 'I was riding, making a sudden shy and dashing against a wall. The iron was so firmly fixed to my foot by this accident, that it could not be taken off until, after much pain and trouble, my foot was 
freed from both bont and stirrup. Had I been unseated, I would probably have been killed, bécause my saddle had not a safety bar.

2. Those which open only when the foot is put into them in one way, are apt to cause a fatal accident if put in the wrong way, which may easily happen from

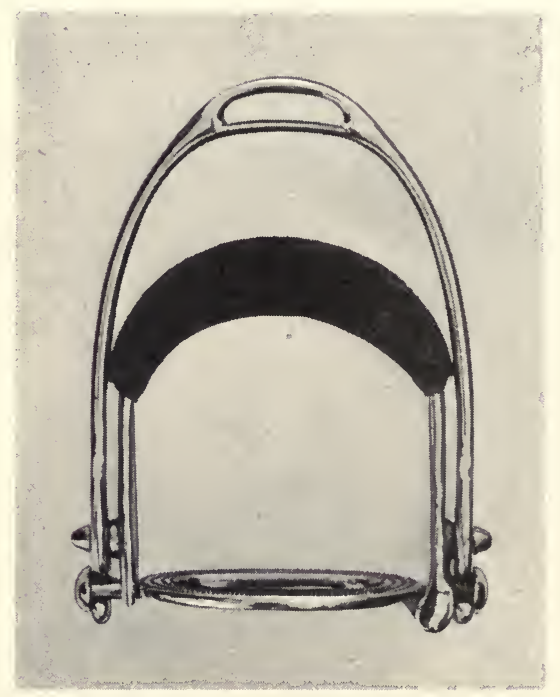

Fig. 25. Cope's stirrup.

carelessness or ignorance (p. 64). The methods (straight edge of " tread," or word "heel ") used with these stirrups, to indicate the proper side on which to put the foot into the iron, may convey no meaning to persons who are not well acquainted with the details of side-saddle gear, and in moments of hurry and excitement may be easily overlooked.

3. Any ordinary safety stirrup which is used without 
a safety bar may cause a lady to get "hung up," if she is thrown to the off side and her heel gets jammed against the saddle in the manner shown in Fig. 28.

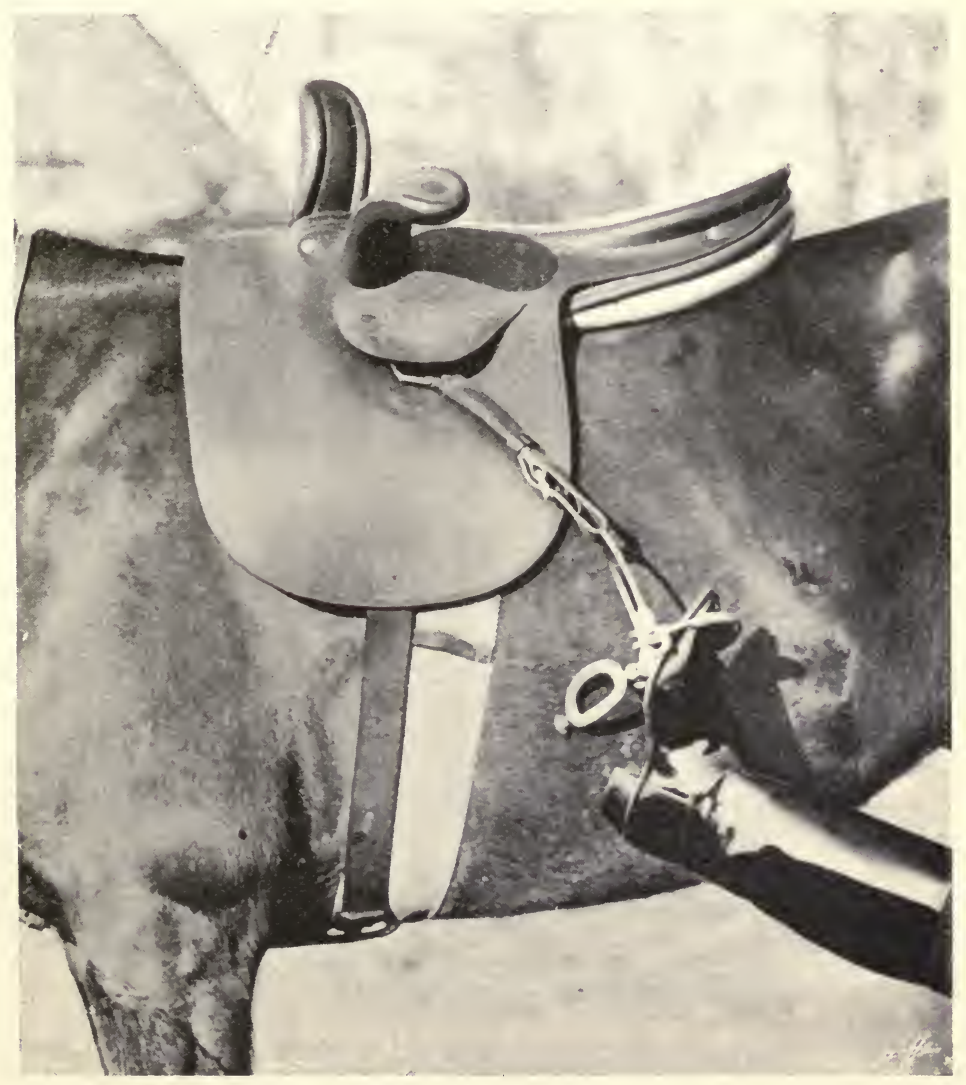

Fig. 26. - Foot released by Cope's stirrup.

4. If the outer iron is small in comparison to the size of the foot, the rider may easily get dragged.

5. If the outer iron of a Scott's reversible safety stirrup is large in comparison to the size of the foot (as 
in the case of a young girl), the rider may get dragged in the event of a fall, by the foot going through the stirrup. Accidents caused by a foot going through a stirrup have often occurred to men from falls when hunting and steeplechasing.

Some ladies think it "smart" to ride with a man's

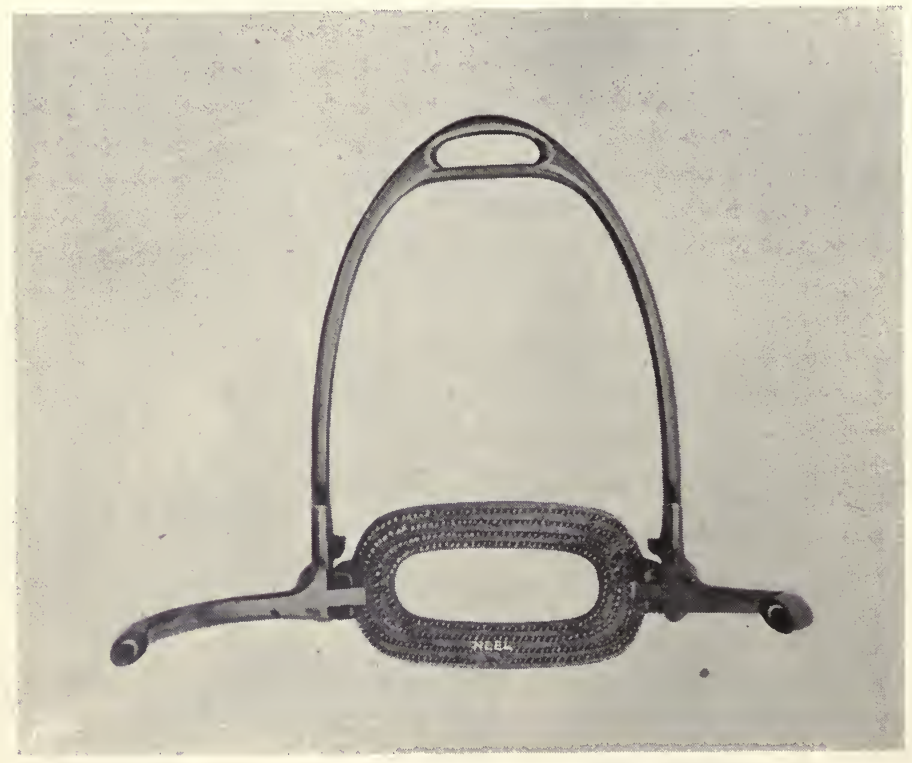

[Fig. 27.-Scott's stirrup.

ordinary stirrup iron, or (madder still) with a small racing stirrup, attached to a leather which does not come out. I once saw a lady who adopted this senseless plan fall and get dragged. By an extraordinary piece of good luck she was saved from a horrible death by her boot coming off.

All that can be said in favour of safety stirrups, is 
that they are less liable to cause accidents than ordinary stirrups. The fact remains, that the danger of being dragged by the stirrup can be entirely obviated only by the use of an efficient safety bar.

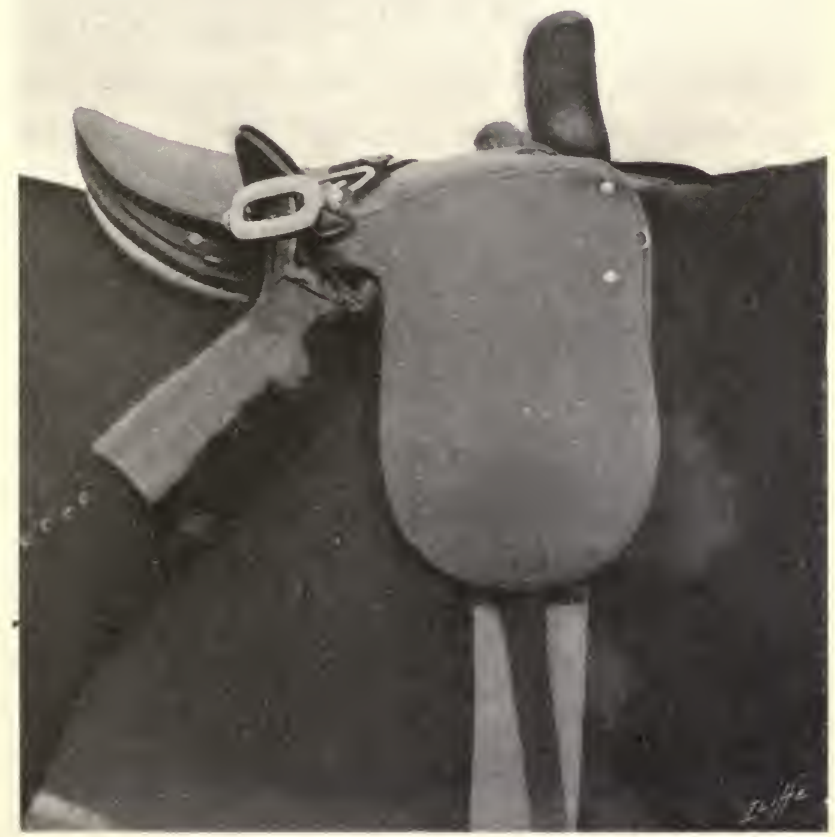

Fig. 28. - Foot caught on off side.

GIRTHS.

In referring to this subject, I cannot do better than give the following extract from Riding and Hunting :"Girths, while fulfilling their duty of efficiently keeping the saddle on a horse's back, should be as 
little liable as possible to hurt the surface on which they press. Hence they should be broad, soft, and constructed so that their tendency to retain sweat between them and the horse's skin may be reduced as far as practicable. They can best fulfil the last-mentioned important condition when they are absorbent and open in texture. It is evident that sweat retained between the girth and the skin will have the effect of the moisture of a poultice in rendering the part soft and unusually liable to injury from pressure or friction.

"As a material for girths, wool is superior to cotton or leather, because it is softer, more absorbent, and does not become so hard on drying after having become wet. The only drawback to ordinary woollen girths is that they are not sufficiently ventilated, an objection which has been overcome in specially constructed woollen girths that are sold by many good saddlers.

"The plan of giving ventilation by slitting up a broad leather girth into several narrow straps, or by using a number of cords of cotton or of plaited or twisted raw hide often acts well; but its adoption may give rise to girth-galls, if care is not taken to smooth out, when girthing up, any wrinkles there may be in the skin underneath the girth. It is evidently more difficult for the pressure to be evenly distributed by these cords, than by a broad girth which consists of one piece.

"Great care should be taken to keep girths clean and soft, and to oil them from time to time, if they be of leather. 
"I prefer a broad girth attached at each side by two buckles to two narrow girths. The Fitzwilliam girth, which consists of a broad girth with a narrow one over it, is handy with a martingale or breast-plate, through the loop of which the narrow girth can be passed."

In a Fitzwilliam girth, the pressure of the narrow one on the centre of the broad one, makes the edges of the broad girth incline outwards, and thus apparently helps to save the horse from becoming girth-galled.

Girths should always be buckled high up on the near side, in order to prevent their buckles hurting the ricler's left leg, by making an uncomfortable bump in the flap of the saddle; and also to allow plenty of space on the girth straps of the off side, for shortening the girths as may be required.

\section{BALANCE STRAP.}

This is a leather strap which is attached to the off side of the rear part of the saddle, at one end; and to a strap close to the girth straps of the near side, at the other end. Before the days of safety bars, its near side end was usually buckled on to the stirrup leather, which was a faulty arrangement, not only as regards the leather (p. 36), but also because its degree of tightness was a constantly varying quantity which entirely depended on the amount of pressure that the rider put on her stirrup. The presence of a properly tightened balance strap helps to prevent lateral movement on the part of the saddle. Also it counteracts, to some 
extent, the excess of weight which almost every rider puts on the near side of her saddle; this good effect being due to the fact that the off attachment of the balance strap is farther away from the centre line (axis) of the animal's body than the near attachment; and consequently the pull of the balance strap on the off side acts to greater mechanical advantage than the pull on the near side.

\section{BREAST-PLATE.}

The breast-plate is attached at one end to the girth or girths, and at the other end to the staples of the saddle. Its use is to prevent the saddle shifting backwards, as it might do if the girths were slack, especially if the animal was very narrow waisted. Even with a well-shaped horse, a breast-plate is often useful on a long day and in a hilly country. It is much in favour with hunting ladies. Staples are small metal loops which are fixed to the front part of the saddle-tree.

\section{WEIGHT OF A SIDE-SADDLE.}

In order to avoid giving a horse a sore back and consequently disabling him for the time being, it is essential to have the tree rigid, so that the weight may remain evenly distributed over the bearing surfaces of his back, which rigidity cannot be obtained without having the tree fairly heavy. The necessary width and length of saddle and strength of upper crutch and leaping head are also questions of weight. Hence if we require a saddle for rough and dangerous work like 


\section{SEAT OF SIDE-SADDLE.}

hunting, we must not entertain the ridiculous idea of having a light saddle, so that it may look particularly smart. A fair weight for a side-saddle is one-seventh of the weight of the rider, that is to say, two pounds for every stone she weighs, with a minimum weight of 18 lbs.

\section{SHAPE OF THE SEAT OF A SIDE-SADDLE.}

The level-seated fad which some fashionable saddlers try to impress on their inexperienced customers is an absurdity from a hunting point of view, because no one out of an idiot asylum would care to sit for several hours on a perfectly level surface, whether it was a saddle or a chair. The discomfort which such an attempt would entail, is due to the fact that the nature of our anatomy requires a certain amount of dip in that portion of the seat upon which most of the weight falls. The level-seated idea is purely theoretical, because no saddles are made in conformance with it. For hunting we must have comfort, without, of course, any undue violation of smartness. Besides, a certain amount of dip in the seat, similar to that shown in Fig. 16, is an aid to security. A cutback pommel (Fig. I I) improves the look of a sidesaddle without diminishing the rider's grip. The seat on the near side should be eased off, so as to allow the rider's left leg to get close to the horse; and the near side, close to the cantle, should be made a little higher than the off side, in order to correct any tendency there may be to sit too much over on the near side.

The saddles which I used on Romance (Fig. 4), 
and Freddie (Fig. 7), about fifteen years ago, were not called "level seated," but we may see that they are quite as neat and smart as those of the present time, which fact shows that very little change has been made in the shape of side-saddles since the eighties.

THE SADDLE MUST FIT THE RIDER.

The two great points in this requirement are that the upper crutch and leaping head should be in a suitable position, and the saddle sufficiently long, so as to be about a couple of inches clear of the back of the rider's seat. The right position of the upper crutch and leaping head can be determined only by experiment. If the tree is so short as to allow any undue weight to fall on the cantle, the horse will naturally run the risk of getting a sore back. The height of the upper crutch and the length of the leaping head will vary according to the thickness of limb. We shall see on pages I5O to I 52, that the position of the upper crutch which will suit a lady who hooks back her right leg, will not be applicable to one who carries her right foot forward; and vice versâ. A saddle which suits a rider's style of equitation will invariably fit her, if its tree and its crutches are long enough. Hence, if more than one member of a family wants to ride and there is only one horse, a saddle which will fit the biggest will suit all the rest.

CRUPPER.

The office of a crupper is to prevent the saddle 
working forward on the horse's back, which it will not do if the animal is of a proper shape and the girths sufficiently tight. In ancient days, when riding-horses were more rotund than they are now, and saddles were not so well made, cruppers were generally used, but within the last forty years they have gone entirely out of fashion. A crupper is not to be despised in out-ofthe-way parts abroad, when we have to ride animals of all sorts and sizes, and when we have only one saddle.

\section{NUMDAHS AND SADDLE-CLOTHS.}

As the principles which regulate the use of these appliances with cross saddles are the same as those with side saddles, I cannot do better than give the following extract from Riding and Hunting, with one or two additions:

"Saddle-cloths are generally made of felt, and their primary object is to prevent the panel from soaking up sweat and becoming thereby soiled and more or less spoiled. The term numdah or numnah, which is applied to felt saddle-cloths, is derived from a Hindustani word that signifies 'felt.' A saddle-cloth should be as thin as efficiency in serving its purpose will allow it to be, so that it may give as little play as possible to the saddle. Although the fitting of the saddle should as far as practicable be limited to the adjustment of the shape of the tree and to regulating the amount of stuffing in the panel; the use of a numdah with a saddle which does not fit the horse or which is not sufficiently 
stuffed, is often a valuable makeshift when necessity gives no other choice. The employment of an ordinary saddle-cloth is accompanied by the slight disadvantage, that the middle line of the back which is covered by the saddle is deprived of the benefit of air circulating along it, by the fact of the saddle-cloth resting on it. An attempt to remedy this objection is sometimes made by cutting a longitudinal piece out of the centre of the saddle-cloth. Here the cure is worse than the complaint, because injurious pressure will be exerted by the edges of the aperture thus made, especially if the edges are bound with tape, to preserve them from fraying out.

"A saddle-cloth should extend about two inches beyond the bearing surfaces of the saddle, so that its edges may not give rise to unequal pressure on the back, which would occur if the saddle-cloth was shorter than the tree.

"Saddle-cloths made of one thickness of leather admirably answer the purpose of saving the panel from injury ; but for hunting and other long-continued work they have the objection of retaining perspiration, instead of soaking it up, as felt ones do. It is a good plan before using a new saddle-cloth, to rub a little neat's-foot oil into its rough (upper) surface, which is much more absorbent than its smooth side. If neat's-foot oil is not at hand, cod liver oil or castor oil may be used. The oily application can be repeated, according as the leather gets dry."

As a substitute for a panel, Messrs. Champion and 
Wilton have devised a numdah lined with spongiopiline and covered with linen, to be used with a saddle, the underneath part of the tree of which is covered with leather. The chief advantage of this numdah is that a saddle which is provided with two or more of them, can always present a dry bearing surface to the horse's back. A stout numdah of this kind can be used with a high withered animal, and a thin one with a horse which has thick withers. Its inventors claim that it distributes the weight better and keeps the saddle steadier than a panel.

\section{SIDE-SAIDLES FOR CHILDREN.}

As children are unable to take the necessary precautions against accident, no considerations of fashion or smartness should outweigh those of safety for the little ones. Even the old handle at the off side of the saddle (p. 3o) might be a valuable help to a very young beginner. The seat of the saddle and the bearing surfaces of the upper crutch and leaping head had best be of rough leather, and particular attention should be paid to the construction of the upper crutch and leaping head, so that a maximum of grip may be obtained, which is a point that is deplorably neglected by many of the makers of side-saddles for children. Children can ride in any comfortable saddle, supposing that it is not too small. I have taught very small girls to ride in my saddle and jump without reins on a horse 5 5-3 high. A lady who attended one of these lessons, which were held in Ward's riding-school in 
London, made two sketches of her little friends which, by the kind permission of the Editor of the Queen, in which paper they appeared, I am able to reproduce. We may see that the small horsewoman is sitting well over her hurdle and is riding with comfort in a saddle that is far too large for her. The lady friend of the two little girls wrote about our work in the Queen of June I7, I893, as follows: "I made the acquaintance of the authoress of The Horsewoman one morning in Ward's Manège, where I went to see two little friends taking their riding lesson from her. It was a novel and pretty sight. Mrs. Hayes has inaugurated a method of instruction hitherto unpractised, and which must recommend itself to any one who sees the extraordinary progress which accompanies it. The children are dressed in gymnastic costume (Fig. 29) and it was the third time only that they had been put on a horse-a large horse it was too, and as patient and kindly as it is possible to be. The first thing Mrs. Hayes teaches is how to sit. By the pupils wearing no skirt she can see at a glance whether the position of the legs is right, and this is all-important.

"By the time I saw the children they were galloping gaily round and round, with radiant faces and flying hair, sitting better into the saddle, even at this early stage, than many a woman who considers herself a complete rider. They are not allowed to hold the reins; the hands lie in the lap, holding the whip across the knees, which accustoms them from the first to keep their hands low, besides teaching them to keep 
their seat without 'riding the bridle,' as so many people do. The horse is driven with long reins, like those used in breaking by Captain Hayes, and managed by him with the dexterity of a circus master. After a few turns at the canter, wicker hurdles are put up, and, to my astonishment, the children, without the slightest fear or hesitation, settled themselves down,

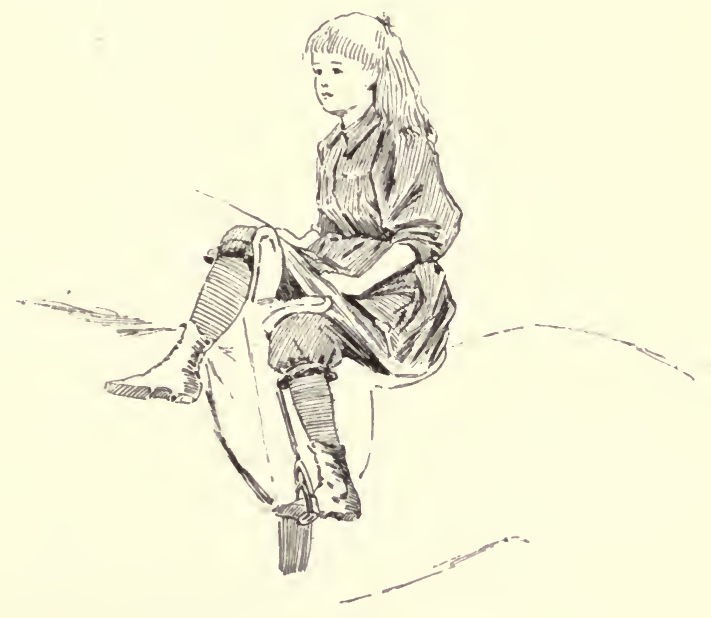

Fig. 29.--Child mounted.

leaned well back, and popped over without raising their hands or altering the position of their legs (Fig. 30). They had been over the same hurdles at the second lesson, and too much can hardly be said in praise of a system that has such results to offer in so short a space of time. Mrs. Hayes herself, as may be supposed, looks every inch a 'workman' in the saddle. She has ridden in most quarters of the globe; and, as if she sighed for other 
worlds to conquer, and were blasée about all sorts and conditions of horses, she rode a zebra at Calcutta which was broken within an hour by her husband sufficiently to be saddled and bridled. Her experiences on his back are entertainingly set forth in her book The Horsewoman, which is well worth the reading, not only for its hints on horsemanship, but for the many amusing sporting anecdotes. Her other book is one which one would hardly have expected from a woman whose life has been in so great a measure devoted to horses and sport. It is called My Leper Friends. A friend indeed they must have thought her, with her devoted sympathy and repeated endeavour to alleviate the sufferings from the most distressing and repulsive malady in the world. Another book is now on the stocks, the preparation of which keeps Captain and Mrs. Hayes for the present in England. That done, they will soon start again on their travels, England being a place that never holds their roving spirits long. The curiosities, and beautiful stuffs and feathers, which they have gleaned in many lands will have to disappear into big boxes and be warehoused, until some fresh store of adventures recalls the wanderers home

"Meanwhile she teaches the art, of which she is indeed a past mistress, in a way which it is a pleasure and profit to see; and I can most conscientiously aclvise any mother to send her girls to her if she wishes them to at once become perfect horsewomen while remaining perfect ladies." 
$\mathrm{W}^{\top}$ e had so many charming pupils during our short stay in London, that I shall always regard this teaching period as one of the pleasantest events of my life. I often think about them all, and wonder how they are getting on with their riding, and, as their various difficulties have been present in my mind while writing this book, I have done my best to solve them all as clearly as possible. We put up small hurdles and got

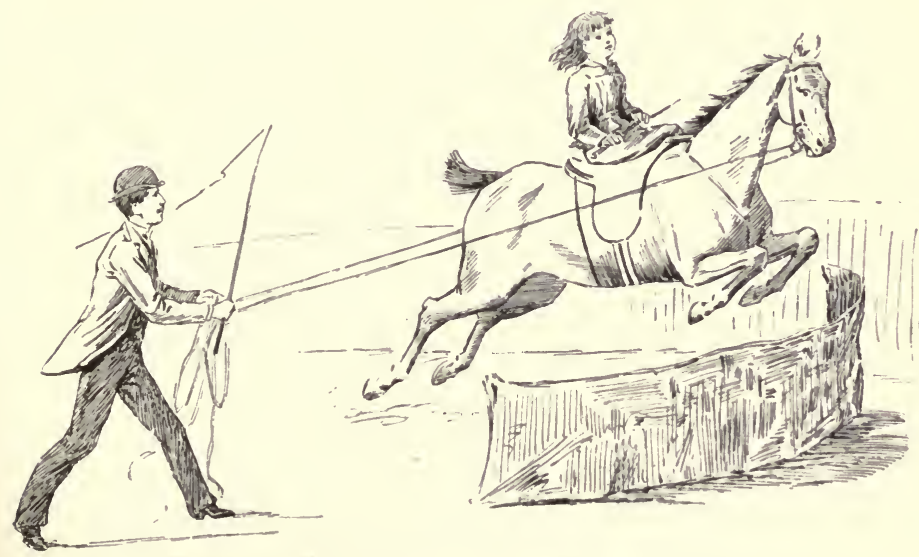

Fig. 30.-Child jumping without reins.

our tiny pupils to ride over them, because I saw that they had grasped my explanation and demonstrations of balance and grip, and it made them mightily proud of themselves, and keen on learning all they could about riding, when they found that they could sit over fences with ease. Although the school hurdles were small, our grey horse which they rode was a big jumper, which could negotiate a five-foot posts and rails with ease, so the children who rode him were 
unconsciously carried a far greater height than they imagined, for we all know that a big jumper makes a fine leap, even over small fences. In teaching children to ride we should always provide them with saddles in which they can obtain the grip that we ourselves require, and should see that the length of the stirrupleather is correct. We should remember that the young horsewoman, however tiny she may be, requires to be provided with the best and safest appliances in the matter of stirrup, safety bar, and safety skirt, that we can give her; and I may say that if I had a daughter I would never allow her to ride unless her saddle was provided with Champion and Wilton's safety bar, which I use, and unless she wore my skirt or the safe little coat shown in Fig. 57. If reliance has to be placed on a safety stirrup in the absence of Champion and Wilton's safety bar, only the capped stirrup-iron (Fig. I8) or the slipper stirrup (Fig. I9) should be employed. I have no faith in one-sided safety stirrups for young girls, for we cannot put old heads on young shoulders in the matter of careful attention about placing the foot in the safety stirrup from the proper side. A groom may put the stirrup correctly on the foot of his young mistress before starting out with her for a quiet ride, but these men naturally know nothing about the correct. length of the stirrup leather, and during the ride the stirrup may come out of the foot and be caught haphazard by the rider, with the result that, should she become unseated and thrown from her saddle by her horse suddenly 
shying with her, she may be dragged and killed. I therefore cannot too strongly recommend all mothers to see that their daughters' saddles are provided with reliable safety bars, and of course that the children are provided with safety skirts, for a safety bar is useless if the rider's skirt catches on the upper crutch and holds her suspended. In July 1897 a young daughter of a well-known nobleman was dragged by her stirrup and killed while exercising her pony in a paddock. As the stirrup was of a one-sided pattern, it must have been negligently placed the wrong way (Fig. $3 \mathrm{I})$ on the foot of the poor girl, who was only fifteen years old. I heard that rider, saddle, and pony were all buried on the same day. I would not be inclined to blame the groom if he were inexperienced, as many are, in the one-sidedness of so-called safety stirrups. Another equally terrible accident occurred in September $\mathrm{s} 893$, when a young lady was dragged by her stirrup and killed while hacking along a road at Kilhendre, near Ellesmere, with her groom in attendance. As far as I could gather from the newspaper report of this sad accident, a butcher's cart driven rapidly round a corner caused the lady's pony to shy suddenly and unseat her, with the result that she was dragged by her stirrup and killed. At the inquest which was held on the body of this poor girl, the jurymen devoted their entire attention to the character of the animal she was riding, and as the father of the young lady, who had bred the pony himself, was able to show that it was a staunch and reliable animal, the 
usual verdict of accidental death was given. These twelve good men and true absolutely ignored the stirrup, which had been the sole cause of this awful occurrence, and concentrated their entire attention on the innocent pony she rode.

\section{SADDLING A HORSE.}

As a horse's loins are ill fitted to bear weight, the saddle should be placed as far forward as it can go, without interfering with the action of his shoulderblades, the position of the rearmost portion of which is indicated by the "saddle muscle," which is a lump of muscle below the withers. The saddle can be placed about three inches behind it. Instead of putting the saddle on the exact part of the back it is to occupy, it is best to place it a few inches too far forward, and then to draw it back, so as to smooth down the hair under it, and thus make it comfortable for the animal. The front girth is first taken up, and then the next one, which is passed through the loop of the martingale or breast-plate, supposing that two girths of equal width are used. To prevent any wrinkles being made in the skin under the girths, and to make the pressure even, the groom should shorten the girths to about half the required extent on one side, should finish the tightening on the other side, and should run his fingers between the girths and skin in order to smooth out any wrinkles, the presence of which would be liable to cause a girth-gall. As girthing up, when the lady is mounted, will have to be 
done on the off side, sufficient space for that purpose will have to be left on the girth-straps of that side. After the rider has been put up, the girths should be again tightened, and it is generally advisable to repeat

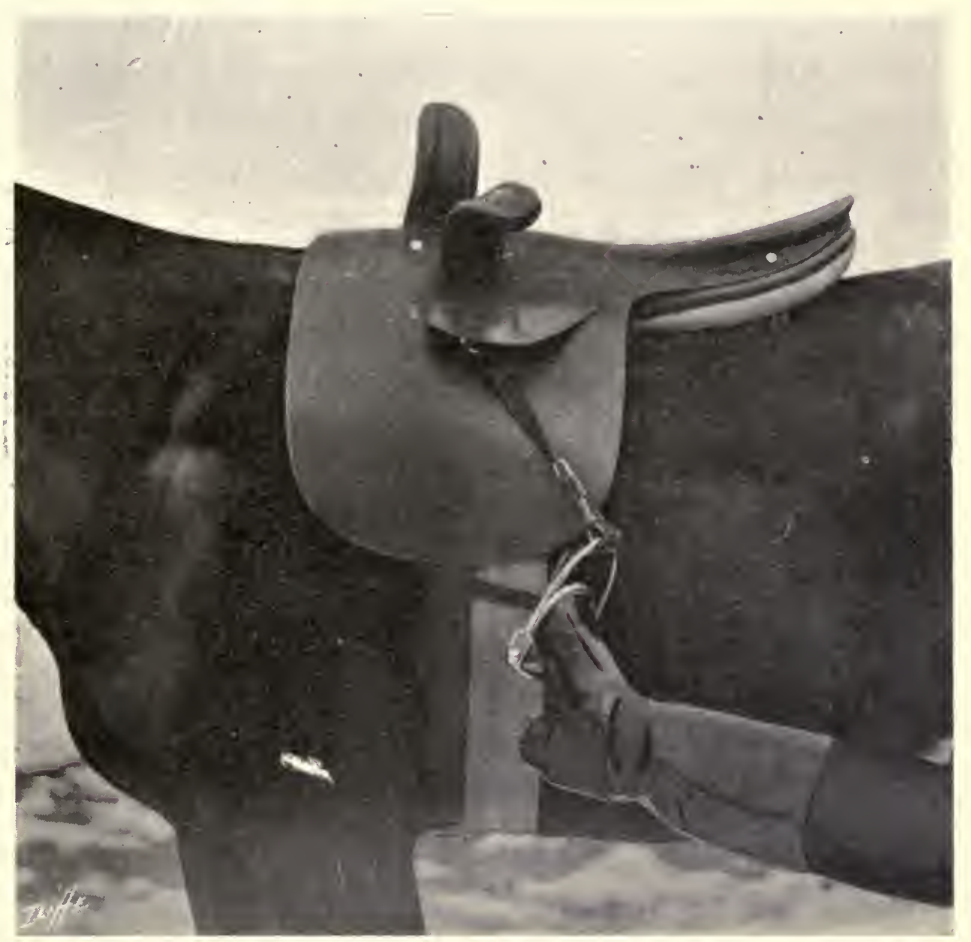

Fig. 31.-Foot caught, on account of its having been put into the stirrup from the wrong side.

this operation after she has ridden her horse for a short time, especially if the animal has the trick of "blowing himself out." With a Fitzwilliam girth, the narrow girth which goes over the broad one is passed through the loop of the martingale or breaststrap, supposing that one or both of these appliances 
are used. The balance strap should be tightened to a fair extent, though not quite so much as the girths, because the portion of the ribs over which it passes, expands and contracts far more than that encompassed by the girths.

If a saddle-cloth be used, the groom, before girthing up, should bring the front part of the cloth well up into the pommel with his forefinger or thumb, so as to prevent it from becoming pressed down on the withers by the saddle.

PREVENTION OF SORE BACKS.

The chief causes of sore backs brought on by sidesaddles are :-

I. Badly fitting saddles. The fitting of saddles has already been discussed in this chapter.

2. Neglect in girthing up sufficiently tight. As the tightness of the girths diminishes according to the duration and severity of the work, the girths should be taken up after the lady has ridden for some time. For ordinary hacking, tightening the girths after, say, five minutes' riding will generally be sufficient; but this operation should be repeated, for instance at the meet, when out hunting. Knowledge of the necessity of having the girths tight enough, to prevent the saddle wobbling, will enable the rider to take the necessary precautions against putting her animal on the sick list from this cause.

3. Undue weight on the near side, which is generally 
caused by too long a stirrup, by the leaping head being placed too low down, and by rising at the trot for too long a time.

4. Mismanagement of the horse after his return to the stable, which is a subject I will allucle to further on.

\section{CLEANING A SADDLE.}

The leather work of a saddle should be kept clean and soft, with the stitches clearly defined, and not clogged up by grease or dirt. No stain should be left on a white pocket-handkerchief or kid glove, if it be passed over any portion of the leather. Beeswax may be used to give the saddle a polish ; but it should be sparingly applied and should be well rubbed in, for it is apt to make the leather very sticky. Nothing but specially prepared or good white soap (made into a thick lather) should be employed to clean the leather work, except a little lime-juice or lemon-juice to remove stains. The use of soft soap permanently darkens leather. A small amount of saddle dressing may be put on once a month, in order to keep the leather soft and pliable. The steel work should, of course, be kept bright. 


\section{CHAPTER IV.}

\section{BRIDLES.}

Description of a Bridle - Varieties of Bits - Snaffles - Curbs - Pelhams Nose-bands-Reins-Martingales-Adjustment of the Bridle.

As there is no difference between the bridles used by men and those employed by ladies, I have compiled this chapter from my husband's Riding and Hunting, to which I beg to refer my readers for any further information they may require.

\section{DESCRIPTION OF A BRIDLE.}

A bridle consists of a bit, head-stall and reins. The bit is the piece of metal which goes into the animal's mouth ; the head-stall or "head" is the leather straps which connect the bit to the horse's head; and the reins enable the rider to use the bit.

Some persons incorrectly restrict the term "bit" in all cases to a curb. This particular application of the word is from custom allowable in the expression "bit and bridoon," in which the bit signifies a curb, and the bridoon a snaffle. 
DESCRIPTION OF A BRIDLE.

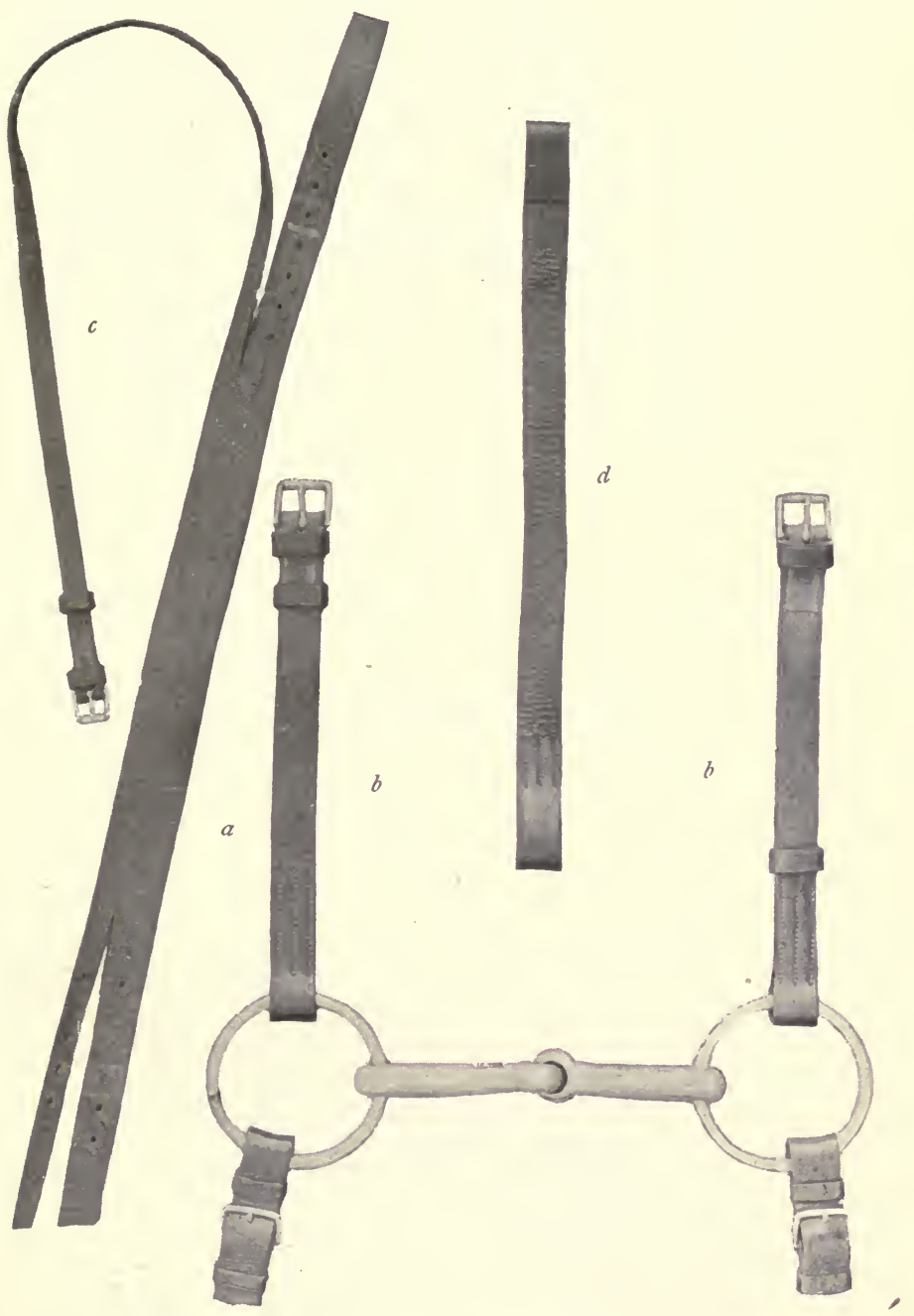

Fig. 32.- "Heal" of a Single Bridle: $a$, Crown-piece; $b, b$, Cheek-pieces; $c$, Throat-latch ; $d$, Front or Brow-band. 


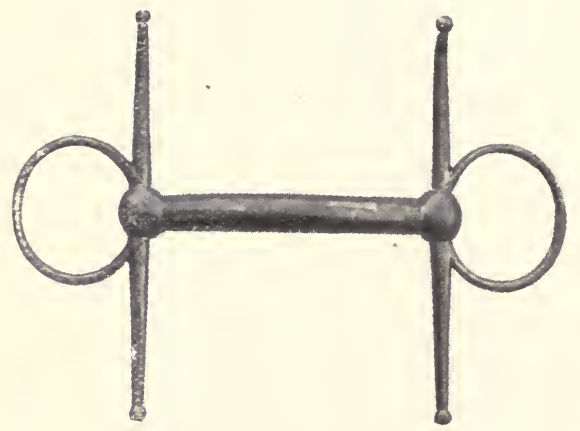

Fig. 33.-Unjointed Snaffle.

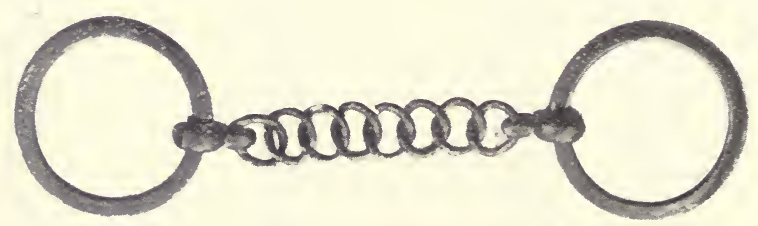

Fig. 34--Chain Snaffle.

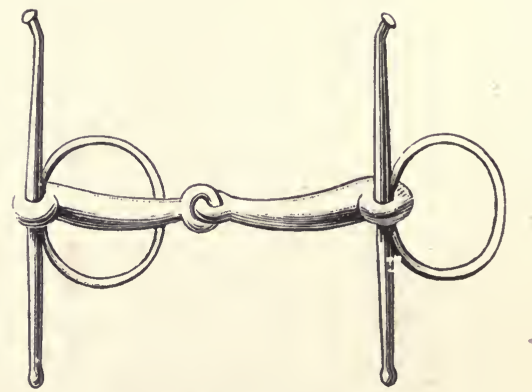

Fig. 35.-Ordinary Snaffle with Cheeks. 


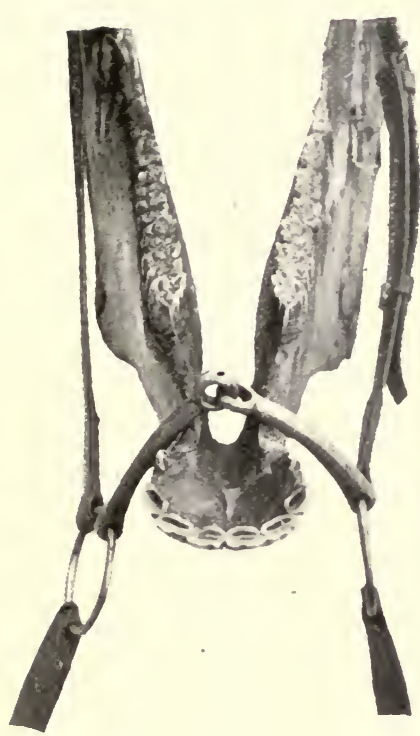

Fig. 36. -Nutcracker action of Jointed Snaffle on Horse's Mouth.

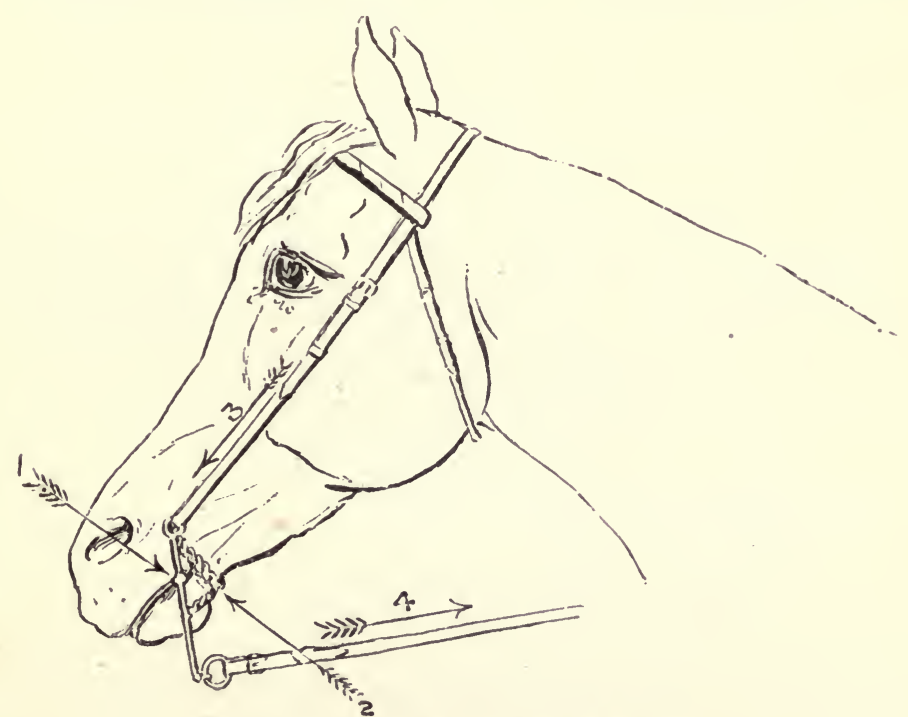

Fig. 38.-Action of the Curb as a Lever. 
The names of the different leather parts of a bridle (Fig. 32) are as follows :-

The crown piece $(a)$ passes over the horse's poll.

The cheek pieces $\left(\begin{array}{l}b \\ b\end{array}\right)$ connect the crown-piece with the bit.

The throat-latch (c), which is usually pronounced "throat-lash," passes under the animal's throat, and

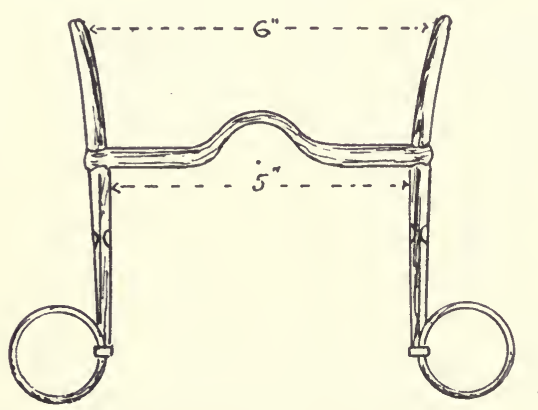

Fig. 39. - Properly constructed Curb for ordinary Hunter.

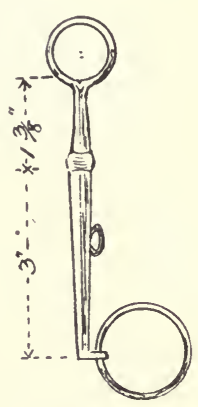

Side View.

serves to prevent the bridle from slipping over his head.

The front, forehead-band or brow-band ( $d$ ) goes across the horse's forehead, and has a loop at each end, for the crown-piece to pass through. "Front" is the trade name for this strap.

The head-stall or head, which is the trade term, is the name given to all this leather work.

VARIETIES OF BITS.

Bits may be divided into snaffles, curbs and Pelhams. 
SNAFFLES.

A snaffle is a bit which acts on a horse's mouth by direct pressure, and not by leverage.

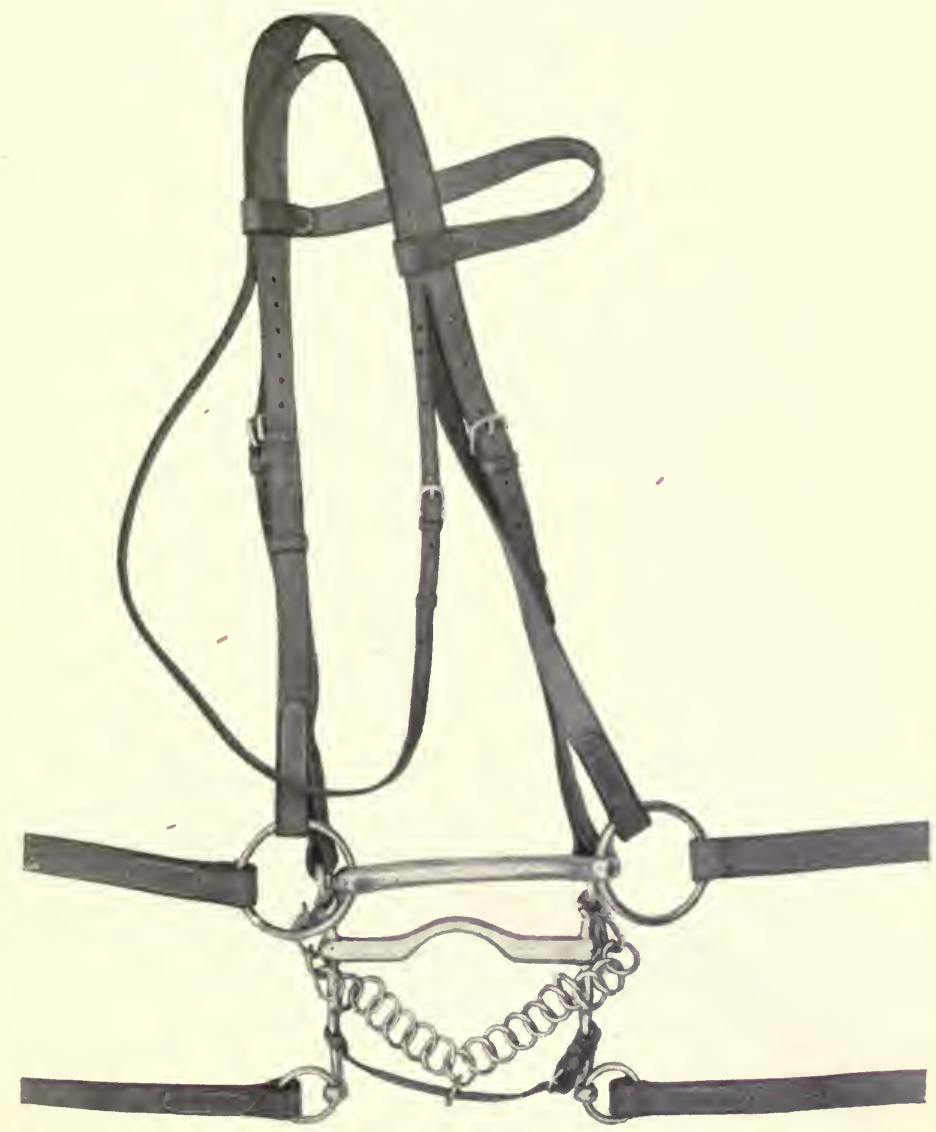

Fig. 40.-Ward Union Curb Bridle with Half-moon Snaffle.

A bridoon is the term applied to the snaffle of a double bridle, which is a bridle that has a curb and a 
snaffle. A double bridle is often called a "bit and bridoon."

The best kinds of snaffles are the half-moon snaffle

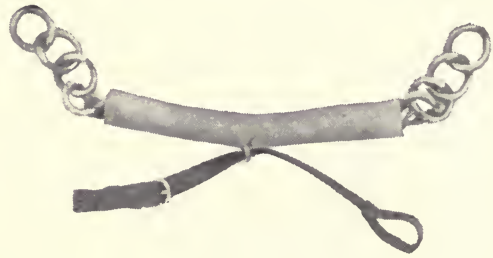

Fig. 4r.-Curb Chain covered with India-rubber Tube.

which has an unjointed and slightly curved mouthpiece (Fig. 33); and the chain snaffle (Fig. 34). The objection to the jointed snaffle (Fig. 35), which

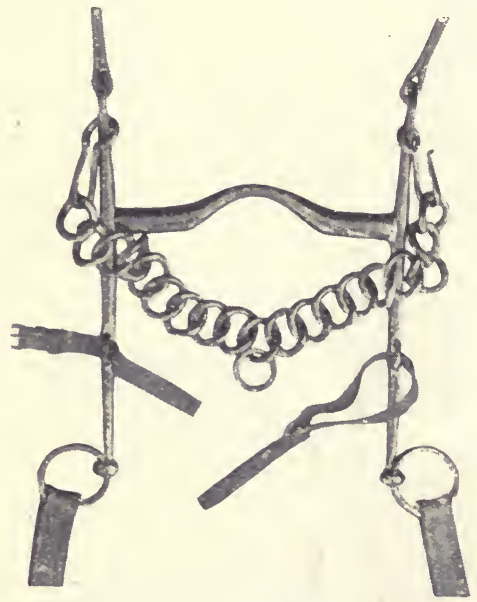

Fig. 42.-Chin-strap unbuckled.

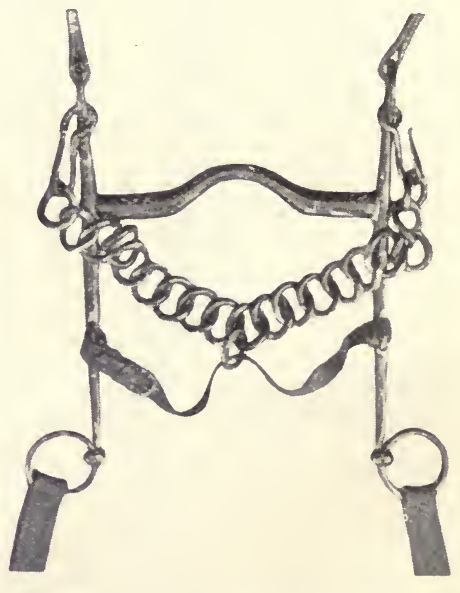

Fig. 43.-Chin-strap buckled.

is the kind generally used, is that it has a nut-cracker action on the animal's mouth, instead of exerting a direct pressure, as shown respectively in Figs. 36 and 37 . 
A chain snaffle should always have a Hancock's "curl bit mouth cover," which is a roll of india-rubber that

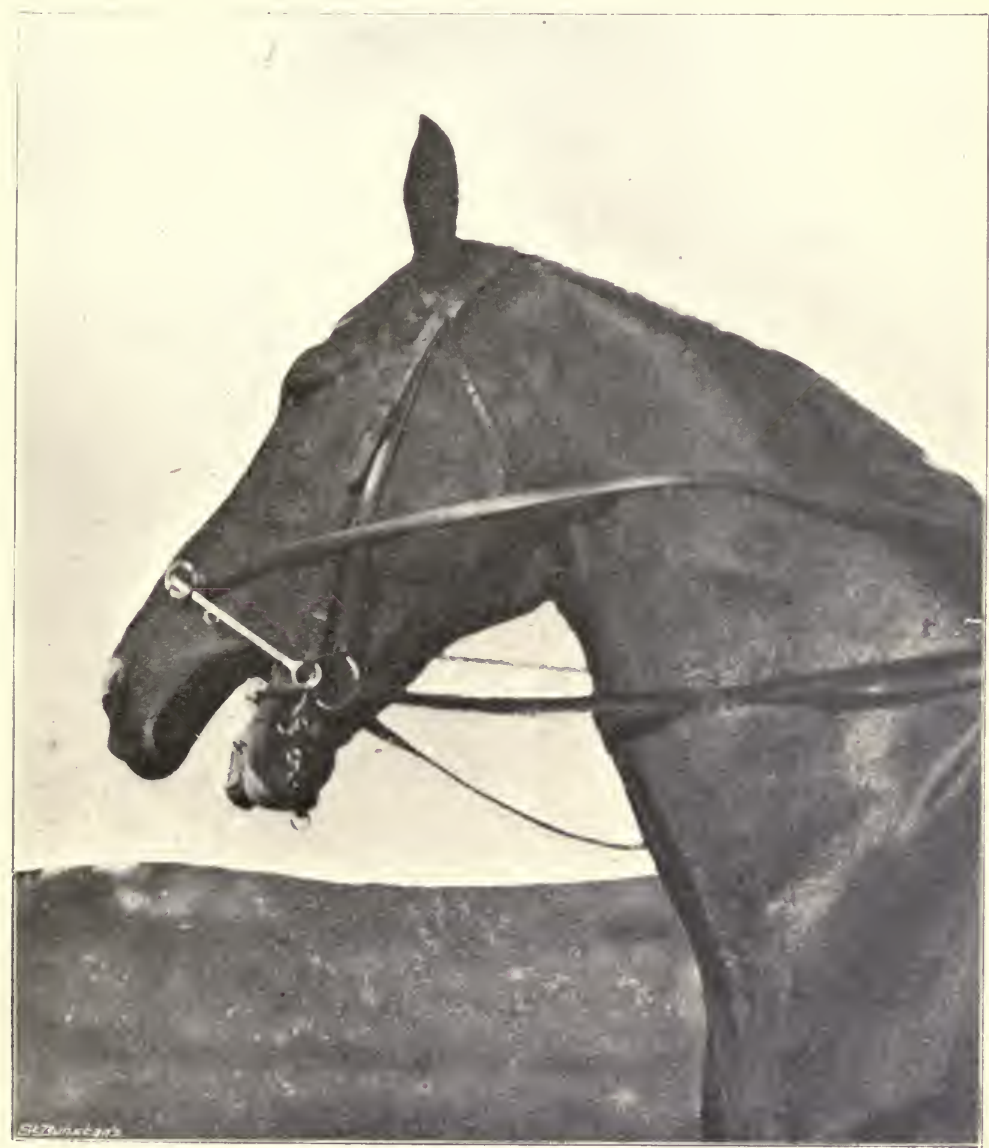

Fig. 44.-Curb reversed by horse throwing up his head, in the absence of a chin strap.

curls round the mouth-piece, and prevents it hurting the mouth. In the absence of this india-rubber arrangement, we may cover the mouth-piece with two or three 
turns of wash-leather, which can be kept in its place by sewing.

In all cases a snaffle should be thick and smooth, so that it may not hurt the horse's mouth.

\section{CURBS.}

A curb is a bit which acts as a lever, by means of the curb-chain that passes under the animal's lower jaw (Fig. 38). Fig. 39 shows a properly constructed curb for a horse with an ordinary sized mouth. The best curb which is in general use is the Ward Union (Fig. 40). The curb-chain should have broad and thick links, so that it may not hurt the lower jaw. This precaution can be supplemented by a leather guard or by passing the curb-chain through a rubber tube (Fig. 4I). A chin-strap (Figs. 42 and 43) is necessary to keep the curb in its place (Fig. 44).

PELHAMS.

A Pelham is a bit which can act either as a curb or a snaffle, according to the reins which are taken up. Unless a lady thoroughly understands the handling of the reins, she should not use a Pelham, because her tendency when riding will be to feel both reins, in which case the snaffle reins will pull the mouth-piece high up in the mouth, which, as we shall see further on, is the wrong position for the action of the curb. Hence, only one pair of reins (either those of the snaffle or those of the curb) should be brought into play when using a Pelham. 


\section{NOSE-BANDS.}

The use of a nose-band is to keep the horse's mouth shut, in the event of his holding his jaws wide apart, so as to resist the action of the bit. To be effective, it

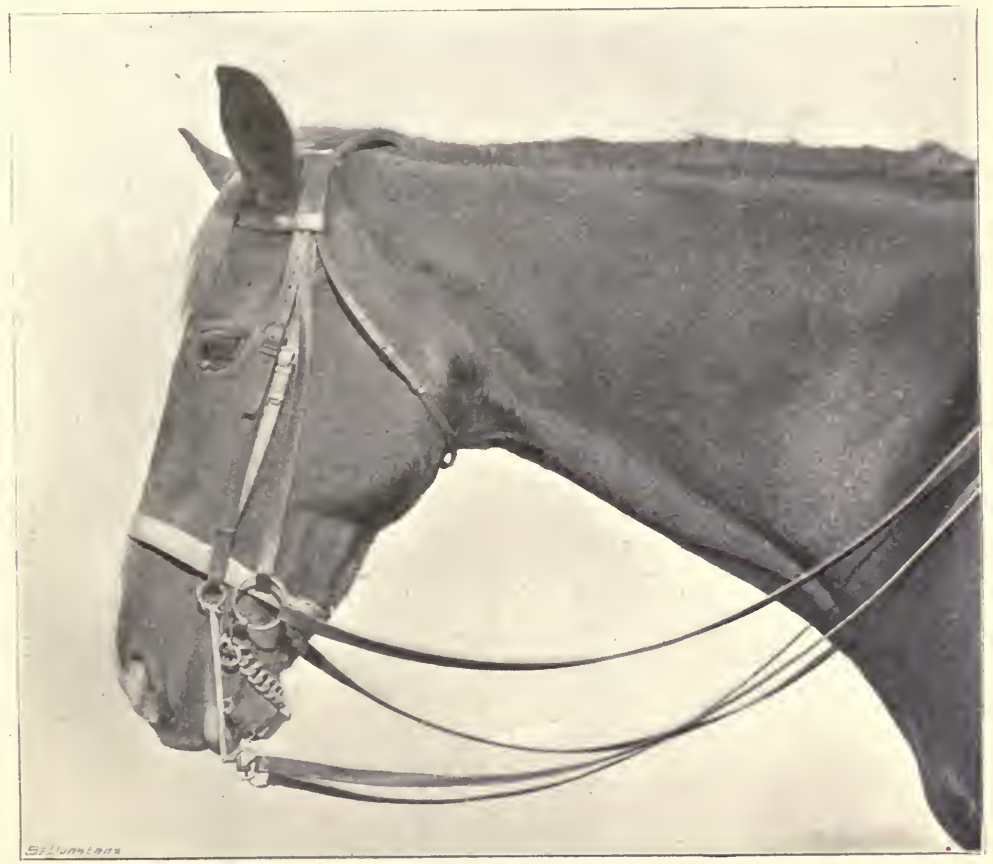

Fig. 45.-Cavasson Nose-band.

should be fixed low down. The cavasson nose-band (Fig. 45) is neat and serviceable.

REINS.

Reins should be fairly broad (say, $7 / 8$ inch) and 
80 BRIDLES.

moderately thin, so that they may be handled with efficiency and ease. With a double bridle, the curb

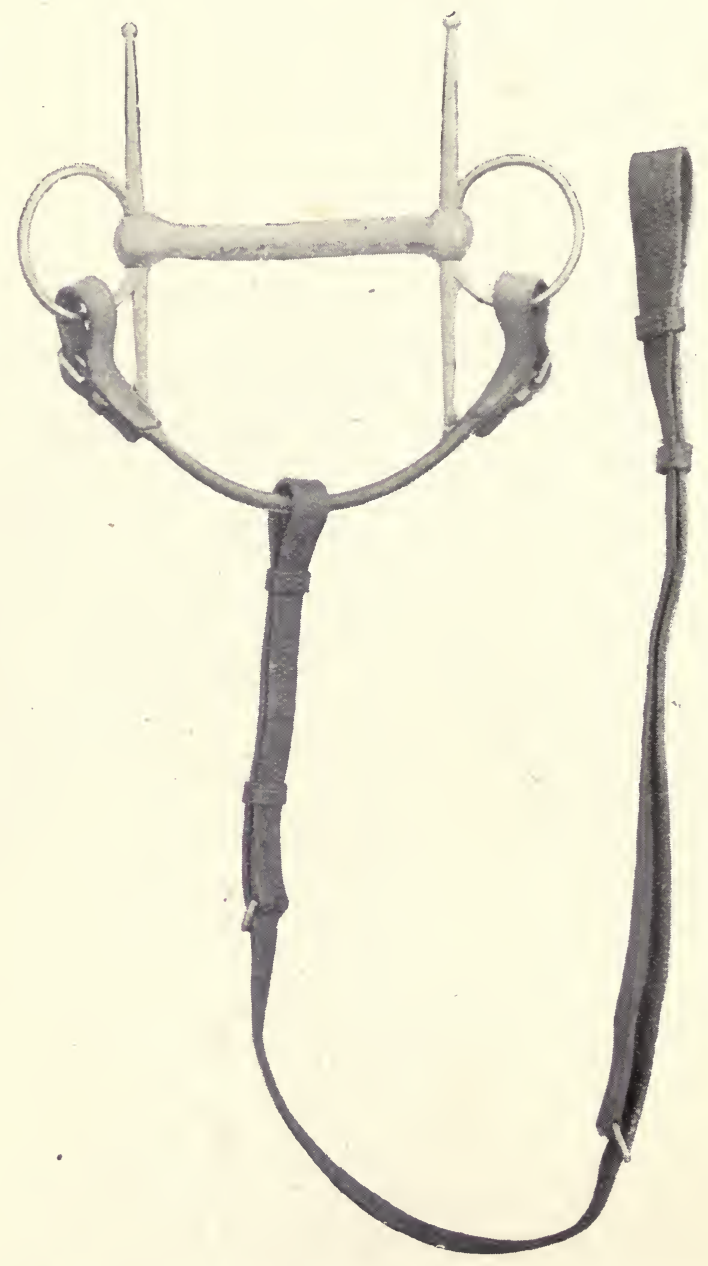

Fig 46.-Standing Martingale attached to rings of the Snaffle.

reins are sometimes made a little narrower than the snaffle reins, which is an arrangement I like, because 
REINS.

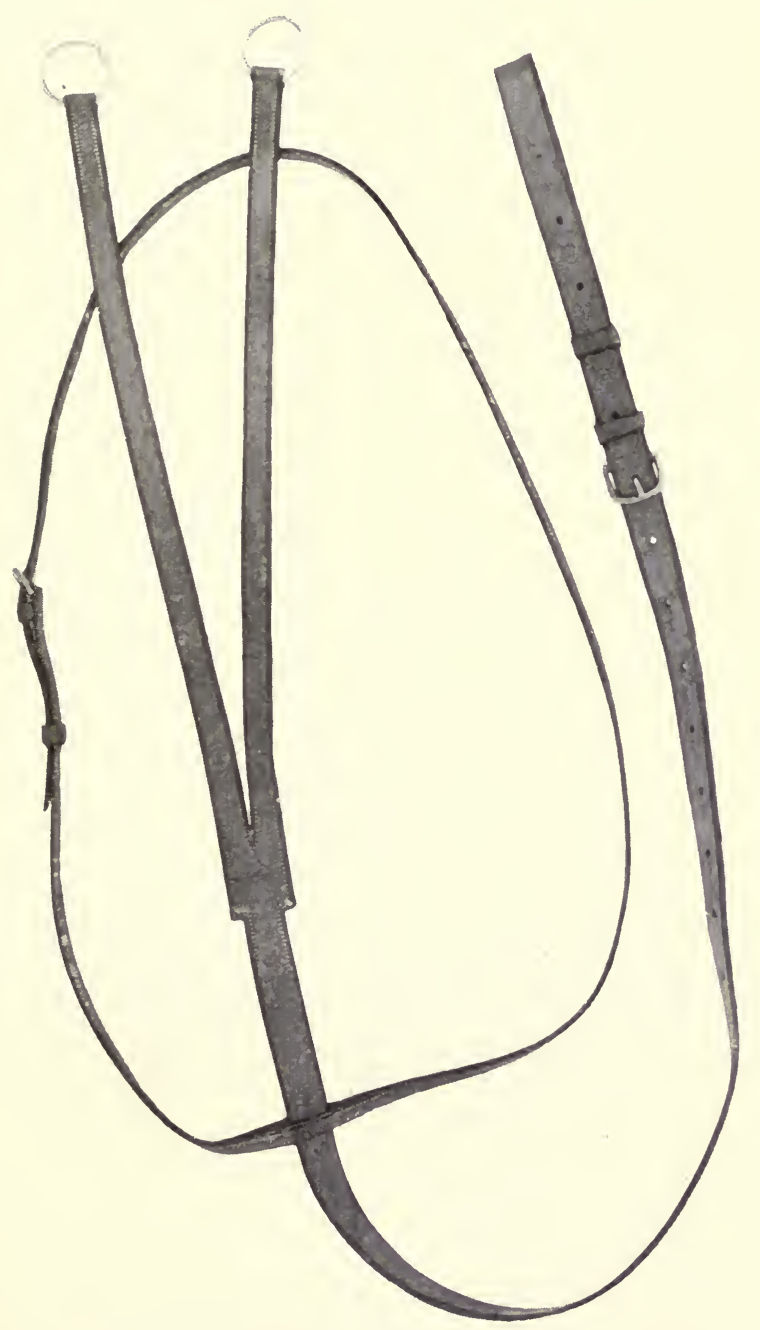

Fig. 47--I ord Lonsdale's registered Running Martingale. 
it greatly helps the rider to distinguish one pair of reins from the other. With the same object, I like the snaffle reins to be connected by a buckle, and the curb reins by sewing.

MARTINGALES.

The only kinds of martingales which we need consider are the standing martingale which is buckled on to the rings of the snaffle (Fig. 46) and the running martingale (Fig. 47). Following in the footsteps of that high priest of Irish horsemanship, Mr. John Hubert Moore, I pin my faith to the standing martingale, as it has enabled me on many occasions to ride, in peace and quietness, horses which without it would have been most dangerous "handfuls." Its great virtue, when properly put on, is to prevent the animal getting his head too high. If he be allowed to do this and is unruly, whether from vice or impetuosity, our power over him will more or less vanish, and besides he will not be able to accurately see where he is going, in which case we will be lucky if we escape without an accident. The famous steeplechase horse, Scots Grey, would never win a race without one of these martingales to keep his head in proper position. When lengthened out to its maximum effective length (Fig. 48), it cannot possibly impede the horse in any of his paces or in jumping. It is, of course, well to accustom a horse to its use before riding him in it over a country. It at least doubles one's power over a 
puller, and is invaluable for controlling and guiding a "green" animal.

It is a common idea that the chief use of a running martingale is to prevent a horse raising his head too high. We find, however, that when our best flat race and steeplechase jockeys and other good horsemen ride

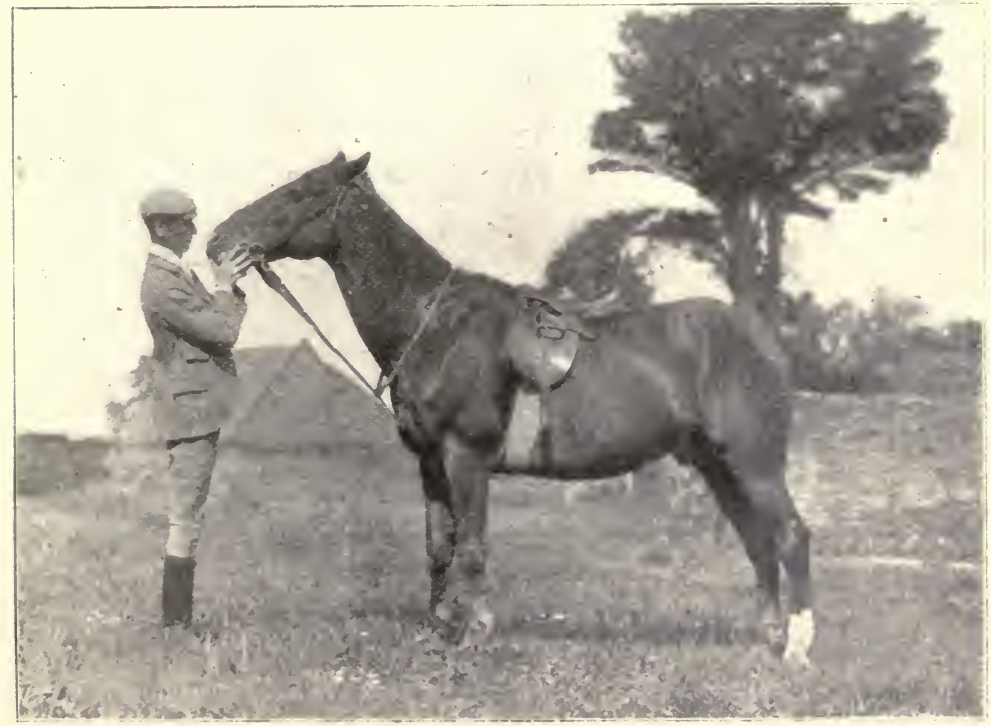

Fig. 48.-Maximum length of Standing Martingale.

with this martingale, they almost invariably have it so long, that it has little or no effect in keeping the head down. When a horse is prevented from raising his head too high by a standing martingale attached to the rings of the snaffle, he is punished by the tension of the martingale being transmitted to the mouth-piece of the snaffle, if he tries to get his head in the air; but 
the moment he brings his head down and bends his neck, cessation of the painful pressure will reward him for his obedience. This automatic means of dispensing punishment and reward is so accurate in its working, that a horse soon learns the lesson set before him. But with a running martingale, the rider, in order to reward the horse for bringing his head into proper position, would have to slacken out the reins with a promptness that would be seldom attainable, and with an entire disregard of control over the animal. In fact, with a running martingale, adjusted so as to prevent the horse from getting his head too high, the reins would have to perform the dual office of keeping down the head, and of regulating the speed, which duties could seldom be successfully combined. With a standing martingale, however, the rider can safely relinquish the adjustment of the height of the animal's head to the martingale, and consequently he is not forced to check the horse's speed, when he wants to get his head down. Some good horsemen, on finding that the running martingale did not perform its supposed office efficiently, have discarded it altogether, and thenceforth have trusted to their hands to act as their martingale. In this they were right not to use a running martingale to keep a horse's head down; but they were wrong in thinking that keeping the head down was the only, or even the principal, use of this article of gear. If we closely examine its action, we shall find that the great value of this martingale is to aid the rider in turning a horse by keeping his neck straight, when cantering or galloping, 
which object is greatly facilitated by the opposite rein exerting a strong pressure on the neck.

In regulating the length of the running martingale, we should carefully guard against making it so short that it would interfere with the horse's mouth, when he is not carrying his head unnaturally high ; for such interference could have no good result, and would probably impede the animal's movements. Although it is impossible to determine with mathematical accuracy

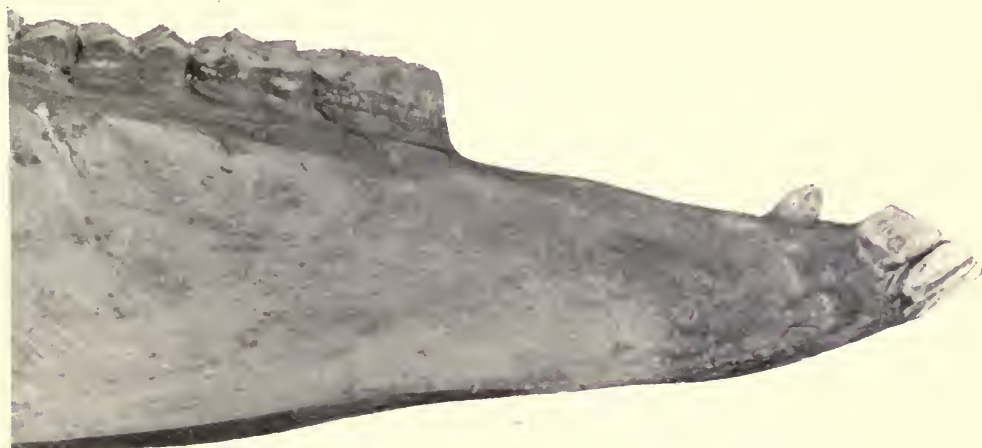

Fig. 49.-Side view of Horse's lower jaw.

the exact length of this martingale, we find in practice that it should not be shorter than a length which will allow it, when drawn up, to reach as high as the top of the withers. Lengthening it out another three or four inches will generally be an improvement. The use of a running martingale shorter than the minimum I have just laid down, more or less irritates the horse; because, even when he holds his head in correct position, he cannot escape from its disagreeable pressure. The employment of a short running martingale for 'cross 
country work is a very dangerous proceeding; for if the rider does not leave the reins loose when jumping; the horse will be almost certain to hurt his mouth, and consequently he will be afraid to face his bit, or will become unmanageable from pain, either eventuality being highly dangerous to horse and rider.

ADJUSTMENT OF THE BRIDLE.

'The bit is placed in the horse's mouth, because there

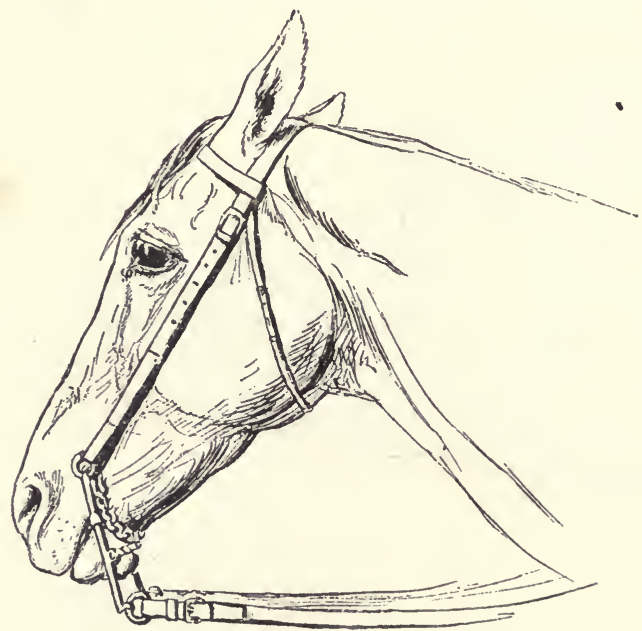

Fig. 50.-Angle made by the Cheeks of a Curb, when the Reins are taken up.

is a vacant space (of about four inches in length) on the gums of his lower jaw, between his back teeth and tushes (canine teeth or eye teeth), as we may see in Fig. 49. A mare has no tushes, or possesses them in only a rudimentary form. The tushes of a horse begin to appear through his gums when he is about 4 years old. If horses had not this convenient gap 
(interdental space) in their rows of teeth, we would probably have to guide and control them by means of reins attached to a nose-band, which is a method practised by many American cow-boys when breaking in young horses. Owing to the fact that their noseband (hackamore) does not hurt the animal's mouth. and that it gives all the necessary indications, excellent results, I believe, are obtained with it.

As the pressure of the bit should be an indication

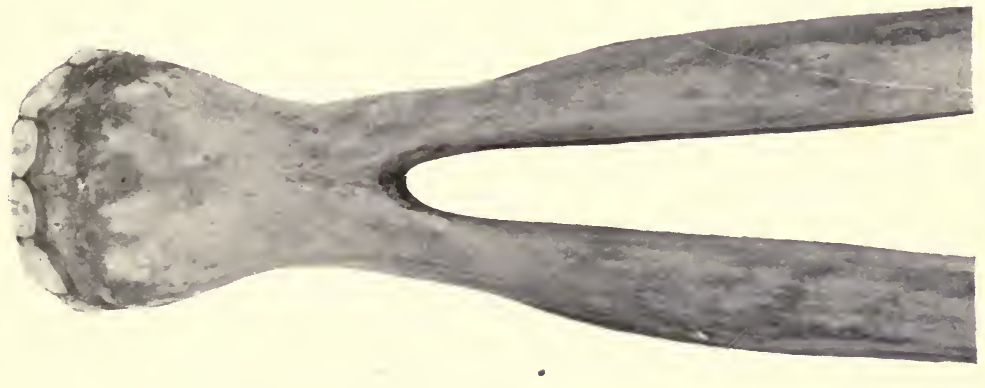

Fig. 5r.-View of under-surface of Lower Jaw.

of the wishes of the rider and not a means of inflicting pain, the bit should rest on the least sensitive portion of the interdental space, namely, on the part just above the tushes; because there the jaw-bone is broader than higher up, and is consequently better able to bear pressure. Hence, with a double bridle, the mouth-piece of the curb should be just clear of the tushes of the horse or gelding (Fig. 49), and about one inch above the corner front teeth of the mare; in fact, as low as possible without making the curbchain liable to slip over the animal's chin. The fact 
of the mouth-piece of the curb being in this position has the further advantage, that it prevents the curbchain from working up on the sharp edges of the lower surface of the jaw. The curb-chain in Fig. 50 rests in what is called the "chin-groove," which is the depression that covers the bone immediately below the point at which the lower jaw divides into two branches (Fig. 5I). The edges of these branches are sharp, but that portion of the bone which is between their point of separation and the front teeth, is smooth and rounded.

The snaffle, whether by itself or in conjunction with a curb, should be placed sufficiently low, so as not to wrinkle the corners of the mouth.

The tightness of the curb-chain should in no case exceed that which will allow the cheeks of the curb the amount of "play" shown in Fig. 50. With a light mouthed horse, the curb-chain might be let out another hole or two.

The throat-latch should be loose, so that it may not exert any pressure on the animal's wind-pipe. 


\section{CHAPTER V. \\ R I D I NG D R ES S.}

Habits and Safety Skirts-Breeches-Underclothing-Hats-Boots-GlovesRiding Under-Bodice, Hunting Ties, Collars, Cuffs, and Ties.

\section{HABITS AND SAFETY SKIRTS.}

The choice of the material for a riding habit is naturally limited to the price which the purchaser intends to pay for the garment. I would, however, strongly counsel the selection of the best possible cloth, as only from it can a really successful habit be constructed. Tailors who make a habit for five guineas, doubtless give the best value they can for that sum; but when we consider that a good Melton cloth costs about a guinea a yard, we can understand that it is impossible to get material of that class in a cheap garment. All good habit makers will admitthough in most cases very reluctantly-that Melton is by far the best material for riding habits which are intended for hard wear, as in hunting; but it possesses, in their eyes, the very grave fault of longevity, for a good Melton habit lasts for several years. Rough-faced cloths, such as cheviot, frieze, and serge, retain moisture 
like a blanket, and shrink after exposure to much rain ; but Melton, which is of a hard and unyielding texture, and has a smooth surface, is almost impervious to wet. The virtues of this material are much appreciated by experienced hunting women for hard wear. There is "a something" about the hang of a perfectly-fitting Melton habit which no other material seems to possess; and whatever the elements may be doing, it never appears out of place. On the other hand, if it is badly cut, it exposes the shortcomings of its maker in the most ungenerous manner, and is so obstinate that all the altering in the world will not make it forgive the insult to its cloth. A Melton habit, therefore, requires to be cut by one who is an artist at his trade. Another advantage possessed by this cloth is that it is far easier to clean than any rough-faced material. An experienced saddler has drawn my attention to the fact that the dye from skirts made of cheap shoddy material, is apt to come off and seriously injure the leather of the saddle.

The colour of a habit is a matter of taste on which I can offer no advice, except that a lady who requires to wear her habit until it exhibits signs of old age, would do well to select an inconspicuous tint. I have always found dark blue the most serviceable shade, because it does not fade, even in tropical climates, nor does it, like black, turn green and rusty-looking before it is worn out. Besides, it admits of a new skirt or new coat, as the case may be, without emphasising the disparity in age of its companion so much as is the 
case with lighter shades, such as grey for instance. Some years ago, various shades of green, brown, and claret colour were worn, but they seem to have been

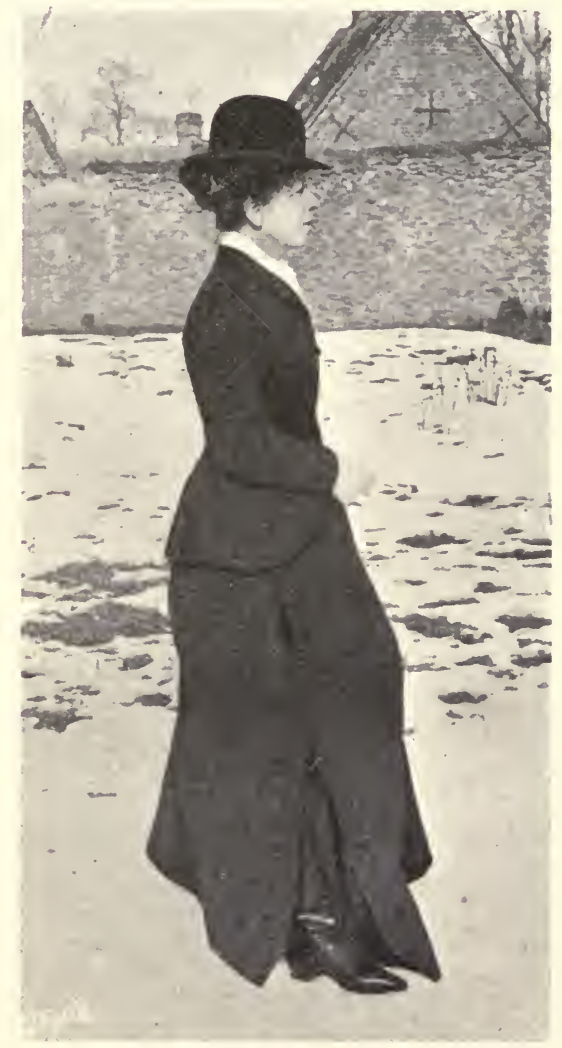

Fig. 52. - The Hayes' Safety Skirt open for mounting.

superseded by dark grey and dark blue, at least in the Shires, though since the death of our lamented Queen Victoria, black has been greatly used.

In selecting a Melton habit, a heavy make called 
treble Melton should be chosen for the skirt, and a lighter one of the same material, which all good habit makers keep in stock, for the coat ; because, in order to hang well, a skirt must be of heavy cloth, which would, of course, be too hard and unyielding for a riding coat. We require a "kind," pliable cloth for our coats, to allow us absolute ease and freedom of movement, but our skirts, even for wear in the tropics, should be of a thick, heavy make. When I went out to India in I 885, safety skirts were unknown, or, at least they were not constructed by Creed, of Conduit Street, who made my habits, and who was in those days regarded as the best habit maker in London. He told me that my thick Melton skirt would be of no use to me in that hot country, and recommended a habit of khaki-coloured drill, for which I paid sixteen guineas, as he would not make any kind of riding habit for less than that sum. I soon found that my investment was a failure, for the skirt flapped about like a sheet in the wind, and the marks of perspiration on my coat looked most unsightly, so I handed over my drill habit to my ayah, a gift which I know she did not appreciate at anything approaching its cost. I found myself more comfortably garbed in my Melton skirt, for heat in riding is not felt to any appreciable extent below the waist, and I provided myself with jackets of white drill, on which marks of perspiration are not so unsightly as on a coloured material.

As safety in the saddle is the first consideration, and as no article of riding dress has proved such a death- 
trap as the skirt, no lady should ride in one of the oldfashioned, dangerous pattern. I am thankful to say I was never dragged in any of those ancient garments, but I was fully aware of this danger, and devised, as

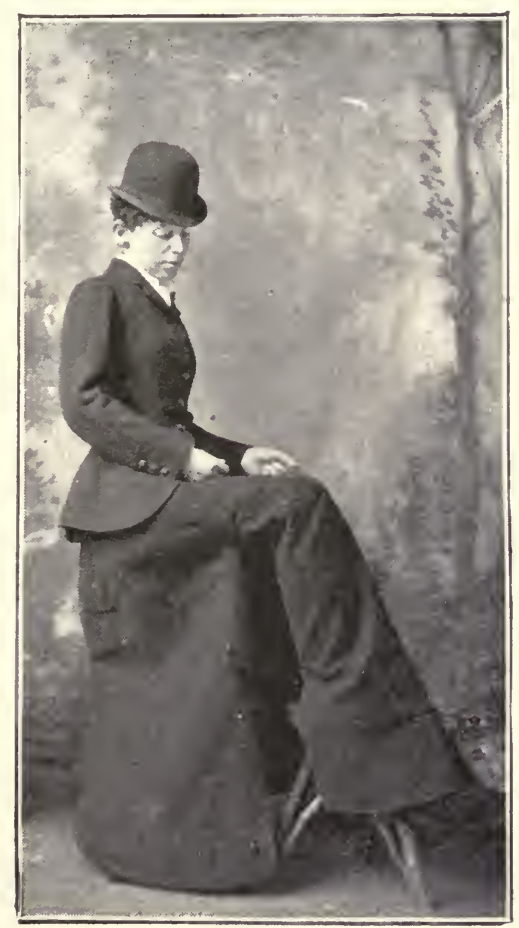

Fig. 53.-Off side of The Hayes' Safety Skirt.

I explained in the first edition of this book, a means of lessening it by buttoning "the under and outer part" of the skirt just above the knee to the breeches, by means of large flat cloth buttons, the same colour as the skirc, being sewn on the breeches, and corresponding button-holes being made in the skirt. The 
idea was a practical one, but I was by no means satisfied with it, and I began to evolve a safety skirt of my own. While I was experimenting with a pair of scissors on an old skirt in which a groom was seated on a side-saddle, a habit maker sent me and asked me to wear and recommend what he called a "perfectlyfitting skirt." This awful thing had glove-like fingers, which were made to fit the upper crutch and the leaping head! I hope no lady ever risked her neck in such a death-trap as that. In puzzling out my safety skirt, I desired to attain two objects, namely, absolute safety in the saddle, and a decent covering for my limbs when out of it, so that I might be able to dismount and walk exposed to the gaze of men at any time or place, without my dress, or rather want of it, being made the subject of remark. I had a nice quiet horse, who allowed me to thoroughly test my invention by falling off his back in every conceivable direction, my husband being present to prevent my voluntary fall from degenerating into a "cropper." Mr. Tautz, the wellknown breeches maker of Oxford Street, witnessed these acrobatic feats, and after we had all been perfectly convinced of the absolute safety of the garment, he took it on a royalty. My skirt has now been on the market for several years, and I am glad to have this opportunity of thanking the numerous ladies who have shewn their appreciation of it. Fig. $5^{2}$ gives the appearance of the "Hayes' Safety Skirt," when its wearer is ready to mount, Fig. 53 shows the off side when in the saddle, in Fig. 54 we see the side 
opening, from which the cloth near the crutches is cut entirely away, closed for walking, and Fig. 6 shows the hang of the skirt when the wearer is mounted. Since

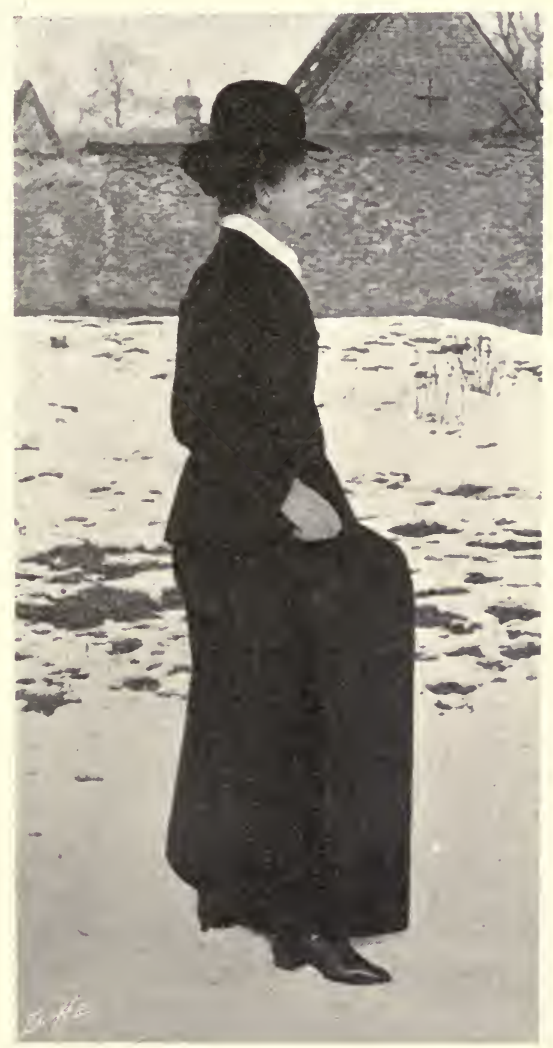

Fig. 54. - The Hayes' Safety Skirt closed for walking.

this skirt was invented, I have had several opportunities of further testing its merits, especially when riding young horses which have fallen with me in Leicestershire, and I would not care to ride in any 
other kind. There are several safety skirts, but it is obvious that the best kind is one that is safe to ride in, presentable when dismounted, and easily arranged, which conditions are thoroughly fulfilled by my patent. There are riding women who object so much to the indecency of apron skirts (Figs. 55 and 56 ) that they adopt the dangerous closed pattern. My skirt would commend itself to those of my sex who are sufficiently old-fashioned in their ideas to desire a safe and, at the same time, decent and graceful covering. Some ladies consider it "smart" to expose their limbs, if we may judge from the free exhibitions to be seen in the hunting field, while others, who are aware of the unbecoming effect, have their breeches made extra baggy behind!

The apron skirt is an extremely cold, comfortless garment for winter wear, because it is merely a left-side covering for the limbs, while the right side being entirely unclothed, the lines and rotundity of the figure are, when the wearer rises in trotting, displayed to the wondering gaze of those who ride behind her. As, in the apron skirt, there is no covering of Melton cloth to sit on and take off some of the wear and tear of the breeches, these garments become quickly worn out at the seat, and necessitate a double thickness of cloth at that part. There is another kind of safety skirt which is a combination of breeches and skirt in one; but I consider this a very unsanitary arrangement, for it is obvious that the undergarment must be kept clean, and handed over when 


\section{APRON SKIRTS.}

necessary to the laundress to be carefully washed, before sending it to a tailor to be pressed and repaired as may be required. It is part of a groom's duty in small households to attend to the cleaning of his

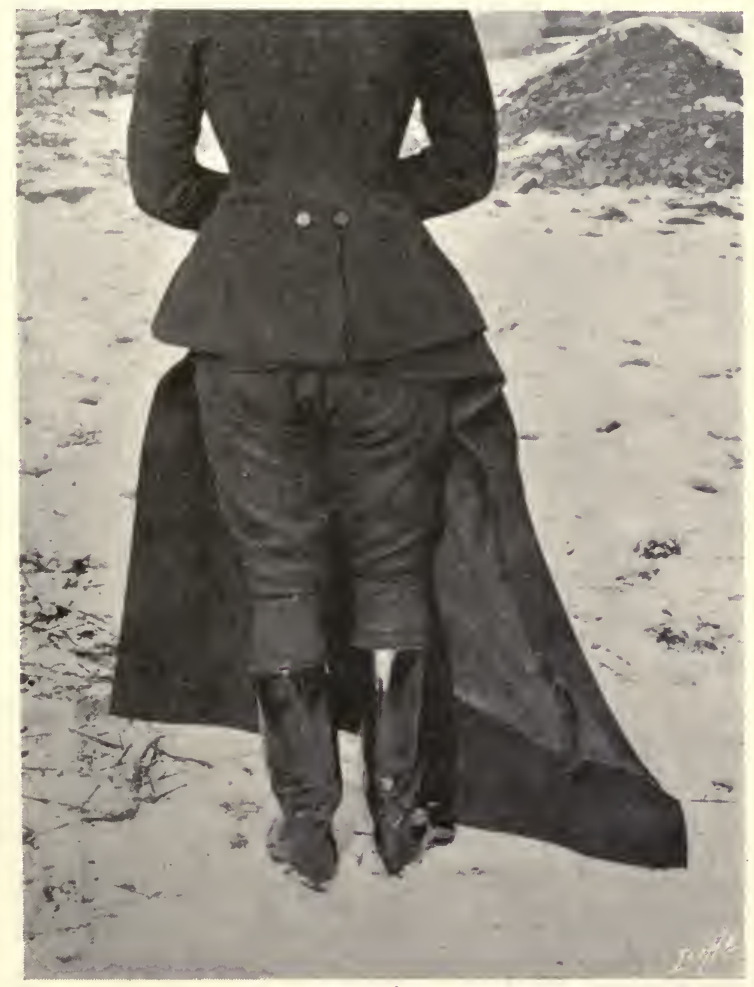

Fig. 55.-Apron skirt open for mounting.

mistress's hunting boots and skirt, but a combination garment should not be cleaned by a male servant.

Any skirt which ensures safety in the saddle is preferable to the old-fashioned shape, with its dangerous 
bundle of cloth over the crutches, a fact which is so well understood by hunting women that none who hunt in Leicestershire, or I hope in any other place, appear in those early Victorian atrocities. Provision of this kind does not appear to be insisted on for the safety of young ladies; for I saw a girl dragged in Leicestershire, and Lord Lonsdale, who fortunately stopped her horse, sent her home, and told her not to hunt with his hounds until she had provided herself with a safety skirt. The young and inexperienced, who, with the fearlessness of ignorance, are prone to rush headlong into difficulties, ought surely to be safeguarded in every possible manner. Fig. 57 shows a safe and comfortable riding dress for a very young girl. For winter wear, the coat and leggings should be made of Melton; and the breeches of elastic cloth or knitted wool to match. It is well to have the coat buttoned over the right leg, so as to protect that limb from cold and wet. For summer use, a linen coat is worn. We may notice that the sweet little horsewoman has a good seat, and is capable of taking sole charge of her nice pony.

The safest and most comfortable length for a riding skirt is when it just covers the rider's left foot when she is seated in the saddle with her stirrup at its usual length. It is best for a lady to use her own saddle when having her habit fitted, as her stirrup will then be at the length she rides in, and the crutches will also receive the necessary consideration from the fitter.

Care should be taken that the skirt fits well over the 
right knee, when the wearer is seated in her saddle. Creed and other good makers of the past always padded this knee part, which gave not only a nice, rounded appearance to the knee, especially in the

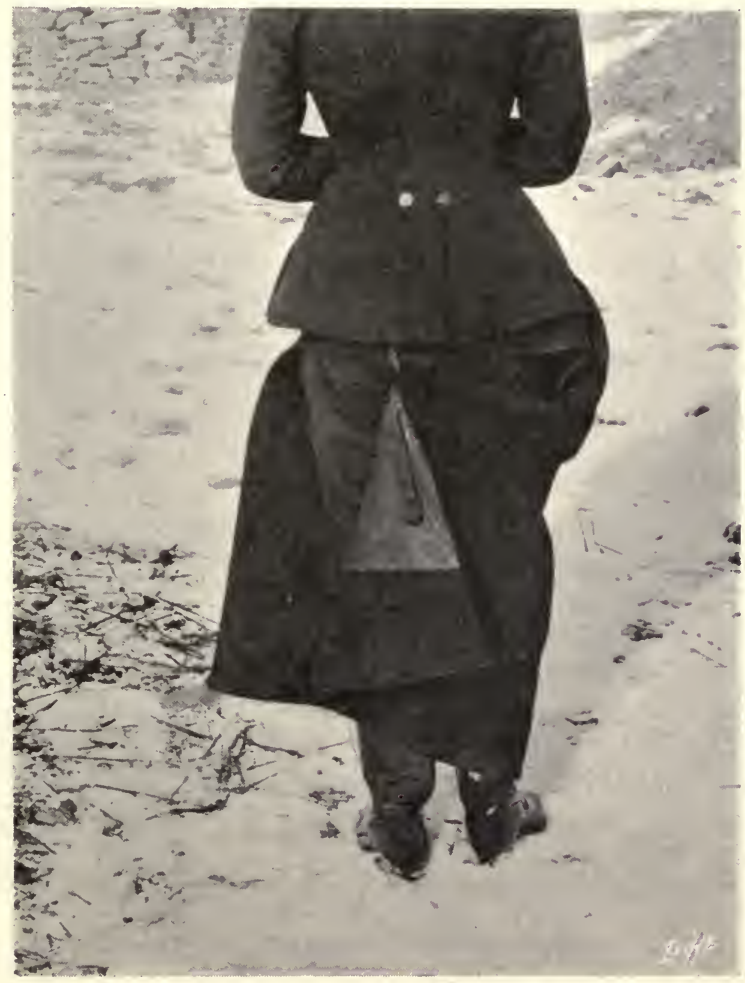

Fig. 56. - The apron skirt closed for walking.

case of a very thin lady, but ensured the skirt being put on straight with a minimum of trouble. Present day skirts have not this small round pad for the right knee to fit into, but its omission is far from being an improvement on the old fashion. 
Whatever shape a lady may select for her riding coat, she should pay particular attention to the fit of the sleeves, which must not in any way hamper the movements of her arms. Before trying it on, its wearer should procure a good pair of riding corsets, which must allow free play to the movements of her hips, and, above all, she must not lace them tightly. Wasp waists have luckily gone out, never, I hope, to return. The size of a woman's waist, if she is not deformed, is in proportion to that of the rest of her body. Therefore, a pinched waist, besides rendering the tightly girthed-up lady uncomfortable, to say nothing of its probable effect on the tint of her nose, deceives no one. It is impossible to ride with ease and grace in tight stays, a fact which we should remember when trying on a habit coat, for the fitter will follow the shape, or mis-shape, of the corsets, and the coat will be built on those lines. The back of the garment should be quite flat, and padding may be needed in the case of hollow backs, as there should be no high water line across the back defining where corset ends and back commences. The collar should fit nicely into the neck at the back, and not gape open from being cut too low. There should be no fulness at the top of the sleeves, for nothing looks more unsightly than "bumpy shoulders" on horseback. It would be well for the wearer when trying on, to lean back and extend her arms, as she would do when giving her horse his head over a fence, in order to find out if 
the sleeves are likely to hamper the movements of the arms, as they sometimes do, from the coat being cut too narrow across the chest. It is no use fitting on a coat once or twice, and then leaving it to

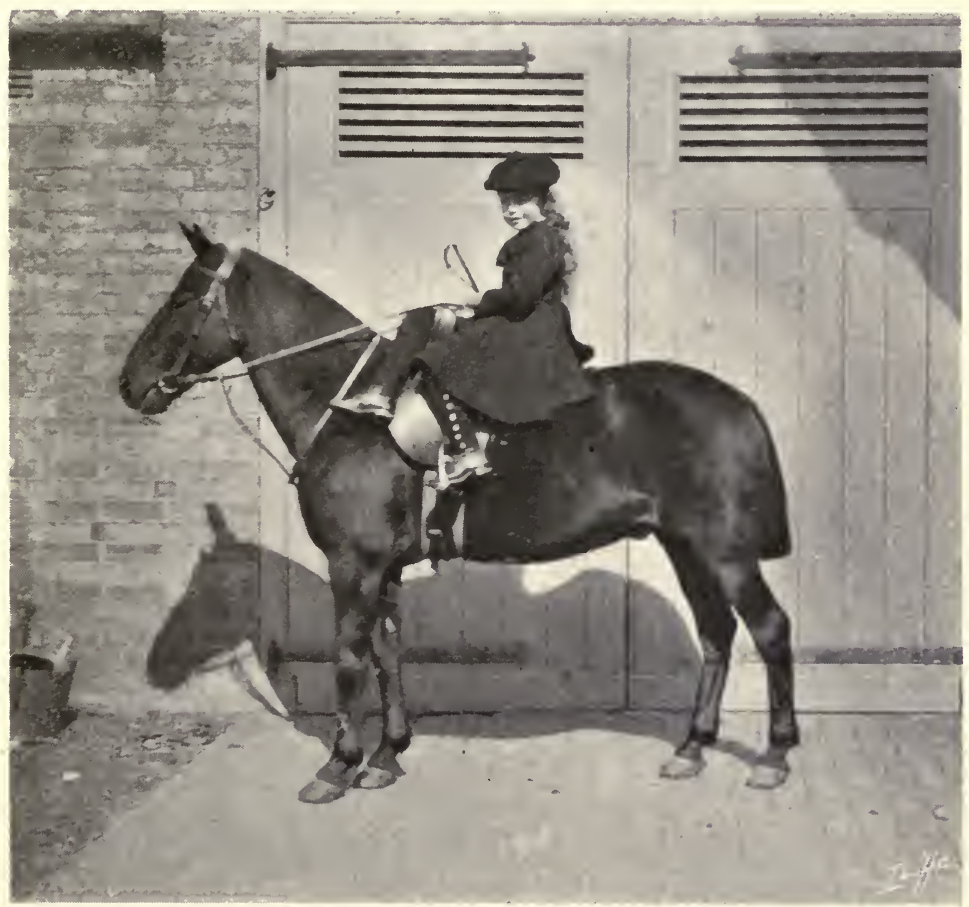

Photo by]

[The Rev. G. BRoke.

Fig. 57.- Riding dress for child.

chance; for, to secure a perfect fit, the garment will require to be tried on until there are no further alterations to be made in it. Whatever shape may be chosen, the coat should not be made too long, or it will flap and flop about in a most ungraceful manner. Fig. $5^{8}$ shows a loose-fitting coat which is not smart, 
because it is too long, and as it rests on the horse's back, it will wrinkle up when its wearer sits down in trotting and will look ugly. If this coat was a good four inches shorter at the back, and graduated off to just cover the right knee, it would be clear of the horse's back and present a far neater and less sloppy appearance. Many habit makers who run apron skirts of their own, insist on making riding coats far too long, of course with the object of hiding the indecency of the apron skirt when its wearer is on foot. Ladies who do not adopt that kind of skirt, should not allow tailors who have had no practical experience in side-saddle riding, to dictate what they consider best, to experienced horsewomen. I find that young habit makers who are new at their business are far more trying in this respect, than their more experienced elders.

We have only to look at fashion plates to see that no dress is suggested for ladies who are inclined to be stout, for in them, only slim figures appear to receive consideration. I would recommend the loosefitting coat as the most becoming for portly persons, because with a loose garment there is no abrupt accentuation of bulk, a fact which many stout ladies who adopt the Eton jacket style of dress, fail to recognise. On the stage, a slim actress may look well in tights, but this skin-like covering on a bulky figure would be ridiculously ugly. As the same lady draped in loose flowing robes may present a graceful and dignified appearance; those who are inclined to be portly would 
do well to wear loose-fitting riding coats, being careful to see that they are made to just reach the saddle and not flop on the back of the horse, or they will not be smart or comfortable to ride in. In Fig. $5^{8}$ I have

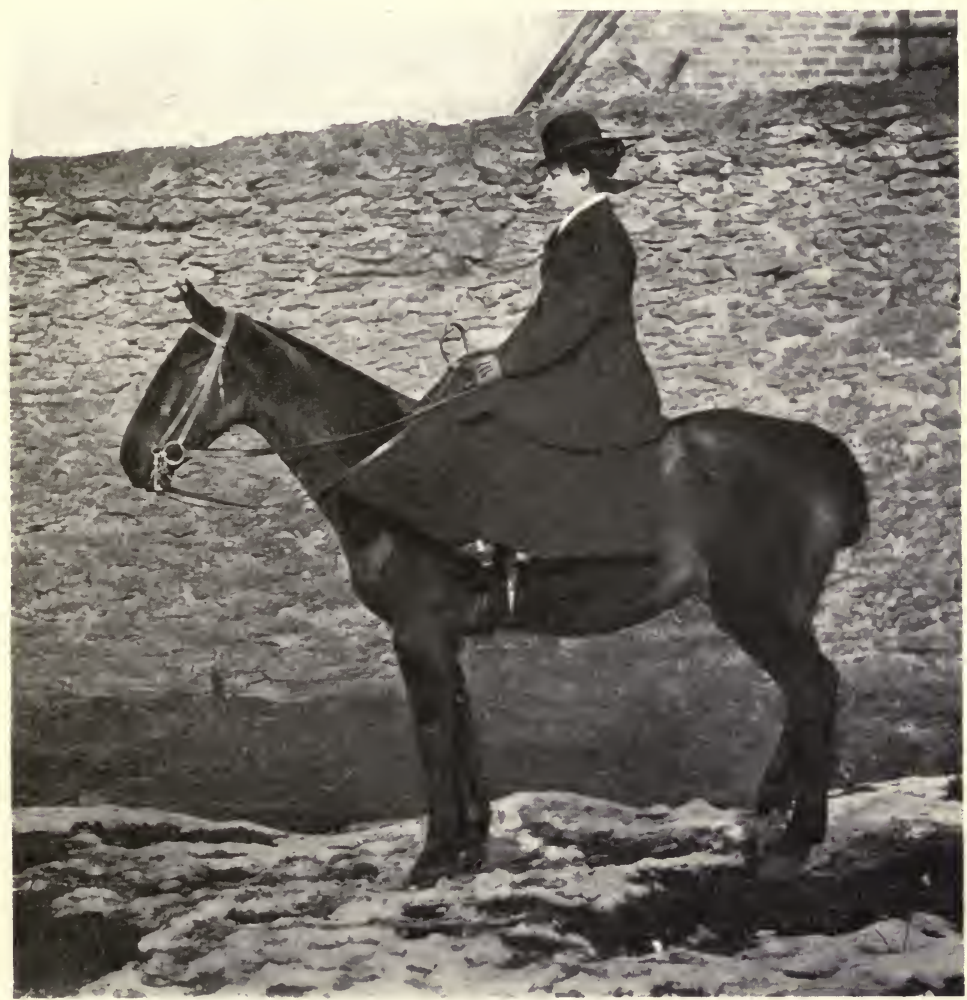

Fig. 58. - Loose riding coat, too long.

shown how unnecessarily bulky a woman with a 25 -inch waist may be made to look in a loose coat which is too long. Tailors do not like making these articles of dress, especially when they are of Melton cloth, because they are extremely difficult to manipulate, and 
the "hang" of such a garment will be hideous if its cutter be not a true artist at his business, for a loose coat is nothing if not graceful in outline. It is impossible to tell, when seated on a wooden horse, how a loose coat will hang when ridden in, so the finishing touches, such as pockets, \&c., should never be made until the wearer has tried the coat on her own horse, with a critical friend to ride with her and tell her if anything is amiss with it. The little extra trouble this precaution may involve, is nothing as compared with the disappointment of having to "put up" with an ill-fitting garment." Some tailors have a Mayhew saddle on their block horse for fitting skirts ; because in that kind of saddle, the crutches give them no trouble as regards "poking up"; but if a lady uses a saddle with ordinary crutches, she should be wary and take her own saddle for the fitting of her skirt. There are habit makers who recommend tight-fitting coats for stout figures, because, they argue, the bulk is there and must go somewhere; but a deaf ear should be turned to such arguments, as an ample figure should be concealed; not accentuated. Naturally these gentlemen are prejudiced against loose coats, for apart from the difficulty in making them, they cut into a much larger amount of valuable cloth than tight-fitting ones. Tailors will readily admit that this shaped coat is the best for young girls, because tight-fitting ones would give them too much of a "grown-up appearance," but not for the stout girl, who has far more need to conceal her "grown-up appearance"! 
Twenty years ago tailors were much more particular over their work than they appear to be at the present time. Creed always insisted on a lady bringing her own saddle, before he would fit a habit, and, if the

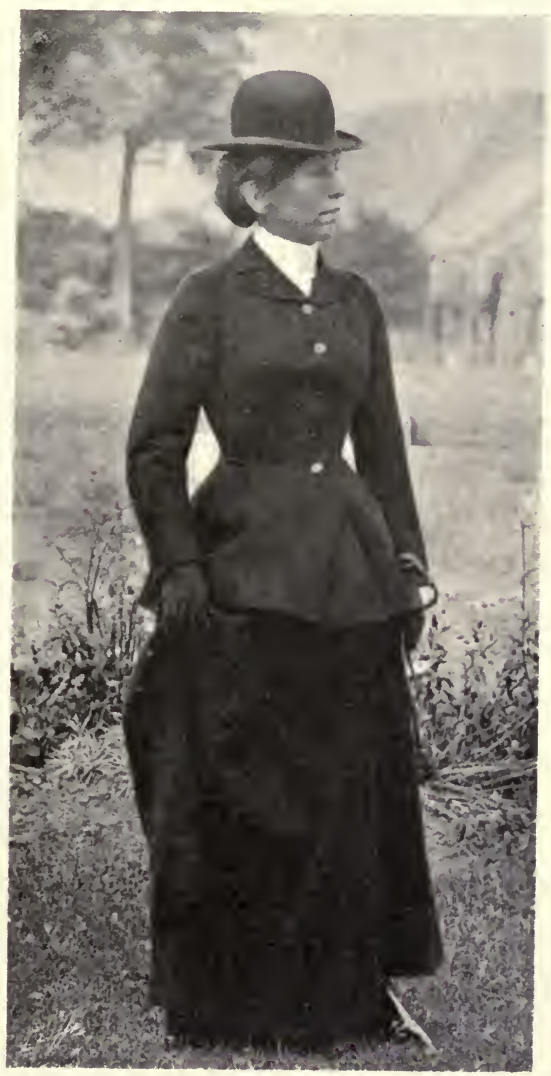

Fig. 59. - Front view of good riding coat.

garment did not please him, it would be discarded and another cut out ready for her when she next came to be fitted. This generous method of dealing was 
amply repaid; because it soon became known that the old man would not allow an imperfect garment to leave his shop.

For hunting, it is best to have a coat which will afford us protection from cold and wet, and therefore its fronts should be made to cover the right knee, the buttons being concealed under the "skirt" of the coat. This shape is in every way good, because there are no floppy fronts to trouble us by blowing back on windy days, and when the rain drips from the hat, the coat-covering helps to keep our right knee dry. In the old-fashioned habits, great care was taken that nothing could become displaced, to spoil the effect, as an old lady friend puts it, of "the beautiful gliding motion of a ship in full sail." I fear now-a-days we allow our sails to flop about far too much, and destroy that "beautiful gliding motion." What could be more ugly than a coat with tails which reach nearly to a horse's hocks, and no front covering whatever to protect the knee in bad weather? Wind, which is no respecter of persons, seizes these long tails and hurls them over the back of the rider's head, as she stands in a wild blast at the covert side looking very "tailly" and cold. Besides covering the right knee, the coat should have a collar that will turn up and fasten at the throat with a button and strap, to keep out wet, and cuffs that will turn down over the hands.

Clad in a sensible garment of this kind, which should be smart and well-fitting, we can defy the elements without running any undue risks. Fig. 59 
shows a coat which is made to cover the right knee. Fig. 60 gives the back view, and is a useful length. Fashion, whoever he or she may be, invents more

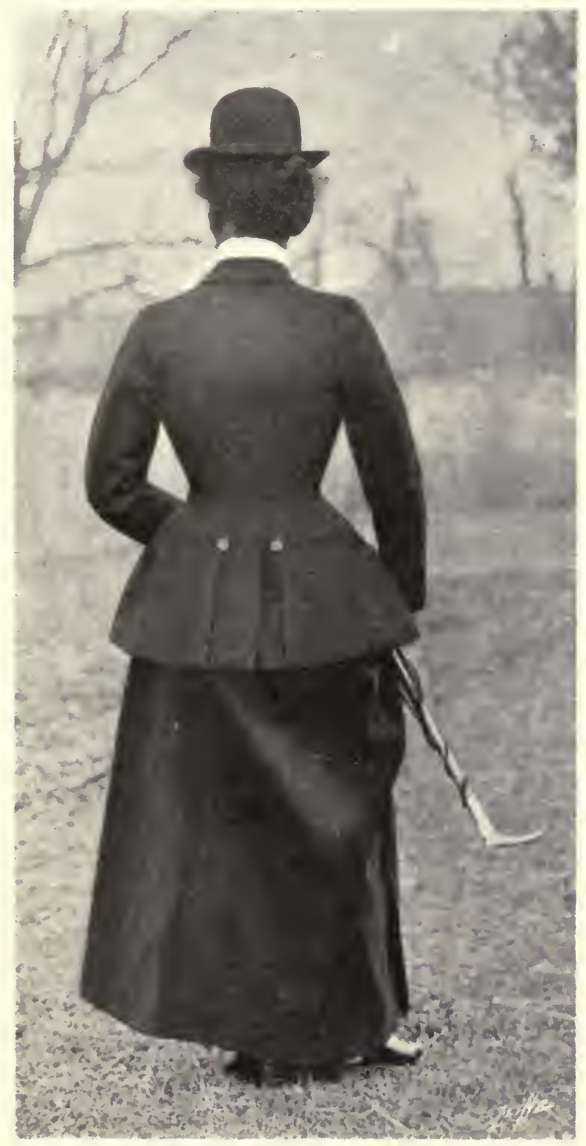

Fig. 60. -Back view of good riding coat.

or less fearful and wonderful coats, which appear every season in the hunting field; but these curiosities "go. out " suddenly, and the end of the season generally 
sees us all garbed in the old motley; for the newcomers have been tried and found wanting.

The best way to clean a mud-stained habit is to dry it thoroughly and brush the mud off. Any white marks of perspiration from the horse which may remain after a skirt has been thoroughly brushed and beaten, may be removed by benzine collas, or cloudy ammonia diluted with water, or they may be sponged with soft soap and water, care being taken to remove all the soap from the cloth.

For riding during the hot weather in India and other tropical countries, a very useful garment is a Norfolk jacket in cream stockinet, which can be purchased ready-made. It fits the figure closely, and has three pleats in front and behind, which are sewn to the garment, the buttons being concealed under the front pleat (Fig. 6r). The best kind of belt, I think, for wearing with this jacket is one made like a girth, of ordinary cream girth webbing, as it is easy to wash when soiled. Jackets in white drill, which may be worn open with soft-fronted shirts (Fig. 62), are also to be commended, as they wash well and always look clean and cool. Some ladies dispense with a jacket, and ride with a shirt and belt; but that style is not generally becoming, and is suggestive of forgetfulness in dressing. In Ceylon I obtained very smart checked flannel for riding jackets. In China and Japan a fine crêpe flannel, which does not shrink in washing, may be had for this purpose, but I have been unable to procure it in other countries. 
A lady who intends to hunt will find a driving coat necessary when travelling by rail, or driving to and from a hunt. Fig. 63 shows a comfortable coat in Melton cloth, with "storm" collar and cuffs of astrakan. A good driving coat is a costly garment, but

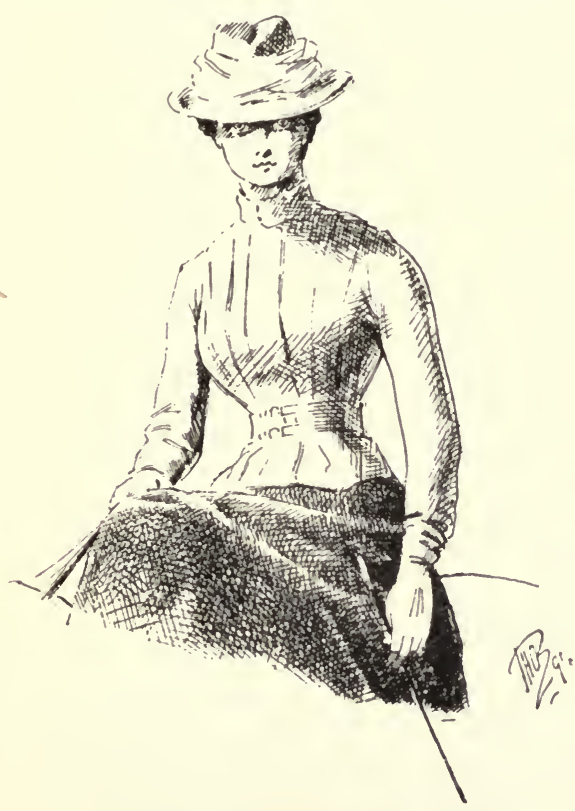

Fig. 61.-Terai hat and Norfolk jacket.

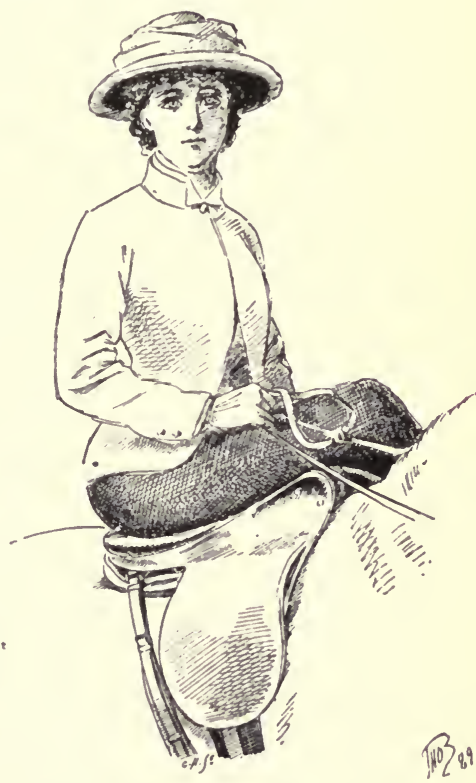

Fig. 62. - Pith hat and drill jacket.

it can be utilised as a winter or travelling coat. The collar of the subject of this illustration was made specially high for use in Russia, where, during winter, the cold is so intense that I often found my pockethandkerchief frozen hard in my pocket, although this thick Melton coat was wadded throughout. The Hayes' Safety skirt worn under this coat is looped 
up from the right knee button to a tab of elastic attached to the waist of the skirt, which obviates the necessity of holding up the skirt.

\section{BREECHES.}

I shall not say anything about trousers, because I do not think they are worn by riding women of the present time, and also for the very good reason that I have never worn them. I think they would be uncomfortable to use for hunting, for, unlike breeches, they do not fit the knees closely. Trousers went out of fashion about thirty years ago, before safety skirts came into general use. It used to be extremely difficult for ladies to get a properly-fitting pair of riding breeches, as no correct measurement for them was taken, and it was not pleasant to be obliged to interview male fitters respecting the cut of these garments. Messrs. Tautz and Sons, of Oxford Street, solved the difficulty by providing us with a competent female fitter, who takes careful measurements for breeches, and rectifies any faults there may be in their fit. The best kind of material for breeches is elastic cloth, which is specially made for that purpose. It is both strong and porous, and can be obtained in any shade to match the riding-habit, which, of course, is necessary. The breeches should be fitted while the wearer is seated on a wooden horse, and special attention should be devoted to their cut at the knees; for if the cloth at the right knee does not lie flat and fit that part like a glove, the wearer will suffer 
discomfort from being "rubbed" by the friction of the superfluous material. Following the senseless custom adopted by men, many of whom hate it themselves, we have our breeches to button on the shin bone. I

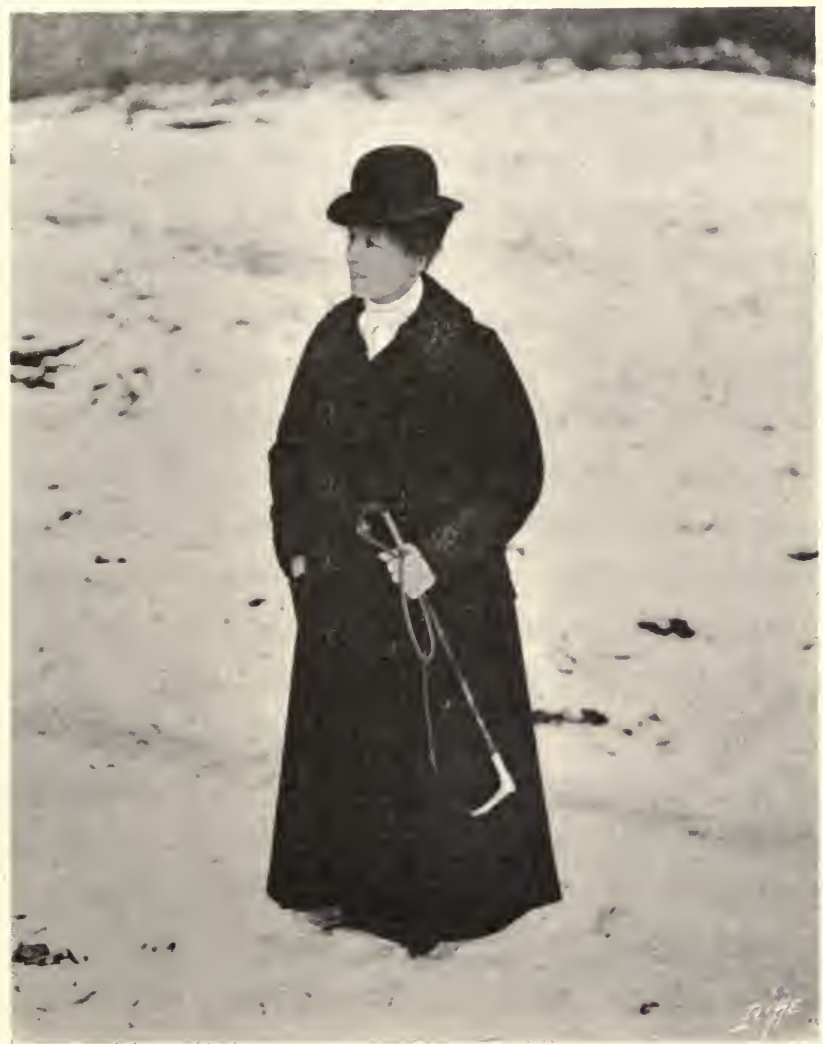

Fig. 63.-Good driving coat.

would recommend ladies who experience discomfort, from the combined pressure of boot and breeches buttoned on the shin bone, either to revert to the old style of buttoning the breeches a little to the outside of 
the leg, or to have their riding boots made shorter, see page I I7. Besides, there is no necessity for us to ape men's fashions in either boots or breeches, because these garments are not seen, and we require them to be thoroughly comfortable. For hunting and winter use I like what are called "continuations" fixed to breeches, as these gaiter-like pieces of cloth cover the leg to a certain distance below the swell of the calf, and keep it warm, besides preventing the knee of the breeches from working round, which men obviate by using garter-straps. Leather breeches for ladies' use are too unsanitary to merit consideration.

For use in the tropics, a lady would require breeches of a very thin make of elastic cloth, and, if continuations were liked, it would be best to have them made detachable, as they could not be worn with comfort during the hot weather.

\section{UNDERCLOTHING.}

Ladies who hunt should always carefully protect themselves against chill by the adoption of warm underclothing, for they are frequently exposed for hours to bitter cold, wind, snow, sleet, hail and fog, and if one is thinly clad, and, as often happens, there is a long wait at a covert side, a dangerous chill may be contracted. An under-vest of "natural" wool should be worn next the skin, and a pair of woollen combinations. which button close to the throat, and are provided with long sleeves, will be found very comfortable and warm. 
Combinations are better for riding use at any time than ordinary underclothing, as there is no superfluous material in them to become displaced and cause discomfort. They can be had in very thin material for use in the tropics and for summer wear. Warm woollen stockings are to be recommended for hunting, and especially for ladies who suffer from cold feet. Those who find woollen garments irritating to the skin may remove the difficulty by wearing them over thin silk. Any trouble in keeping the stockings in place can be best overcome by the use of plain sewn elastic garters, which have no buckles or straps, being placed below the knees, and the upper part of the stockings turned back over them and pulled down the leg as far as they will go, so that each stocking may lie perfectly flat on the leg. The elastic bands should be of the usual garter width, and should be sufficiently roomy not to hurt the legs. As I found chamois leather, with which breeches are usually lined, unsatisfactory, I invented a comfortable substitute for it in the form of a removable pad, which has met with the approval of several hunting women. I would be happy to give privately any particulars concerning this invention to ladies who may be interested in it.

IIATS.

The tall silk hat has, during recent years, been largely superseded by the more comfortable if less elegant-looking bowler. On hunt full-dress occasions, such as a Quorn Friday, the ladies of the hunt generally 
wear tall hats, but I notice that bowlers have as a rule been worn during the rest of the week. The high hat is said to be the more becoming of the two, but it takes a lot of trouble to keep in order, and a bowler is more comfortable and useful for rough work. A lady who is wearing a tall hat for the first time, should not forget to lower her head well in passing under trees, as this kind of head-gear requires more head room than a bowler. The best arrangement for keeping a riding hat firmly fixed on the head is to have a small piece of velvet sewn inside the front, so that it comes on the forehead, and to have for the back, a piece of elastic an inch wide sewn to the hat, well to the front. Care should be taken that the elastic is not too tight, in which case it might cause a nasty headache, as well as a ridge on the forehead from the pressure of the hat. In selecting a bowler, a lady should be careful to choose a becoming shape, as these hats vary greatly in form. To my mind, the kind most generally becoming has a low crown and rather broad brim. High-crowned hats with closely turnedup brim are trying to most faces.

Although it is not usual for hunting women in the Shires to wear hat-guards, I would strongly recommend their adoption, because, however well a hat may be secured by elastic, an overhanging branch at a fence may knock it off, and it is as well to be able to recover it without assistance. When hunting this season, I lost my hat at a fence, and my long-suffering husband had to give up a good place in à run to go 
back and fetch it, whereas, if I had had a hat-guard, this tiresome occurrence would have been prevented. It is best to attach the cord of the hat-guard to a button-hole of the habit-jacket, for then, if the hat comes off, the cord can be more easily caught than if it is fastened inside the back of the collar of the coat. On windy days the advantage of a hat-cord is obvious. Ladies who object to its use may say that overhanging branches should be avoided, but when hounds are running, and one is mounted on a tall horse, it is impossible to always steer clear of stray twigs, and therefore men find a hat-guard very useful.

For tropical climates the pith hat or sola topee (Fig. 62 ) is best for the hot weather. Helmets, besides being apt to give one a headache on account of their weight, do not afford sufficient protection to the rider's temples from the sun. The double Terai hat of grey felt (Fig. 6I) is becoming, but it is very heavy. Pith is lightest and most suitable for wear during intense heat. In the cool weather a bowler or straw sailor may be worn; but even in the cold season ladies should avoid wearing a small hat when the sun is above the horizon, for its rays are treacherous. I have had many a splitting headache from disregard of this precaution.

In trying on a riding hat, the hair should be dressed low down, as it will be worn when riding, in order to obtain a comfortable fit; for the hat must fit the head and not be perched on the top of it, or it will not "remain" if the horse goes out of a walk. The old 
arrangement of dressing the hair in a coil of plaits at the nape of the neck has quite gone out, but it was a far neater one for riding than the "tea-pot handle" and other curious knobs and buns of the present time. The pulled-out style, in bad imitation of Japanese hair dressing, gives a dirty and untidy appearance, and looks perfectly hideous on horseback, and especially when the place where the back hair ought to be, is adorned with a round brooch! If ladies who adopt this bad style could only see how much it vulgarises an otherwise nice appearance, they would at once abjure it. A neat way to arrange the hair for hunting is to coil it firmly round the head, and fasten it with plenty of hairpins - those bent in the centre and with ball points are, I think, the most reliable-and to pin over the hair an "invisible" silken net the same colour as the hair, which will keep it tidy.

\section{BOOTS.}

I wish to lay particular stress on the necessity of riding boots having thin pliable soles, and being easy over the instep; because I once saw a lady dragged by her stirrup and only saved from death by her boot coming off and thus releasing her. I do not think that sufficient attention is paid either by ladies or bootmakers to the fact that a loose riding boot may be the means of saving its wearer's life: I never devoted much thought to the subject before witnessing this accident. The use of tight boots in winter has the great disadvantage of keeping the feet very cold, 
even when warm stockings are worn. Saddlers have invented safety bars and stirrups, habit makers have provided safety skirts, but bootmakers have not yet thought out a hunting boot which would release the foot in the event of a safety bar failing to act, or of a safety or other stirrup being crushed in a fall. A thin pliable sole and plenty of room over the instep to allow of the left foot being easily pulled through the boot, would greatly minimise the danger in question. We seldom hear of a jockey being dragged, although flat races are ridden in saddles that have no releasing bars, and even steeplechases are often .ridden in these saddles, when a rider has a difficulty in getting down to the weight; but all jockeys wear boots which have thin, and, consequently, very pliable soles. Fashion dictates that ladies' top-boots should be as high as those worn by men, which is very absurd ; because they are not seen, and the hard, unyielding leather of a high top-boot pressing either on the breeches buttons, or on the under part of the right leg is apt to cause great pain and discomfort. Then, again, when a Champion and Wilton saddle with safety bar flap is used, the top of the left boot is liable to catch in the flap when its wearer is rising at the trot and is thus apt to release the stirrup leather. Fig. 64 shows the top of the boot in position to raise the safety bar flap in the manner mentioned. I have obviated these inconveniences and have ridden in comfort by wearing boots made two inches shorter than the regulation height, and by wearing breeches 
with "continuations," no stockings are exposed to view, even when one gets a fail. With boots of this length there is no possibility of the left leg being hurt by pressure of boot and breeches buttons on the shin bone. Fashionable bootmakers who build boots for ladies on the pattern of those worn by men, seem to be unaware of the fact that a woman's grip in a side-saddle is entirely different from that of a man in a cross-saddle, and many ladies suffer unnecessary discomfort by meekly accepting what they are told is "the proper thing." Our friend Mr. James Fillis, in his interesting work, Breaking and Riding, says that for ladies' wear he prefers " ordinary boots to long boots, which are too hard, and are consequently apt to cut the wearer under the knee, and to prevent her feeling the horse with her leg; " but as ordinary boots would not be considered sufficiently smart for hunting, or even hacking in the Row, the compromise I advocate will be found to answer all requirements. In ordering a pair of riding boots we should go to a good maker and have them of patent leather, which is smarter and cleaner than blacking leather. For wear in tropical countries, I found that boots which have the foot part of patent leather and the leg of morocco, with a thin leather lining to stiffen and keep the leg part in place, are cooler and more comfortable than any other kind. A pair of boot-hooks will be required for putting them on, and a boot-jack for taking them off. A little Lucca oil used occasionally prevents 
patent leather from cracking. The dry mud should be brushed off soiled boots with a soft brush that will not scratch the leather, and they should then be

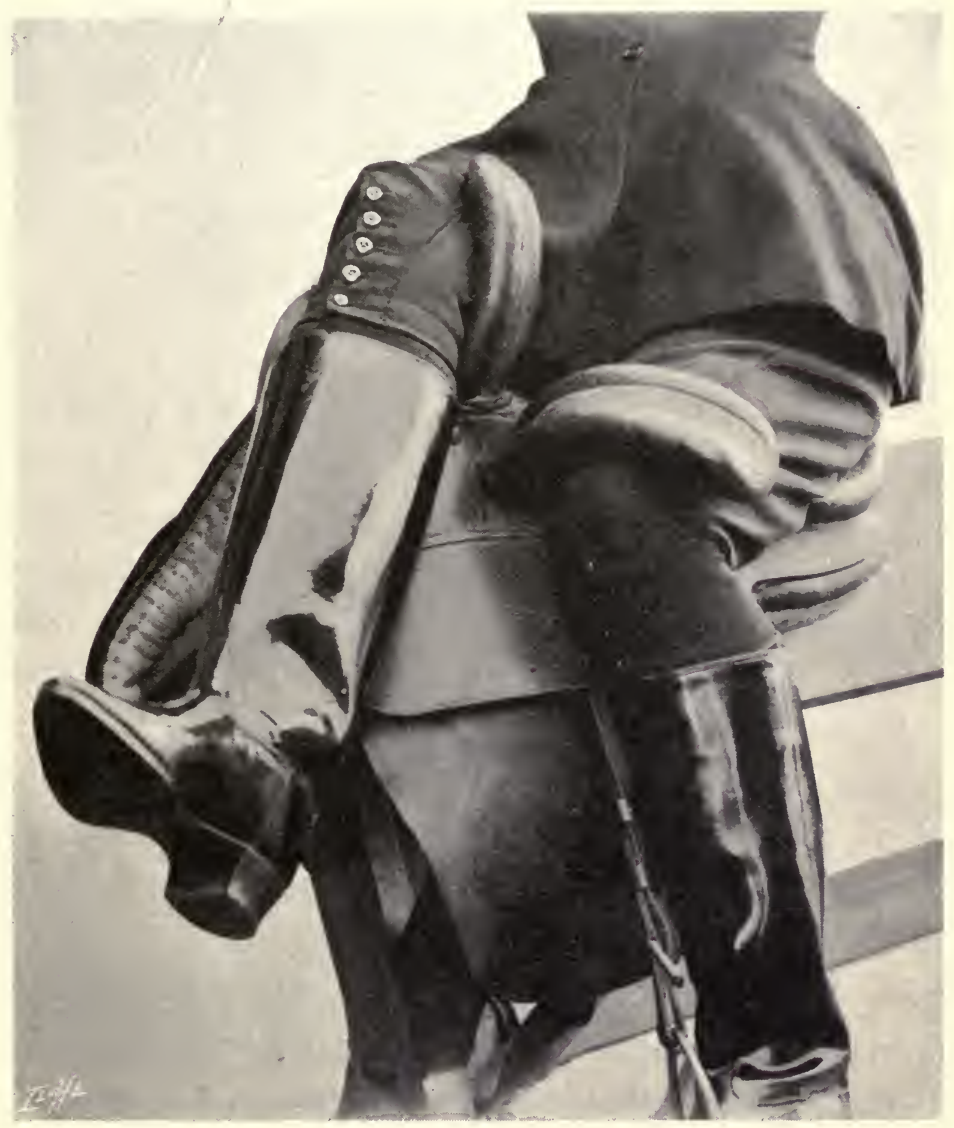

Fig. 64.--Top of boot catching on safety bar flap.

sponged over with a damp sponge and polished with a selvyt or chamois leather. Patent leather, which has lost its brightness from wear, can be polished with 
Harris's Harness Polish or any similar preparation which does not cake on the leather or injure it in any way. We should remember that boots will last much longer and retain their shape to the end if they are always kept, when not in use, on trees. It is best to wear new riding boots in the house before they are ridden in, so as to make them pliable to the "tread" in walking, and to work off their stiff and uncomfortable feeling.

\section{GLOVES.}

Antelope-skin or dog-skin gloves are, I think, the best for hunting. I prefer the former, as they are very soft and pliable. Whatever kind of gloves are chosen, care should be taken to have them sufficiently large to allow perfect freedom to the hands; for tight gloves make the hands ${ }^{\circ}$ cold, and greatly impede their action in the management of the reins. In selecting gloves, a careful measurement of the fingers should be taken, so that they may not be too short. Although gloves of the best quality are somewhat expensive, they are well cut, they wear better and are altogether more satisfactory than cheap imitations. On very cold days, I prefer white woollen gloves to any other kind. In wet weather they are indispensable, for a better grip of slippery reins can be got with them than with leather ones. I agree with Jorrocks that "Berlin gloves are capital for 'unting in, they keep your 'ands warm, and do to rub your nose upon in cold weather," though I have not tried their effect in this respect! 
During a winter which I spent in Russia, I derived the greatest comfort from the use of woollen gloves, which I found far warmer than any other kind. For the

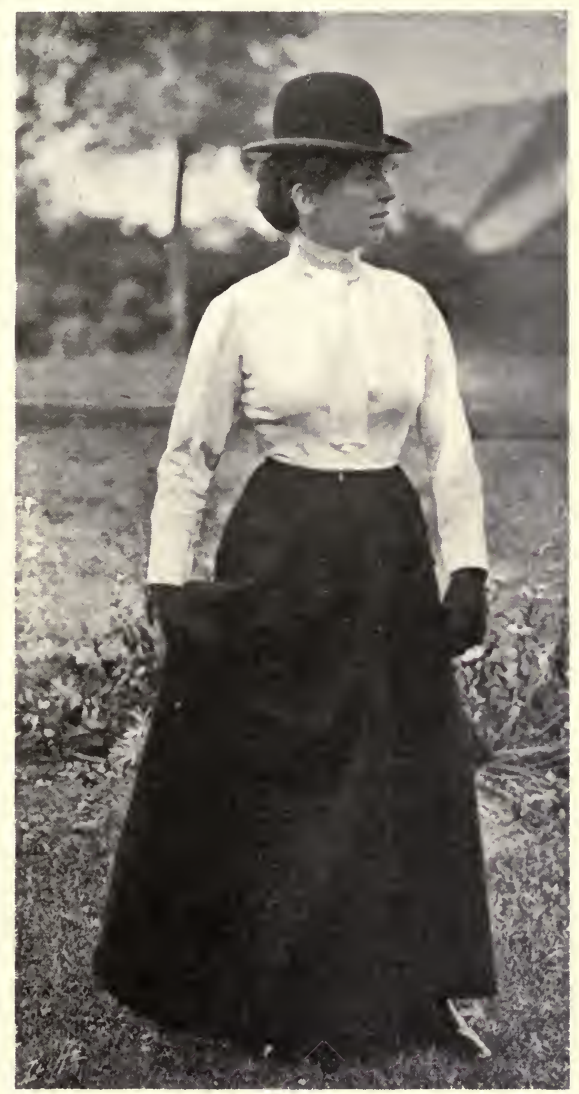

Fig. 65.-Front view of riding under-bodice.

tropics, kid or suède gloves may be worn in the cold weather, but in the hot months I found white cotton the most comfortable kind, as they are cool, thin and soft, and wash and wear better than silk, which the 
reins quickly destroy. Perspiration from the hands will show through leather gloves, which, on drying, will become as stiff as a board. It should be remembered that rings worn when riding, especially those containing stones, hamper the action of the fingers, and are very destructive to gloves.

RIDING UNDER-BODICE, HUNTING-TIES, COLLARS, CUFFS AND TIES.

A garment which I have thought out, and which I believe will fill a want, is a riding under-bodice with long sleeves and wristbands, to which cuffs can be attached, and also a stud at the throat for the attachment of a hunting-tie or collar. This bodice is in stockinet, and fits closely, without, as in the case of ordinary shirts, any superfluous material marring the outline of the figure (Figs. $6_{5}$ and 66). Ladies generally have so much difficulty in fastening cuffs, that they will doubtless welcome a close-fitting garment of this description, and it will do away-with the tiresome habit-shirts and dickeys which have an irritating trick of following one's neck about, instead of remaining in a fixed position. Besides, collars which cannot be kept firmly in place generally necessitate the use of pins, which should never be employed with any article of riding attire.

A hunting-tie or stock, which is a combination of collar and tie, the collar part being either starched or soft, according to choice, is the warmest and most becoming kind of neck arrangement for hunting. It is 
not easy to put on neatly, and it would be well for a novice when purchasing these ties to get the shopman to initiate her into their mysteries, and to take one

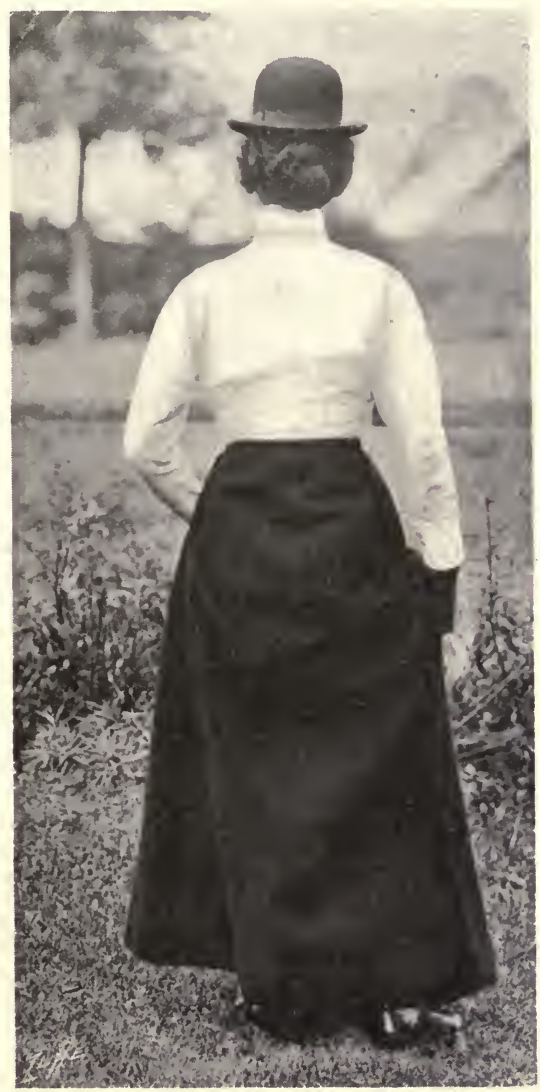

Fig. 66. - Back view of riding under-bodice.

home correctly tied, to be kept as a copy until its somewhat intricate manipulation has been mastered. My husband's directions for the arrangement of a 
hunting-tie are as follows :- " The centre of the stock is placed on the front of the neck, the ends are passed in opposite directions round the back of the neck, brought in front, tied in a reef knot, crossed in front of this knot, and finally secured, as a rule, by means of a pin or brooch of the safety or horse-shoe or fox pattern. A gold safety pin is often used. A brooch pin is naturally safer than an ordinary pin. Nowadays, hunting ties are nearly always made of white cotton material" (Riding and Hunting).

If a collar is preferred to a hunting-tie, it should not be too high, for nothing is more uncomfortable in riding than a collar which compels its wearer to preserve a stiff neck and runs into her whenever she tries to turn her head. The best kind of cuffs are those which have button holes for links or solitaires in the centre, as they allow room for thick gloves to be passed under them. The necktie to be worn is a matter of choice, but white and black ties are always becoming, the former for preference, as they brighten up a dark habit. It is always well to abjure startling colours; for the dress, saddlery and gear of a horsewoman should be characterised by simplicity and neatness. On this point I can offer no sounder advice than that given to Laertes by his father, who said :

"Costly thy habit as thy purse can buy, But not express'd in fancy; rich not gaudy ;

For the apparel oft proclaims the man;"

and also the woman. 


\section{CHAPTER VI.}

MOUNTING AND DISMOUNTING,

\section{MOUNTING.}

Supposing, as is usually the case, that there is a groom to hold the horse, and a gentleman to put the lady up; the groom, after the reins are placed on the animal's neck just in front of the withers, should stand in front of the horse, and should keep the animal's head up by holding the snaffle reins, one in each hand, close to the rings. If a double bridle be employed, as is usually the case, he should on no account hold the bit reins, lest an accident may happen from the curb hurting the horse's mouth. If there be no snaffle, the cheek-pieces of the headstall of the curb or Pelham should be held. With a strange or uncertain tempered animal, it is best for the lady to approach him from his "left front," and she will do well to speak kindly to him and pat him on the neck, for these two forms of conciliation are greatly appreciated by horses. Having arrived alongside her mount, she should stand just behind his near foreleg, close to, but not touching him, and facing to the front, with her shoulders at right 
angles to his side. She now places her right hand, with the whip in it, on the upper crutch, and raises her left foot about twelve inches from the ground, while keeping the leg; from knee to ankle, in a more or less vertical position (Fig. 67). The whip should be held as in this illustration, so as to avoid alarming the horse. The gentleman who is to put her on her horse, places himself close to, and in front of her, bends down, and places the palm of one hand (generally the left one) under the ball of her left foot, while he supports that hand by putting the palm of the other hand under it. The lady then places her left hand-with the elbow turned out a little, so as to be able to utilise that arm in raising herself-on his right shoulder (Fig. 68).

Having finished the "prepare to mount" stage, she straightens her left knee by lightly springing upwards off the ground by means of her right foot, and at the same time pressing on her cavalier's shoulder so as to straighten her left arm. The moment he feels her weight on his hands, he should raise himself into an erect position, so as to bring her on a level with the saddle, on which she places herself by turning to the left while she is being raised, and bearing on the upper crutch with her right hand. It will be difficult for the gentleman to do this lift properly, unless the lady keeps her left knee and left elbow straight during the ascent. The gentleman's task will be greatly facilitated if he takes advantage of the lady's spring; but even if he lets that helpful moment pass by, he can do the lift in a satisfactory manner with the small 
drawback of an extra expenditure of muscular effort. The fact of the lady exerting a strong clownward pressure on the gentleman's left shoulder, makes the lift much easier for him than if he had to do it entirely

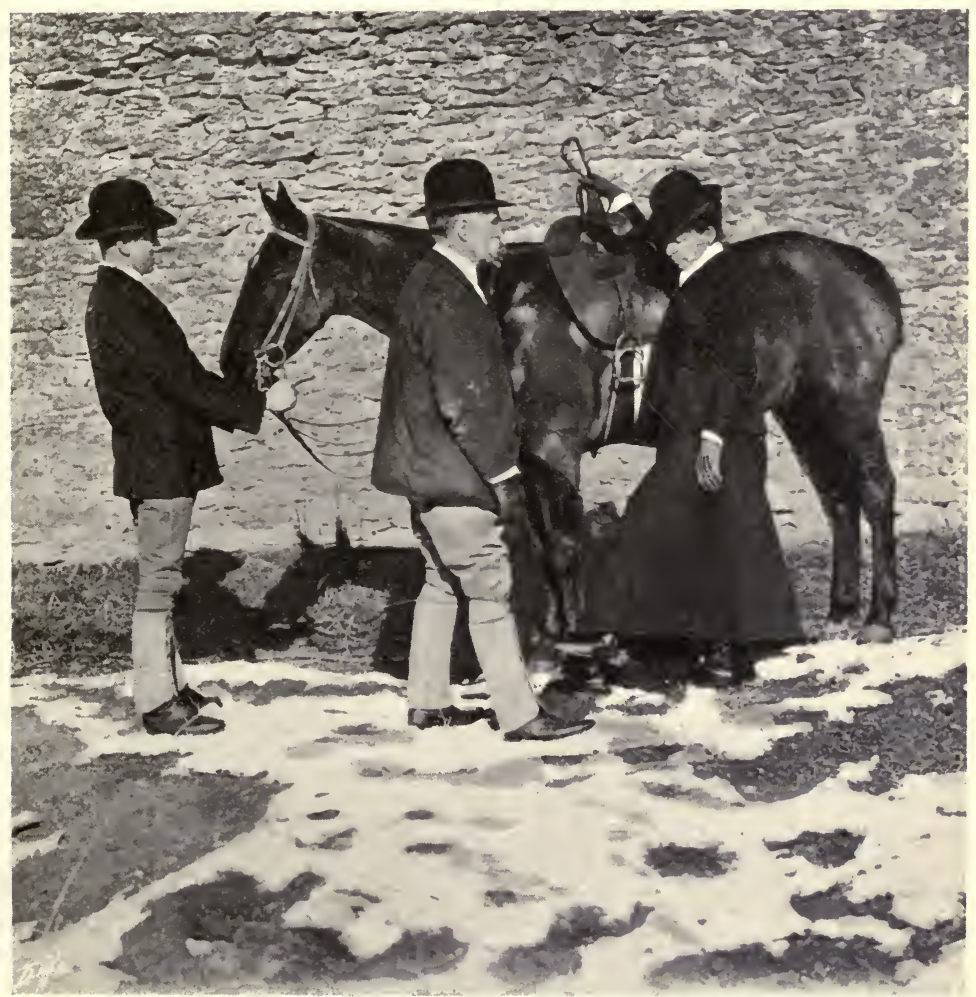

Fig. 67. - Foot raised for mounting.

by his arms. It is most important for the beginner to understand this extremely simple method of mounting, so that, if failure results, she may know who is in fault. Her only serious error is that of neglecting to 
straighten her knee. His crimes in this respect are many. First, he may catch hold of the heel of her boot in the preliminary stage, and will thus prevent her utilising the play of her left ankle joint in her spring. Experiment will show that this trick of catching the heel hampers a lady's movements in mounting much more than might at first be thought possible. Second, from knowing no better, or from a desire to show off his strength, he may use only one hand to lift the lady, and will then almost always have cause to regret his superfluity of self confidence. Third, he may stand too far away from her, and thus bring her left foot too much forward, in which case it will be almost impossible for her to straighten her left knee. Fourth, he may also prevent her from doing this indispensable part of the performance, by trying to raise her before she has put her weight on his hands. Fifth, he may stand too far away from the side of the horse, in which case he is liable to throw her over to the off side of the horse (as happened once to me), by giving her an oblique instead of a vertical propulsion. A minor form of this mistake is attempting to put the lady on the saddle, instead of raising her to the height at which she can easily take her seat. After a lady has suffered from clumsy attempts to put her up, it is not to be wondered at if she regards the feat of mounting as one which requires some peculiar knack to accomplish; and, as failure in mounting is particularly ungraceful, she naturally becomes nervous about attempting it. If she has any doubts as to her 


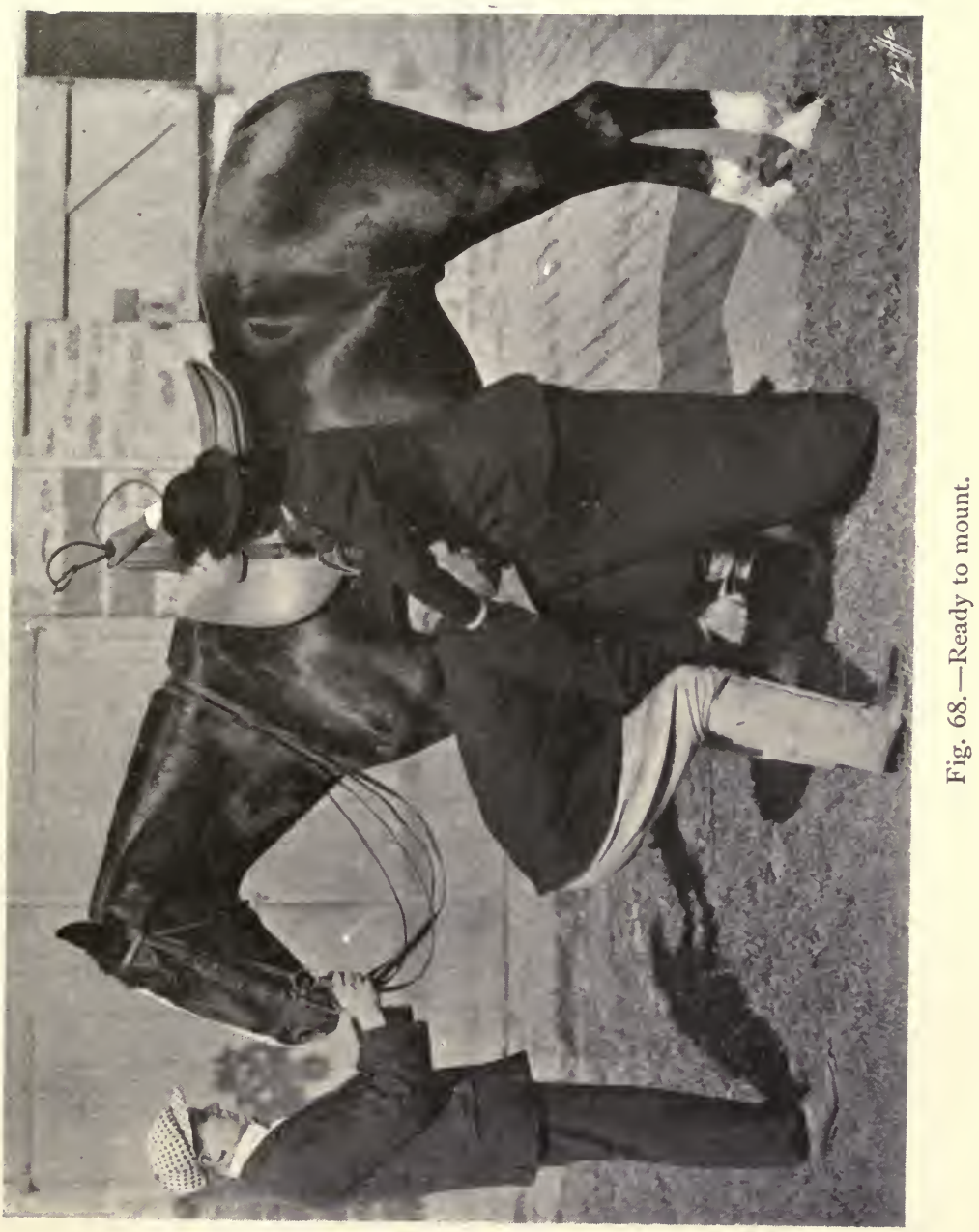



capability to mount easily, she might make some preliminary attempts to stand and support herself for a few seconds on a gentleman's hands, with her left hand on his shoulder and her right hand on the upper crutch. When she finds that she can do this successfully, she may, when her leg is again straight, give him a signal (or take one from him) to raise her to the necessary height, so that she may sit in the saddle. If she be very timid, she may practise mounting indoors, with her right hand on the top of an upright piano, and her left on a gentleman's shoulder as before. Although it is usual for the gentleman to give the words, "One, two!" as a signal for her to make her spring and straighten her knee before he raises her, no such caution is necessary; for he will know, by feeling her weight on his hands, when she is in a proper position to be raised.

Having arrived on the saddle, the lady places her right leg over the crutch, while her attendant puts her left foot in the stirrup, adjusts any elastic loops that may be present, and straightens her skirt, as may be required. She then takes up the reins. It is advisable for the lady not to touch the reins until she is securely placed in the saddle and is ready to use them, because the act of placing her right hand on the crutch while holding the reins in it, is liable to render the horse unsteady, and the reins are of no use to her until she is firmly seated.

If there is only one man to help the lady to mount, he should place his left arm through the snaffle reins, 
so as to prevent the animal from getting away while putting her up.

I think all hunting men should know how to put a lady up, because accidents in the field are constantly occurring, and some poor Diana who has had a tumble is always grateful to any good Samaritan who renders her this small service. A well-meaning sportsman who kindly offered me his help on such an occasion, knew so little about the mysteries of side-saddle riding, that he attempted to give me a "leg up," as if I were a man!

It would be well for every school where riding is taught to be supplied with a wooden horse, on which pupils could learn the method of getting into the saddle, and would thus avoid becoming flurried or nervous when mounting, especially if the horse is a stranger. Also, a dummy horse would be an admirable subject on which to do preliminary practice in other details of riding, such as grip, length of stirrup, leaning back (as when going over fences), position of the hands, holding and handling the reins, etc. In this way, beginners would learn what they had to do, before getting on a horse.

Mounting from the ground unaided depends for its success chiefly on the respective heights of horse and rider, although a lady can be helped considerably in this attempt by letting out the stirrup leather, which she will have to shorten after climbing into the saddle. Unless a lady is tall and athletic, it will be almost impossible for her to perform this feat on a full-sized horse. This method of mounting should, as a rule, be 
avoided, because, apart from its not being very graceful, it is apt to disarrange the position of the saddle, by pulling it to the near side, and the animal would

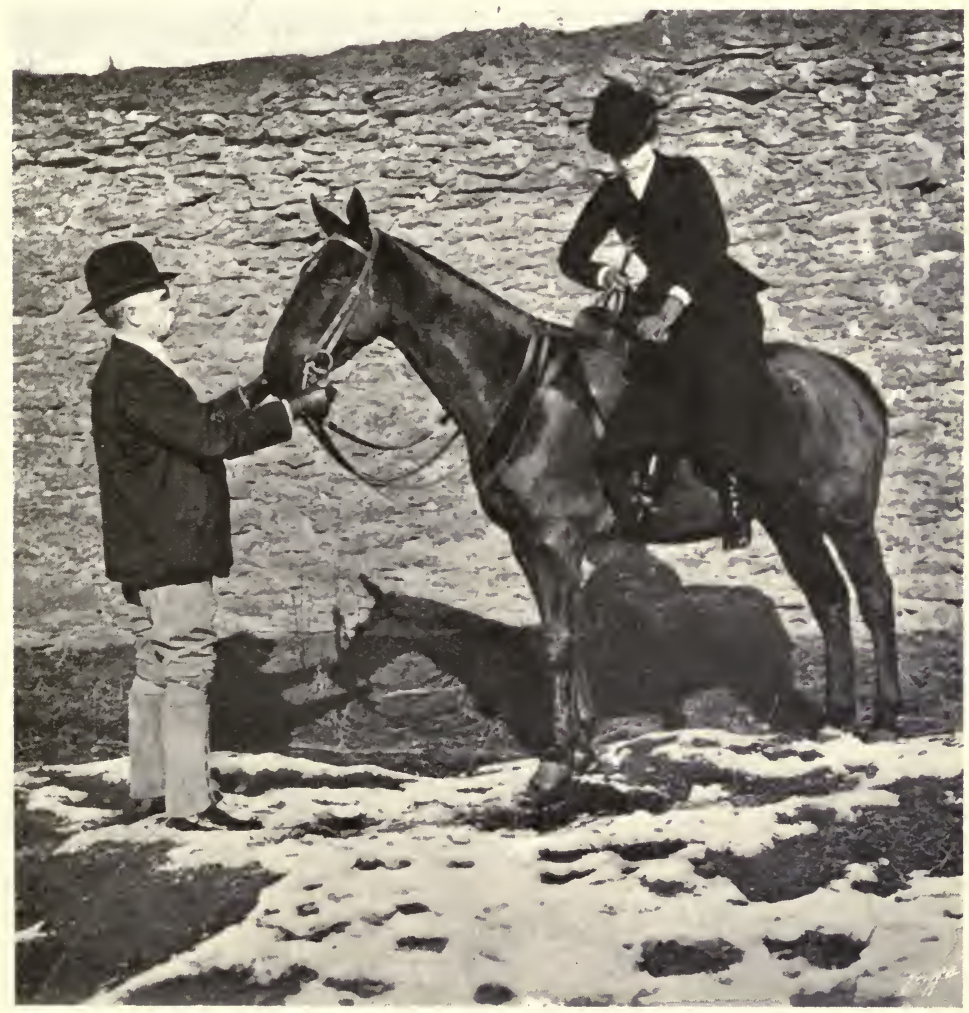

Fig. 69. - Dismounting without help.

then be liable to get a sore back, especially if he had to go through a long day with hounds.

Mounting from a block, low wall, or other suitable object, may be done without help, if the animal is "confidential" and accustomed to the work. If a man 
be present, he may stand in front of the horse and hold him in the way already described for the groom to do (page I 25). If the animal shows unwillingness to approach the mounting-block, the man should hold the off cheek-piece of the headstall of the bridle with his right hand, and, with the flat of his left hand, prevent the horse from swinging his hind quarters out. When the horse is sufficiently close, the lady should take the whip and reins in her left hand, put her left foot in the stirrup, take the upper crutch with her left hand and the cantle with the right, and spring lightly between both hands into the saddle. The right leg is then put over the upper crutch and the skirt arranged.

\section{DISMOUNTING,}

in the days of voluminous skirts, was a far more serious business than it is now ; for the "knee recess" had to be carefully freed from the crutches of the saddle, and the skirt gathered up in the hands of the rider, so that she might not tread on it. Riding women of to-day generally prefer to dismount without assistance, for they are no longer hampered with an early Victorian skirt. While a man holds the horse, the rider releases her foot from the stirrup and loop, removes her right leg from the crutch, and placing her right hand on it and her left hand on the leaping head to steady herself (Fig. 69), springs lightly to the ground. If help is required from a male attendant, it is best for him to offer his right arm, on which the rider places her left hand (Fig. 70), as she leaves 
the saddle. If there is only one man present, he should take the snaffle reins in his left hand, before offering his right arm to the lady. Another plan is for the lady to give her hands to the man who assists her to dis-

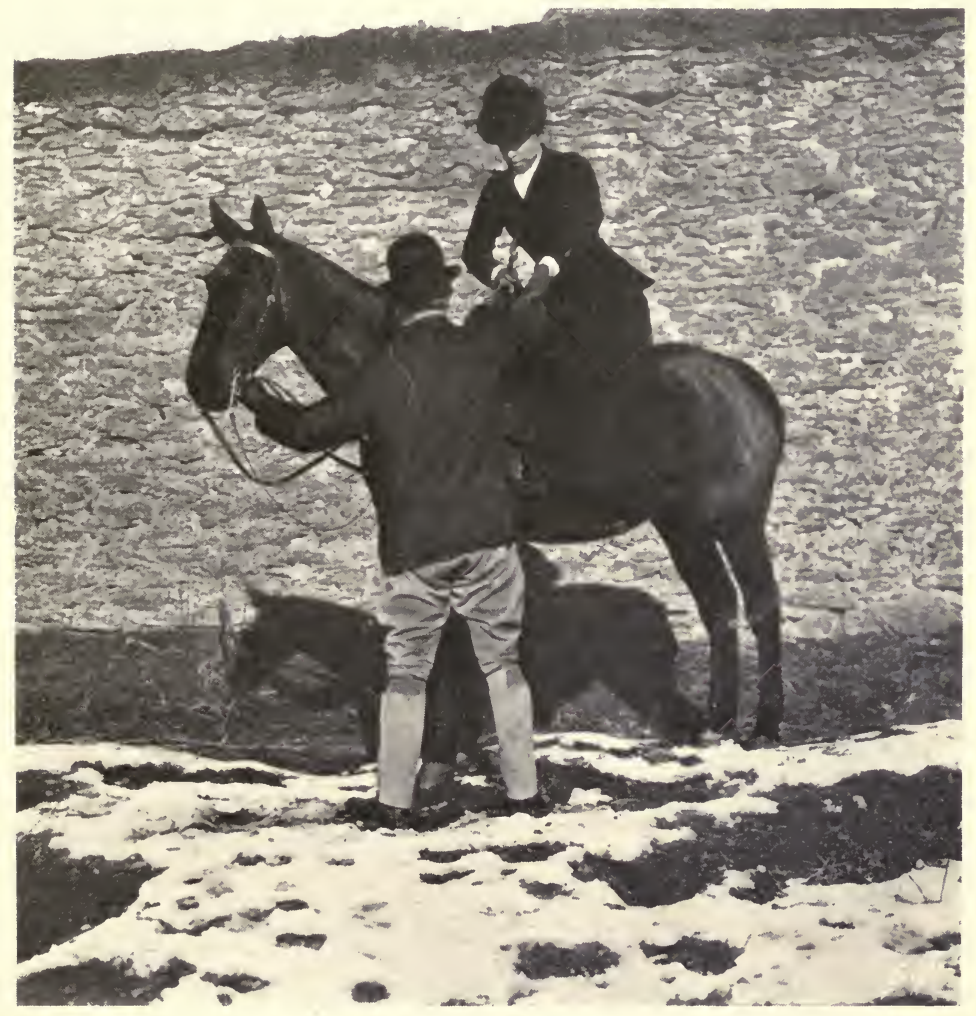

Fig. 70.-Dismounting with help.

mount, but that would not be pleasant in the case of an ordinary groom. An old-fashioned way of helping a lady to dismount, was to put an arm round her waist and lift her from the saddle! 


\section{CHAPTER VII. \\ HOW TO HOLD THE REINS.}

Principles-Holding Single Reins in Both Hands-Holding Single Reins in One Hand-Holding Double Reins in Both Hands-Holding Double Reins in One Hand-Shortening the Reins-Military Method of Holding the Reins-Respective Merits of One-Handed and Two-Handed Riding.

As there is but little difference between the respective ways men and women should use their reins, I have taken the most of this chapter from Riding and Hunting.

\section{PRINCIPLES.}

The following are the usual principles to be observed in holding the reins :-

I. A secure grip of the reins should be maintained, with as little stiffness as possible, because stiffness implies continued muscular contraction, and consequent defective manipulation from fatigue.

2. When both hands are used, we should hold the reins so that we can freely use our hands, either separately or together, in any required direction.

3 . When both hands are used, the manner of hold- 

ing the reins by one hand should be the same as that by the other, so that the feeling of the hands on the reins may be the same on both sides

4. When a horse which has an "even" mouth is going in a straight direction, the action of one rein should be the same as that of the other rein.

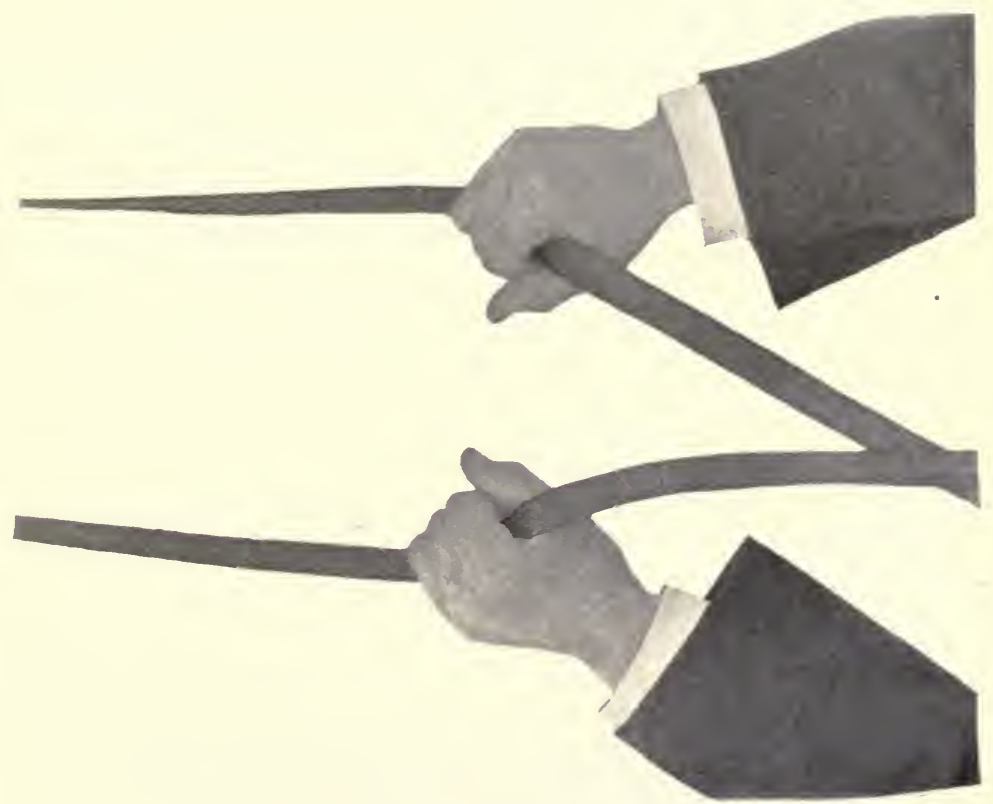

Fig. 71.-A rein in each hand.

HOLDING SINGLE REINS IN BOTH HANDS.

Pass the near rein between the little finger and the ring finger of the left hand, bring it out between the forefinger and thumb, and take up the off rein in the same manner in the right hand (Fig. 7I). The reins 
thus held will be in the best position for general use, especially as the hands can then be readily separated,

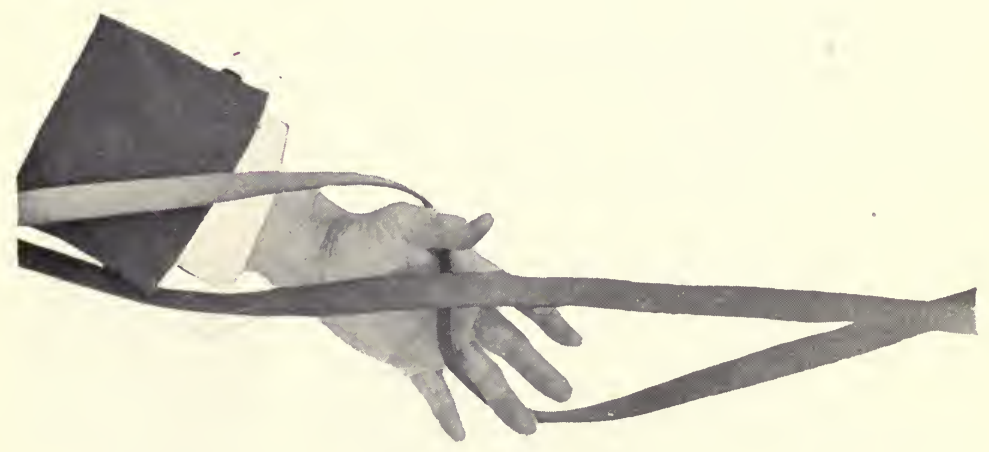

Fig. 72.-Single reins crossed in one hand.

if we wish to turn the horse to one side or the other.

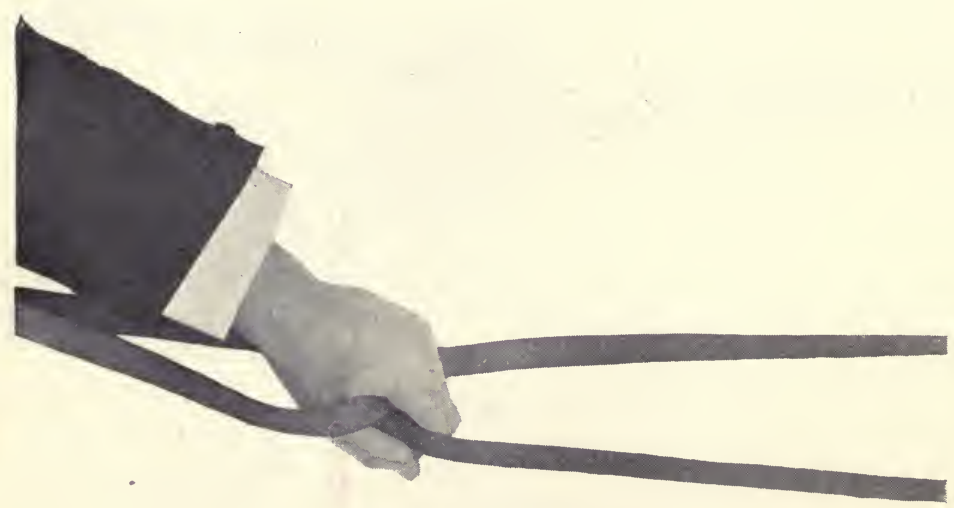

Fig. 73.-Singie reins crossed in one hand.

HOLDING SINGLE REINS IN ONE HAND.

While holding the reins as in Fig. $7 \mathrm{I}$, pass the oft rein into the left hand between its forefinger and 
HOLDING SINGLE REINS IN ONE HAND. I39 thumb, and across the portion of the near rein that is in the palm of the left hand (Fig. 72). On letting go the off rein with the right hand, we close the fingers of the left hand, turn the left hand inwards, and let it fall from the wrist in an easy manner
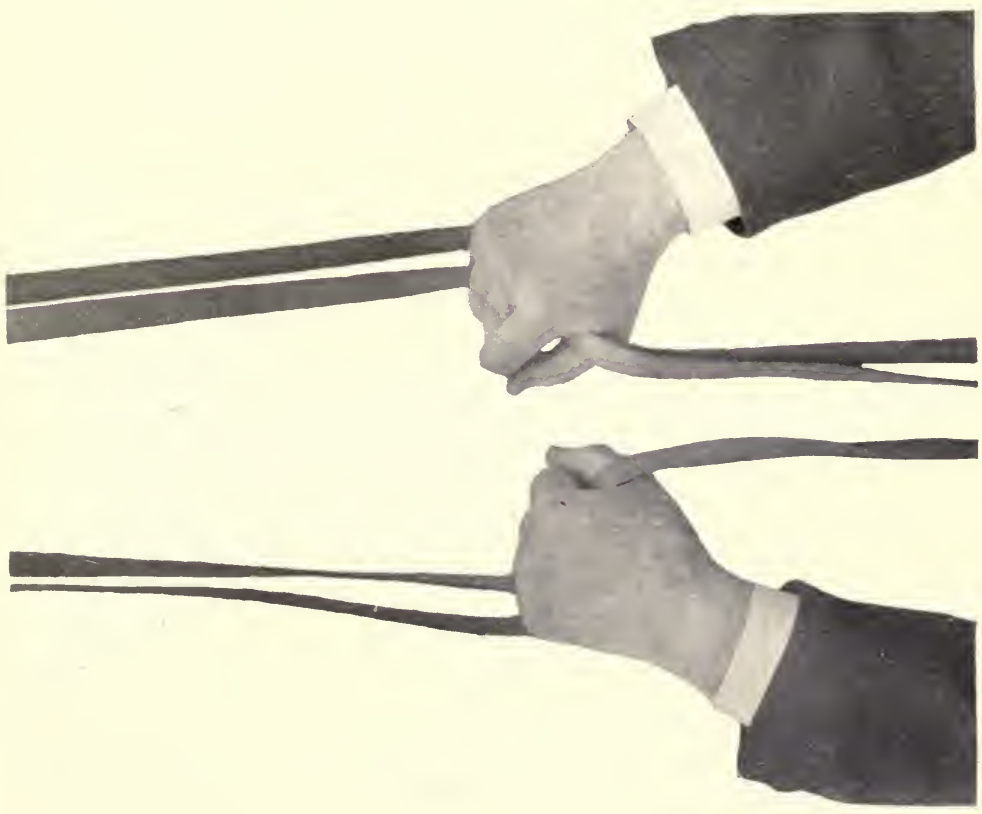

Fig. 74.-Double reins held separately in two hands.

(Fig. 73). When holding the reins in one hand, we should not keep the knuckles in a vertical position, because, by doing so, one rein will come up higher on the horse's neck than the other rein. On the contrary, both in one-handed and two-handed riding, the knuckles should be held more or less horizontally, as they would 
be when the hand is allowed to fall without stiffness from the wrist.

Whether the reins are held in one hand or in two, we should avoid "rounding the wrists," not only on account of the consequent stiffness imparted to these joints, but also because that action tends to make us carry the elbows outwards, and thus diminishes the

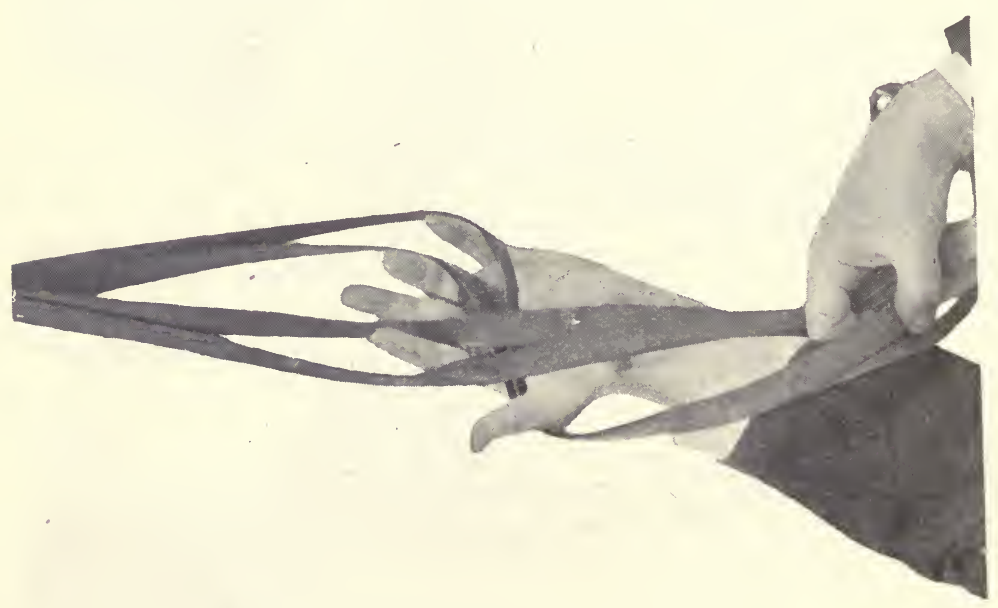

Fig. 75.-Holding double reins crossed in one hand.

force which the arms are capable of exerting on the reins.

HOLDING DOUBLE REINS IN BOTH HANDS.

We may hold double reins in both hands in the same way as we hold single reins, except that the little fingers separate the reins on each respective side (Fig. 74). The question as to which rein should be on the outside may be decided by the amount of 
control which is required to be obtained over the horse; because, by the rotation of the hand, we can work the outward rein more effectively than the inward rein. If the snaffle is to be the predominant bit, its reins should be on the outside, and the curb-reins slack.

HOLDING DOUBLE REINS IN ONE HAND.

The forefinger of the left hand separates the two

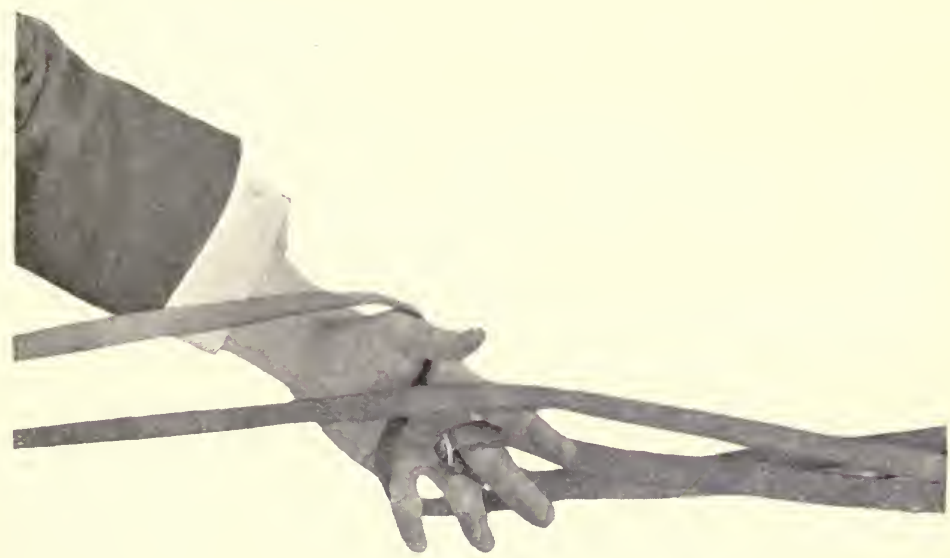

Fig. 76. - Double reins in left hand: one crossed, the other hooked up on middle finger.

off reins, the little finger divides the two near ones, and the reins are crossed in the palm of the hand (Fig. 75 ), as with single reins. It is convenient to have the reins on which we want to have the stronger pull on the outside. If the rider wishes to use only one rein, she may hold it crossed in her hand, and may hook up the other on the middle finger, and let it loose (Fig. 76), or draw it up to a greater or less extent. 
SHORTENING THE REINS.

In shortening the reins we should alter the feeling on them as little as possible, and should carefully keep them at the same length, so as not to interfere with the horse's mouth. If a rein is in each hand (Fig. 7 I ), we had best pass the off rein into the left hand (Fig. 72); close the left hand on both reins (Fig. 73); slip the right hand forward on the off rein till the proper length is obtained; take up both reins in the right

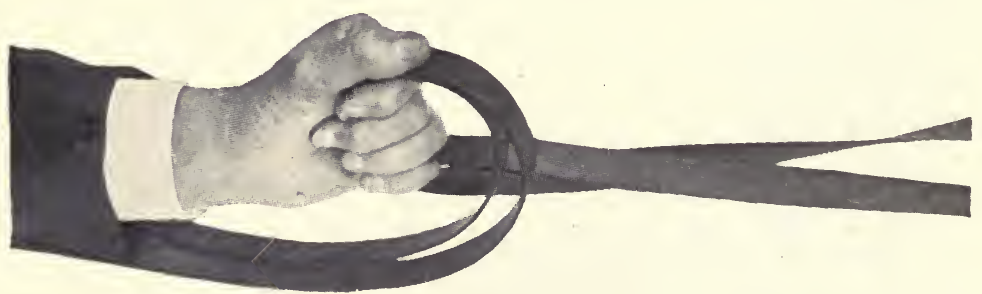

Fig. 77. - Reins held in one hand in military fashion.

hand; let go the slack of the reins with the left hand; take up the near rein with the left hand; and separate the hands.

- If the reins are held in one hand (the left, for instance), take them up in the right hand; slip the left hand forward on the near rein ; and, when the desired length is. obtained, take up both reins with the left hand.

MILITARY METHOD OF HOLDING THE REINS.

In almost all riding schools, ladies are taught to hold the reins in military fashion, which enacts that 
they should be held in the left hand, with the little finger dividing them, and their ends brought up between the finger and thumb (Fig. 77). Thus, the hold on the reins is chiefly maintained by the lateral pressure of the fingers and by the downward pressure of the thumb on them. As the muscles

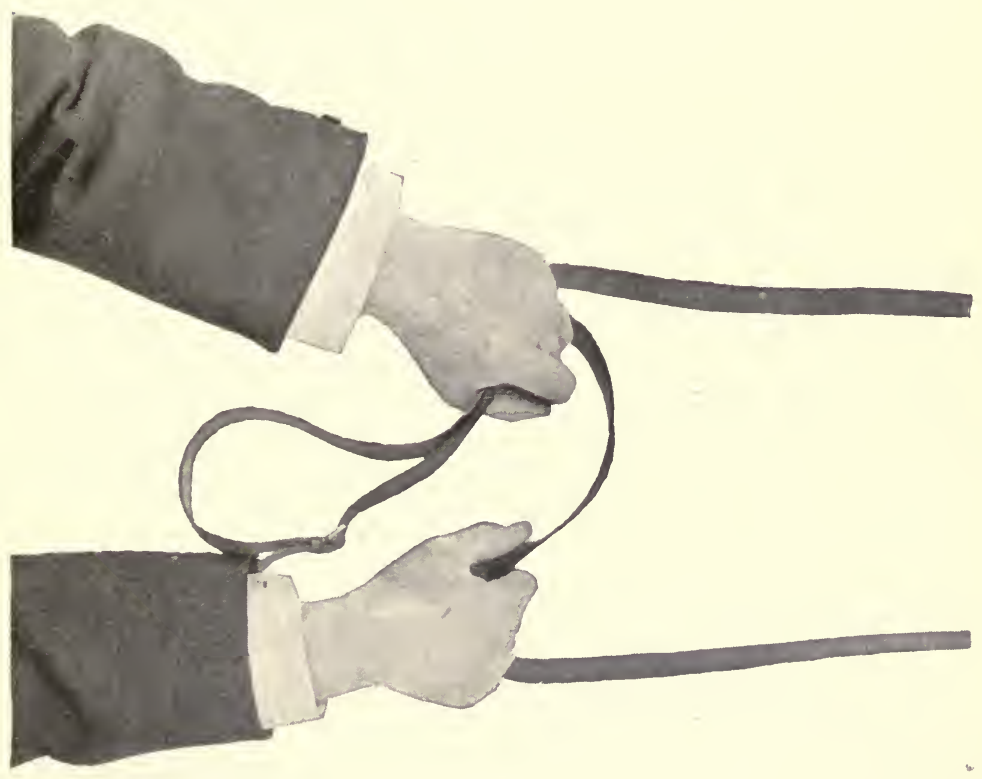

Fig. 78. - Off rein taken up by right hand from position shown in Fig. 77 .

which draw the fingers laterally together, are far weaker than the muscles which cause the hand to become clenched, it follows that this method of holding the reins is much less secure and a good deal more tiring than the crossed plan (Fig. 73), which has the further advantage of utilising the friction 
between the opposing surfaces of leather. This method is also unsuitable for two-handed riding; because it violates the principle laid down on pages 136 and 137 , that the manner of holding the reins by one hand should be the same as that by the other hand (compare Figs. $7 \mathrm{r}$ and 78 ).

RESPECTIVE MERITS OF ONE-HANDED AND TWO-HANDED RIDING.

All good horsewomen, especially when out hunting, ride with both hands on the reins, because, even with the quietest animal, the two hands may be needed for control or guidance. Besides, an even feeling on the reins when they are held in one hand, can be maintained only by keeping the hand in the centre-line of the horse's body, which is naturally a more or less irksome task for the rider. With only one hand on the reins, the rider's available strength is reduced by nearly one-half, and the reins have to be held much shorter than if both hands were on them. Onehanded riding is all right for military men, who have to wield a sword or lance, and polo players, who have to use a polo-stick, but it is ridiculous for ladies. 


\section{CHA P T E R VIII.}

THE SEAT.

Theory of the Seat-Practical Details.

THEORY OF THE SEAT.

THE best seat for all practical purposes is evidently one which affords security and comfort to the rider and freedom from injury to the horse. The lady should sit (not lean) forward in the saddle, so as to get a good grip of the crutches; and should bring her seat well under her ("sit well into the saddle"), in order to bring the centre of gravity of her body well back, as regards her base of support, and thus to increase her stability, which will depend almost entirely on her power to resist forward propulsion, when the horse suddenly stops or swerves to the left. Her hold of the reins will in any case prevent her from toppling backwards over the animal's tail, in the event of his making an unexpected movement forward from the halt, or suddenly increasing his speed when in motion. The faulty practice of riding the crutches, instead of sitting down in the saddle, brings the weight forward, 
and places the lady in the best possible position to fall off.

The greater difficulty which a rider has in keeping her seat when her mount abruptly swerves to the left, than when he goes to the right, is due to the fact that in the former case, the upper crutch is drawn away from the right thigh ; but in the latter case, it forms a more or less effective obstacle to the forward movement of the right thigh, and thus helps the rider to retain her seat. To explain this subject more fully, I may point out, that if a person is standing on the foot-board of the right side of a rapidly moving train which suddenly turns to the left, he or she would be far more inclined to fall off, than if a similar change of direction had been made to the right, in both of which instances the side of the train would play the part of the upper crutch. The fact that the lower part of the rider's right leg rests against the horse's near shoulder, as in Fig. 79, will materially help her in keeping her seat, in the event of an abrupt swerve to the left.

The side position of the seat, combined with the fact that the head has to be kept more or less in the direction the horse is proceeding, causes more weight to be placed on the near side than on the off. Although the rider cannot entirely remove this disadvantage, she may lessen this unequal distribution of weight, ( I) by avoiding the use of too long a stirrup leather, for the longer it is, the more inclined will she be to bring her weight to the near side, in order to obtain the assistance of her stirrup; (2) by sitting a 
little over on the off side, so as to place her weight as much as possible on the middle line of the seat of the saddle, namely, over the backbone of the horse ; and (3), as already pointed out (p. 34), by having the leaping head close to the upper crutch. In order to meet the second requirement, she should rest her weight

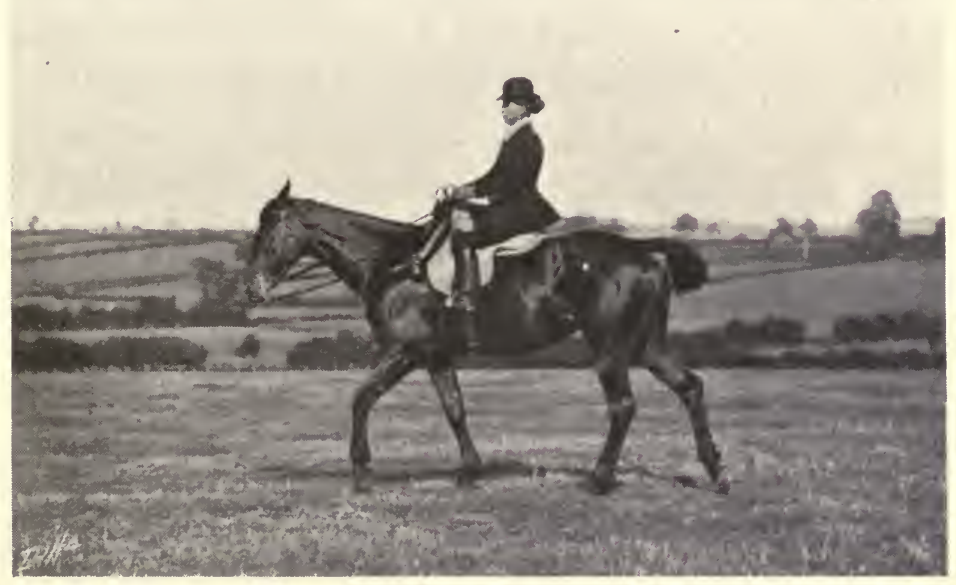

Fig. 79. - Position of rider's legs at the walk.

on her right leg, which in any case will have less fatigue to bear than the left one. Putting the weight on the right leg has the further advantage of lessening the tendency of the right shoulder to go forward, and of diminishing the pressure of the left foot on the stirrup.

The preponderance of weight on the left side of the saddle is liable to cause undue pressure on the off side of the withers, and also, though to a lesser 
extent, on the off side of the backbone, under the cantle of the saddle, with the result that ladies' horses frequently get sore backs at these places. As this unequal distribution of weight on the near side varies more or less at each stride of the horse; the saddle has a strong inclination, during movement, to keep working from one side to the other, and consequently, in order to check this hurtful tendency, a lady's saddle has to be girthed up much tighter than a man's saddle, and also to be provided with a balance strap (p. 53).

The only means by which the rider can maintain her position in the saddle are balance and grip, both of which are accomplished by muscular action, though in different ways. What is popularly known as "grip," is effected by continued muscular contraction, which speedily gives rise to fatigue, and consequently can be kept up for only a comparatively short time. The balance required for holding the body more or less erect, as in walking, standing and sitting, is, on the contrary, preserved by the alternate contraction and relaxation of a large number of muscles, the work of which, being intermittent and more or less evenly distributed, can be maintained for a long period without fatigue. It is therefore evident that a lady should ride as much as possible by balance, and that she should use grip only when its aid is demanded for keeping her secure in the saddle. It is obvious that grip is the riding function of the legs; and balance, that of the body. As grip has generally to be put in action at a moment's notice, the legs should be kept in such a position as to enable 
them to apply the necessary grip with promptness and precision. Hence the rider should not move about in the saddle, as some are inclined to do, in the attempt to "sit back" when going over a fence.

While keeping the legs in a uniform position, the rider will obtain all the balance she needs, by the play of her hip joints and by that of the joints of the body above them, and will thus be enabled to sit erect, lean back or forward, or bring her weight to one side or the other, as may be required.

Grip from the left leg is obtained by pressure against the leaping head, which can be effected either by certain muscles of the thigh or by those of the ankle joint. The amount of pressure which can be obtained by the former method is far less than by the latter, for which a short stirrup leather is necessary. The comparative feebleness of this action of the thigh muscles can be readily seen by the small resistance which they can make against downward pressure, when the knee is raised with the foot off the ground. If, however, the foot is on the ground, the muscles which straighten the ankle joint will enable the knee to be raised, even against strong downward pressure. It might be objected to this mode of obtaining grip, that the powerful pressure thus exerted on the stirrup iron, would cause a downward pull on the (near) left side, which is, however, counterbalanced by the upward pressure of the left leg on the leaping head, and consequently it has no displacing effect on the saddle. It is evident that this action of the ankle joint can be performed 
effectively, only when the ball of the foot rests on the stirrup. If the foot is put "home," the ankle joint will have little or no play. When using the leaping head, we should bear in mind that the action of the muscles which straighten the ankle joint, should be independent of the body. If this condition is not observed, the tendency will be to put undue weight on the stirrup, and to bring the body forward.

It is evident that placing weight on the stirrup, without at the same time exerting counterbalancing pressure against the leaping head, will not only put undue weight on the near side, but will also bring the body forward.

'The right leg can help in obtaining grip, either by bending the knee and bringing the calf of the leg round the upper crutch, or by lateral pressure of the knee against that crutch. The former method is entirely wrong, because it cannot be fully carried out, except by bringing the body forward, ${ }^{*}$ which action is

* The muscles of our limbs are attached at each end to bones, between which there are one or more joints ; and they act by their power of contraction, which enables them to become shortened to about two-thirds of their length. The full effect of this contraction can be obtained by a muscle only when its points of attachment are separated to their utmost extent, and it becomes diminished in proportion as the distance between them is shortened by the bending of the intermediate joint or joints, up to a length equal to that of the muscle in a fully contracted state, at which limit the muscle is out of "play." The muscles which bend the knee are attached, at one end, to the back of the shin bone, close to the knee; and at the other extremity, to the end of the ischium (lower part of the pelvis), which is below the hip joints. Consequently, the more the knee is bent and the more the upper part of the body is drawn back by the play of the hip joints, the nearer are the opposite points of attachment of these respective muscles brought together, and the less power will they have to hook back the knee. Hence the more a lady leans back, when going over a fence for instance, the less firmly will she be able to hook her leg round the upper crutch. 
incompatible with firmness of seat, when going over fences, or when the horse makes any abrupt and discon-

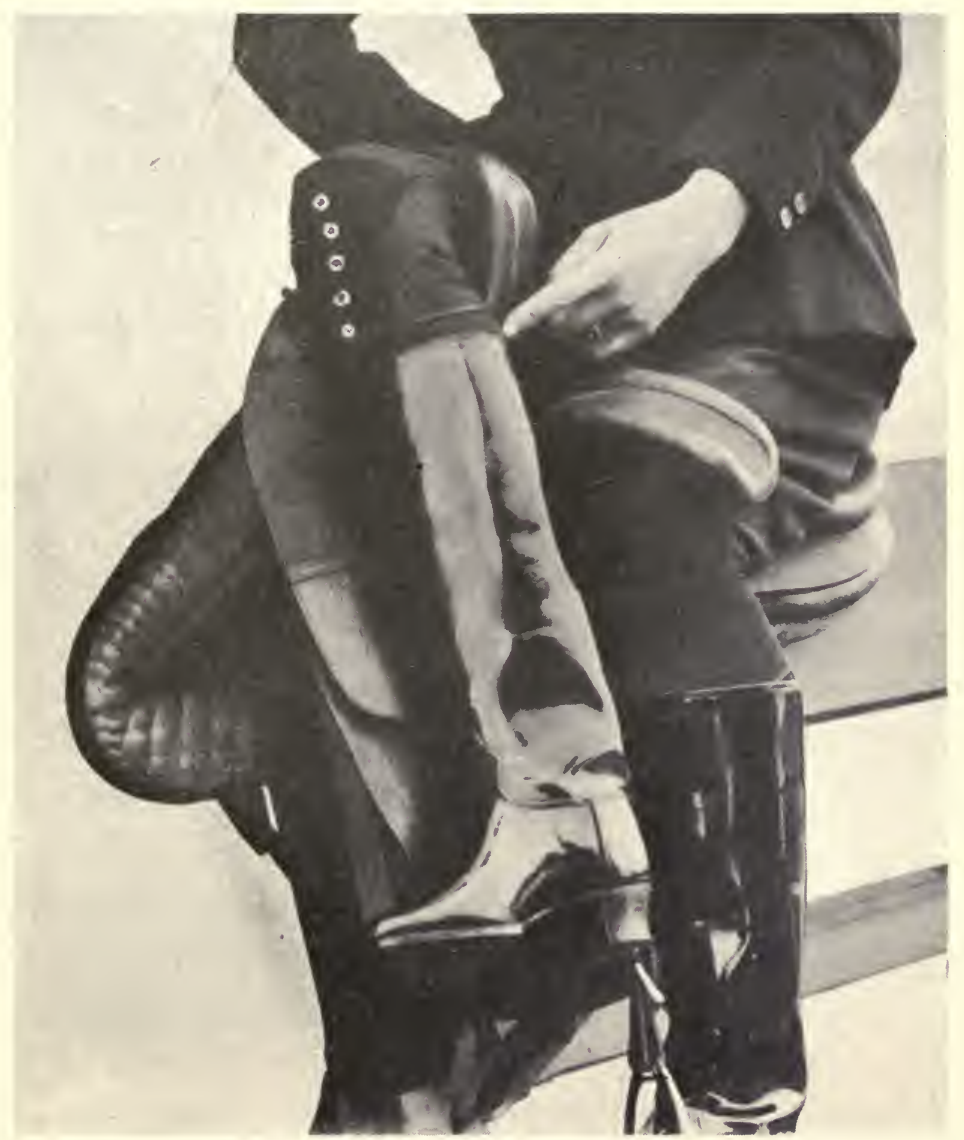

Fig. 80. - Hooked back leg, the direction of the pressure of which is shown by the fore finger of the left hand.

certing movement. This "hooked-back" seat also predisposes a lady to fall over the off shoulder of an

Therefore, ladies who adopt this hooked-back seat, are invariably prompted by the requirements of this position, to bend forward, and have more or less difficulty in bringing the upper part of the body back. 
animal which suddenly swerves to the near side; the reason being that in such a case, the upper crutch acts as the pivot of revolution. On account of causing the weight to be brought forward, this hooked-back style also tends to make her bump up and down in her saddle. The lateral method, which is effected by the inward rotation of the right thigh, is free from the foregoing objections ; and by causing the lower part of the right leg to be placed against the horse's shoulder, it affords the rider valuable indications of the animal's movements. Also, as the lateral pressure is as nearly as practicable in a direction opposite to that of the pressure of the left leg against the leaping head; it will act to the best advantage, and it will allow the body full freedom to be drawn back by the play of the hip joints. The pressure of the hooked-back leg is, on the contrary, nearly at right angles to that of the left leg (Fig. 80), and consequently it affords very little help in the attainment of grip.

'The hooked-back style of riding induces fatigue by continued muscular contraction, and is a fertile cause of ladies becoming cut under the right knee, which fact is fully proved by the numerous devices which have been brought out by saddlers with the view of obviating this injury.

It is easy to prove by experiment, that when we sit in an unconstrained position on a chair or saddle for instance, the direction of our shoulders will be at right angles to that of our legs, or, more correctly speaking, at right angles to a line bisecting the angle 
formed by our legs. Hence, when riding, we cannot continue to sit absolutely "square" (having our shoulders at right angles to the direction of our mount) without keeping our body in a stiff position, which in a short time will be productive of discomfort and fatigue.

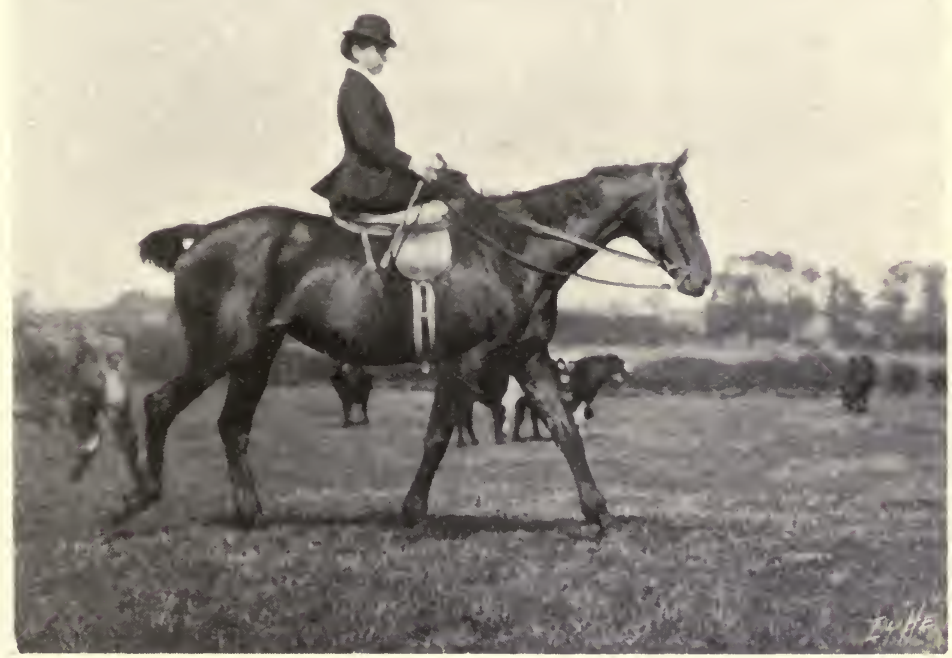

Fig. 8I.-Seat at the walk.

Although the maintenance of a twisted position of the body to the right is incompatible with ease, no discomfort will arise from looking more or less straight to the front, because the muscles which regulate the direction of the neck and eyes are gifted with great mobility, and their respective periods of contraction and relax- 
ation are comparatively short, when we are looking to the front. Even when walking at ease, the direction of the shoulders, which alters at every step, in no way affects that of our line of sight; and it certainly would not do so, when we are riding. The continued maintenance of a perfectly square seat entails so much muscular rigidity, that it is unsuitable for 'cross-country work, or for the riding of "difficult" horses. In any case, it causes the body to assume a twisted and therefore an unnatural position; because the fact of the right hip joint being more advanced than the left one, will prevent the lower and posterior part of the trunk (the pelvis) from being parallel, as it ought to be, with the line connecting the shoulders. To facilitate the attainment of a "square seat," some saddlers incline the upper crutch a good deal towards the off side. and thus curtail the space between that crutch and the near side of the horse's shoulder and neck so much, that the rider is unable to get her right leg into proper position, and is consequently obliged to " hook it back." I need hardly say that such saddles do not suit good horsewomen.

An absurd fallacy of some of the "square seat" school is that the right thigh (from hip joint to knee) should be kept parallel to the horse's backbone, a position which would put a great deal more weight on the near side of the saddle than on the off, and would consequently be liable to give the horse a sore back. On the contrary, the even distribution of the rider's weight is an essential condition of comfort to the 
animal and of security of seat to the rider, and is of infinitely greater importance than the attainment of a conventional and unnatural attitude.

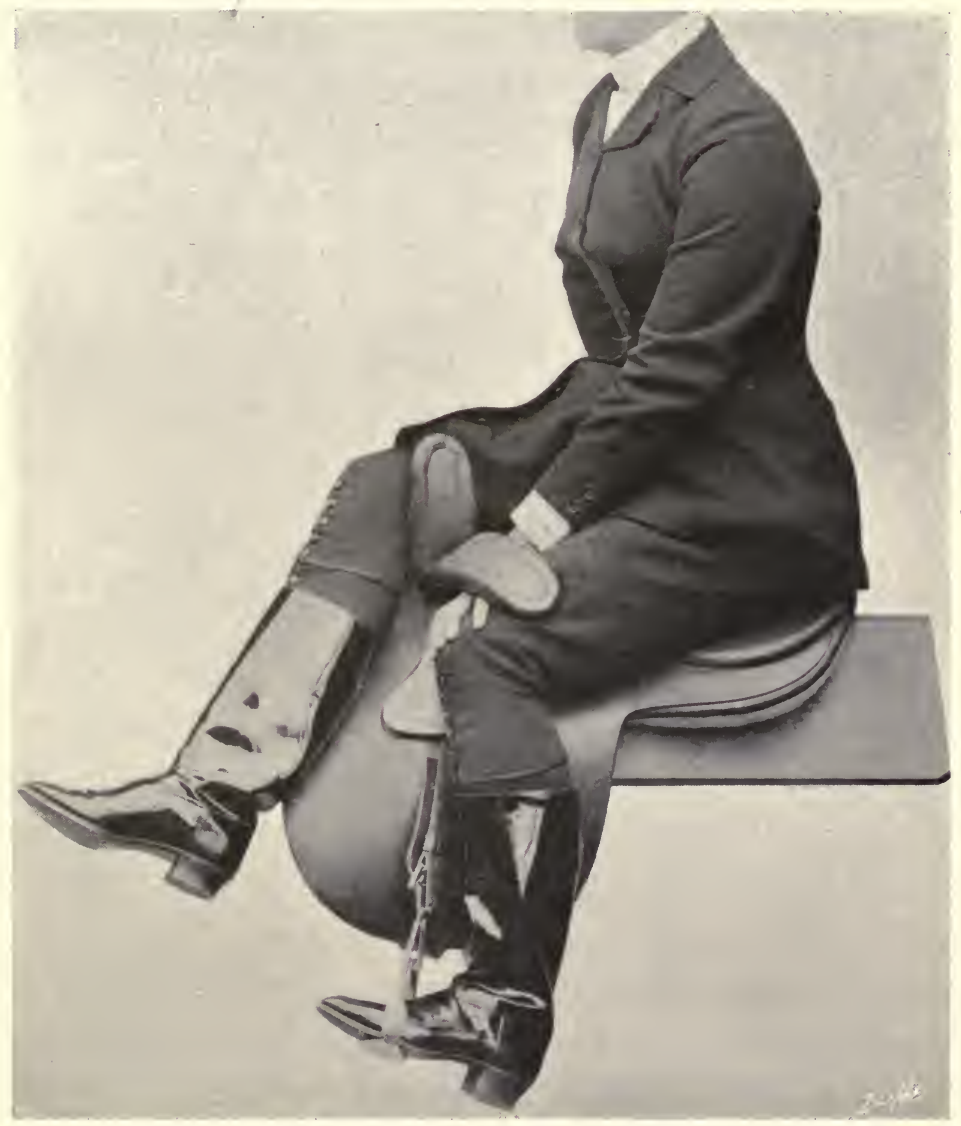

Fig. 82. - Length of stirrup.

The majority of riding-masters are such admirers of the "square seat," that when giving a lady her first few lessons, they will as a rule keep constantly telling 
her to keep her right shoulder back, which she cannot do without twisting and stiffening her body.

For practical requirements, as out hunting or on a long journey, the seat should be free from all constraint and rigidity, so that it can be maintained without undue fatigue for several hours, during which time the rider should be able at any moment to utilise the grip of her legs with promptness, precision and strength. A lady, with a good seat and properly made saddle, will ride quite square enough (Fig. 8I) to avoid any lack of elegance in her appearance without having to adopt a conventional twist.

PRACTICAL DETAILS.

The first thing for a rider to do is to place herself in a thoroughly comfortable position on the saddle. She should sit well down in it, in the same manner as she would sit on a chair in which she wished to lean back, and would thus get her seat well under her, and would be able to obtain, when required, a strong grip of the crutches. In this position she will be able to increase her stability by bringing her shoulders back, which she could not do with the same facility, if, instead of leaning back, she sat back. In order to see where she is going, she should sit more or less erect. Her left foot should be placed in the stirrup only as far as the ball of the foot, so as to allow the ankle joint full play. The stirrup leather should be long enough to enable the left thigh to clear the leaping head, when the lady rises at the trot; and short enough for it to exert full 
pressure against the leaping head, by the action of the ankle joint. A correct compromise between these two opposing conditions is obtained when the length of the leather will just allow the flat of the hand to be easily placed between the leg and the leaping head (Fig. 82).

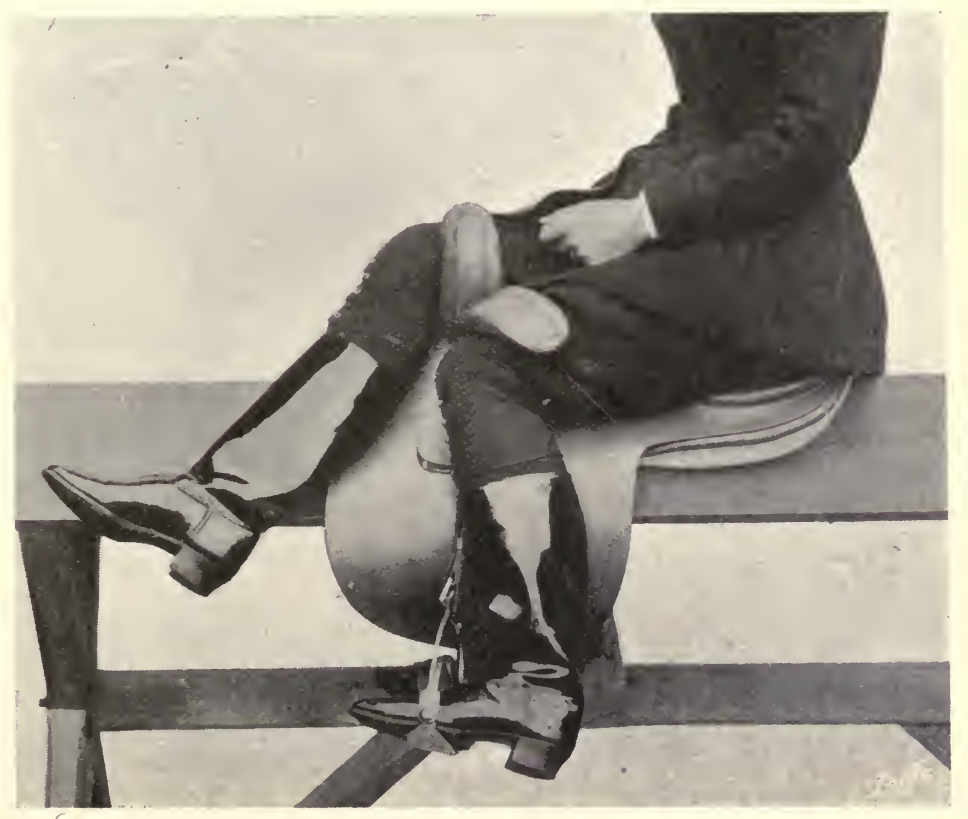

Fig. 83.-Correct position of legs.

The rider should obtain her grip of the leaping head just above the point of the left knee, as shown in Fig. 83 ; and by rotating the right thigh inwards, she should press the flat of that knee against the upper crutch, as if she were trying to bring her two knees together. While gripping in the manner described, the portion of the right leg which is below the knee, 
should rest in an easy position against the horse's near shoulder, as in Fig. 79.

When the beginner has learned how to sit in the saddle, she should practise leaning back, which she can best do by gripping the crutches, while keeping her legs in proper position (Fig. 84), and leaning

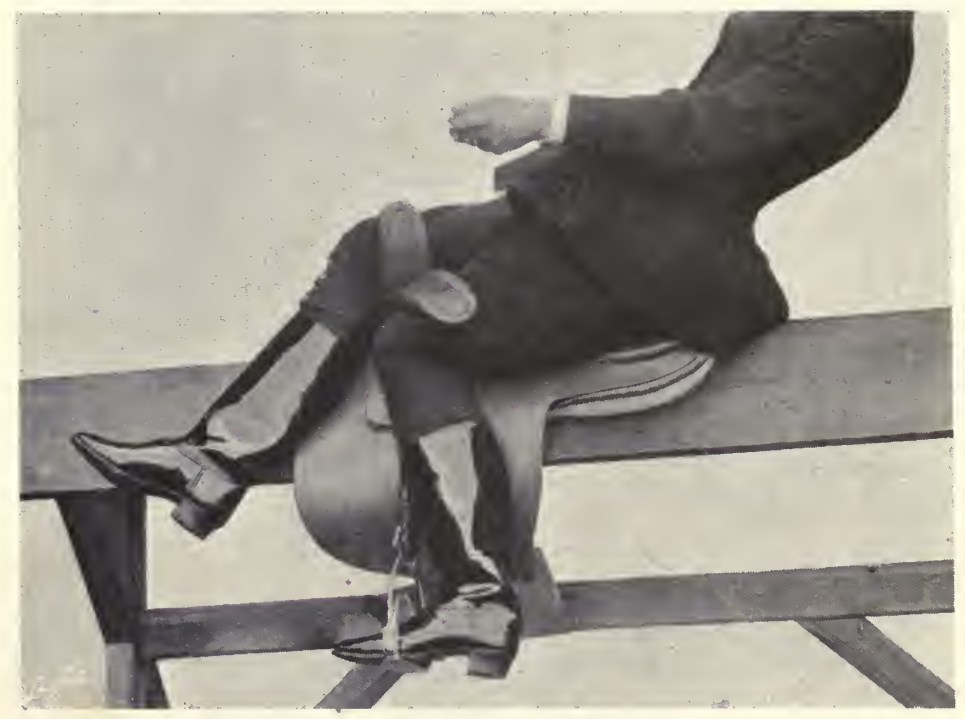

Fig. 84.-Leaning back.

her body back until she can almost touch the horse's croup. When doing this for the first few times, her teacher should support her, in order to give her confidence, and the groom, if necessary, should hold the horse, which should of course be a quiet animal. The object of this practice is to show her that the movements of her body are entirely independent of her grip of the crutches, and that the forward and backward 
motion of her body is regulated by the action of her hip joints, and not by altering her seat, which should remain fixed, and, as it were, glued to the saddle, at the walk, canter, gallop and jump; the trot being the only movement at which she should rise. Having learned the meaning of grip and leaning back, she can take a snaffle rein in each hand, as in Fig. 7 I, while keeping her hands low and well apart; she can then "feel" the horse's mouth by drawing her hands towards her through a distance of a few inches, and then keeping them in a fixed position. 


\section{CHAPTER IX.}

HANDS, VOICE, WHIY AND SPUR.

\section{HANDS.}

NEARLy every writer on the subject of riding is of opinion that "good hands" are inborn and cannot be acquired. This may be so, but the worst of hands may be greatly improved by good teaching and practice. Continental horsemen do not, as a rule, learn how to ride across country, but the majority of them devote much study to the various methods of bitting and handling horses, and, as far as hacking is concerned, their horses are better broken and better handled than they are in this country. I am not alluding to the question of seat, as I think Britons, and especially our Colonial cousins, can beat them on that point; but it is evident, as can be seen any day and in any hunting field, that more study should be devoted to the acquirement of good hands. A course of school riding, especially on a made "school" horse, which is a very light-mouthed animal, would greatly lessen the clumsiness of heavy hands; or, if such instruction were unobtainable, good practice might be 
had on a young horse which had been carefully broken by a competent horseman. No young horse will pull until he is taught to do so by bad handling, and a lady who wishes to improve her hands might ride a young animal, in the company of an old steady horse, and ascertain in this way what the natural condition of a horse's mouth really is and how easily it may be controlled. I do not think that many ladies have heavy hands with horses - their chief fault lies in their want of control over their mounts. Many ride with the reins so loose that their horses get out of hand and go in an uncollected manner, and accidents not unfrequently occur from this cause. As horses which are not well in hand in the hunting field will, sooner or later, bring their riders either to grief or to disgrace, this slipshod method of handling should be avoided. Although the grip which a lady obtains in a side-saddle should render her entirely independent of the reins as a means of support, she is handicapped by being unable to lower her hands to the same extent as a man. I have found that with horses which carry their heads too high, and throw them up if the rider tries to lower them, a standing martingale attached to the rings of the snaffle affords considerable help in obtaining perfect control, especially with young horses. But I would not recommend a lady to use a standing martingale with a horse which has not previously been accustomed to it, nor indeed at all, unless she rides chiefly on the snaffle; for although it is perfectly safe to use the curb with a standing martingale in steadying 
and collecting a horse, it would be highly dangerous to touch it when the animal is jumping. The majority of riding men regard the standing martingale as dangerous-and rightly, for only men with good hands can safely use it. If any sudden snatch or jerk were made at the curb, and the horse in throwing up his head found himself caught by the standing martingale, a very serious accident might happen. The standing martingale in no way impedes a horse's jumping, for horses do not jump with their heads in the air, unless they fear the curb. Fig. 48 shows its maximum length. It may be said that ladies ought not to ride horses which carry their heads too high, but many of us have to make the best of what we can get in the matter of horseflesh, and employ the surest methods at our command for keeping such animals under perfect control. The standing martingale is dangerous in hunting only when going through gates, as it is liable to catch in a gate post and cause trouble.

The faster a horse goes at any particular pace in a natural and unconstrained manner, the more will he try to extend his head and neck, so as to bring the centre of gravity of his body forward, and also to aid the muscles of the neck in drawing the fore limbs to the front. The pulling in of the head and neck by the reins will, therefore, be a direct indication to the animal to slacken his speed. If he be well broken he, will not only go slower, but will also signify the fact of his obedience by yielding to the bit by the play of the joints of his head and neck. When he keeps these 
joints (namely, those which connect the lower jaw to the head, and the head to the neck, and the joints of the neck themselves) free from all rigidity and bears lightly on the bit, he is what is called "well in hand," in which state every horsewoman should endeavour to keep her mount, as it is the beau idéal one that admits of full control by the rider and of perfect freedom of movement on the part of the horse. Having the horse well in hand, the rider should be careful to keep the reins at one unaltered length for the particular rate of speed at which she is going. If she desires to increase it, she should give her horse a signal which he understands, and should lengthen the reins as may be required. If she wishes to go slower, she should proportionately shorten them; but she should always preserve uniformity of speed at any pace by keeping a fixed length of reins. Nothing is worse for a horse's mouth than the constant "give and take" (in Ireland they call it "niggling" at a horse's mouth) which is practised by almost every bad rider. This fact is so well recognised by our jockeys that "Keep your hands steady" is the chief order which competent trainers of racehorses give to their lads. When a rider keeps shifting the position of her hands, her bewildered animal will be unable to know at what speed she wants him to travel. All this reads very simple, but sometimes we find that horses, especially when excited by hounds, insist on going at their own pace. If the coast is clear in front, and the horseman in advance has got safely over and away from the fence to which 
a lady is approaching, it would not be wise for her to interfere with her hunter, because, if he knows his business, he won't fall if he can help it. But if, on the other hand, the only practicable place in a fence is not free, the keenness of the animal must be checked by a judicious use of the curb. If he is so headstrong as to refuse to obey this command by slackening speed, he should be turned round either to right or left, whichever may be the easier for his rider. When we find ourselves in such a tight corner we must, for our own safety as well as for that of our neighbours, exercise a certain amount of force in controlling our horses. The "silken thread" method of handling, which is, or should be, employed at any other time, stands us in poor stead in the face of this difficulty. There are horses which will neither slacken speed nor turn for their riders, and a runaway in the hunting field is by no means rare. If any lady has a hunter who takes charge of her in this manner, I would strongly advise her to ride him in a standing martingale (p. 82), because with its aid she will generally be able to turn him, even if she cannot stop him in any other way. A horse which will neither slacken speed nor turn in any direction gallops on, as a rule, with his head up, and, having succeeded in shifting the snaffle from the bars to the corners of his mouth, he is impervious to the action of the curb, because his head is too high for the curb to act with advantage. On such an animal the standing martingale is valuable, because it makes 
him keep his head in a proper position. A great deal of sound sense has been written by different horsemen on the subject of "hands." Sam Chifney tells us to use the reins as if they were silken threads which any sharp pull would break, and Mr. John Hubert Moore always gave the advice to take a pull at the reins as though you were drawing a cork out of a bottle without wishing to spill one drop of its contents. I have often, in my own mind, likened a horse's mouth to a piece of narrow elastic which is capable of expansion up to a certain point. When vigorously tugged at, it is no longer elastic, but as unyielding as ordinary string. Good hands maintain its elasticity, bad ones convert it into string. A sympathetic touch on a horse's mouth can only be made by "good hands." A musician, if he is an artist, will accompany a weak-voiced singer so sympathetically that the sweet though not robust notes of the voice are heard to the best advantage: he is a man with good hands. A heavy-fisted player, desiring to show his command over the instrument, will try to turn the accompaniment into a pianoforte solo, and the nice notes of the struggling singer will be entirely drowned by noise. He is like the heavyhanded, unsympathetic rider.

\section{VOICE.}

For pleasant riding, it is essential that the horse should understand his rider's orders, which are usually given to him only by the reins and whip. However efficiently a lady may use these "aids," the fact 
remains that a good understanding between herself and her mount is better established by the voice than by any other means. With a little vocal training any ordinary horse, when going fast, will pull up more promptly and with greater ease to his mouth and hocks, by a pleasantly uttered "whoa," than by the action of hands and reins. Young horses, like foxhound puppies which are taken out for the first time, show great reluctance to pass moving objects; but if the rider speaks encouragingly to her mount in a tone of voice that means he must go on, he will try his best to obey her, although his attention may be divided betwixt fear and duty. As a reward, his rider should give him a few pats on the neck and speak encouragingly to him, and she will doubtless find that he will make a bolder effort to obey her voice when he again finds himself confronted with a similar difficulty ; because he will associate his first escape from apparent disaster with her voice, and will in time have such confidence in her guidance that a word from her will be quite sufficient to assure him that all is well. When riding bad horses at my husband's breaking classes abroad, I found it best not to speak to them; for a bond of friendship had not been established between us, and I noticed that the sound of my voice often stirred up their angry passions by reminding them, I suppose, of some former rider who had scolded them while ill-treating them. It was unsafe even to pat and try to be friendly with such spoiled horses. I remember a very violent animal in Pretoria which 
showed resentment in this respect by rushing at me after I had dismounted, simply because I endeavoured to pat and say a kind word to him. I have no doubt that he would have accepted my well-meant advances if we had had time to mutually understand each other. A show jumper named Mons Meg was so terrified of the man who used to ride her that, on hearing his voice, even from a distance, she would break out in a perspiration and stand trembling with terror. The mare was really so kind that we had her for a time at Ward's Riding School, and she was ridden without reins over jumps by several of our pupils. I took her to ride in a jumping competition at the Agricultural Hall; but, unfortunately, the rider she disliked came to her stall and spoke to her, with the usual result, and when I got on her back she was violently agitated, and refused the second fence, which was a gate. At one moment it seemed as though she would have brought us both to grief, for she tried to jump out of the ring among the people-a feat, I was afterwards told, she had performed on more than one occasion. She would always jump kindly when away from the hated show ring, where she must at some time or other have been badly treated. When animals get into a state of nervous excitement, a few pats on the neck and a soothing word or two often act like magic in calming them down. A mare which was lent me in Calcutta by a horse importer, and on which I won a cup in an open jumping competition, was in such a state of 
nervousness that she would not let me take the trophy until I patted and spoke to her, and the presentation was then effected without a scene. This animal, which was a well-bred Australian, was a stranger to me, and had never carried a lady before that day. Nevertheless, she passed successfully through a terribly trying ordeal, and I am certain that she would not have made the great efforts she did in jumping, if I had not soothed and encouraged her with my voice. She was only $\mathrm{I}^{-2}$ in height, and was competing against big horses, some of which were ridden by steeplechase jockeys. The competition took place at night in a circus which was lighted by electricity, and which was open at each end. The object to be jumped was a white gate placed midway across the arena, and raised each time that it had been successfully cleared. From the glare of electric light in this crowded place, we had to go into outer darkness and carefully avoid the tent pegs and ropes in finding our way to the other entrance. While we were waiting our turn to jump, we had to stand near a cage of lions which growled savagely during the whole time, and also in the vicinity of two camels. My mount disliked the camels far more than the lions; in fact, she hated the sight of them, and would have done her best to escape, if I had not turned her head away from them and patted and soothed her. Mr. Frank Fillis, who was the proprietor of the circus, told me that horses have such an antipathy to camels that they will not drink, however thirsty they may be, from a bucket which has been used 
by one of these long-necked animals. By-the-bye, my acquisition of this cup caused me to be branded as a "circus rider" by the ladies in a Little Pedlington village in this country; for when the local society leader called on me, I was out, and my son, by way of entertaining her, showed her "the cup that mother won in a circus!"

In order for the voice to be effective, the word of command must be given at the moment when a horse is about to play up in any way, not after he has committed a fault, and therefore a knowledge of horses and their ways is necessary before we can use the voice properly. It is always advisable to keep an eye on our mount, because if we do not do so, we shall be unable to seize the generally brief moment which exists between the thought of evil in the animal's mind and its execution. Those who have lived much among horses must have frequently noticed this preparatory period before a horse plays up, and no doubt have profited by the warning their experienced eyes gave them; for if we see what is about to come, and know how to avert it, we are often able to save ourselves from disaster.

In order that the animal may thoroughly understand our words of command, we should have as few of them as possible, employ them only when necessary, and always in the same respective tone of voice, whether it be a soothing word of encouragement accompanied by a few pats on the neck, or the word "steady" given in a determined tone, and accompanied by a restraining 


\section{I70 HANDS, VOICE, WHIP AND SPUR.}

pull on the reins as may be necessary. The word "whoa" is best uttered in rather a high key and in a drawling tone, when we begin to pull up a horse during movement; but we should reserve "steady," like the curb, for use in emergency, and should utter it in a threatening tone of voice. The words of command which an inexperienced rider will find most useful are a click of the tongue for a walk, trot, and canter; "whoa" to pull up; "steady" when he is going too fast, or indulging in unnecessary leaps and bounds; "go on," with a few pats on the neck, if he is nervous about passing any object, or shying; and a quiet word or two of encouragement, with more pats on the neck, when he is in a state of nervous excitement, as, for instance, on his first day with hounds.

When visiting a horse in his stable to give him a carrot or other tit-bit, his mistress should call him by his name, and he will soon neigh on hearing her voice, if she always gives him something nice; for horses, like poor relations, don't appreciate our visits unless they can get something out of us. Lady Dilke had a horse which she had trained to lick her hand. On going up to him in his box she would put out her hand and say "Lick her, dear," and the animal would give her his mute caress like a dog: it was very pretty to see how well the pair understood each other. We may see the power of the voice exemplified in cart horses, which will turn to right or left, go faster or slower, or pull up, according as they receive the word 
WHIP.

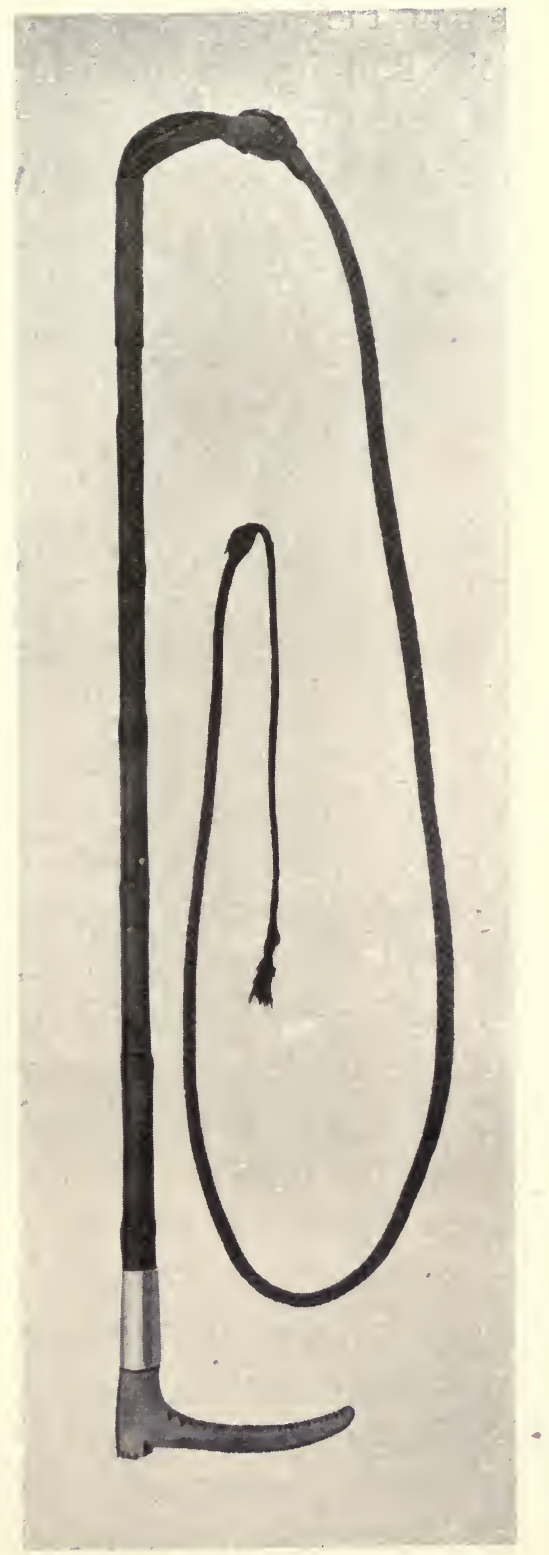

Fig. 85.-Hunting whip. 
I72 HANDS, VOICE, WHIP AND SPUR.

of command from the wagoner who walks beside them. The voice is also greatly used by polo players. Horses are very catholic in their admiration for titbits. They like all kinds of sweets and fruit, and will even crunch up the stones of plums and peaches, which require good teeth to crack. An old favourite of mine was particularly fond of chocolate and jam tarts!

\section{WHIP.}

The chief uses of a hunting whip are to help the rider to manipulate gates, and to be cracked; the former being much more necessary to a horsewoman than the latter. The crop should therefore be of a serviceable length. It is the very silly fashion at present to have hunting whips that are less than two feet long. Many are made of whalebone, and are covered with catgut, their special advantage being that their flexibility greatly facilitates the process of cracking. A more serviceable crop for a lady is one of stiff cane, the thick end of the handle of which is made rough, as in Fig. 85 , or is provided with a metal stud, so that the handle may not slip when it is pushed against a gate. Formerly, two feet three inches was the usual length of a hunting crop for both sexes. Three feet is a much better length for ladies, who cannot "get down into their saddle" like men. Besides, a fairly long crop is very useful for keeping a horse straight by the rider touching him with it on the off flank when he wants to run out to the left, which is 
his favourite side for refusing in the large majority of cases. A short crop is useless for this purpose, as the right hand will be fully occupied on such trying occasions in keeping the animal's head toward the

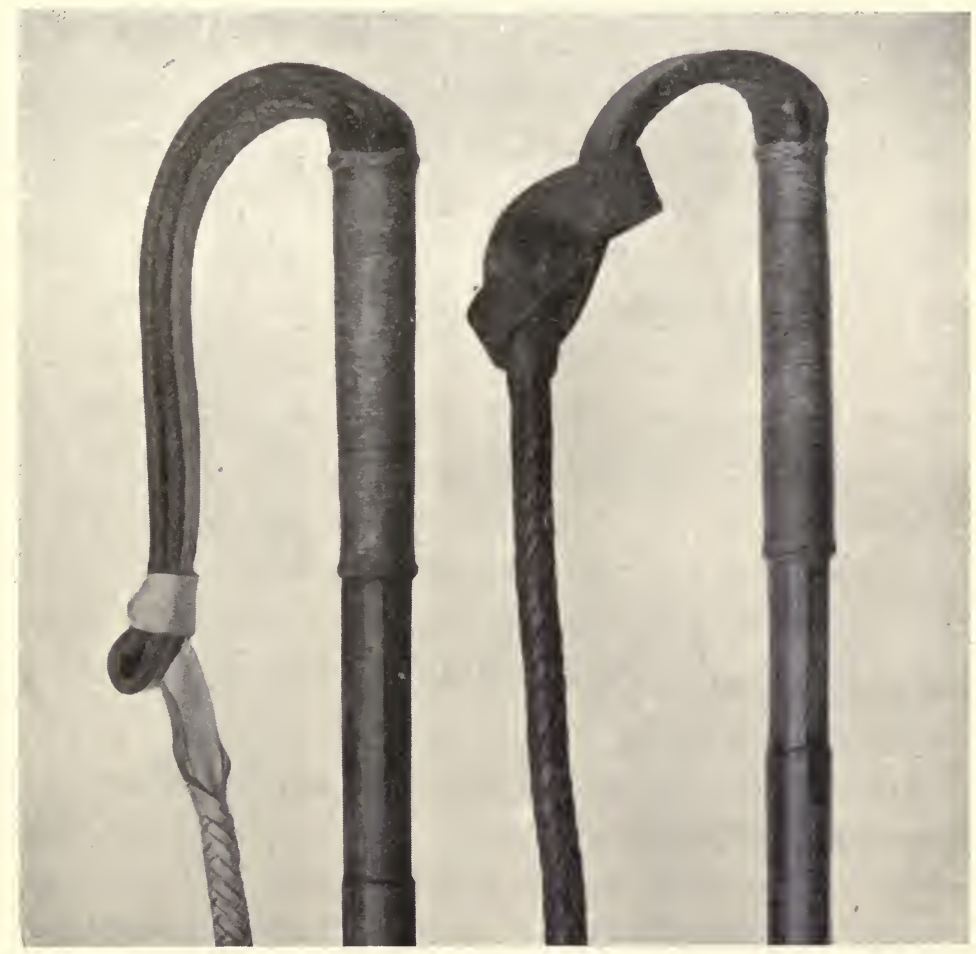

Fig. 86. - Thong properly put on.

Fig. 87.-Thong properly put on.

obstacle, and the crop should be able to perform its share of the work by a turn of the wrist, care being taken that no jerk is communicated to the rein.

The thong is about three feet ten inches long, is furnished with a lash, which is about a foot long, and 


\section{I74 HANDS, VOICE, WHIP AND SPUR.}

is attached to the keeper, which is a leather loop at the end of the crop. Men generally like a thong of white pipe-clayed leather, but as the colour is apt to come off and soil one's habit, a brown leather thong is best for ladies.

The keeper of the modern hunting whip has a slit, near its end, through both thicknesses of leather. In attaching the thong, the loop at its upper end is placed over the end of the keeper, and it is then passed through the slit and drawn tightly (Fig. 86). The old-fashioned keeper, which is still greatly in use, is a simple loop of leather, over which the loop of the thong is put, and the remainder of the thong is threaded through the opening at the end of the keeper (Fig. 87). A wrong way to put on the thong is, in the first instance, to pass the loop of the thong through (instead of over) the keeper (Fig. 88). Some authorities might take exception to the way the thong is put on in Fig. 89.

To facilitate the use of the thong, it is well to have a long keeper, as in Fig. 86. The keeper of the whip which is shown in Fig. 85, and also in Fig 87, is too short.

The chief use of the thong in hunting is to recover the crop if it happens to be pulled out of the hand when opening a gate, before doing which, one or more turns of the thong are consequently taken round the hand. It also enables us to warn off hounds who approach too near our horses' legs, on which occasions the whip should be held at arm's length, with thong 
and lash vertical. A touch of the lash may aid in encouraging a friend's horse to go through something to which he objects, but a man would doubtless be handy to do the needful in such a case. It would be

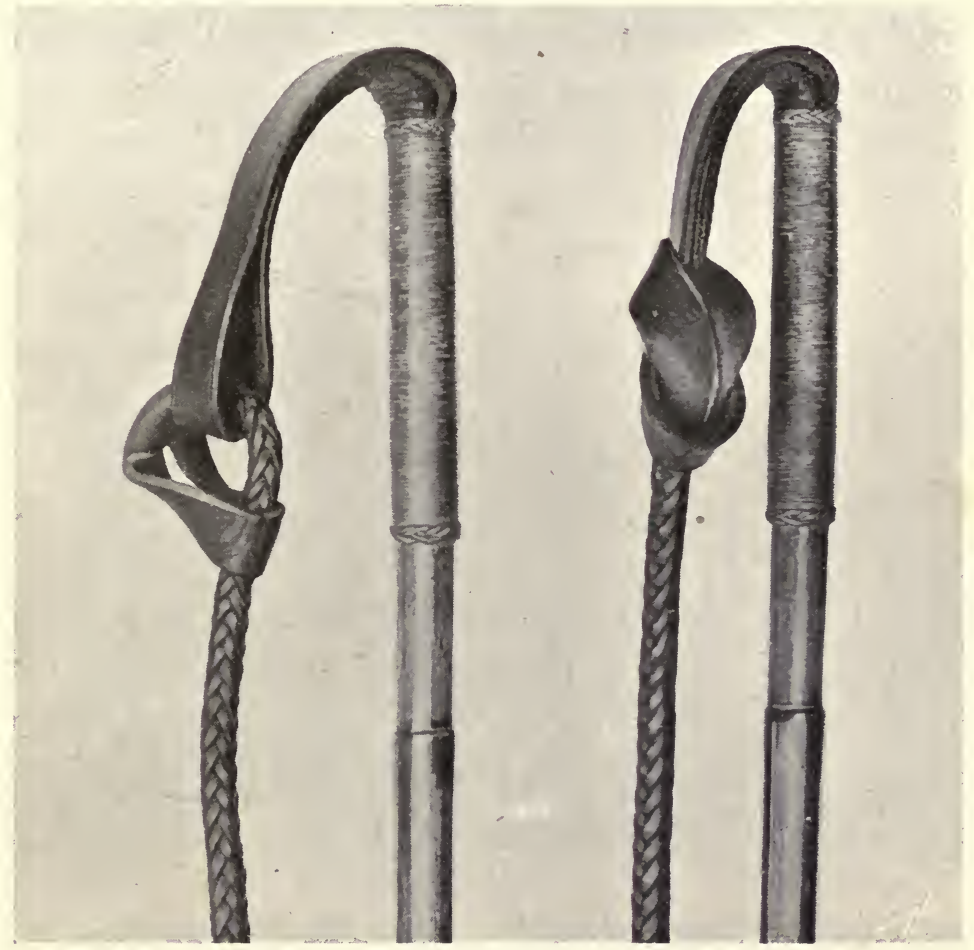

Fig. 88.-Thong incorrectly put on.

Fig. 89. - Thong not quite right.

well for a lady to know how to crack her whip, if her help were required in turning hounds, or in hurrying up a laggard hound; but this art should first be learnt on foot, under the tuition of a competent man, in much the same way as Mr. Frank Ward teaches his pupils to 
I76 HANDS, VOICE, WHIP AND SPUR.

catch the thong with precision for four-in-hand driving; and the lady's hunter must also be trained to stand having a whip cracked on his back, before any experiment of that kind is performed in the hunting field. It is a good plan to first accustom hunters to the cracking of a whip in or near their stables, letting them see the performance, and, after a ridden horse will quietly stand the whip being flicked, his rider may safely crack it, supposing, of course, she is able to wield her flail correctly, and without touching the animal; hence the necessity of acquiring precision in this art before attempting it on horseback. An experienced hunting woman tells me that women should be as useful in the field as men; but I fear that is impossible, for we cannot get on and off our horses as easily as men, to render prompt help in cases of emergency; hold open a gate on a windy day, or perform the numerous kindly acts which fall to the lot of the mere male. Besides, however active and wellintentioned we may be, we are hampered by our dress, and still more so by the want of it, in the case of an apron skirt. If a crop is used for hacking, say in the Row, the thong should be taken off, for it would look as much out of place there as a pink hunting coat. The whip should be always carried handle downwards, on the off-side, as if we were trying to conceal its presence, and not as though we were riding with "a rein in each hand, and a whip in the other."

In a country of hedges, like the Shires, it is well to acquire the habit of holding the whip in such a way 
that the handle of the whip will point directly backwards ; for if it is inclined outwards, it will be apt to catch in a branch or twig, when going through a bullifinch (Fig. 90) or straggling hedge.

\section{SPUR.}

The spur is inapplicable to the requirements of

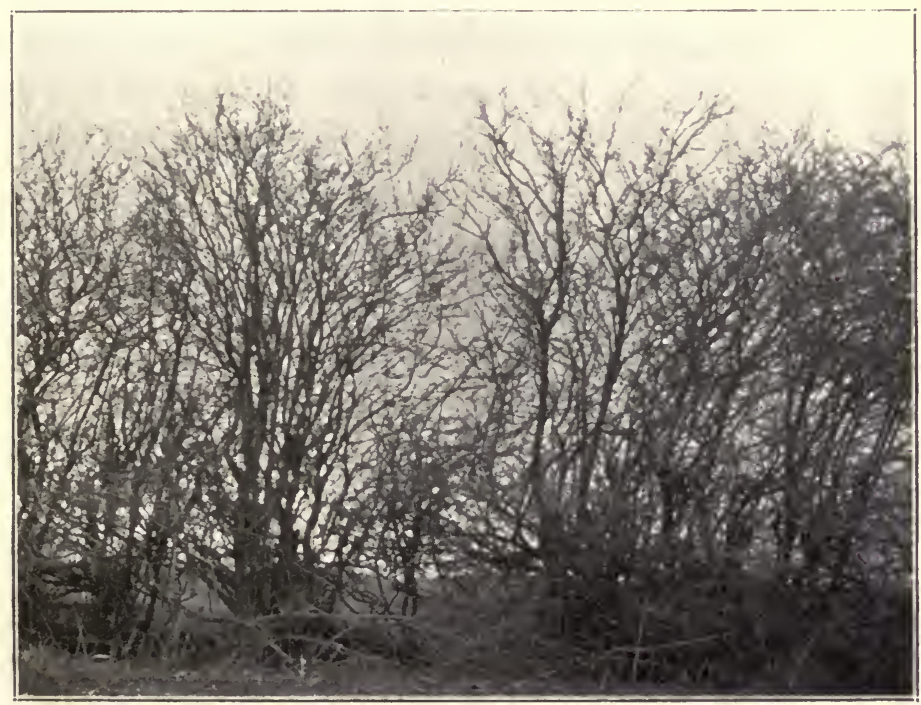

Fig. 90.-A practicable Bullfinch.

ordinary side-saddle riding; because, in order to use it properly, it should be applied, as nearly as practicable, at right angles to the side of the horse, so as to touch him only on one spot, in which case the knee would have to be brought well away from the flap of the saddle, and the toe of the boot turned outwards. This would necessitate the use of a long stirrup leather, 
which would bring the rider's weight too much to the near-side, and would also render her seat insecure; because, instead of being able to get grip by the play of her left ankle joint (p. 149), she would have to draw back the left foot, and press the upper part of the thigh against the leaping head. Her forced adoption of this feeble attempt to obtain firmness of seat is due to the fact that if she raised her left knee to put pressure on the leaping head, her foot, in all probability, would come out of the iron, owing to the long leather being slack at that moment. Besides, with a leather at that length, it would be impossible for her to press her leg strongly against the leaping head by the action of the ankle joint. A lady who rides with her stirrup leather at the correct length (Fig. 79), can use the spur only in a more or less parallel direction to the animal's side, in which case, the spur, if it is sharp, will be almost certain to tear the skin, instead of lightly pricking it.

The entirely wrong system of handling, feeding, and leading horses: almost always on the near side, teaches them to turn much more easily as a rule to that side, which is a lady's weak side, than to the right. Consequently, when they "run out" at a fence, they almost invariably swerve to the left. In such a case, a man has his hands to turn the animal's head and neck, and his drawn back right leg to straighten the hind quarters; but the handicapped lady can supplement the action of her reins only by the whip, which she cannot use very effectively, owing to her perched-up position on the saddle. If she 
used a spur she would be at a still greater disadvantage. because, in order to escape the pain of the "persuader," the animal would naturally swing his hind quarters round to the right, and would consequently bring his fore-hand still more to the left, by the action of this misapplied "aid." If the lady's whip is not sufficiently long to give her mount the requisite reminder on the off flank, either by being pressed closely against it, or by the administration of a sharp tap, it will be useless for straightening him. Lady Augusta Fane, who is one of the best horsewomen in Leicestershire, and who certainly rides a greater variety of hunters during a season than any other lady in the Shires, is strongly opposed to the use of the spur. She tells me that "if a horse is so sticky as to require a spur, he is no hunter for this country ; and if he is a determined refuser, no woman, spur or no spur, can make him gallop to these big fences and jump. I consider a spur a very cruel thing, and feel certain that many men would find their horses go better, and jump better, if they left their spurs at home, and many accidents would be avoided." Lord Harrington, who is well known as a fine horseman, also dislikes spurs, and has advocated their abolition in the Yeomanry. In this he should receive the support of all good riders, as they know that placid-tempered horses have better paces, higher courage, superior staying power, and greater cleverness and tact in times of danger than excitable ones. In polo, where the legs are far more required for guiding the horse than in hunting, the use 
of sharp spurs is forbidden, except by special permission. Whyte-Melville points out that my sex are unmerciful in the abuse of the spur. He says:"Perhaps because they have but one, they use this stimulant liberally and without compunction. From their seat and shortness of stirrup every kick tells home. Concealed under a riding habit, these vigorous applications are unsuspected by lookers on." I have seen more than one poor animal's side badly torn and bleeding from a lady's spur. A lady who rides a horse in the ordinary way with this instrument of torture, which she is unable to use correctly, brands herself in the eyes of her more experienced sister as an incompetent horsewoman. I have heard hunting men advocate the spur for ladies; but they would probably change their opinion if they were to try the effect of riding with one spur, and that on the left foot, especially in a lady's hunting saddle. Very few men who wear spurs are able to use them properly; Whyte Melville says not one in ten, and "the tenth is often most unwilling to administer so severe a punishment." The late George Fordham wholly repudiated " the tormentors," and said they made a horse shorten his stride and "shut up," instead of struggling bravely home. My husband, in Riding and Hunting, says it is the fashion to wear spurs with top-boots, but many good horses go much better without them. Whyte Melville remarks that "a top-boot has an unfinished look without its appendage of shining steel; and although some sportsmen assure us that they dispense with rowels, it is rare to find one so 
indifferent to appearances as not to wear spurs." Men wear spurs in hunting because it is fashionable to do so, but there is no such arbitrary law laid down for ladies, and the presence of the spur certainly adds to the danger of dragging by the stirrup; for, as Whyte Melville points out, its buckle "is extremely apt to catch in the angle of the stirrup iron, and hold us fast at the very moment when it is important for our safety we should be free."

In Continental high school riding, a spur is a necessity, as, without its aid, the écuyères would not be able to perform many of their airs de manige. These ladies, in order to apply the spur with freedom, have the stirrup leather so long that they are deprived of the immense advantage, which the play of the anklejoint gives us, of applying pressure with the leg against the leaping head, and with the flat of the knee against the saddle flap. The "school" rider seeks to strengthen her weak seat by the employment of a very long and greatly curved leaping head, which serves to sup-

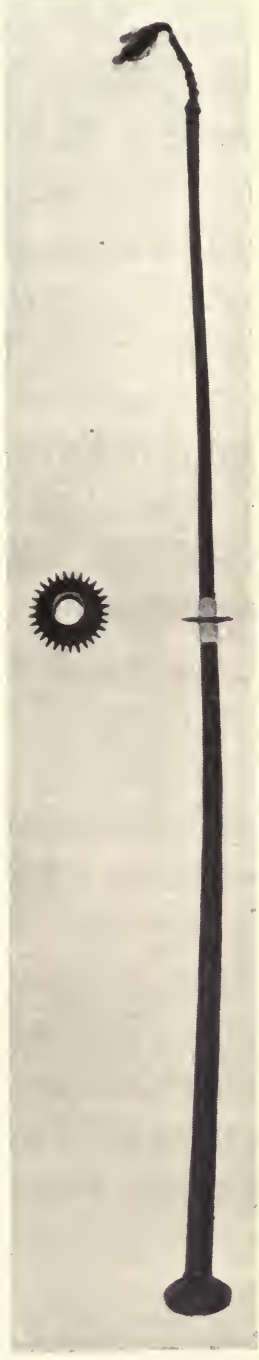

Fig. 91.-Spur-carrying whip used for high school riding. 
port her leg while her knee is removed from the flap of the saddle when using the spur. This leaping head, which almost encircles the left leg, would, of course, be a most dangerous thing to use when hunting. The spurred lady also has a spur clamped on to her whip, in order that she may be able to prod her horse equally on both sides. The whipspur (Fig. 9I) is like a wheel with sharp spokes and no tyre. The application of the spur by Continental écuyères, especially in obtaining the more difficult airs, is more or less constant, so as to keep the animal in a continued state of irritation. I went behind the scenes in a well-known circus in Paris, where I saw a lady mounted and waiting to go on and give her performance. A man was holding her horse's head, and a second attendant, with a spur in his hand, was digging the unfortunate animal on the near side under her habit, which he was holding up for the purpose. He took care to inflict the cruel punishment on a part of the horse's body which would not be seen by the public! The animal, being unable to advance, was lifting his legs up and down (doing the piaffer), and sighing and groaning in agony. When the circus doors were opened and relief thus came to him, he bounded into the arena like a fury, amidst the thunderous applause of the audience! I should have liked to have seen that spur-man punished for cruelty to animals, for if the performance went on, as I believe it did, every night, that horse's near side must have been in a shocking condition! It is by no means an unusual 
occurrence for high school lady riders to be securely tied to their saddles.

We must remember that a hunter has to carry his rider for several hours. Hunting is not steeplechasing, and if a reluctant fencer cannot be sufficiently roused by a touch of the whip, I fail to see what is to be gained by spurring him on the near side, and thus giving him a direct incentive to refuse to the left. Besides, as it is the opinion of some of our best horsemen that nine out of every ten men who hunt would be better and more safely carried if they rode without spurs, I certainly think that no lady should subject her hunter to "the insult of the spur," especially as she can inflict the punishment only on the near side, and thus provoke a defensive attitude which she has no compensating power to successfully resist.

Some years ago I rode in a jumping competition at Ranelagh. There were about twenty men and one lady besides myself among the competitors. The lady found at the last moment that she had forgotten her spur, and a servant was sent to her trap for it, as she said she could not ride without it. She used her.spur, but was unable to get her horse over even the first fence! Lufra, a well-known prize winner at the Agricultural Hall and elsewhere, won the Cup, after a strong contest against my horse Gustave, who was given a red rosette for being second. Gustave had never jumped in a competition before. He was ridden in a plain snaffle, and the only mistake he made was in just tipping the raised gate with his hind legs. He was 
evidently unaware that it had been raised, for when I took him at it again, just to show the ladies that he could jump it, he cleared it beautifully, and his temperate style of fencing was greatly admired. 


\section{CHAPTER X. \\ FIRST LESSONS IN RIDING.}

The walk-Turning-The halt-The trot - The canter-The gallop-JumpingReining back.

THE IVALK.

A HORSE which is held by a groom for a lady to mount, will generally start off at a walk without any given signal to do so, when the servant leaves his head, unless his rider desires him to remain at the halt, when she would give him a command, by saying "whoa!"; and when she wants him to proceed on his journey, she should say "go on," or click with the tongue. It is best to put a beginner on an animal which has been trained to await the commands of his rider, in order that she may from her very first lesson in riding, learn the rudiments of horse control. She should never jerk the reins as a signal to start, because this practice is very apt to confuse and consequently to irritate the animal, especially as the perpetrator of this bêtise will, in all probability, use the same means for stopping him. Before she gets on his back, the instructor should show how the reins should be held, and how the horse should be given the order to walk. It is the 
custom in many riding schools to place the curb and snaffle reins in the rider's left hand and leave her to find out their use as best she can, but as the lady will require to devote almost the whole of her attention to her seat, and as in hunting she will ride with both hands on the reins, it is better to give her a snaffle rein to hold in each hand, and not introduce the curb until she is sufficiently secure in her seat to be able to manipulate it properly. The unusual feeling of sitting on the back of a moving animal will often cause a lady to lean forward and grip her crutches, in order to retain her seat, especially at the turns in the school or enclosure, where she may be receiving her lesson, but the instructor should watch her carefully, and should call a halt when the pupil is observed to be riding her crutches instead of sitting well down in her saddle, and obtaining the necessary steadying power without bringing the weight of her body forward. The rider will not require to grip her crutches while proceeding in a forward direction at a walk, although their aid may be necessary when executing a turning movement, and she should also be ready to apply grip at any moment of emergency. She will at first experience some difficulty in being able to dissociate balance from grip, and as her efforts to do so may be somewhat fatiguing to her, her first lessons should be of short duration. Fig. 92 shows an easy, comfortable position when riding at a walk.

After the rider has mastered the art of sitting comfortably and firmly in her saddle at a walk, she 
should be given a whip to hold in her right hand, which should also hold the right rein. I think the best kind of flail for a beginner is a long cane. A cutting whip is not sufficiently stiff to be used as an indication, and it is apt to tickle the horse's sides, and make him unsteady.

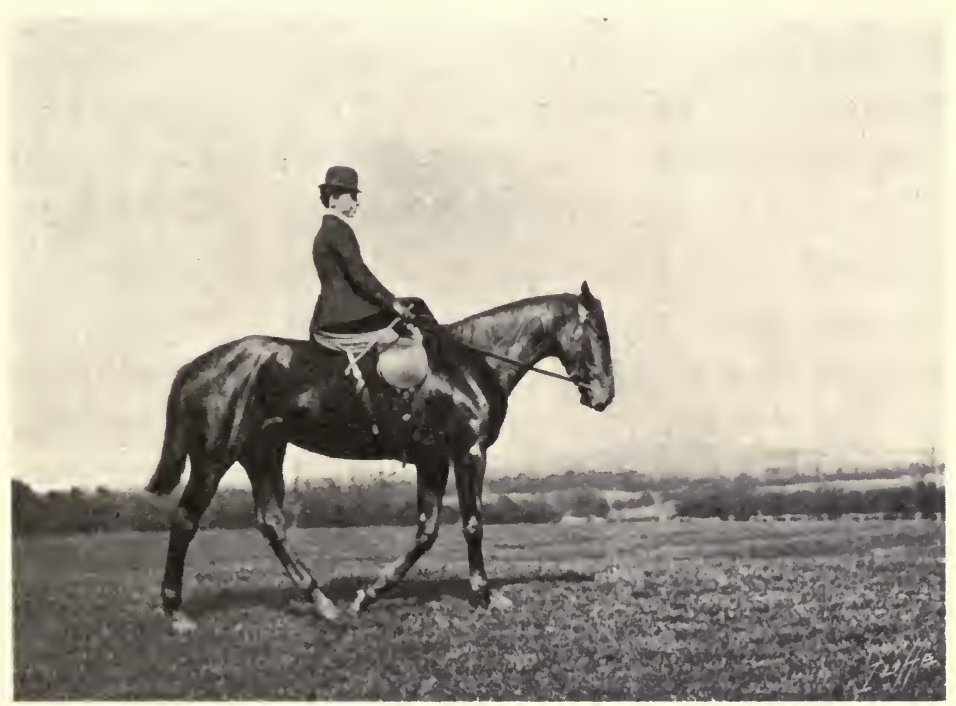

Fig. 92. - Thorough-bred mare at a walk.

TURNING.

A lady should not be initiated in the mysteries of any other pace, until she is able to turn her horse at a walk, in any direction, while maintaining a correct balance of her body, and applying only sufficient grip to aid the movement.

In turning a horse to the right, she should lower her right hand and carry it well away from his shoulder, 
while "feeling" the right rein, so as to give him as clearly as possible, the indication to turn; she should press the left rein against his neck, by moving her left hand to the right; she should grip her crutches, and lean to the right; and should resume her erect position when the turn is completed. If the animal answers these indications only by turning his head to the right, and does not bring his hind quarters round to the left, she should touch him lightly with the whip on the off flank, so as to make him bring his hind quarters round. In turning to the left, the opposite indications are employed; the only difference being that the whip cannot be used on the animal's left side, owing to the presence of the skirt. This inability to employ the whip on the left side is not of much consequence as a rule, because almost all horses readily bring their hind quarters round to the right, when they are turned to the left.

Having turned to the right, she may ride her horse in a circle to the right, while inclining her body slightly inwards, and keeping a nice feeling of the right rein, and a firm grip of her crutches round the circle, which at first should be large, as the smaller the circle the more difficult it will be to ride and guide one's mount. The reversed aids are used when cirçling to the left.

\section{THE HALT.}

In pulling up a horse from a walk, or any other pace, the rider should say "whoa," should lean back, and at the same time draw in the reins with an even, 
steady feeling, while keeping her hands low. If she has any difficulty in halting with precision, she should practise walking her horse short distances and stopping him at the word "whoa," which should be given to him in a tone that he can understand, for he cannot obey orders unless he knows their meaning.

\section{TIIE TROT.}

When learning to ride, ladies should endeavour to be thorough, and should not proceed to study a new pace, before the previous one has been entirely mastered. If the body is nicely balanced at sharp turns at the walk, with the weight evenly distributed on the saddle, and both legs kept perfectly steady and in their right position, a great deal will have been done towards acquiring a firm seat.

When the pupil is able to ride with ease and grace at the walk, she may receive a lesson in trotting. I think it is best to teach the trot before the canter, because the majority of horses trot a few steps before they strike off into the canter.

As an ounce of practice is worth a ton of theory, the instructor should first of all show her pupil how the trot is correctly executed, either without a skirt or with one pinned back, so that the position of her legs may be seen. She should try to make her practical demonstrations perfectly clear, and should encourage her pupil to question her concerning any points in this difficult pace which she does not understand. It is a good plan to trot both with and without a stirrup, in order 
to show that the weight of the body during the rise should be placed on the right leg, and not on the stirrup. Reference to Figs. 79, 93, 94, 98, 99, I00, IO2 and IO4 will show that the right leg remains in precisely the same position at the walk, trot, canter, and leap. The great difficulty in trotting is to keep this leg absolutely steady, and to prevent it from working backwards and forwards with the motion of the body, which can be done only by maintaining a steady pressure against the upper crutch with the right knee. When this has been obtained, and the rise can be made with the right leg held motionless, the rider will find herself able somewhat to relax this pressure, but in a mild form it is always necessary to press the right knee against the upper crutch in trotting, so as to aid the balance and to avoid putting too much weight on the stirrup. The right leg from the knee down should lie flat and in a slanting position against the horse's shoulder (Fig. 79), the movement of the animal's limb being distinctly felt by the rider's leg which is resting against it. Having ascertained that the stirrup is sufficiently long to admit of the flat of the hand being placed between the left leg and the leaping-head when the rider is not exercising grip (Fig. 82) - which will allow the lady to clear the leaping-head when rising at the trot-she should take rather a short hold of her horse, and induce. him to bear on the snaffle to aid her to rise ; for a horse which will not bear on the reins is not a comfortable animal to trot with. A lady should lean slightly forward and 
rise when the animal's near fore leg comes on the ground. In Fig. 93 we see the horse's off fore on the ground and the lady preparing for the rise with her body inclined forward. Fig. 94 gives us the position of the rider at the rise, and that of the horse's near fore leg. As a well-executed trot can be acquired only

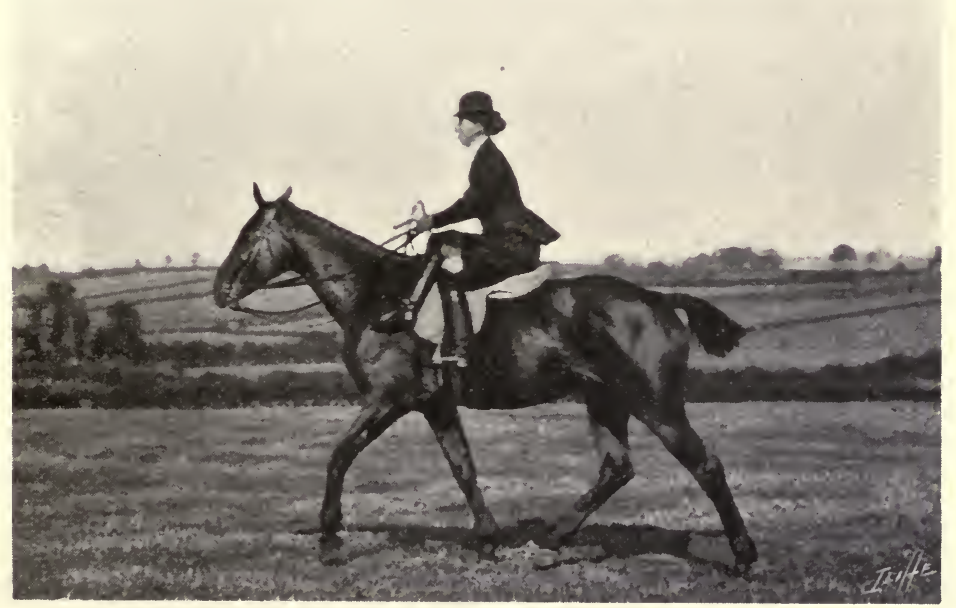

Fig. 93--Preparing to rise at the trot, with stirrup at correct length.

after a great deal of practice, a lady should not be disheartened if she makes but slow progress. She will find it difficult to time the rise accurately, and until she can do this it is best for her to sit down in the saddle and bump up and down à la militaire, keeping her seat by the aid of her crutches, and occasionally making an effort to rise. If she rises at the wrong time, her effort will be productive of a churning movement, 
which should at once be discontinued, for that slipshod style of trotting is not only incorrect, but is liable to give the horse a sore back, and will prove very tiring to the rider. In making the rise she should straighten her left knee as in mounting, and bear slightly on the stirrup, executing her upward movement by the aid of the ankle-joint and by simultaneously pressing the upper crutch with her right knee, when she will return to her former position without being in any way jerked during the movement. The stirrup should always be kept in one fixed position at the ball of the foot, and both foot and stirrup should act with automatic precision, without the slightest jerk or wriggle, exactly as though the lady were making an upward step from the ground. The pressure of the foot should be directed on the inner side of the stirrup-iron, in order that the leg may lie close to the flap of the saddle. She will not require to lift herself from the saddle, for the horse will put her up to the necessary height, if she straightens her left knee and prepares to rise at the right - moment. The height of the rise will vary according to the size and action of the horse. An animal of, say, I5-3, with a long, swinging trot, will cause his rider to rise higher in the saddle than a smaller horse with a short, shuffling gait. Many ponies have a short, quick trot requiring a hardly perceptible rise from the rider; but they are not, as a rule, comfortable trotters. The lady, as I have already remarked, rises when the animal's near fore leg is 
placed on the ground, and remains seated while the off fore leg rests on the ground, but the height and duration of the rise will depend on his power of forward reach. Some ladies exert themselves far too much in rising, and flop down on their saddles with a noise which attracts attention to their faulty riding, and which

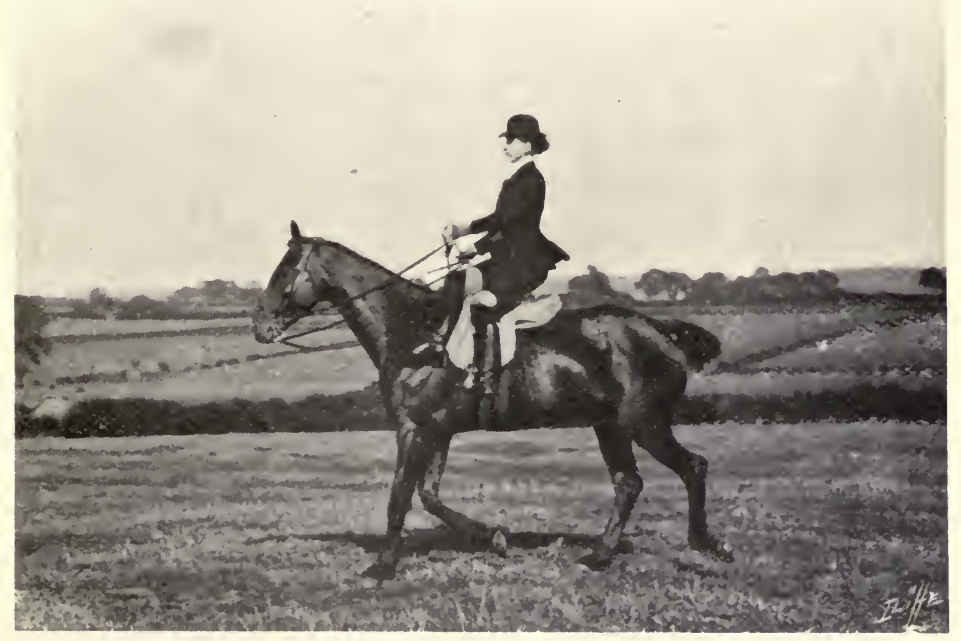

Fig. 94.-Rising at the trot, with stirrup at correct length.

must be very uncomfortable both to them and their mounts. The chief cause of this faulty style is the adoption of a long stirrup (Figs. 95 and 96), by which the weight of the body is brought so much to the near side that the rider can rise only with great muscular exertion, and with the risk of giving her mount a sore back, by the downward drag of the saddle to this side. If the horse were to break into a canter, the lady with 
a long stirrup would obtain her grip by bringing back the left leg as in Fig. 97 and pressing against the leaping-head high up on the thigh, which would give her a very insecure and ungraceful seat. I have seen ladies trying to trot with the left leg, from hip to foot, swinging about like the pendulum of a clock, as if they had no knee-joint at all. When we see an effort to trot with a stiff left leg swinging along the horse's shoulder, we may safely conclude that the rider has her stirrup too long, and knows nothing about the art of trotting, or that the leaping-head of her saddle is placed so low down on the near side that she is unable to ride in it, and has to stick on as best she can. As we do not use the leaping-head in trotting, its position on the saddle may appear unimportant, but this is not the case; for, even if a lady has her stirrup at its correct length, the fact of the leaping-head being placed low down on the near side, compels her to ride with her stirrup longer than she would have to do if this crutch were properly placed. The farther it is away from the upper crutch, the greater difficulty will a lady have in rising at the trot. I have tried to ride in saddles in which I have found trotting such a tiring business, and requiring so much muscular exertion on my part, that it was much more comfortable for me not to rise, but to bump in military fashion. Many ladies, probably from the same reason, never rise in the trot. It is both wrong and unkind to put girls on bad saddles and then reproach them for not sitting straight at the trot, for I have found it absolutely impossible to 
do so in some saddles. Much of the soreness and misery which ladies suffer in their efforts to trot, would be obviated if the leaping-head of their saddles were placed as in Fig. I6.

Although a-well executed trot looks nice, it should be only sparingly indulged in, because it is more

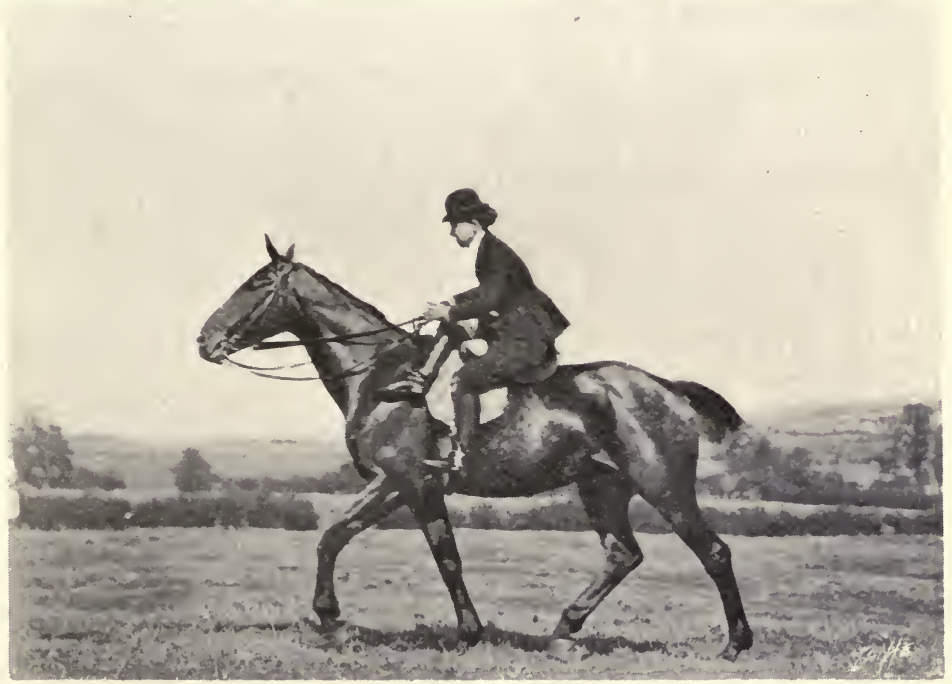

Fig. 95.-Preparing to rise at the trot, with stirrup too long.

fatiguing to the rider than the canter and is particularly liable to give a horse a sore back; for, do what the lady will to sit "square," the saddle, supposing she rises, cannot fail to have some side motion. Of course the rider should walk or trot, and not canter, on metalled roads and hard ground, but she should always take advantage of any bit of soft "going" and indulge in a nice easy canter on it. 
A lady learning to trot will require to do her hair up securely with plenty of hair-pins, pay attention to the fit of her hat, and see that it is provided with elastic an inch wide (p. I I4), because she will find her head jerked about a good deal during her first lessons. The trot should be properly studied in a school or enclosure before a lady is taken out on the roads, for she can learn nothing by "slithering" along anyhow, and will be liable to contract a bad method of riding, which will probably prevent her from ever becoming a good horsewoman. We must remember that the trot is the most difficult of all paces, and can be correctly acquired only after much patient practice; but it is worth doing well. Very few ladies excel in this art, for the simple reason that they do not care to go through the drudgery of it. Some ladies are so impatient that they give up the study of a pace as soon as they can stick on their saddles. How few who hunt can, really ride well! In Leicestershire a fine horsewoman remarked to me that several ladies ride hard who are indifferent horsewomen-a fact which I think we may see demonstrated in every hunting-field; but what is worth doing at all is surely worth doing well, and a lady should strive to be a good horsewoman as well as a plucky rider. When a horse increases his pace without being ordered to do so, he should be at once checked by a pull, not a jerk, on the reins, which should be accompanied by a word, such as "steady," uttered in a warning, determined tone that he will understand; because he should never 
be allowed to take the initiative, which he would do by breaking into a canter. The trot should be slow at first, until the rider is secure in her seat, when it may be increased gradually to its fullest limit. The faster a horse trots, the stronger bearing should we have on the reins, but when we find the pace degenerating into

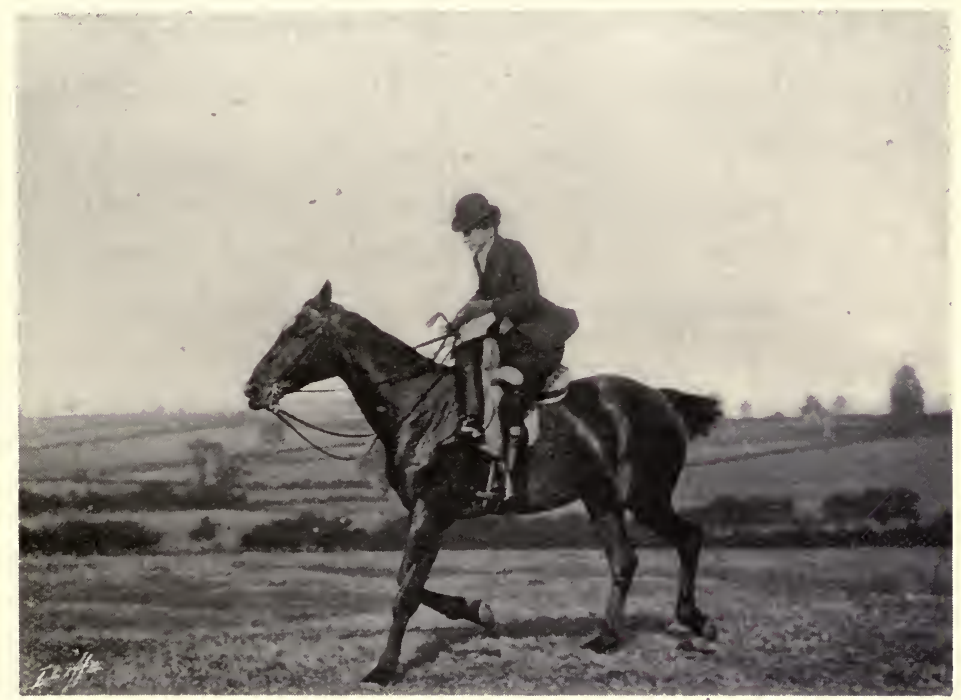

Fig. 96.-Rising at the trot; with stirrup too long.

a rocking movement, the animal should be steadied and collected, because he is exceeding the limit of his speed, and is probably trotting with his fore and cantering with his hind legs, as we may frequently see with horses which are being overdriven in harness. After practice has been acquired in trotting in a forward direction, and the rider is able to sit with ease and grace, she should trot in a circle to the right, 
taking care to keep a good grip, incline her body inward, and guide her horse with precision. 'The circle, which should be large, may then be made to the left, which will more strongly test the rider's seat, and particularly her command of her right leg. If she does not ride correctly, this circling should be stopped, and the mistake rectified by more practice in a forward direction.

If a horse, during the trot, suddenly breaks off into a canter, the rider should sit down in her saddle as in the walk, and grip her crutches as may be required. She should not be the least bit alarmed at this new pace, supposing that she has not been taught to canter, for all she will have to do will be to sit down and allow her body to follow the movements of the horse by the play of her hip joints, as explained in the first lesson (p. 159). The lady who has practised leaning back (p. I 58) will be able almost at once to adapt herself to the requirements of the canter ; but as the trot is the subject of her study, the horse should be instantly pulled up. In order to do this safely, she should lean slightly back in her saddle, and stop him gradually, employing her usual word of command, and, while keeping her hands low down and well apart, exert a firm and fixed pressure on the reins. The rider must never allow herself, however disobedient her mount may be, to "job" his mouth with the reins, or to use them at any time as a means of punishment. Also she must not try to pull him up suddenly, but always gradually, in order that he may not strain the 
ligaments or tendons of his legs. If a horse hears and understands his rider's word of command, he will pull up in a manner most easy to himself. In practising the trot, the pupil should try to look between her horse's ears, and should keep her elbows as close to her sides as is comfortable, for she would lose

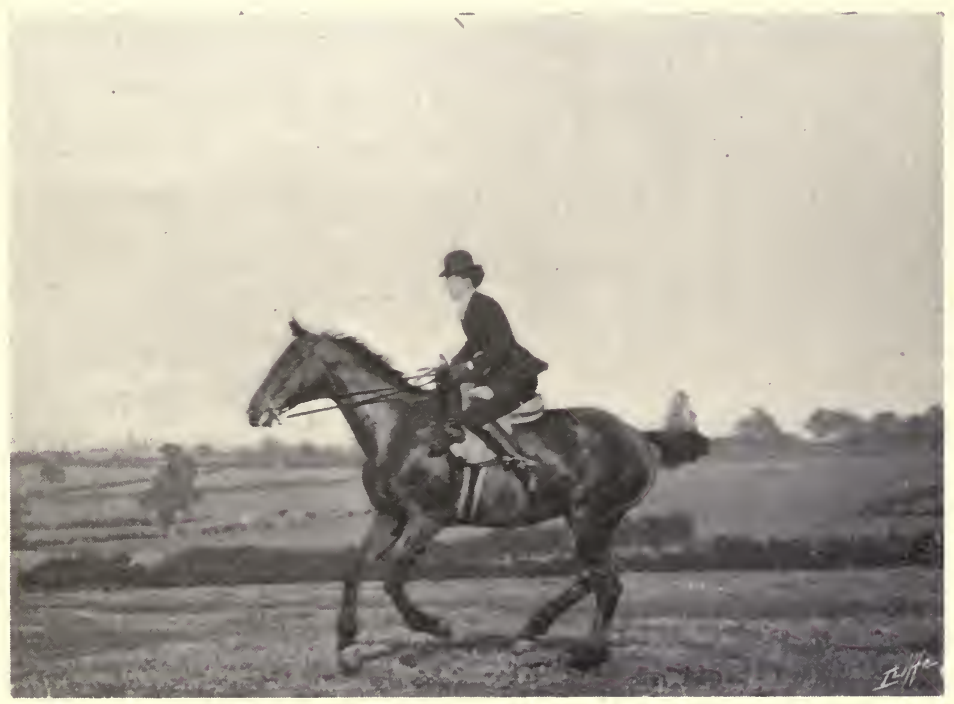

Fig. 97.-Canter, with right leg hooked back, and stirrup too long.

power over her mount by turning them out. If she interferes with the horse's mouth, and does not keep her reins at one fixed length, the animal will naturally become unreliable in his paces. If she feels a pain in her side or gets a headache while trotting, the lesson for that day should be at once stopped, because she will not be able to ride properly if she is enduring any kind of discomfort. Parents should pay great atten- 
tion to this matter, especially if the riding instructor is a man, because a girl would naturally be disinclined to mention any personal ailment to him. Whoever the teacher may be, he or she should always humour a nervous pupil, and not, as many do, start with the idea of getting her "shaken into her seat," at the risk of ruining her riding nerve for ever and causing her to loathe her lessons. If a pupil during her first trotting lesson suffers from nervousness, it is best to discontinue the trot and finish the lesson at the walk, in order to settle her nerves and not frighten her out of her wits. Her next trotting lesson should be commenced at the walk, and an occasional effort be made to trot a short distance, so that she may gradually obtain the necessary confidence, and an encouraging word should always be given her when she does well.

THE CANTER.

After the pupil has mastered the difficulties of the trot, she will appreciate the enjoyable motion of an easy canter, which is the lady's pace par excellence. In the canter a horse should lead with his off fore leg, except when he is turning or circling to the left, and a beginner should be given a horse or pony which has been trained to canter correctly. As the majority of horses are not taught to start from a walk to a canter, the pupil should proceed at a smart trot, and, while holding the reins somewhat slack, turn her horse's head slightly to the left, and touch him on the right 
shoulder with her whip, to make him break into a canter with his off fore leading.

She should sit firmly into her saddle, should lower her hands (Fig. 98) more than in the trot, and should fix the speed at which she wishes her horse to proceed, while keeping an easier feeling on his mouth than

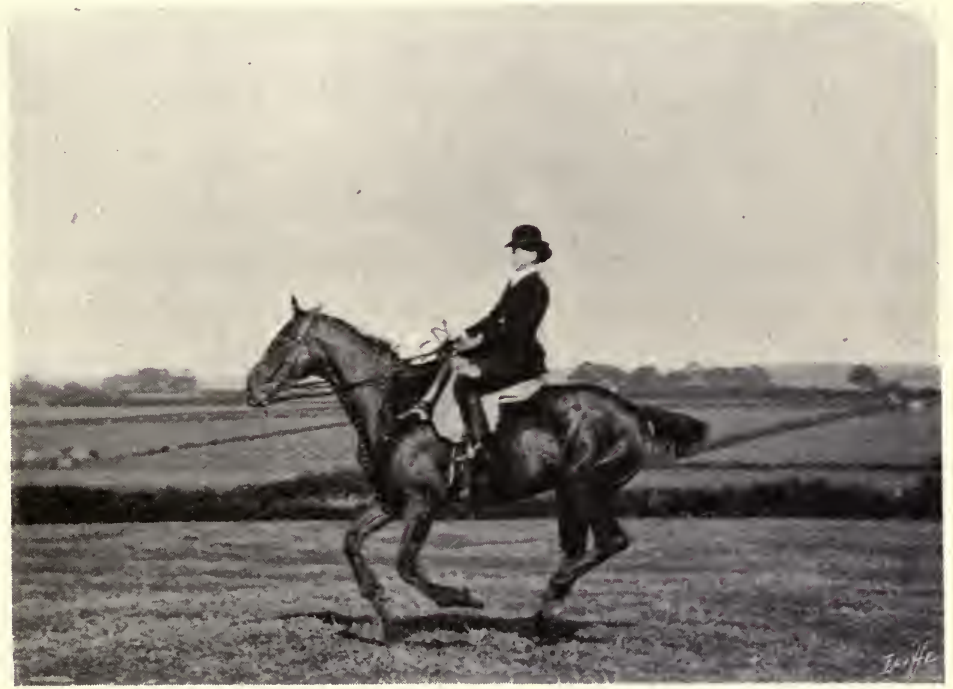

Fig. 98. - Good seat at canter or gallop.

when trotting. She should indulge in no snatches at the reins, but should always preserve one fixed length of rein, unless she requires to alter the pace. The legs should remain perfectly still as in the walk, the knees should be kept ready to grip the crutches at any required moment, and the body from the hips upward should conform to the motion of the horse. Figs. 98, 99 and 100 show a nice easy position in the different 
phases of the canter. It is absolutely essential for a lady to acquire a good strong seat at this pace, because it is practically the same as in the gallop and jump, and must therefore be regarded as her hunting seat. One of the first things to remember in the canter is to allow no movement of the seat, which should remain nailed as it were to the saddle, the hip joints supplying all the necessary motion to the body, and, as I have already said, the legs should be kept perfectly steady. To increase the adherence of the left knee against the flap of the saddle, the left foot should be carried a little outwards away from the horse's side, and its pressure chiefly applied to the inner side of the stirrup-iron, which will consequently be more depressed than the outer side. It has been remarked that an ugly seat at the canter is a sight that would spoil the finest landscape in the world, so a lady who desires to ride well should not be satisfied if she can merely stick on, like the lady in Fig. IOI, but should try to ride correctly. Her head will perhaps at first be jerked to and fro like a "vexed weathercock," but practice will enable her to overcome the tendency to fix the muscles of her neck and to allow her head to follow the motion of her body. She should take care that her elbows do not flap up and down like the pinions of an awkward nestling learning to fly, but should keep them close to her sides, where they will be of more assistance to her in controlling her horse. In cantering on a circle to the left, a horse should of course lead with his near fore, for if he then 
leads with his off fore he will be liable to cross his legs and fall. If the canter is false-that is to say, if a horse is leading with the wrong leg-the movements of the limbs will be disunited, and the rider will find the motion rough and unpleasant, in which case she should pull him up and make him lead with the correct leg.

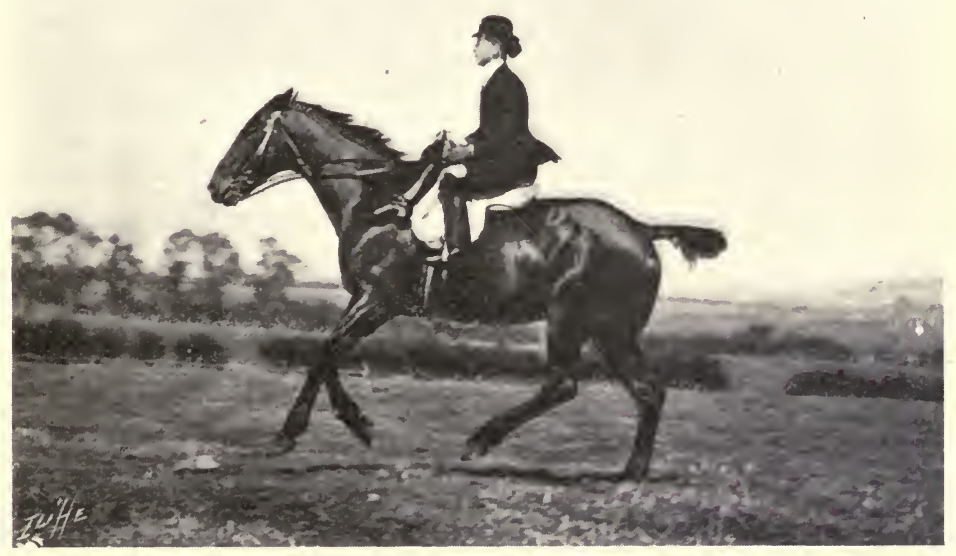

Fig. 99.-Good seat at canter or gallop.

When the pupil feels herself becoming tired or unsteady in her seat, she should give the horse her verbal signal to stop, at the same time taking an even and gradual pull at the reins. As I have already said, a horse should be gradually pulled up from a canter into a trot or walk. Although a beginner's mount will, or at least should, allow a certain amount of liberty to be taken with his mouth, it must be remembered that every horse will go better with a rider who tries to 
save his mouth as much as possible when conveying her orders to him by means of the reins. When he is going too fast, the warning word "steady" should always accompany any restraining action of the reins, until the horse is accustomed to his rider's handling, when the pull may be taken in silence. As the voice is a valuable "aid" in riding, I would strongly advise the inexperienced horsewoman never to speak to her horse when he is at work, except when giving him an order. He will then be able to understand the meaning of her words of command. Particular attention should be paid to the observance of this rule, for a lady who is incessantly talking to her horse, reproving or caressing as the case may be, renders him more or less indifferent to the voice as a means of control on an emergency. After he has carried her well, a few pats on the neck will establish a feeling of good fellowship between horse and rider, and the animal will always regard these caresses, and the kindly words that accompany them, as a sure sign of his mistress's approval. After she has dismounted she may "make much" of him, but while on his back it is wiser to reserve her voice for giving orders. A "funky" rider as a rule keeps continually talking to her mount, and the animal gets to know that she is nervous, and soon becomes the master. A horse, like a domestic servant, will not be obedient and respectful unless he thoroughly understands that his first duty is to obey. Neither a horse nor a servant who fails to recognise this fact is worth his keep. Every girl who is learning 
to ride, naturally desires to establish a feeling of friendship between herself and her mount, because she knows that he can get rid of her off his back any time he likes; but she should remember that a horse, like a servant, is always ready to take a liberty, and therefore any kindness she may bestow on him should be

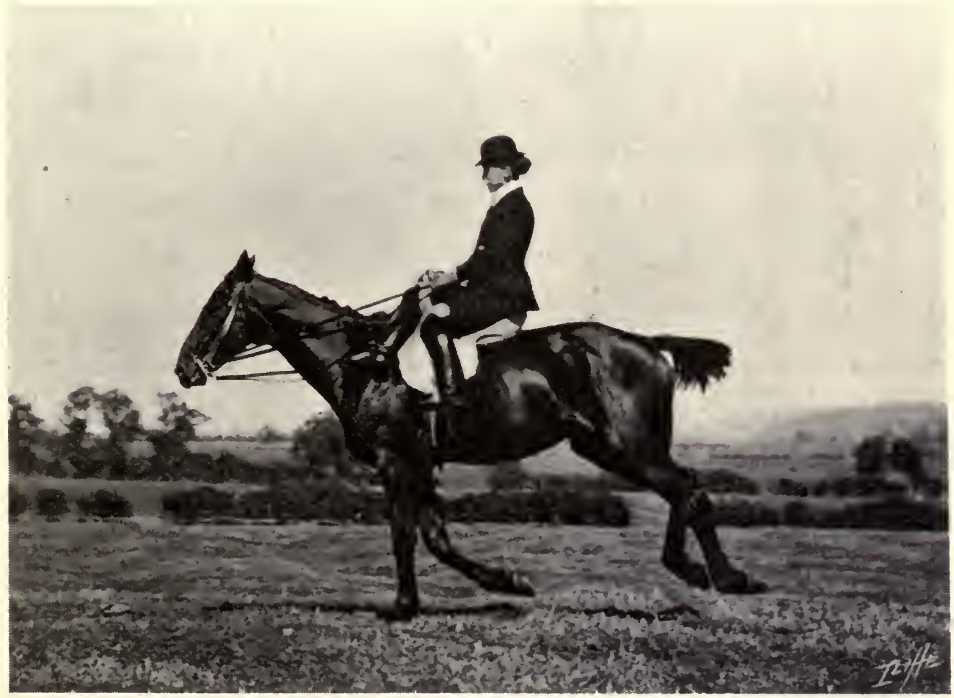

Fig. I00.-Good seat at canter or gallop.

tempered with discretion and forethought as to its future results. She may pet him as much as she likes, but she should never allow him to have his own way, in opposition to her expressed command. 'The adoption of a conciliatory method with horses which deliberately refuse to obey orders is fatal, because the lady who takes that course literally allows the reins of authority to slip through her fingers. 


\section{GALLOP.}

An experienced hunting man remarked to me that a large number of ladies who hunt, fail in ability to make their horses gallop, which is a pace never taught by riding masters. The gallop is not only necessary to acquire, especially by a lady who intends to hunt, but it improves the strength of seat more than any other gait. Besides, a rider who is unaccustomed to it, is always in danger of coming to "grief," if her horse breaks away with her, either from being startled or from mere "light-heartedness." For a lady's first lesson in galloping, a piece of nice soft smooth ground, free from stones and holes, and, say, a quarter of a mile or three furlongs in length, should be selected. The pupil should be provided with a rather sluggish horse, which requires some "riding up to his bridle," and should be told to canter her horse at his highest speed, for the canter and gallop merge imperceptibly into each other. The seat in the canter is precisely the same as that in the gallop, except that when the horse is going very fast, a lady will find it easier to lean slightly forward, take a good steady hold of the reins, and keep her hands in one fixed position, as low down as possible. If she has any difficulty in getting her mount to extend himself, the instructor should ride with her and set the pace. When the lady's horse is really galloping, he should slacken speed a little, and let the animal pass him, in order that the pupil may learn to ride a gallop without a lead. The chances are that her 
horse will want to follow the example of his companion and go slower; but she should keep him going at the same fast pace by a touch with the whip and a click of the tongue, until she has arrived at the end of the specified distance. As a fast gallop is very trying to a horse's legs, it should be limited to occasional short spins on soft and smooth ground. In the next lesson the

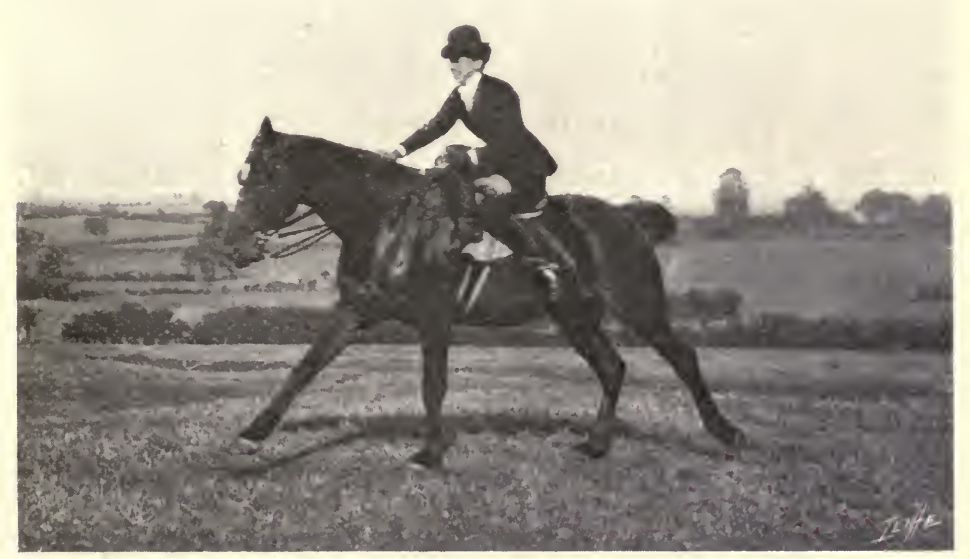

Fig. Ior.-Bad seat ; right leg hooked back, stirrup too long, and foot " home."

instructor should assume the lead, and tell his pupil to pull her horse up at à given distance, while he gallops away from her. This would be excellent practice for testing her power of horse control, because in hunting it is of vital importance that she should always have her mount in hand, and be able to stop him when necessary, even if a crowd of horses are galloping away 
in front of her. To do this when riding at a fast gallop, she should gradually slacken his speed, using the word "steady," and taking an even pull on the reins. It may be necessary for her to ride at this pace with a double bridle (curb and snaffle). Fig. Ioo shows how the curb and snaffle reins should be held. I have not advocated giving a beginner a bit and bridoon, because in hunting she should always ride with the snaffle, and reserve the curb for use in cases of emergency, such as steadying her mount when galloping over plough or heavy ground, or in slackening his speed. The pupil who is learning to gallop should try the effect of the curb in stopping her horse while another horse is galloping away from her. As it is a severe bit, she would be wise to "feel" her horse's mouth with it only just enough to induce him to slacken his speed according to her indication. It should be used with the object of reminding him that it is in his mouth. If he does not obey the hint, the lady should take a stronger pull, and be ready to release her pressure when she feels her horse restrained by its influence, and then she should ride on the snaffle. My husband, in Riding and Hunting, says:- "With a double bridle we may ride on the snaffle as much as we like, and keep the curb for emergencies; although, from not knowing how to hold the reins properly, men frequently get into the habit of always riding on both reins, and then they blame the double bridle for being too severe. . . . A curb is indispensable with many horses for crossing an English hunting country 
in good style. We must also remember that out hunting, and with large fields, like what we see with the Quorn and Pytchley, the ability to obtain instant control over one's mount, even in the midst of exciting surroundings, is essential for the safety of one's self, one's horse, and one's companions, and for avoiding interference with sport. . . . I have known some horses, whose mouths had evidently been spoiled by injudicious, if not cruel, treatment, that would go quietly only in a snaffle." Whyte Melville, discussing the merits of the snaffle, says:- "This bit, the invention of commonsense going straight to its object, while lying easily on the tongue and bars of a horse's mouth, and affording control without pain, is perfection of its kind." Of the double bridle he says :- " I need hardly explain to my reader that it loses none of the advantages belonging to the snaffle, while it gains in the powerful leverage of the curb a restraint few horses are resolute enough to defy. In skilful hands, varying, yet harmonising, the manipulation of both, as a musician plays treble and bass on the pianoforte, it would seem to connect the rider's thought with the horse's movement, as if an electric chain passed through wrist, and finger and mouth, from the head of the one to the heart of the other."

JUMPING.

After the pupil has mastered the art of trotting, cantering, and galloping, and understands how to handle and control her mount with correctness and 
precision at these paces, she should be given a lesson in riding over fences. We may put up a small hurdle, or some easy obstacle, in an enclosed place, and tell her to canter her horse straight to the centre of it and jump it. All that she need be instructed to do, is to give the horse his head when he is rising at the jump, and to lean well back when he is about to land over it. By giving her horse his head, I mean that she is to extend her arms to their utmost length, and bring them again into position after he has landed. Fig. IO2 shows a lady leaning back and extending her arms at a fence. The pupil will not require to alter the length of her reins when riding over fences, presuming, of course, that she has been taught from the first to keep a nice easy feel on her horse's mouth. She should be careful to leave the curb alone, and always ride over fences on the snaffle. The lady in Fig. IO2 is riding only with a snaffle, and with a nice easy length of rein. I must pause here to draw attention to the fine riding of the lady, Miss Emmie Harding, of Mount Vernon, New Zealand, who is jumping this formidable wire fence on her hunter Marengo. Our hard riding Colonial sisters have nothing to learn from us in the matter of sitting over stiff fences, even high wire barricades that would certainly stop a whole field in the Shires. Some critical ladies may consider that her left foot is carried too far back, but this is not the case, as she is riding with her stirrup at the ball of the foot and obtaining her grip of the leaping head without depressing the left knee. When we require to obtain the maximum 
amount of grip, as in jumping, we instinctively draw back the left foot, as shewn in Fig. I02, in order that the ankle joint may exert its utmost power in pressing the leg against the leaping head. In Fig. $\mathrm{IO}_{4}$ the

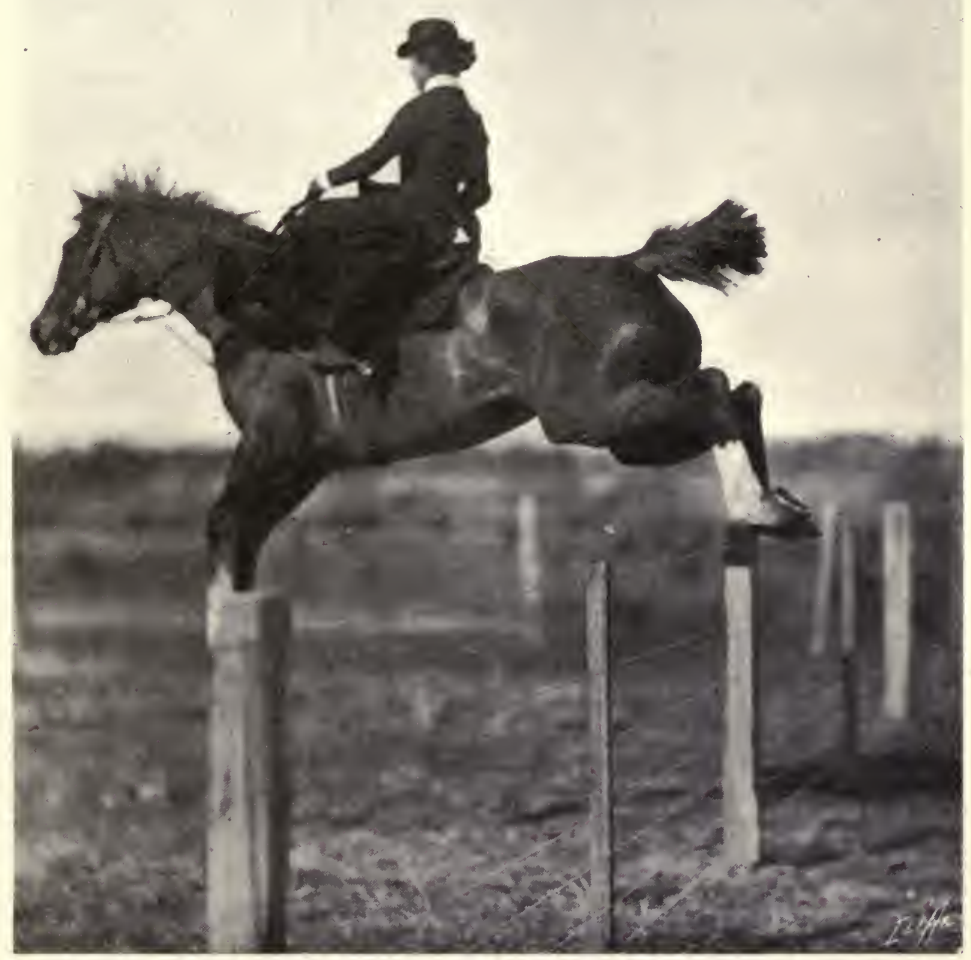

Fig. I02.-Miss Emmie Harding jumping wire.

position of the legs is identical with Fig. IO2. We can see that Miss Harding rides with her right leg forward, in the manner I have advocated. The rider should take a good grip of her crutches, and keep her 
legs perfectly steady and close to her horse. She should always ride him straight, not sideways, at his fences. There should not be the slightest movement of her seat in the saddle. As I have already explained, she should try to imagine that she is nailed down to the saddle and cannot be shifted, and that the movement of her body must come from the play of the hip joints.

If her small brother possesses a rocking-horse, she should mount it and rock herself on it, if she does not entirely understand what is meant by " the play of the hip joints." If she rides over her first fence incorrectly, she should not be allowed to do so a second time without being put right. It would, therefore, be advisable for her to have her skirt pinned back, in order that the instructor, who should be standing by the fence at the near side, may see exactly how she obtains her grip. It is obvious that this lesson in jumping should be given either by, or under the supervision of a person experienced in side-saddle riding. The pupil may be allowed to hold a whip, but she should not use it, for she might acquire the bad habit of hitting her horse every time he jumps a fence. The whip in hunting should be kept for use at specially big fences, and as a reminder to the horse that he must exert his best efforts to clear them with safety. Even then it is employed as an aid, but not as a means of inflicting punishment. No good horsewoman cuts her horse about the body with a whip. If the fence has been nicely jumped, the pupil extending her arms pro- 
perly and keeping her hands low, we may "make much of her," and that will recompense her for any uncomplimentary things we may have said about her

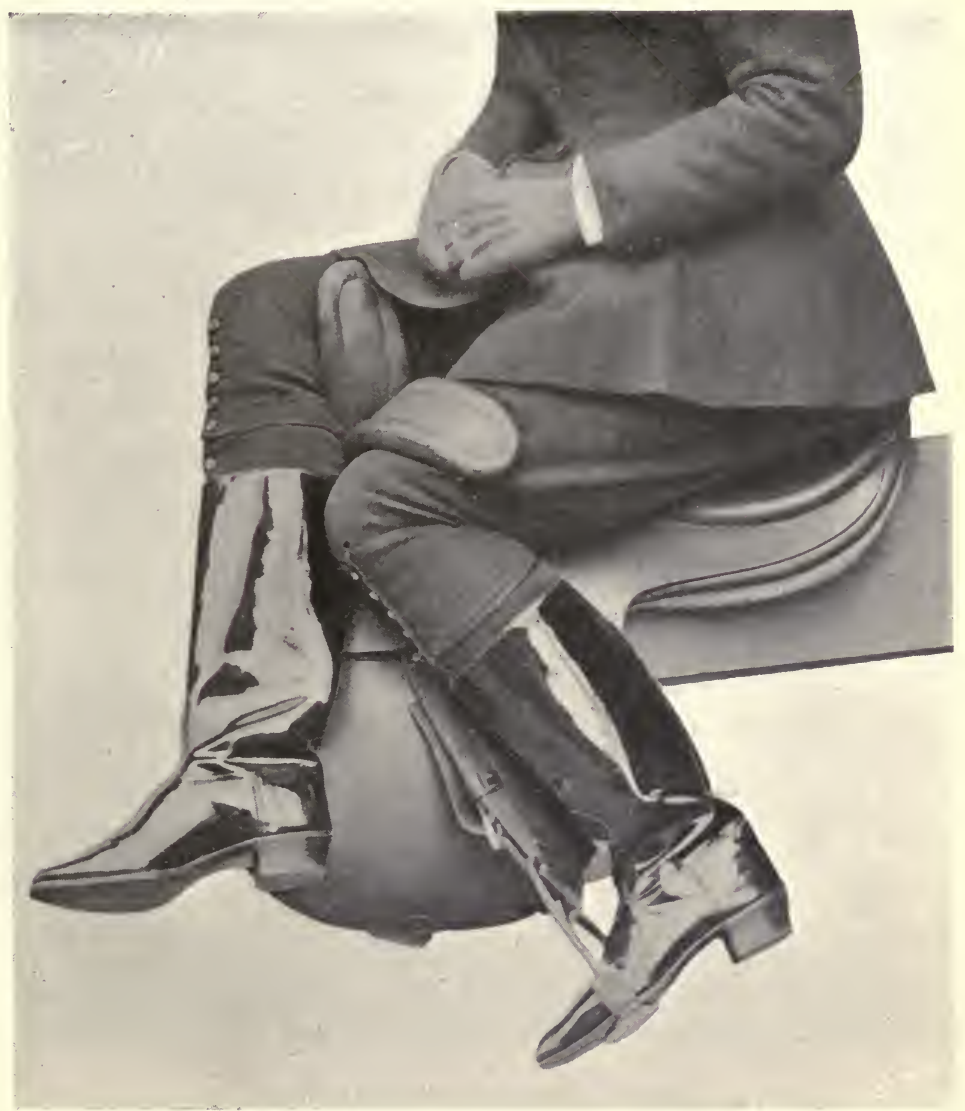

Fig. 103.-Maximum amount of pressure on leaping head

riding. After the small fence has been jumped nicely, it may be replaced at the next lesson by one somewhat higher ; and when the lady has had practice over it on 
her steady horse, she may ride another mount who is a bigger jumper. No extra instructions need be given to her except that the higher the fence, the more must she lean back on landing. This jumping practice will probably teach her to always lean back when riding over a drop fence, or going down a steep hill. Some ignorant people shout, "Sit back," when a lady is riding at a fence; they should say, "Lean back," which means quite another thing.

If a lady, when taking her riding lessons, finds herself in any way uncomfortable in her saddle, she should at once stop and have the fault, whatever it may be, rectified. She should always be careful, when dressing for riding, to see that all her garments are put on correctly, so that nothing may get displaced and cause discomfort when she is in the saddle. If this does happen, she should dismount, if possible, and arrange matters without delay; otherwise she may be severely cut or rubbed and be unable to ride again for some time. After she has been taught to ride, she should be given a nice horse and a safe jumper, for she well deserves one, and will be able to ride him. She should hack him along quiet roads and bridle paths and learn to open gates and go through them nicely, always shutting them after her.

REINING BACK.

As a lady will be unable to open gates correctly unless her horse will rein back readily, it will be necessary for her to obtain practice in this useful 
exercise. A horse which has to carry a woman should have previously been taught to rein back, chiefly by word of command and with only slight indications of the reins, because in the rein back a lady is greatly

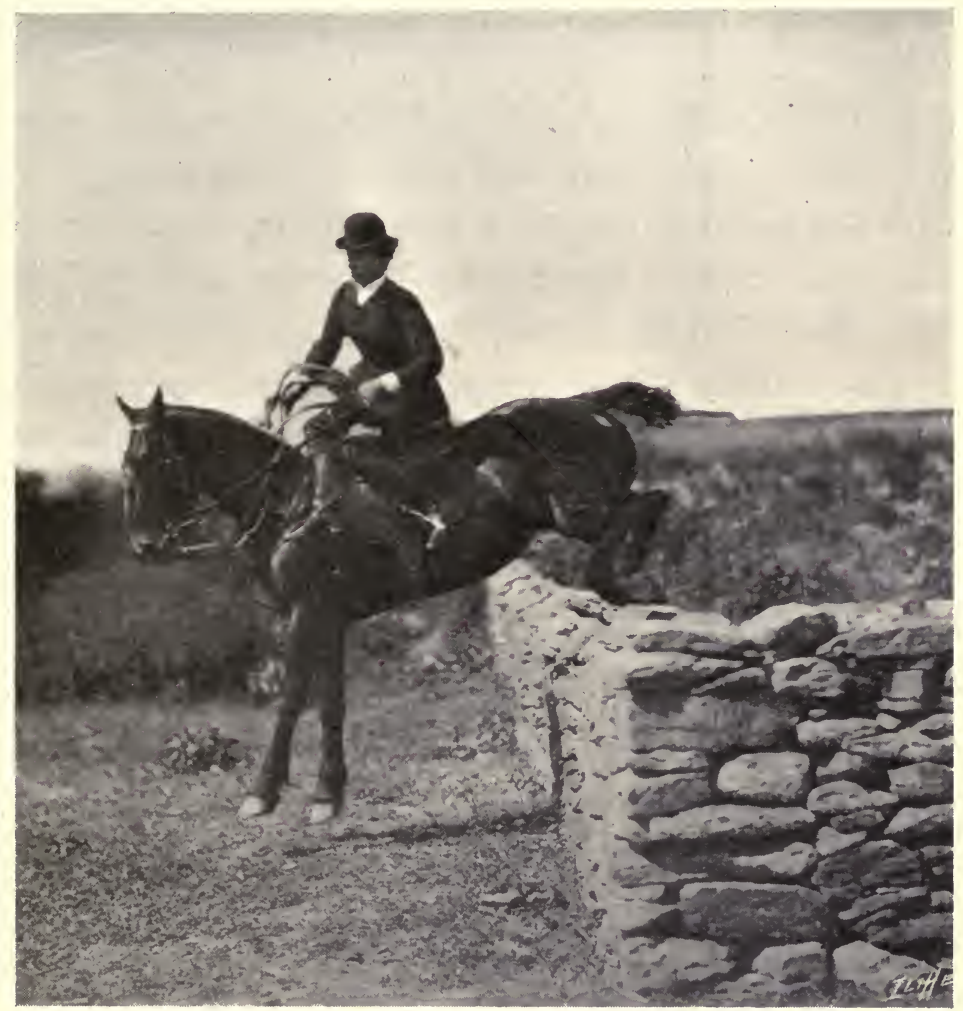

Fig. 104.-Position of legs in jumping.

handicapped by her want of control over the animal's hind quarters. In this movement we should above all things avoid leaning back and putting an equal feeling. on both reins, for that would be the very thing to prompt him to rear. It is evident that as a horse has 
to be light in front when going forward, he should be light behind when reining back. Therefore, the rider should lean forward. Also, she should feel the reins alternately, turning the horse's head towards the fore leg which is more advanced than the other fore leg. When she takes a steady pull with her right rein and finds that the horse draws back his off-fore, she should slacken the right rein and take a similar steady pull with the left rein to induce him to bring back his near fore, and so on. During this alternate feeling of the reins she should keep her hands as low as practicable, so that the horse may lower his head and put weight on his forehand, and consequently facilitate the movements of his hind legs. For each step the lady should use the words of command, " rein back," in a decided tone of voice, supposing of course that the animal has been taught the meaning of this verbal order. However well a lady may carry out these directions, she may not effect her purpose with precision, because the side pulls of the respective reins will prompt the horse, if he has not had previous training, to bring round his hind quarters in the opposite direction. The rider can prevent him doing this to the right by pressure of the whip on his off-flank; but owing to the necessary shortness of her stirrup, she will not be able to prevent him from swinging his hind quarters round to the left. Here, the fact of a man having a leg on each side of his horse and fairly long stirrups, makes him far more capable of reining back a horse properly, than a lady seated on one side of the animal. A man obtains 
command of a horse's hind quarters by the pressure of his legs, especially when the feet are drawn back. As horses very much dislike reining back, I would caution the rider not to disgust her animal by continuing it for too long a time. He should be occasionally reined back a couple of times for four or five paces, and after each rein back should be allowed to go forward, and he should be rewarded for his obedience by a few pats on the neck and some words of encouragement. If the animal's temper be upset by too much reining back, he will probably adopt the dangerous habit of running back, when he would be very liable to fall, or he may rear. As inconsiderate people will persist in taking kickers into the hunting field, every lady who desires to hunt should be able to rein back her horse, in order to remove him, if possible, from the dangerous vicinity of an animal whose tail is adorned with a red bow, which is a sign that he is a kicker, and not that he has been recently vaccinated.

Her next lessons should be devoted to obtaining practice in jumping various kinds of fences, and in riding up and down hill, over ridge and furrow and difficult ground, which we will deal with in another chapter. A lady should remember to always keep an eye on her mount, and never let her attention be diverted from the order of his going, however much she may be otherwise occupied. To people who have had much practice in riding various horses, this forward outlook becomes almost automatic.

I would advise my imaginary pupil to learn the 
following ancient rhyme by heart, and to observe its teaching, although it is not entirely applicable to ladies-

"Your head and your heart keep boldly up, Your hands and your heels keep down, Your knees keep close to your horse's sides And your elbows close to your own." 


\section{CHAPTER XI. \\ RIDING ACROSS COUNTRY. \\ "Made" fences-Practice over natural fences. \\ "MADE" FENCES.}

IT is necessary for a lady who intends to hunt, to obtain as much practice as possible over the various kinds of fences which she may have to negotiate when hunting, before she appears in the field. Although ladies living in the country may have an opportunity of obtaining practice over natural fences of gradually increasing size, it is generally more convenient, and perhaps safer, to utilise "made" fences in a field or paddock. These obstacles need not be very high to commence with, but they should assume various forms, due prominence being given to the most common kind of fence encountered in the country in which the rider desires to hunt. Two or more specimens of this particular obstacle may be included in the artificial collection. To imitate Leicestershire fences we may make, for the first jump, the nearest approach we can to an ordinary hedge; the second, a hedge with a 
ditch on the taking-off side; the third, a post and rail fence; and the fourth, another hedge, with a ditch on both sides. We may follow that with a "cutand-laid" fence with a ditch on the take-off side; and a stone wall, made up of loose stones or bricks. In the middle of the field, where the rider can obtain a good run at it, we may construct a water jump. The other fences should be built by the side of the boundary fence of the paddock or field, which may have to be artificially heightened for the purpose, but not supplied with wings; for in hunting, fences are not protected for us in that way. The pupil should first learn to jump them riding from left to right, as horses generally refuse to the left, and that side being blocked by the boundary fence, the horse will be more liable to go straight. The animal should, of course, first be ridden over them by the teacher in the presence of the pupil, who will see exactly at which jump her mount may be likely to give trouble. She should also observe the pace at which the animal is ridden, especially at the water jump. If he is sluggish, it would be wise for the lady to give him a touch with the whip when riding at timber, which he must not chance, and at cut-and-laid fences, which must also be jumped cleanly; for if a horse gets a foot in the top binder, the chances are that he will fall. Besides, he must exert himself to clear the ditch on one or both sides. He should be ridden over the course at a canter, and allowed to jump the fences without interference from his rider, for he will try 
his best to avoid falling. He should be ridden fast at water, as a certain amount of speed is necessary for jumping length; but he should not be taken at full gallop, as he would then be too much extended to raise himself in his spring. If the correct pace could be gauged to a nicety, I should say it is just a shade faster than a hand gallop. Horses, as a rule, jump water badly, perhaps for the very good reason that they seldom get schooled at this kind of obstacle.

A line of "made" fences in a field or paddock would have to be comparatively close together, say, with intervals of not less than 30 yards between them; although double that distance would be much better. A lady riding over these obstacles could hardly help going at the same speed, and, therefore, there would be but little opportunity for teaching her how she ought to regulate her pace for each of them, which would not be the case if they were a quarter of a mile or so apart. One advantage of riding over a line of "made" jumps is, that it strengthens a rider's seat, for no sooner has she landed over one fence, than she must be ready to negotiate the next one. She should remember to keep her hands low down and as steady as possible, carefully avoiding shifting in the saddle, flourishing her whip, checking her mount with the reins, shouting to him, or committing any other act which is likely to distract his attention from the fence in front of him. The horse given to the pupil to ride should be an experienced hunter, and, in that case, she may safely trust him to carry her over the 
various leaps without any interference whatever. If he takes them a shade faster than did the animal on which she rode over her first fence, she should not try to check him. As it is impossible for her to know the exact moment he is going to take off, she should give him his head, when he is coming up to the obstacle, and be ready to lean well back as he is landing over it. If a lady is riding with her reins too short, and the horse, in jumping, makes a sudden snatch to get more rein, she should at once let them slip through her fingers, and learn, from that experience, to ride with the reins sufficiently long to enable her to have an easy feel of her horse's mouth, without in any way hanging on to his head. Some inexperienced ladies get alarmed when a horse is about to take off, and check him with the reins, which is a most dangerous proceeding. I have known the safest of jumpers pulled into their fences and caused to fall by the adoption of such tactics. A lady should remember that when her mount is going straight for a fence, with the intention of getting safely to the other side, any interference on her part will cause him to either blunder badly, or, if the jump is a fixture, to fall. If a horse slackens speed when near a fence, and suddenly runs out, his rider should let him refuse and take him at it again. I once got a very bad fall through turning a horse quickly at a fence which he was in the act of refusing. We were close to the jump, he had no time to take off properly, so he breasted the obstacle, a stiff timber jump, and blundered on to his head. That taught me 
a salutary lesson, and therefore I would warn all ladies to let their horses run out when the animals have taken the first step in the wrong direction, as it is then too late to keep them straight with safety, and a sudden turn, with the object of trying to do so, is very apt to make a horse blunder.

When a touch with the whip is given to remind a horse that he has to clear a big ditch on the landing side, or when riding at timber, it should be used on the off flank by a turn of the wrist, but without jerking the reins. The whip, as I have before remarked, should be employed as an aid and not as a means of inflicting pain. A lady should not bustle her horse at his fences, except perhaps at water, for every horse has his own pace at which he prefers to jump, and the clever sort will always manage to put in a short stride, or take a longer one at the last moment, if they find that the strides they are using will not bring them up to the correct spot from which to take off. In hunting, the fences are generally taken at a canter, and the pace is increased in galloping over the open ground. Horses are thus what is called "steadied" at their fences, but the pull should not be made nearer the fence than 30 yards. When a lady has made up her mind to ride at a fence, she should think of nothing else but getting over it. Some women go at their fences in such a half-hearted, irresolute manner that their horses learn to refuse. Too much practice over "made" fences is monotonous to the rider and hateful to her horse, - who is only too apt to become "re- 
luctant" in such cases. Hence, if the lady has ridden over the fences nicely, from left to right and from right to left, and taken her artificial brook at a good pace, she should not be required to do any more jumping on that occasion. The ground near the fences should be laid down with tan, stable litter, or anything else which will make the falling soft, in the event of the pupil having a tumble. It would be better for a lady not to be given a lead in riding over these "made" obstacles, because it is necessary for her to have as much practice as possible, at first, in controlling her mount without assistance.

\section{PRACTICE OVER NATURAL FENCES.}

A lady who has gone through the hard drudgery of learning to sit well, will be repaid for her efforts on finding herself able to ride with ease over natural fences. Her companion should select the obstacles, and give a lead, but the pupil should not send her horse at a fence until she has seen her pilot safely landed and going away from it. She should occasionally assume the lead, in order that she may not always rely on the guidance of others. Unless there is a paucity of obstacles, no fence should be jumped twice, and the companion or attendant should: be a man who knows the country, so that he may direct his pupil to obstacles without going out of the way to meet them. The more these fences are treated as adventitious circumstances, and not the main object of the ride, the steadier and more safely will a horse 
jump them. A lady should ride as many different horses as she can, and in company, for when four or five horses are cantering together, the lady's mount will, doubtless, be sufficiently excited to require steadying in approaching his fences, and she may then learn to gauge the distance at which to take a pull at him. Those who are riding with her should require her to wait her turn at the only practicable place in a fence, as she would have to do when hunting, to pull her horse up to a halt, and to send him at his fence with a run of only a few strides. She should also practise trotting her horse up to a fence to see what is on the other side of it, and, if it is negotiable, she should turn him away from it, give him a short run at it, and jump it. After she has obtained as much practice as possible, on different horses, over various kinds of natural fences, and has shown ability to control her mount at a gallop, and when excited by the presence of other horses galloping in front of him, she should be considered competent to commence her hunting career, and take her place in the field at the beginning of the cub-hunting season. She should remember on all occasions of difficulty and danger to keep a cool head and trust to the honour of her mount. A good horsewoman, even if she has had no experience in hunting, will not be likely to incur disgrace by wild and incompetent riding, for, having been accustomed to keep her mount under thorough control, she will carefully avoid spoiling the sport of others, while seeing as much 
of it as she can in a quiet, unobtrusive manner. A lady should remember that strangers are not hailed with delight in any English hunting field; but when they are found to be competent to take care of themselves and their horses, they are far more kindly received, than if they go there as recruits in the great slipshod brigade. 


\section{CHAPTER XII.}

\section{HACKING.}

IT is necessary for a lady to acquire a knowledge of the rules of the road before riding in public, especially if she be attended by a groom, who would of course ride behind her. Persons, whether riding or driving, when proceeding in opposite directions, pass each other on the near (left-hand) side of the road, and when going in the same direction, the more speedy party goes by the other on the off (right) side. A male companion would ride on her off side. In military riding, the rule when meeting a rider proceeding in the opposite direction is "bridle hand to bridle hand."

When the young horsewoman assumes charge of her mount in the open, she should always keep a watchful eye on the road in front of her, in order to avoid as far as possible dangerous ground and approaching vehicles. Her eyes and ears should enable her to mentally note objects coming behind her, as well as those on either side, such as, for instance, loose horses or cattle in fields, the approach of trains, etc., in order that she may be prepared for any sudden movement on 
the part of her animal. Loose horses which we meet in fields have such a playful way of galloping up behind, and frequently taking great liberties, that it is often necessary to get into the next enclosure as quickly as possible. Even when quietly cantering on grass by the side of the road, the vagaries of loose horses or cattle, or even the sudden flight of birds on the other side of the dividing boundary, may cause a rider to be taken by surprise, if she has not previously made a mental note of her neighhourhood. Also, she should always have reassuring words on the tip of her tongue for her animal in case of momentary alarm. The quietest horse in the world may occasionally exhibit fear, but if his rider uses her eyes and ears, she will generally be prepared for any sudden flight of fancy on his part, and will not be likely to lose her head.

A lady should avoid trotting on broken or uneven ground, or on a road which is covered with loose stones, as her horse would be liable to fall and perhaps cut his knees. Unless in a hurry to reach her destination, she should not, like a butcher's boy, trot her horse at his fastest speed. The ground chosen for a canter should be soft and, if possible, elastic, and she should, of course, avoid the "'ammer, 'ammer on the 'ard 'igh road," which is a fruitful cause of lameness. Any soft parts at the side of a road may be used for the canter, or if the ground is very hard and dry, as it sometimes is in summer, and also in frosty, weather, only quiet trotting and walking exercise could be taken with 
safety to the horse. A lady should always study her mount, and carefully select the "going:" It is best to ride down-hill at a walk. If a horse stumbles he should never be hit or jobbed in the mouth, because he takes no pleasure in making false steps, or even in breaking his knees.

A lady should always give any passing vehicle as much room as possible. If her animal is afraid to pass any object on the road, the groom or attendant should at once ride in advance and give him a lead. If he still evinces fear, his rider should speak encouragingly to him, pat him on the neck, and tell him to go on. If this fails, and he shows an inclination to turn in an opposite direction, she should check him at once, and order him to go on in a severe tone of voice. It will be on such occasions as these that a rider who has never acquired the silly habit of constantly talking to her mount, will find the voice a powerful factor in horse control. Unfortunately, many people, when a horse shies, lose their heads, clutch at the reins, hit the horse, and commit other foolish acts which only irritate the animal, without in any way allaying his fear, supposing, as we do, that the horse is good-tempered, and is not shying from vice. The voice of his rider will inspire him with confidence, and, therefore, when he has made an anxious and fearful step in the right direction, he should be patted and spoken to in an encouraging tone, so that his mind may not be wholly occupied with the terrifying object in front of him. It is a good plan to incline his 
head away from it as much as possible. I have ridden young horses who have shied at almost everything, but have never worried them to go up to and smell the object of their aversion, as some recommend, because it is not always practicable to do so, as, for instance, in the case of a motor car. It is not wise to give undue importance to comparative trifles. The voice has always stood me in good stead with shying horses, who soon get to regard it as a sure sign that they have nothing to fear. A lady who has been properly taught to ride, and sits correctly, should remember that whatever her horse may do in plunging about from one side of the road to the other, he cannot unseat her, so she need feel no alarm on that point. The greatest danger is that the horse may dash into something which in his fright he has not seen, but that, fortunately, is a very rare occurrence, even with young horses. However frightened a lady may herself feel, she should never reveal her secret to her horse by speaking to him in a terrified tone of voice, or by otherwise displaying fear; and above all things, she should never lose her temper and hit him, no matter how obstinate he may be, as doing so will only make him shy on the next occasion, with a display of temper thrown in, and he will then be more difficult than ever to manage. The best way to act with a horse which shies from desire to "play up," is to take as little notice as possible of his antics, give him more work, and less corn.

A lady should always ride slowly round a corner, and keep a good look out in front of her. Many things 
may happen during the course of a ride to try the nerve of both horse and rider, but if anything should startle a horse, his rider should keep her head cool, sit tight, and do her best to pull him up. She will have doubtless accustomed him to the meaning of the word "steady," or other verbal order which she may have employed when slackening speed. This word, accompanied by a steady and vigorous pull on the reins, should succeed in stopping him before he has had time to get up much speed. If, however, a lady finds she cannot pull him up, she should try to turn him to the left, as that will be the easier, supposing, of course, she has sufficient room in which to turn. If not, she should saw his mouth with the bit by working it from side to side. The groom, or attendant, should on no account gallop after her, as doing so will only tend to make the lady's horse go all the faster. I remember riding a very hard puller belonging to Mr. Wintle, of Shanghai. One day this animal bolted with me, and the stupid native mafoo behind galloped on after me. I managed to stop the animal by turning him to the left, and pointing his head away from the homeward direction in which we were proceeding, but I was greatly hampered by my mount hearing the footfalls behind him. The native groom was frightened, and no doubt thought he could help me, which he could best have done by pulling up. I cannot too strongly impress on all ladies who ride the necessity of using a safety-bar on their saddles (p. 38), and wearing a safety skirt, even when hacking; for a sudden cause of fright may make 
the animal unseat his rider, and it is no uncommon thing for a horse to fall when going over apparently level ground, even at a walk, in either of which cases she might get dragged by her stirrup or skirt, if it is of the non-safety pattern. In any case of difficulty with a horse, a lady should contrive at all hazards to retain her self-possession and her seat, remembering that the least symptom of alarm on her part will increase the terror or obstinacy of the animal. My advice for stopping a runaway is not so easy to follow as drawing on a glove, but it has extricated me on many occasions from a dangerous position and, therefore, I k know it to be practicable; but I hope no lady may ever have occasion to put it to the proof. Although all quarrels between horse and rider should be avoided, a woman should never, by over-indulgence, induce her mount to consider that she is afraid of him, because if he once gets that idea into his head, he will exert every means to convince her that he is the master, and will end by doing precisely. what he likes, instead of implicitly obeying her commands. By watching my husband reduce to subjection vicious horses in various parts of the world, I have seen that although equine demons cannot be conquered by physical strength, they can be controlled by coolness, patience and knowledge, which is a fact that every riding woman should bear in mind. 


\section{CHAPTER XIII. \\ RIDING WITHOUT REINS.}

UNDOUBTEDLY the best and quickest way for a lady to learn to ride well is the one which I shall now describe, and which I believe I have been the first to practise.

Before putting up the pupil, it is well to teach the horse the work he has got to do, which should be performed, if possible, in an enclosure not less than I 7 yards in diameter: 20 yards would be a better size. The track should be soft. A thick, smooth snaffle having been put on, the leather reins are taken off, and others (the best are of "circular" or "pipe" webbing, I $1 / 2$ inches broad) about 22 feet long are substituted. If circular webbing cannot be obtained, ropes or ordinary leather reins, if of the proper length, will do. The animal is made to circle round the driver by the outward rein (the left rein if he is going to the right) passing round his quarters, while the inward rein (the right in this case) leads him off and bends him in the direction he has to go (Fig. 105). The horse should be made to circle in a thoroughly well-balanced 
manner, so that the circle described by his fore feet will be the same as that made by his hind feet, and he should be taught to turn smoothly and collectedly. The driver should stand partly to one side of the horse and partly behind him, as in Fig. I05, but should on no account keep following the animal; for, if he does so, he will throw too much of his weight on the reins. This should, of course, be avoided; for the lighter the feeling on the reins, the better, so long as the horse goes up to his bridle. The pressure of the outward rein should act like that of the outward leg of a man who is riding a horse on a circle, in keeping his hind quarters "supported"; so that the circle described by the hind feet may not be greater than that made by the fore feet. In order to give adequate command over the horse, a standing martingale, put at a proper length, will be required for this driving on foot. This method of mouthing horses is fully described in my husband's Illustrated Horse Breaking. When the horse circles and turns equally well on both reins and jumps cleverly, the beginner may be put on the saddle without giving her any reins to hold. In order to keep her hands down and occupied, she may hold a whip or stick in both hands resting on her lap, as shown in the illustration, or she may fold her arms in front of her. Whatever may be the pace, if the pupil begins to lose her balance, to be frightened, to sit awkwardly, or to become tired, the driver should at once halt the horse and should try to rectify matters as far as possible. 


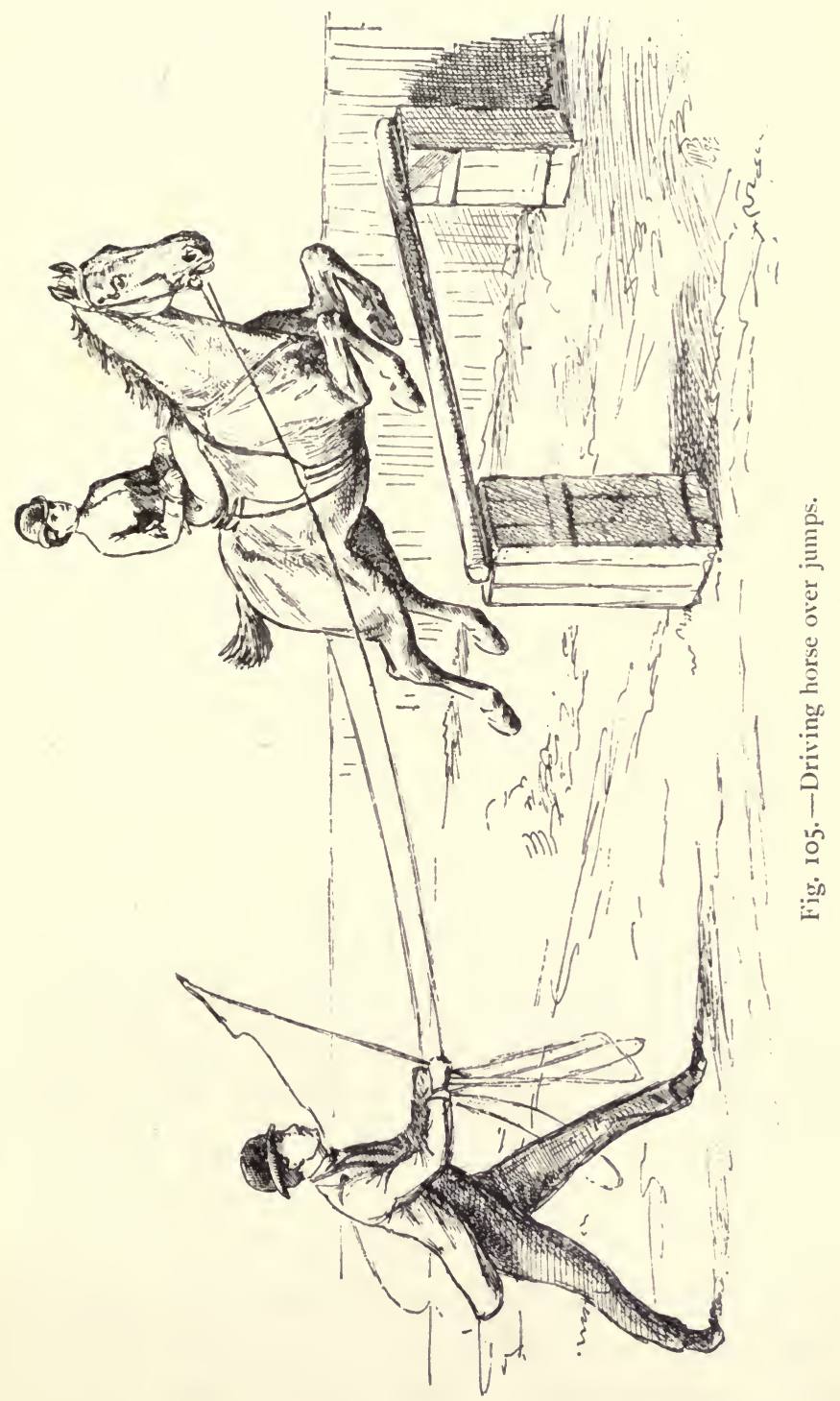


The lesson should be commenced by the driver starting the horse into a steady walk, on a circle to the right, as that will be easier than going to the left. After a few circles, and when the rider has acquired some confidence, the driver may give her the "caution" that he is going to turn the horse, which he does by turning him to the "left-about" by means of the left rein, while "supporting" the hind quarters by the right rein. After the required number of circles has been made to the left, the caution may be repeated, and a "right-about" turn done. When the pupil has become sufficiently advanced, a steady trot on the right circle may be attempted; the turns being executed as before. Subsequently, a canter may be tried. As the rider gains expertness, the turns may be made without giving any caution, and the sharpness with which they are done may be gradually increased. When the rider has acquired a good firm seat, she may get a jumping lesson. The best kind of fence is a round thick (at least 6 inches in diameter) log of wood. It should be of good substance and weight, so that, if the horse hits it once, he will not care to repeat the experiment. It should be free from any sharp points or edges that might blemish the animal, if he "raps" it. This log should be at least I 5 feet long, should have one end a little outside the circumference of the circle on which the animal works, and the other end pointing towards the centre of the circle. The log, at each extremity, may be propped up on empty wine or beer cases 
(Fig. 105). No wing or upright pole which might catch in the reins should be placed at the inner end of the log. If a log such as I have described be not procurable, a hurdle or gate might be employed. It is well to begin this lesson by placing the log on the ground, and first walking the horse, who carries his rider, over the log, which might then be raised 5 or 6 inches. The bar need not be put up higher than 3 feet. The whole of this jumping practice should at first be given while circling to the right. As the capabilities of all are not alike, the teacher, who ought also to be the driver, should exercise his judgment in apportioning the work done. As a rough approximation, I should say that an apt pupil who had never been previously on a horse, ought to do in fairly good style, after a dozen lessons, all I have described. These lessons, which had best be given daily, ought not to exceed half an hour in duration. Great care should be taken that the rider gets neither fatigued nor "rubbed." As a rule, a man will be required to drive the horse on foot with the long reins; for few women would be able to do this work, and teach at the same time. If the instructor be a lady, she might get an experienced man to drive for her, while she gives the cautions and orders.

While receiving her first lesson in riding without reins, the pupil should try to keep her seat by the combined help of balance and grip, and should not attempt to hold on to the saddle with her hands, which, subsequently, will be required solely for the 
manipulation of the reins and whip. As a rider can manage a horse in a moment of danger twice as well with two hands as with one, it is impossible for her to become a fine horsewoman if she acquires the fatal habit of clutching hold of the saddle, which she inevitably will do the instant she feels insecure in her seat, or becomes nervous, if she be that way afflicted. To guard against this evil, the learner should be taught to ride in a modern English saddle, which, as we all know, has got no off pommel.

By allowing her body to be perfectly lissom from the waist upward, she will be able to conform to the movements of the horse, and will not feel herself violently jerked from side to side by any quick turn or untoward movement he may make. If she stiffens her body and assumes an awkward position in her saddle, she will find herself, on the animal being sharply turned, unable to retain her seat with ease. As it is difficult, even for an accomplished horsewoman who is not accustomed to riding without reins, to do this when mounted on a light-mouthed horse, and without a signal from the driver of his intention to turn sharply in the trot or canter to "right" or "left" as the case may be; the pupil, until she has acquired the knack of conforming to every movement of the animal, should receive due warning from the driver. When he signifies his intention to turn the horse, she should grip the crutches with her legs, and incline her body in the direction to be taken by her mount. By watching the animal's 
ears, she will soon learn to become independent of the driver's signal.

She will find, until she has acquired practice in riding without reins, that it is far more difficult to retain her balance in the saddle during these turns, than in riding over a fence; for when an obstacle has to be negotiated, she is made aware beforehand of the intended movements, but in turning without a signal she has not that advantage. If the lessons are given, first at a walk, and the pace gradually increased according as she becomes secure in her saddle, she will soon acquire a good firm seat, and will have no tendency to be displaced by her horse shying with her, or by making a sudden plunge to right or left.

I have described in Chapter VIII. how a lady should sit in her saddle, so I need not repeat these directions. While being driven with the long reins, the rider should endeavour to sit as upright as she can, without any stiffness, and leaning neither to the front nor back, except when rising at the trot, when the body should be inclined a little forward, so as to make the movement smooth.

The walk requires no special mention, At the trot, before she has learned when and how to rise in her stirrup, it is best for her not to make any attempt to do so, but to let herself be bumped up and down until she feels that, although the movement may be unpleasant, it does not render her seat insecure. While doing this, she should be careful not to put any weight on the stirrup. After she has thus learned to trot without 
rising, she should try to feel her stirrup just before her body is bumped upward by the horse, and she will soon become able to time her movements, so as to rise in her stirrup with grace and ease. To do this, her effort should be strictly confined to aiding the upward lift which the horse gives to her body, and should be free from any jerk or wriggle. She should have her weight well on her right leg, and should keep her stirrup in one unaltered position (p. 192). The ankle acts here as a spring to take away any jerk that might occur during the movement. The stirrup, as I have said on page I92, should be at the ball of the foot, and the left knee should be kept steady and close against the flap of the saddle. If the horse, during the trot, suddenly breaks off into a canter, the rider should sit down in her saddle, and be ready to grip her crutches with both legs, if necessary.

When cantering, the lady should try as much as possible to ride by balance and not by gripping her crutches tightly the whole time. She will thus be able to sit in a nice, easy position, and will be ready to grip the moment she requires to do so, as when turning, or if she feels she is losing her balance. Whenever the pupil gets displaced in her saddle or frightened, the horse should at once be pulled up; for the lesson will be of no use to her, if she feels forced to adopt a stiff, awkward position in her saddle for the sake of safety.

It is well to know that an almost infallible sign of a rider being frightened of her horse is a tendency to 
unduly bend or "crane" forward. Hence, the instant this sign becomes apparent either to learner or teacher, the lesson should be discontinued, or the pace, if that was the cause of the nervousness, should be decreased as might be required. This "funky" seat on horseback looks bad, is particularly unsafe, and is hard to correct when once acquired.

In riding up to a fence the lady should in no way alter her position, but should merely grip the crutches firmly, while keeping her body perfectly lissom, with her head and shoulders slightly back. Many persons have a notion that the proper way to sit over all jumps is to bend forward when the animal is rising, and to lean back when he is descending. 'This is quite wrong; for, as the horse, before propelling himself forward and upward by his hind legs, has to raise his forehand oft the ground by the straightening out of one or both of his fore legs, it is evident that it would be inadvisable to put any additional weight, at that moment, on the forehand. As most persons have a natural tendency to bend forward too much when going at a fence, I have advised the rider to bring her head and shoulders a little back, just sufficient to correct such a tendency. When a horse is in the act of taking off at a standing jump, the rider should lean forward, and bring her head and shoulders back, when he is landing. It is always sound practice to lean well back when landing over a fence, so as to take the weight off the horse's fore legs as much as possible. An experienced rider solves all these problems automatically. 
The fact of a side saddle giving the very strong grip it does, induces many ladies who find they can sit over a fence without falling off, to become so well satisfied with their own riding, that they neglect to acquire a good seat over a country. Their slipshod style is neither graceful, nor does it enable them to give their horse any assistance, if he happens to make a mistake; for they are certain to tumble off, if they receive any unusual provocation.

The hold the lady has on the crutches should prevent her falling, if the animal stops dead when coming up to a fence. A lady who has acquired a good firm seat ought never to be displaced from her saddle while her mount remains on his legs.

Though progress in the art of riding without reins must of necessity be slow and somewhat tedious at first, still, I would strongly recommend all ladies who are able to do so to practise this method, for they will find it the best and most rapid by which they can acquire a good and firm seat on horseback. The great difficulty in this work is to find a man who can use the long reins and manage a horse with correctness and precision in the various paces, and in jumping. It would be most dangerous for a lady to allow herself to be driven by the long reins by any man who was not a thorough master of this difficult art of horse guidance and control. Even with such a man, the horse to be ridden and jumped without reins should be previously trained for this work, and should be taught to stop dead the instant he receives the word of command. As a lady 
who is inexperienced in this kind of riding, may get a toss when being turned, especially if she tries to hook back her right leg, it is obvious that the "falling" should be soft and that the pupil be supplied with a safety bar and a safety skirt. It will be seen by the extract from the Queen, page 6o, that even small girls who were taught to sit their horses in the manner that I have described in this book, were able to ride well over fences without reins after two lessons. 


\section{ÇHAPTER XIV.}

NERVE.

No lady can enjoy riding, or become proficient in that art, unless she has good nerve. Luckily, the large majority of girls who learn to ride possess abundance of nerve and pluck, an excess of which is often a danger to safety in the hunting field. It may be noticed, however, that the finest horsewomen do not make any showy display of their prowess, for they ride to hunt, and do not hunt to ride. Pluck is an admirable quality as far as it goes, but it must be supported by nerve.

It is the custom to laugh at people who are suffering from temporary loss of nerve, but it is heartless to do so, as we have all, I believe, felt, more or less, what Jorrocks would term, "kivered all over with the creeps," at some period or other of our lives. Bad horses and bad falls are apt to ruin the strongest nerve, and there must be a cause to produce an effect. For instance, I never feared a thunderstorm until our house was struck by lightning; but now, when a storm comes, I feel like the Colonel to whom a Major said on the field of Prestonpans: "You shiver, Colonel, you are afraid." “I am 
afraid, Sir," replied the Colonel," and if you were as much afraid as I am, you would run away!" It may, however, be consoling to ladies who are battling against loss of nerve, to hear that I have known brilliant horsemen lose their nerve so utterly that they were unable to take their horses out of a walk. With quiet practice their good nerve returned again, and they have ridden as well as ever. Nerve in riding is recoverable by practice on a very confidential horse. Some men give their wives or daughters horses which are unsuitable for them, and which they are unable to manage. Is it any wonder that such ladies have their nerve entirely shattered in their efforts to control half-broken, violent brutes of horses? It is customary to blame ladies who are unable to control their horses in the hunting field; but the men who supply them with such animals are, in many cases, the more deserving of censure. There are men, not many, I hope, who consider it unnecessary for their womenkind to learn to ride before they hunt ; but no one has a right to thus endanger the lives of others. Such ladies possess plenty of pluck, but not the necessary knowledge to guide their valour to act in safety. A Master of hounds told me that his nerve was so bad that he positively prayed for frost! At the end of one season he gave up the hounds; but he is again hunting them, so his nerve must have become strong. Mr. Scarth Dixon, writing on this subject, says: "It is a curious quality, that of nerve. A man's nerve, by which I mean his riding nerve, will go from him in a day; it will sometimes, but not frequently, come back to him as 
suddenly as it departed. Everyone who has hunted for any length of time and kept his eyes open must be able to call to mind many a man who has commenced his hunting career with apparent enthusiasm, who has gone, like the proverbial 'blazes,' for two or three seasons, taking croppers as all in a day's work, and then all at once has given up hunting altogether because his nerve has gone. He has, perhaps, tried to ' go' for a season, enduring unknown tortures in the attempt, and then he has given up altogether. He has never joined the skirting brigade, not, perhaps, as some would suggest, because he was too proud to do so after having once been a first-flight man, but because he did not care sufficiently for hunting." This writer knew a man who gave up riding to hounds because he had lost his nerve, and yet he continued to ride in steeplechases, which may be explained by the fact that the rider on a "Hlagged course" knows what is in front of him, and has little or nothing to fear from bad ground. Mr. Otho Paget considers that "a failing nerve may be always traced to the stomach," and recommends moderation in eating, drinking, and smoking. Frank Beers, the famous huntsman of the Grafton, had his hunting career closed by a severe illness, which apparently deprived him of all his former dash. Mr. Elliot says: "At the commencement of the season (I890-9I) an attempt was made by the poor man to resume his duties, but one hour's trial proved to Mr. Robarts and those present that all hope had vanished, and the above-named gentleman, being in charge during Lord 
Penrhyn's absence, sent the hounds home." Huntsmen, like other riding men, generally lose some of their nerve after forty. Mr. Otho Paget tells us that the late Tom Firr was the only huntsman he ever knew who retained his riding nerve to the end. He was riding brilliantly at fifty-eight, in his last season with the Quorn, when he met with an accident which compelled him to resign his post. With Lord Lonsdale as Master, and Tom Firr as huntsman, the Quorn possessed two of the most perfect horsemen who ever crossed L.eicestershire.

I think the best treatment for a lady suffering from loss of nerve is, first of all, to attend to her health, which will probably be out of order; then get a steady horse or pony and ride him quietly for a time, and the chances are that the good nerve will all come back again. It grieves people who have been unable, from various causes, to keep up their riding practice, to think that they have lost their nerve, and they brood over it until they often imagine they are past hope of recovery, but that is a great mistake. This feeling can be struggled against, and, in most cases, conquered, by quiet measures. Nothing but the most "confidential" animal will help to do it, so I would warn my riding brethren not to make matters worse for their womenkind by providing any other kind of mount. 


\section{CHAPTER XV. \\ FENCES, COUNTRY AND GATES.}

From a hunting point of view, the chief value of fences lies in the fact that they retard the hounds more than the horses, and help the foxes to save their brushes. On arable land, fences as a rule are used merely as boundaries; but on grazing land, they are needed to prevent stock from roving beyond their assigned limits. Hence, in a grass country, the obstacles are generally much more difficult to negotiate than on tilled ground. Also, the nature of grazing stock demands variation in the stiffness and height of the fences, which, in the Midlands, have to restrain the migratory propensities of frisky young bullocks; but in dairy-farming counties like Cheshire, much smaller and weaker ones amply serve their purpose in acting as barriers to placid bovine matrons.

Farmers in the Shires have found that hawthorn hedges make the most serviceable fences under old time regulations. When these hedges are allowed to grow in a natural manner, they take the form of a bullfinch (Fig. 90), which, though impossible at many 
places, often leaves a gap at others. Consequently, bullfinches are gradually going out of fashion in the Shires, and are generally converted into cut-and-laid fences, of which there is an example in Fig. so6. This alteration is usually made in winter, and is effected by cutting with a bill-hook about half way through the small trunks of the hawthorn shrubs, turning them to the left, and interlacing their tops and their branches, as we may see in Fig. 107, which shows us the appearance Fig. Io6 presented during its construction. A cut-and-laid is usually about 3 feet 9 inches high, and is the wrong kind of obstacle to "chance," because it is very stiff. Some hunting people who know very little about country life, call a cut-and-laid fence a "stake-and-bound fence," which (Fig. I08) is an artificial barrier made by putting a row of stakes in the ground and twisting brushwood between them. Stake-and-bound fences are common in Kent, and are not nearly so dangerous to "chance" as a cut-and-laid, because the ends of their stakes are only stuck in the ground. The practice of cutting and laying hedges is so general in the Midlands, that we rarely see a bullfinch which does not show signs of having been tampered with in this manner. Even the height to which the hawthorn bushes in Fig. 90 have attained, does not entirely conceal the traces left by the bill-hook, some years before this photograph was taken.

Posts and rails are often used in the Shires to strengthen decrepit fences (Fig. I09), and to take their 
place when no hawthorn bushes are present (Fig. I ro). Their difficulty of negotiation is naturally increased by the presence of a ditch on the taking off or landing side, as in Fig. I I I. As a rule, they are about 3 feet 6 inches high. A not uncommon form of posts and rails is a Midland stile (Fig. I I2). A familiar combination of a hedge and posts and rails is an oxer (Fig. I I3). The gap in this illustration has been repaired by wire, and $\mathrm{I}$ am much indebted to the ox who kindly allowed us to take his portrait, as well as the fence which owes its name to his family.

Although the Whissendine is a prominent feature of the Cottesmore country near Stapleford Park, I need not dwell upon brooks as a form of hunting obstacle in the Shires, for they are seldom jumped; not from faintheartedness on the part of riders, but because the ground on the taking-off or landing side is often treacherous, and the presence of posts and rails or wire on one or both of the banks is a frequent occurrence. Also, the width of these brooks and bottoms varies greatly according to the amount of rainfall. People whose experience of leaping is limited to that of fences on firm and level ground, like those in a jumping competition, are naturally apt to overlook the severe manner in which a hunter is handicapped when coming up to an unknown fence, after a long and fast run through heavy, rough and hilly ground.

Wire (Fig. I I4) is terribly common in some parts of the Shires, and often makes any attempt to ride straight impossible. In countries where it is prevalent, 
FENCES, COUNTRY ANI) GATES.

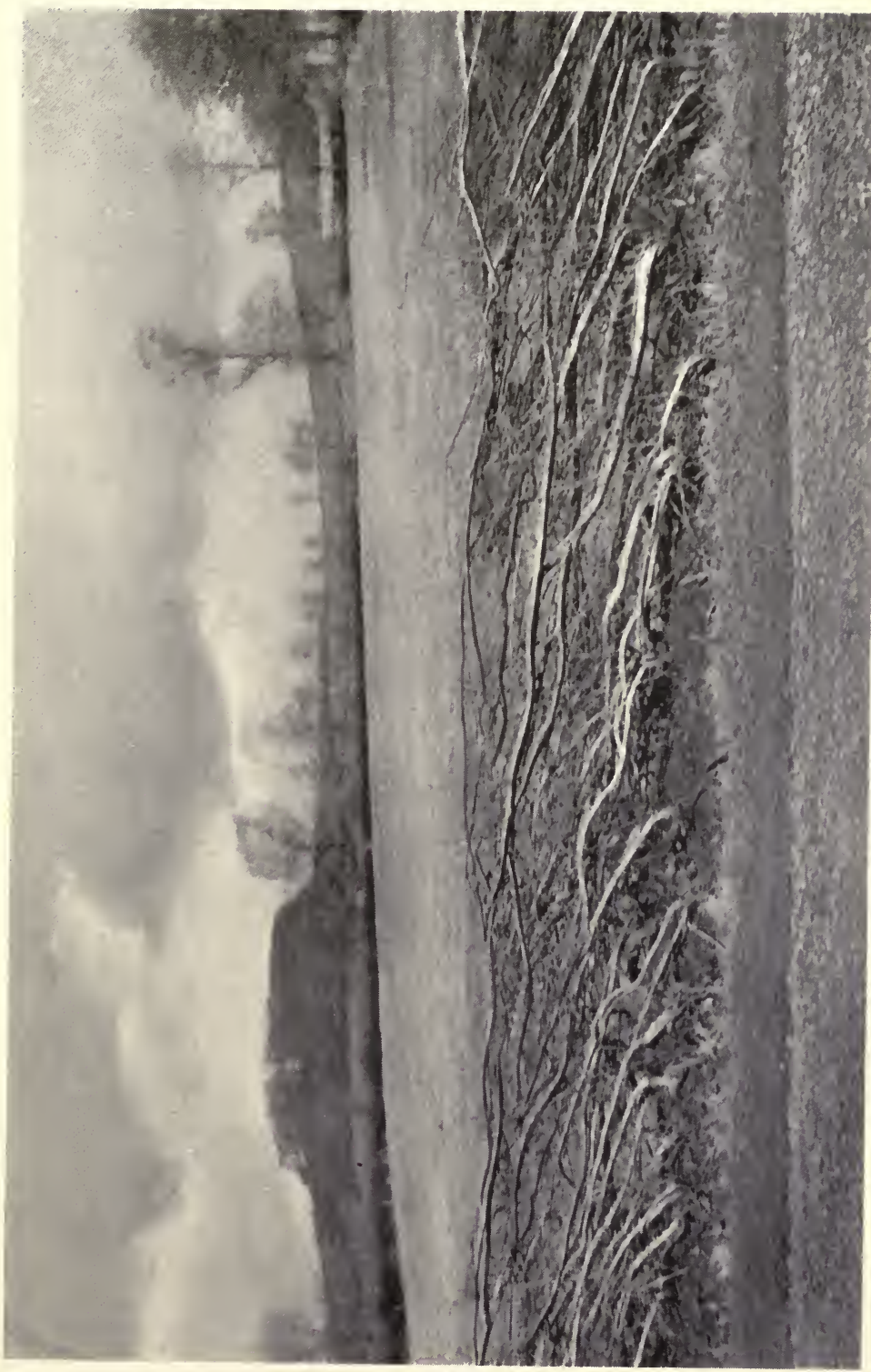

ปัن 

FENCES, COUNTRY AND GATES.

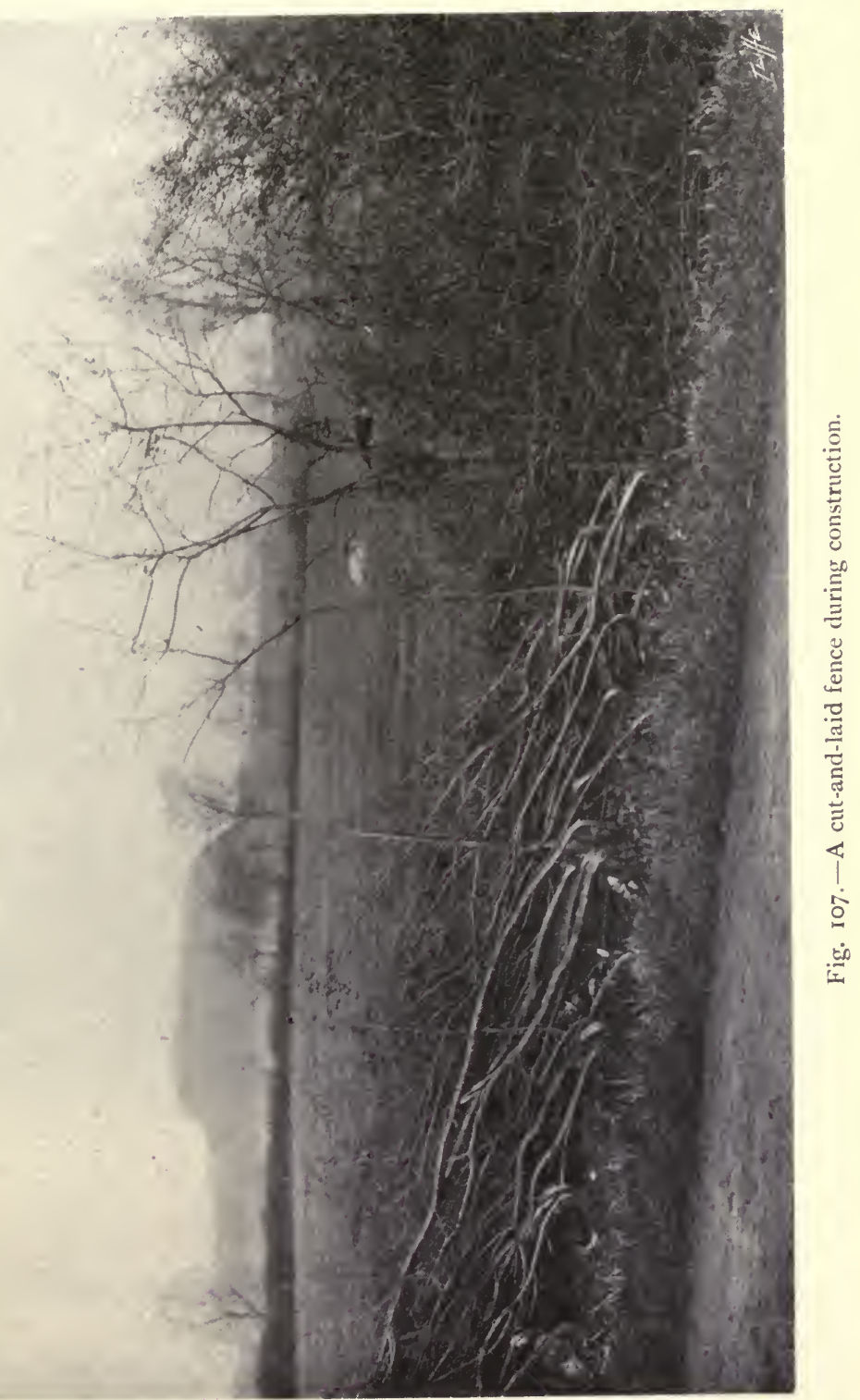



FENCES, COUNTRY AND GATES.

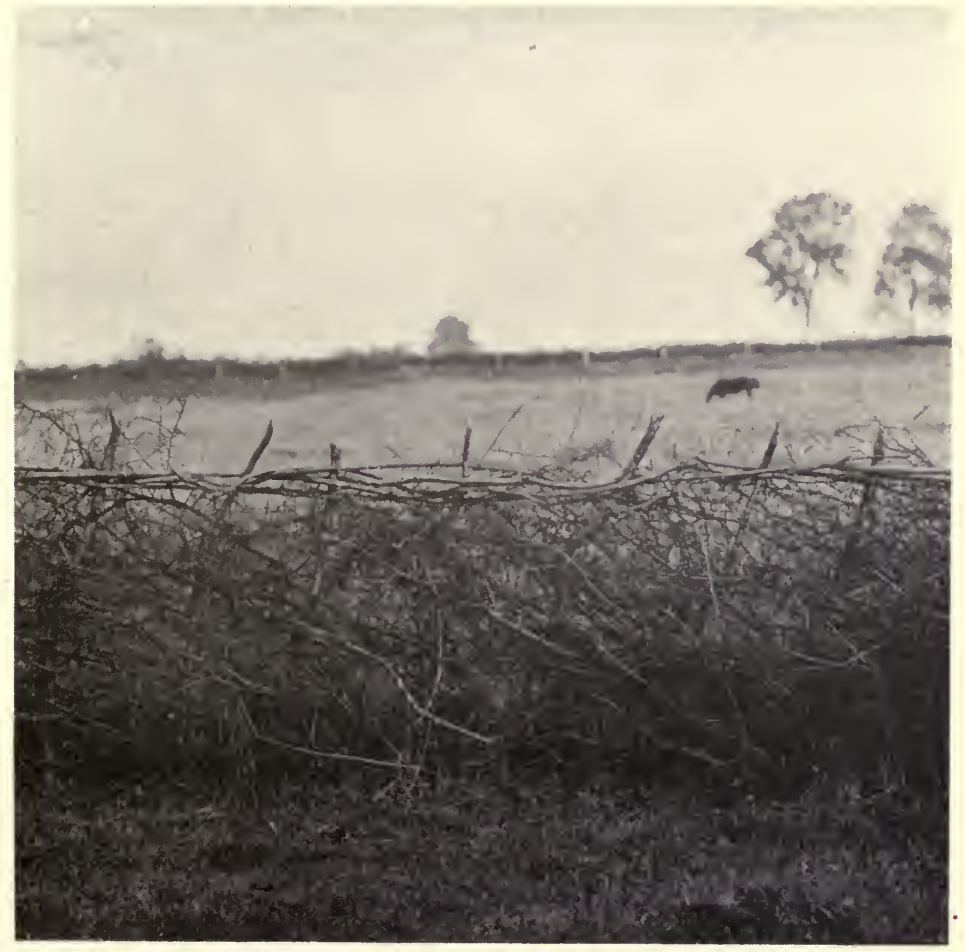

Fig. I08. - A stake and bound fence. 



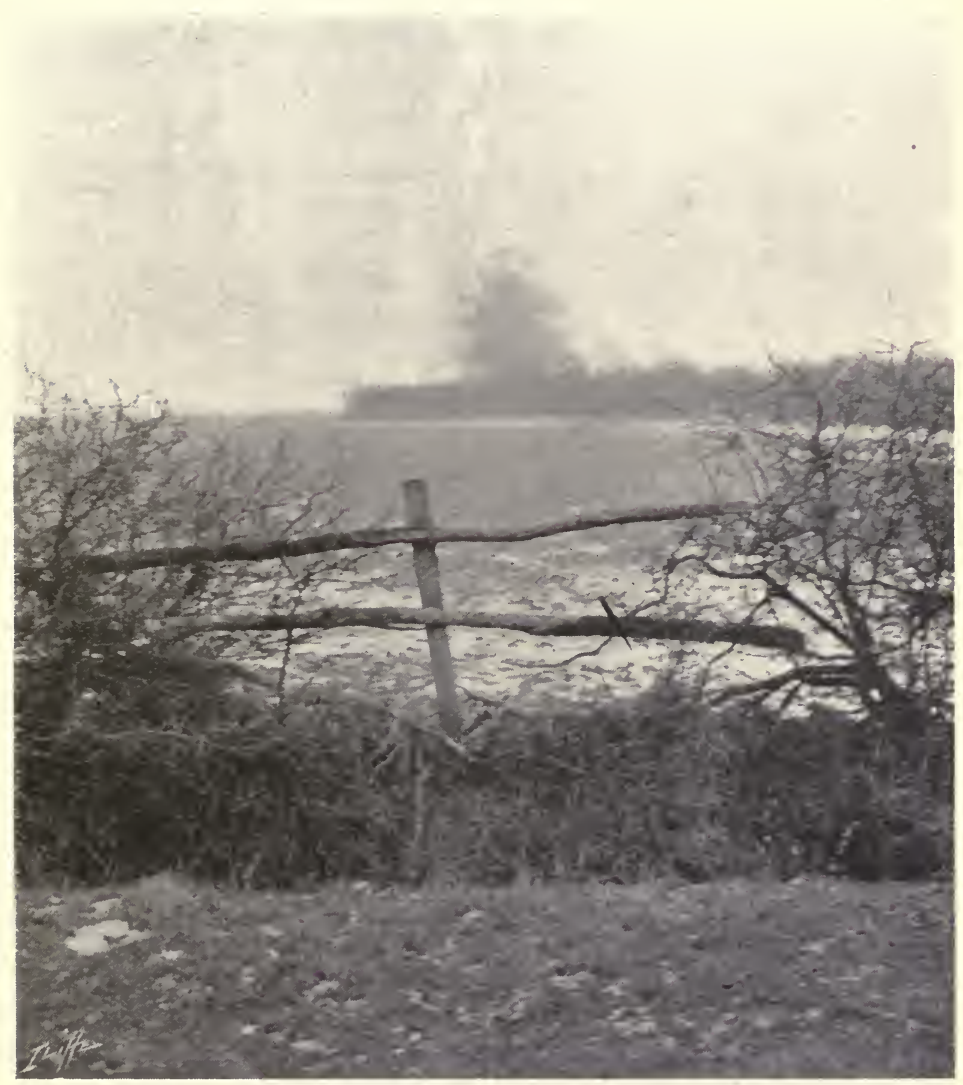

Fig. I09.- Post and rails to close gap in hedge. 

FENCES, COUNTRY AND GATES.

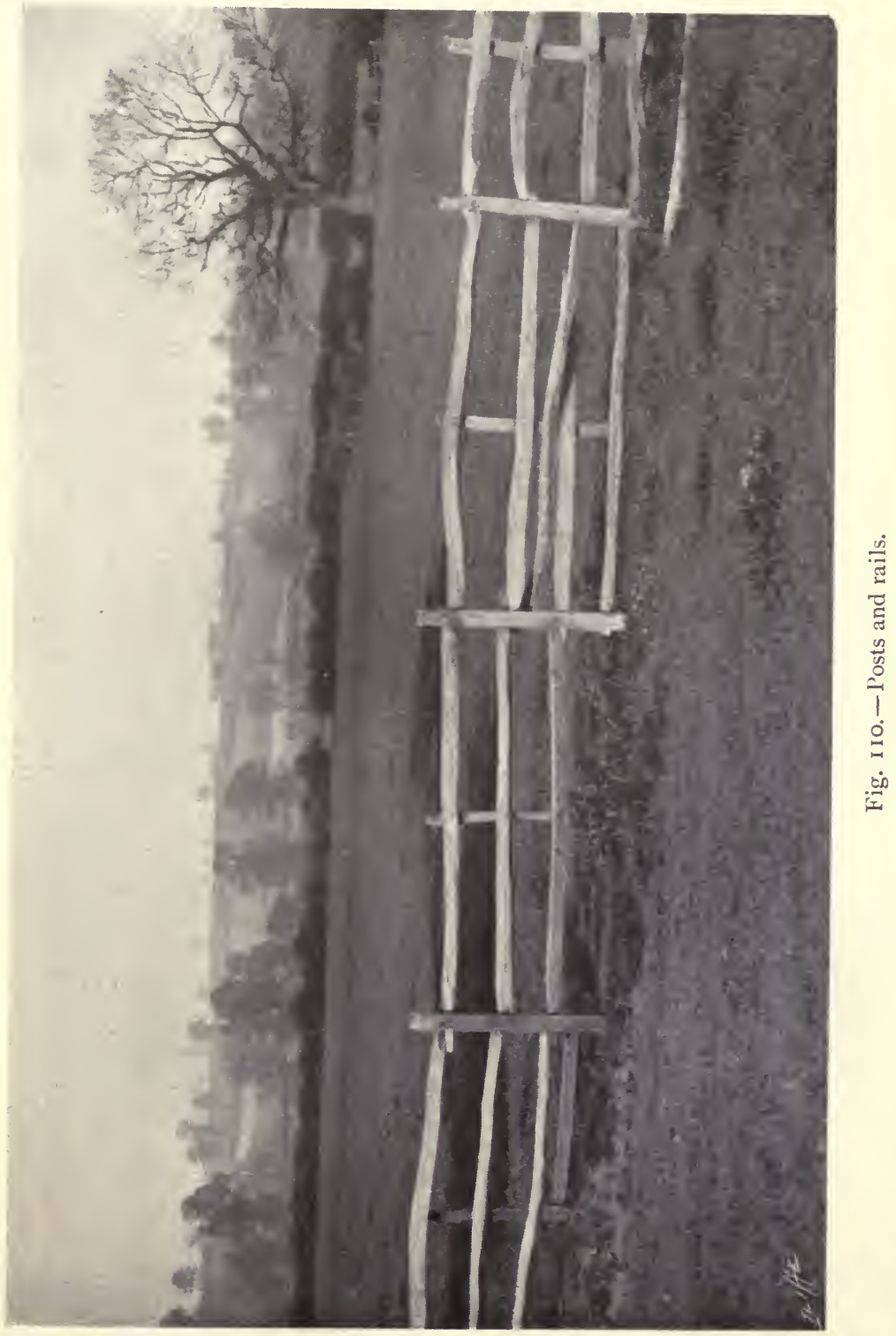



FENCES, COUNTRY AND GATES.

$26 I$

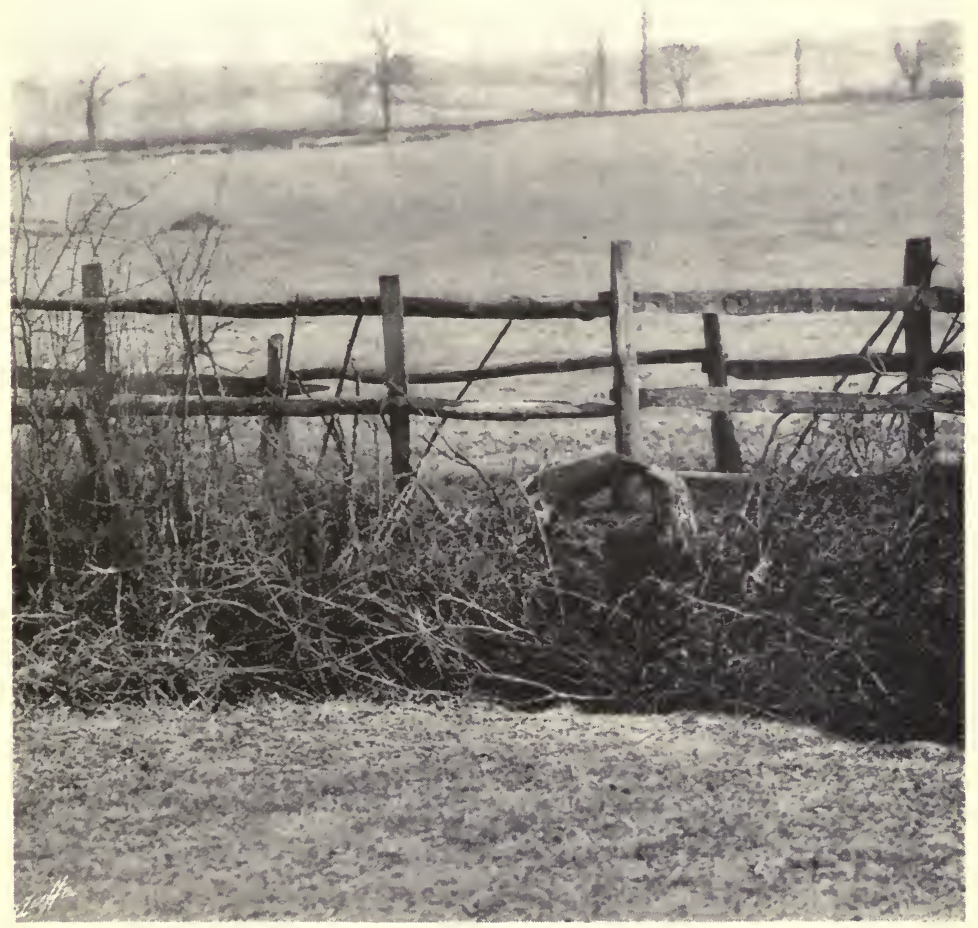

Fig. I I I. - Posts and rails with ditch. 



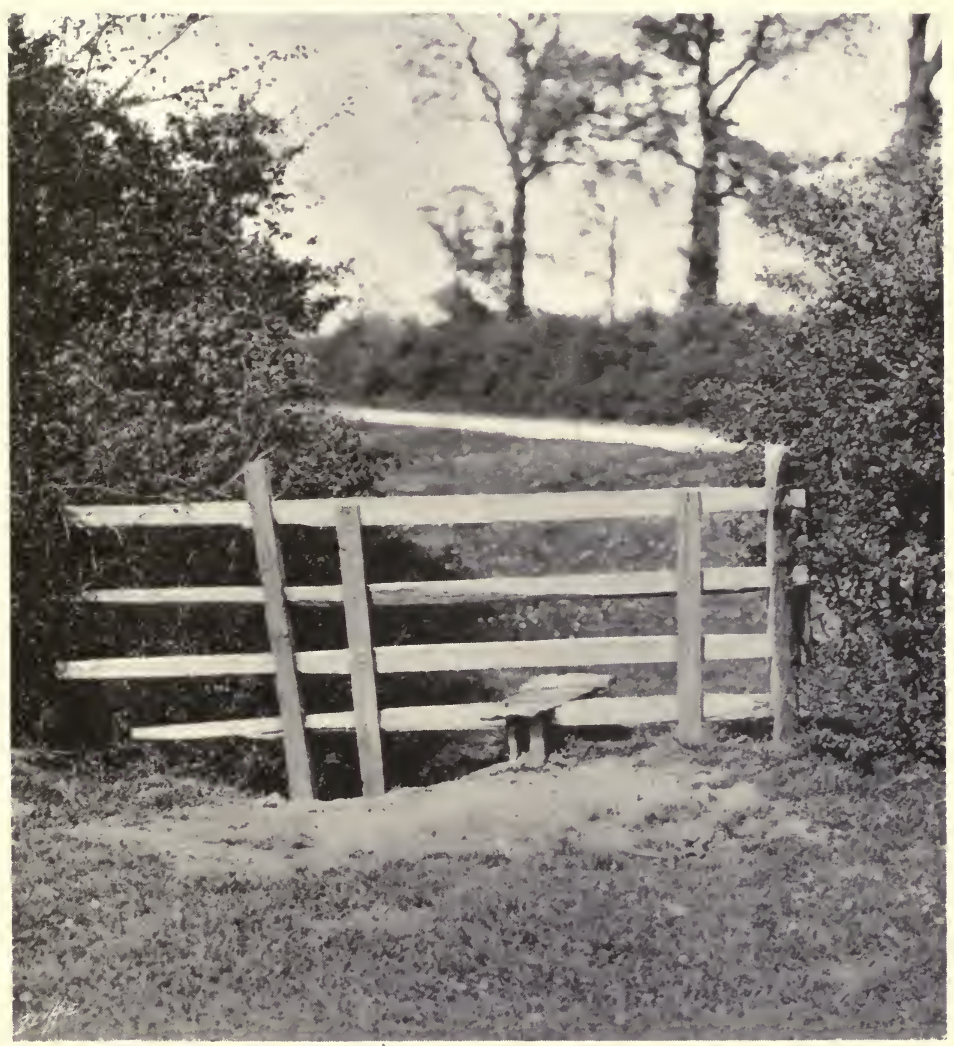

Fig. I I2. - Midland stile. 

FENCES, COUNTRY AND GATES. 265

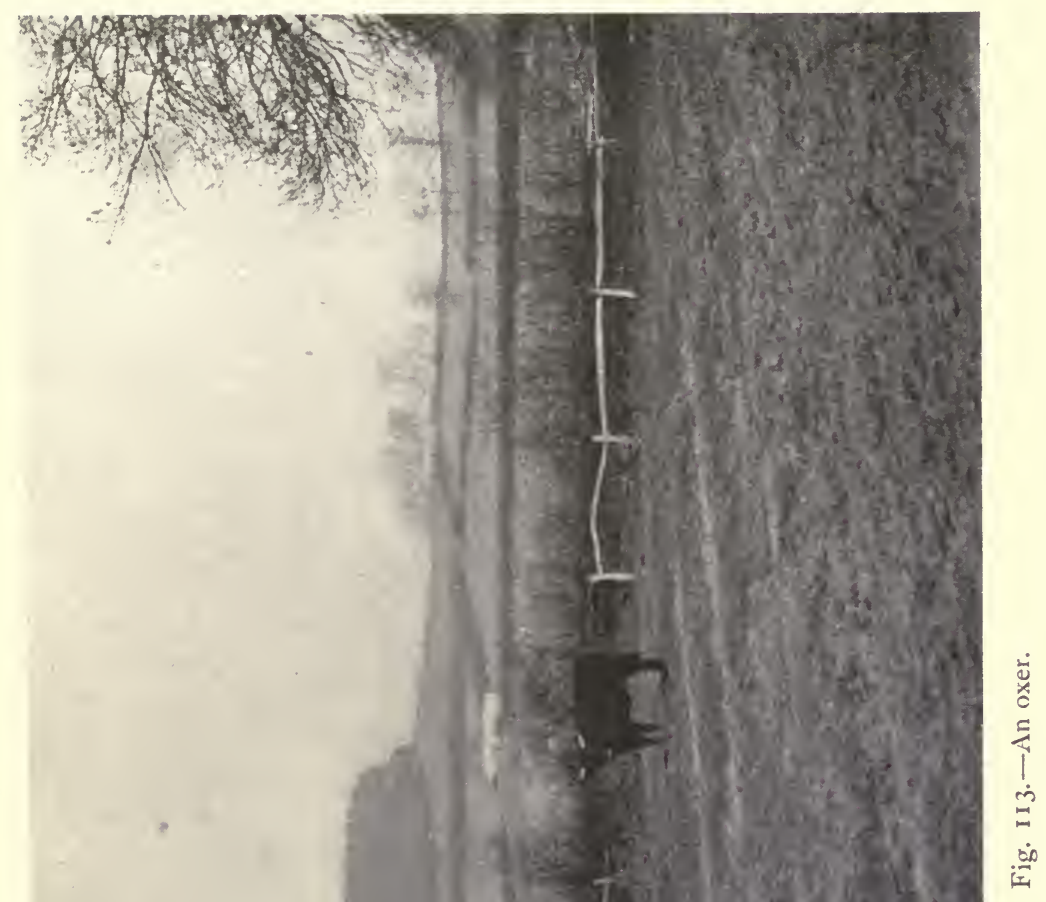





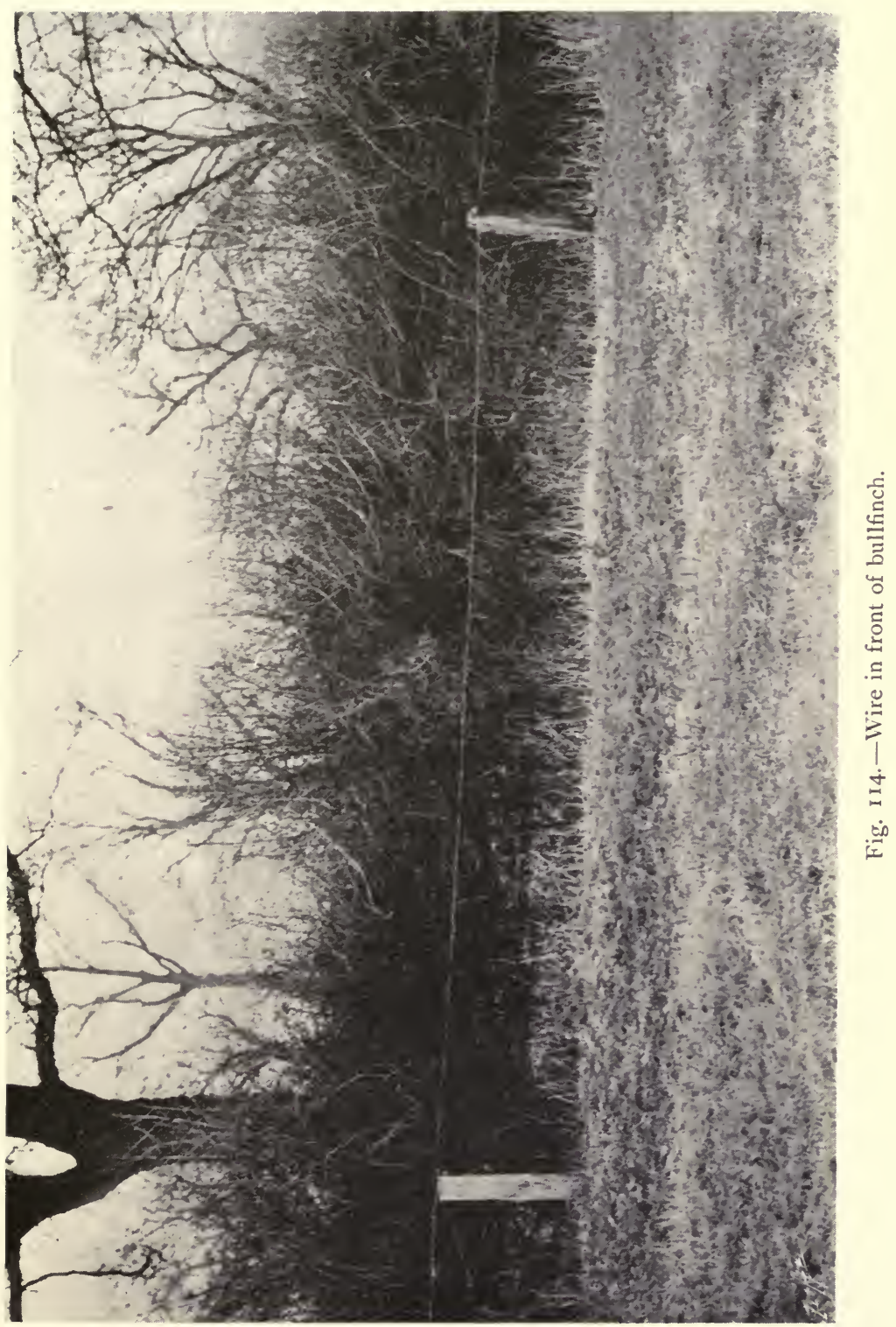



speed is a much more valuable attribute of a hunter than cleverness in jumping, because the main object of the rider will then be, as a rule, to get over fields and through gates with a minimum of "lepping." Some of our Colonial sisters might taunt us for not trying to leap wire in the brave manner done by Miss Harding (Fig. IO2) and other New Zealand and Australian horsewomen, but their conditions of country are entirely different from ours. In the Shires, for instance, wire, as a great rule, is visible only from one side of the fence which it contaminates, and often takes the form of a concealed trap. Hence it is carefully avoided both by horses at grass and by riders.

My husband tells me that banks, stone walls and "stone gaps" are the chief fences in Ireland; that hedges are seldom encountered, except in the form of furze on the top of banks; and that he has rarely seen posts and rails in his native land. While enjoying a very pleasant visit last winter with Mr. Arthur Pollok, the Master of the East Galway Hounds, he took the photographs of Figs. I I 5 to I 20 . Fig. I I 5 shows a broad bank about 4 feet high, with a deep ditch on each side, and a tall man standing on the top of it, so as to give an idea of its dimensions. Fig. i i6 is a side view of Fig. I I5. In Fig. I I 7, Mr. Pollok, who is also tall, is standing beside a higher and more upright bank which has the usual accompaniment of broad ditches. In Fig. I 8 , the very popular Master of the East Galway is close to a typical Galway stone wall of the "cope and dash" order and close on 5 feet 
in height. This formidable obstacle derives its name from the fact that the stones on its top are firmly cemented together by a dash of mortar. The Masters, hunting men, hunting ladies, and horses of the East Galway and Blazers think nothing of "throwing a lep" over a cope and dash of this kind. Ordinary second flighters in the Shires would probably prefer the Galway "loose stone wall" depicted in Fig. I I 9 or the small bank shown in Fig. I 20. He also tells me that although there is wire in East Galway, it is used only for fencing-in large spaces of ground, and as it stands out alone by itself, it is no source of danger to horse or rider. My husband returned to Crick delighted with the people in County Galway, especially because, when he went out hunting, almost everyone of the small field, both ladies and men, seeing that he was a stranger, were glad to meet him, and went up and spoke to him in a very friendly manner. Over there, hunting is evidently a sport, and not a social function.

Fig. I 2 I, which was very kindly taken from the top of Yelvertoft Church for this book by the Rector of that nice parish, gives a good idea of the country over which we hunt in Northamptonshire. In that county, the grass fields are smaller and the country more wooded than in Leicestershire, which has the inestimable advantage of possessing so many bridle paths, that people who hunt in it have very little road tramping to do. Even that trying infliction is mitigated to some extent in most parts of the Shires, by the presence of grass on the sides of country roads, as in Fig. I 22. 
FENCES, COUNTRY AND GATES.

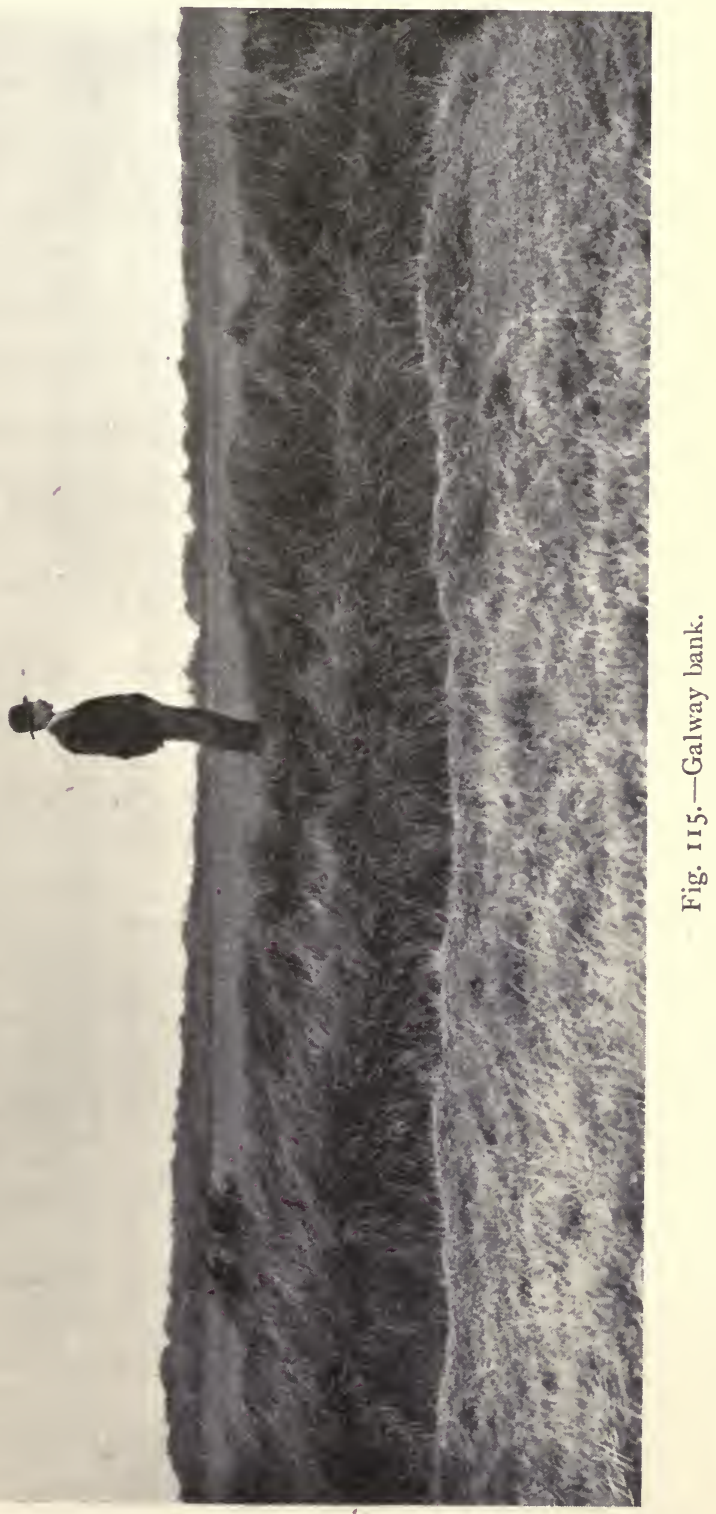



FENCES, COUNTRY AND GATES.

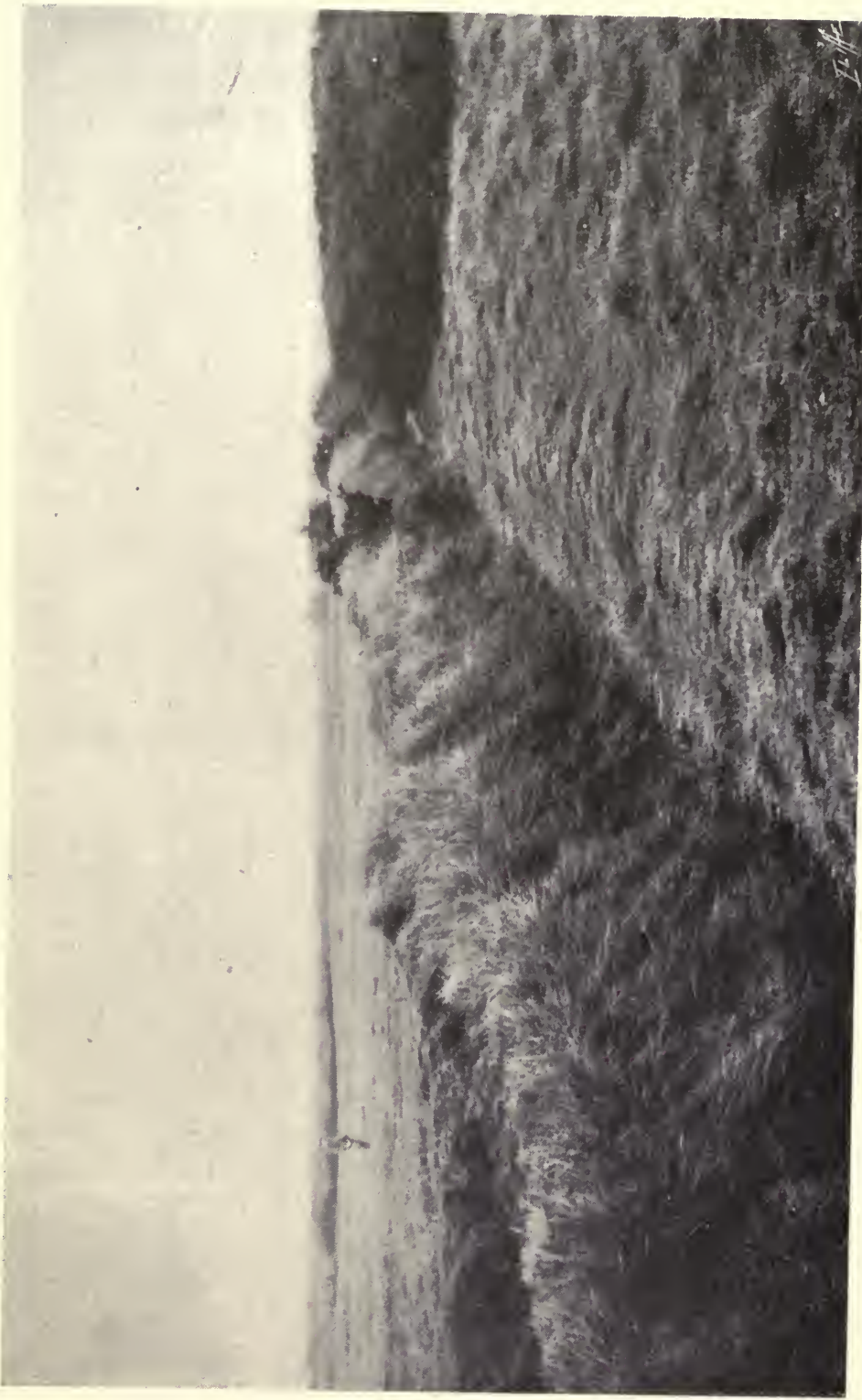

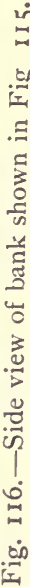





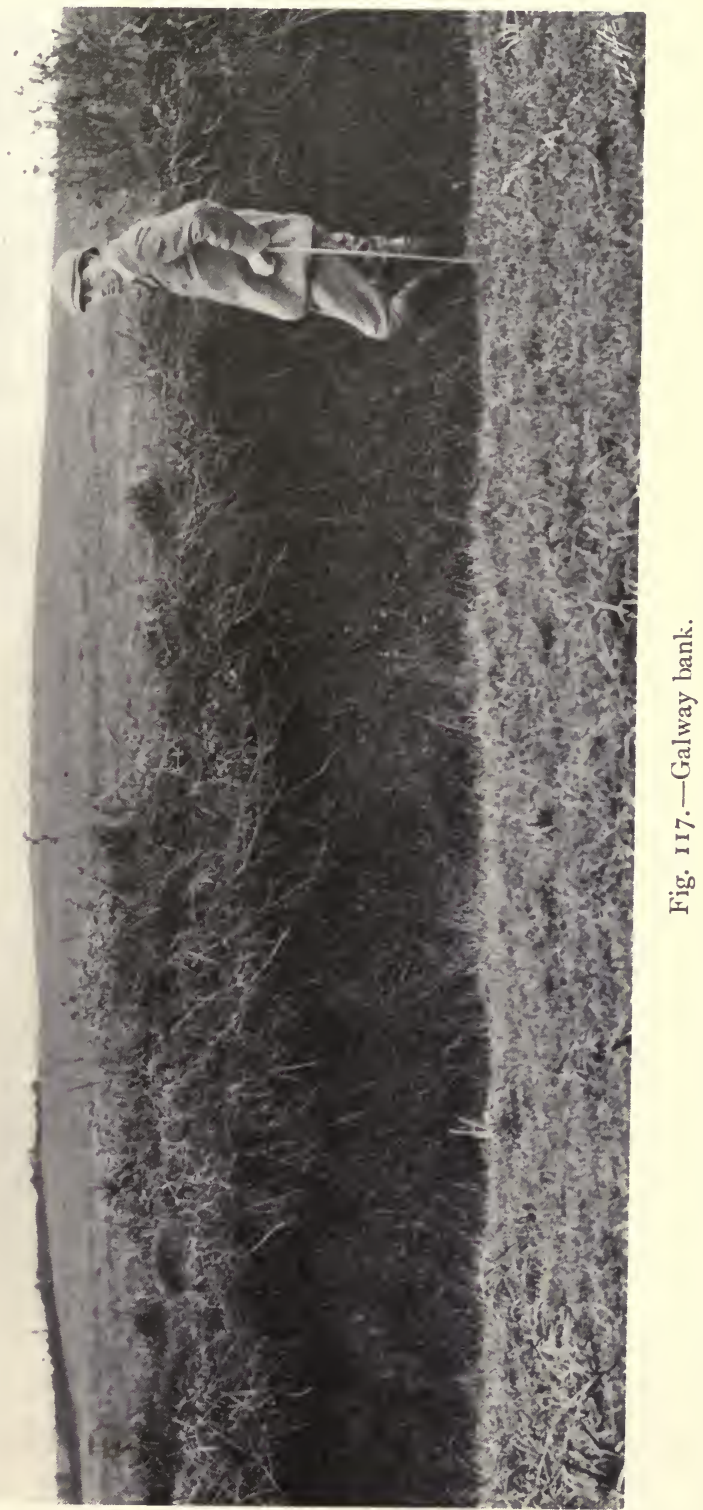



FENCES, COUNTRY AND GATES.

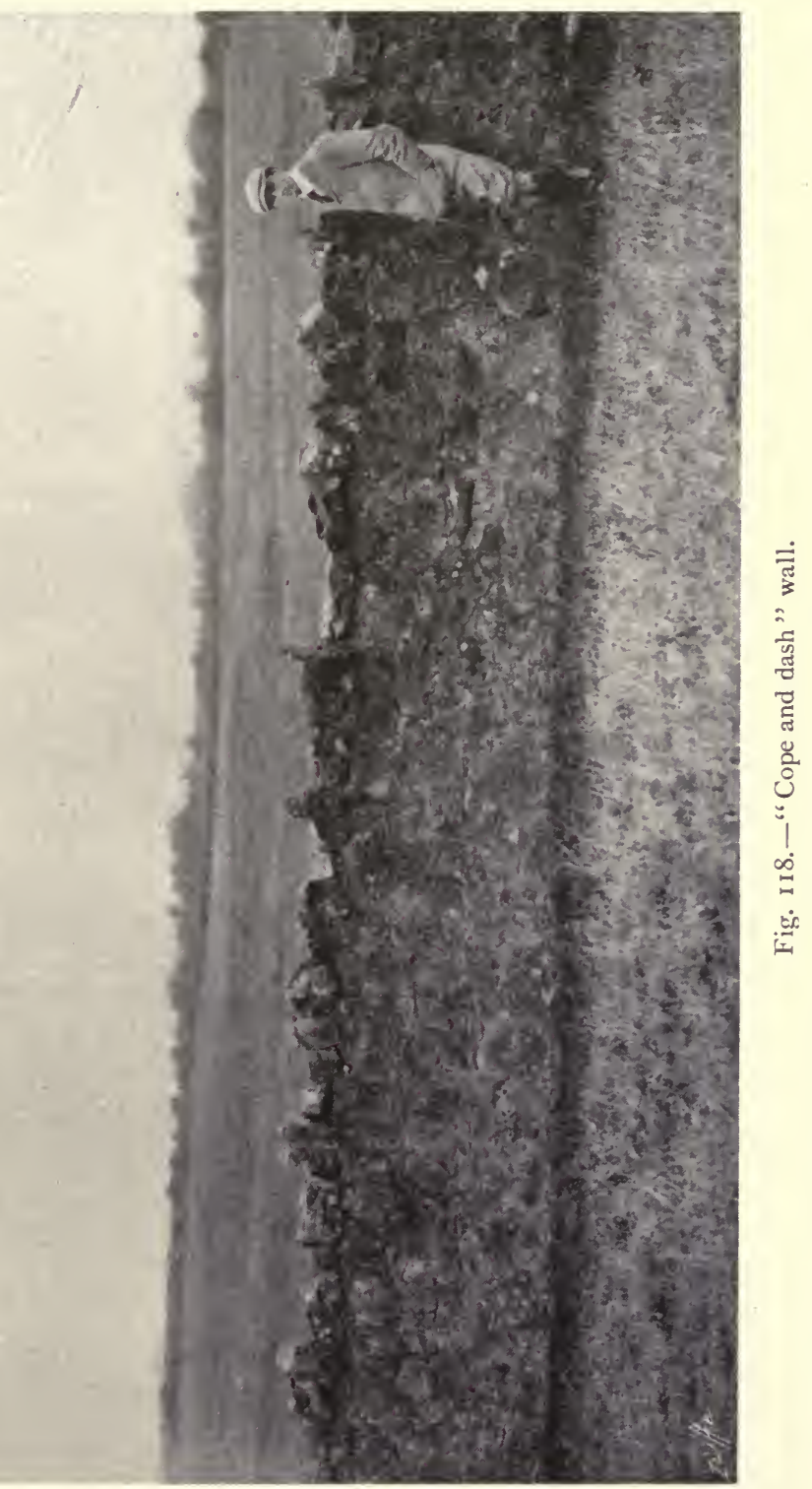



FENCES, COUNTRY AND GATES.

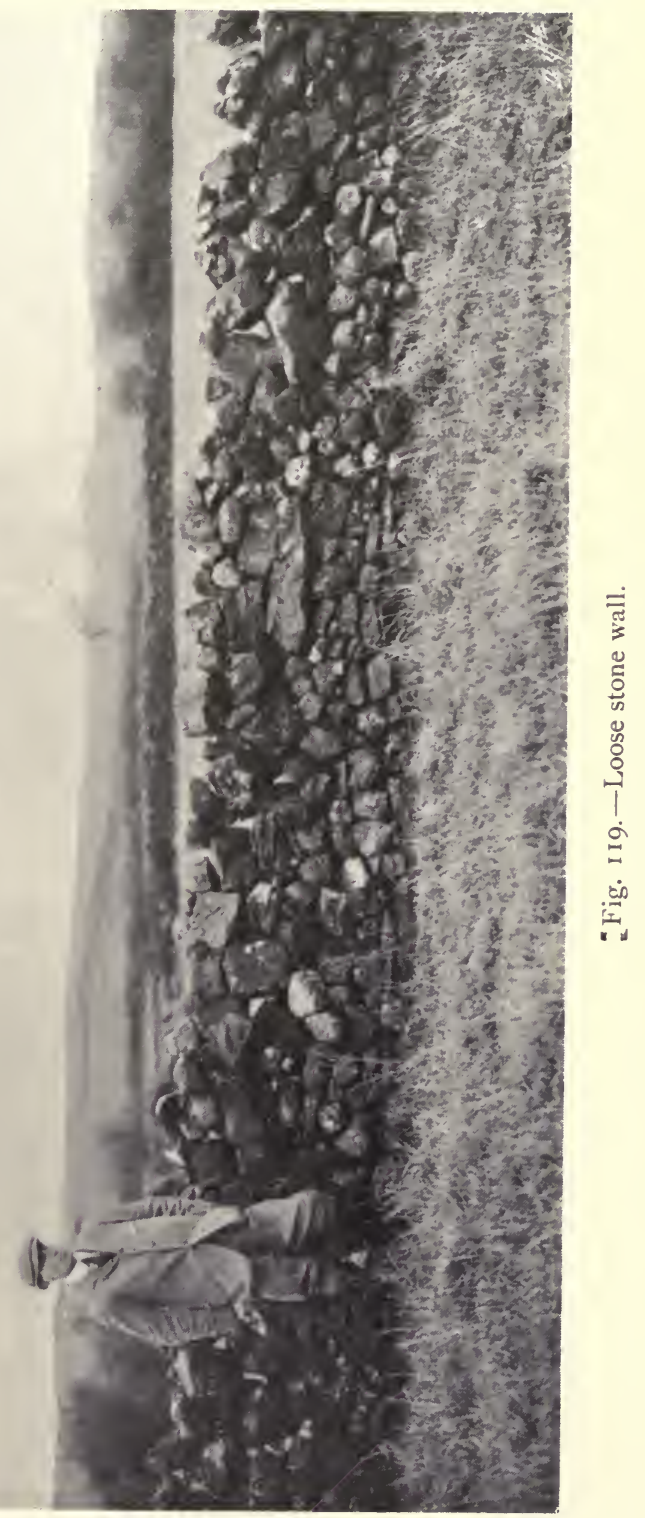



FENCES, COUNTRY AND GATES.

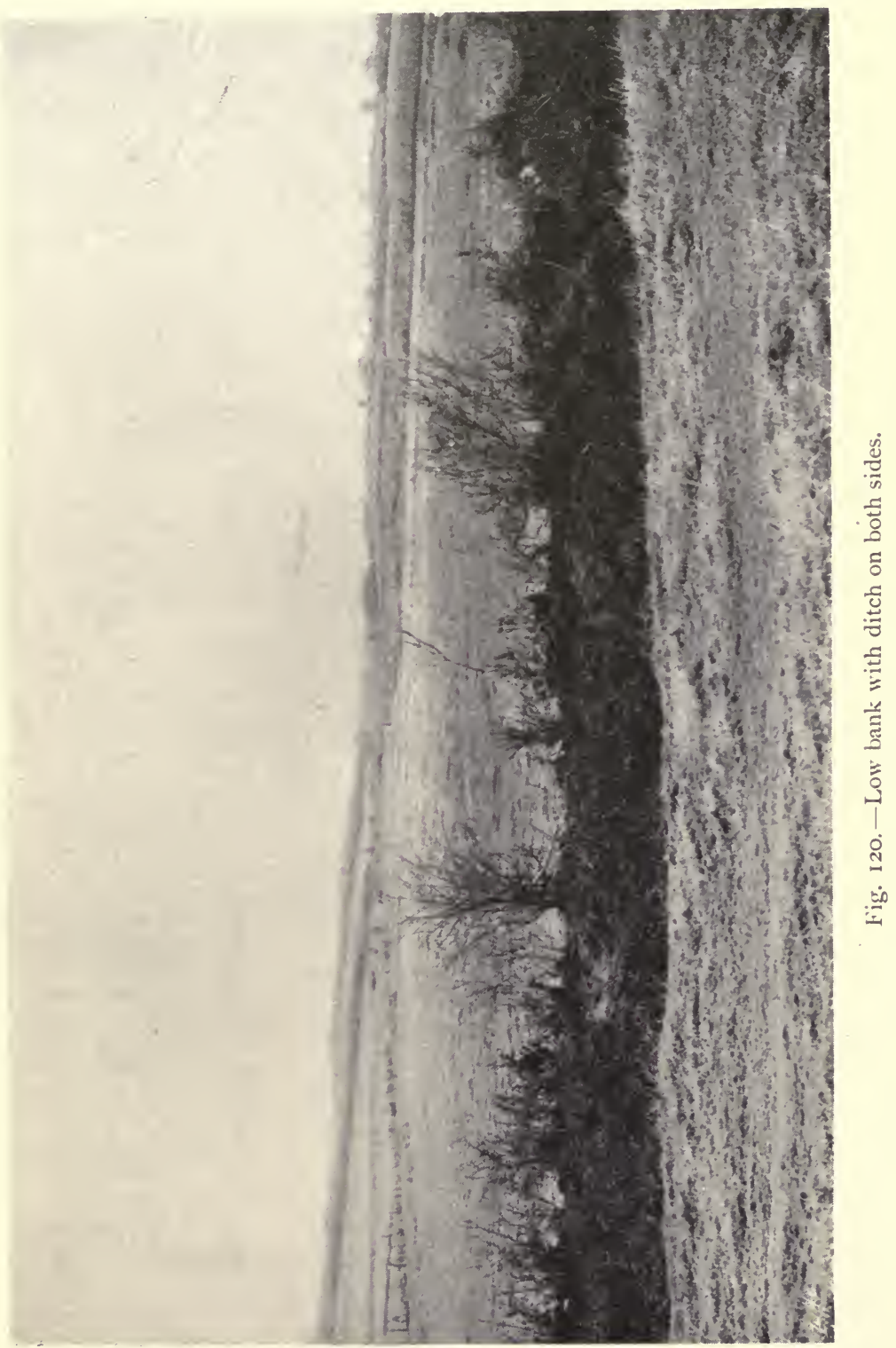



FENCES, COUNTRY AND GATES.

283

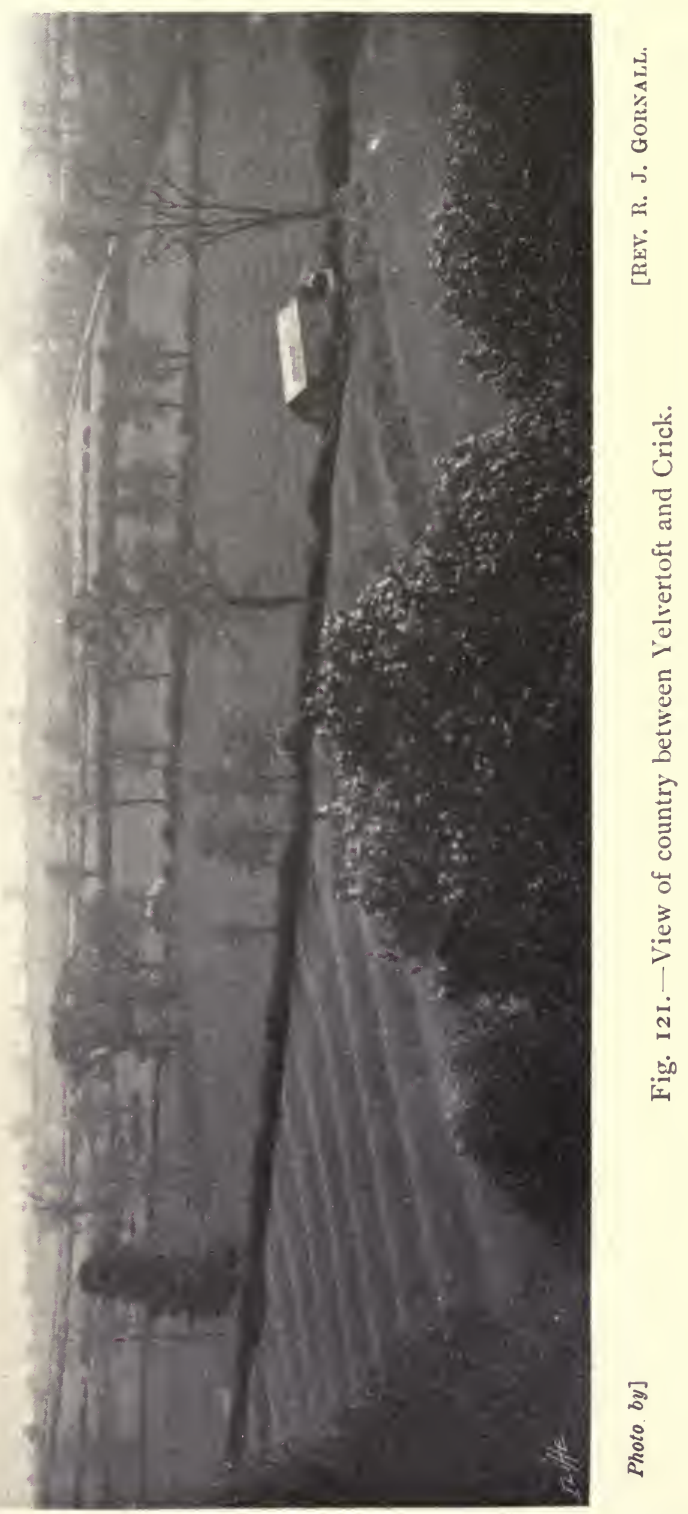



FENCES, COUNTRY AND GATES.

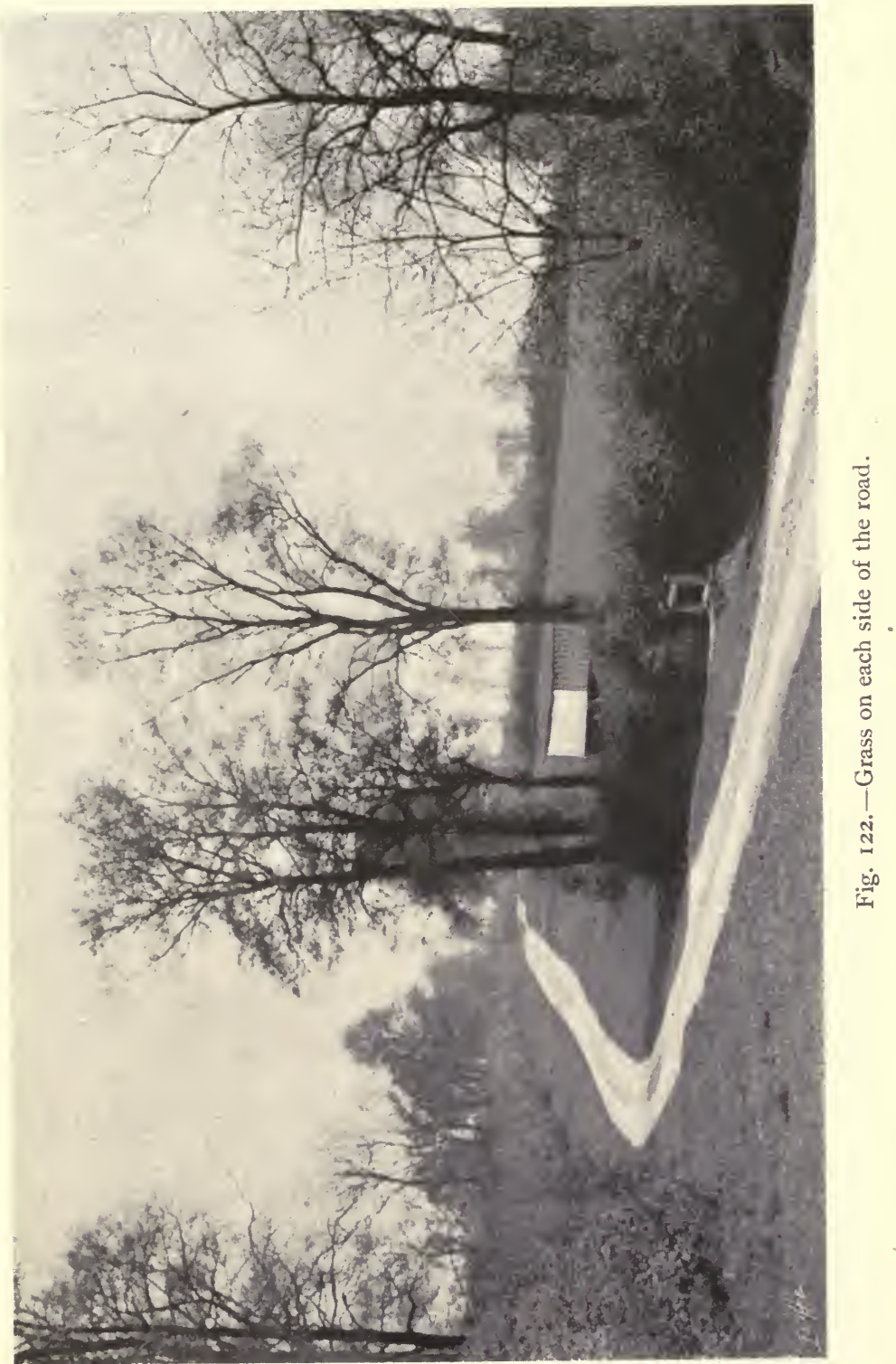



When hunting in England, gates are hardly ever jumped, for two very good reasons. First, because it would take a Manifesto or a Cloister to negotiate a series of them safely during a long run; and second, because the habit of leaping gates would be almost certain to unfit a horse for the task of steadily going through the various phases of opening and shutting these means of ingress and egress. Besides, gates are often in such positions, as regards taking off and landing, that it would be impossible to fly them safely, even if the way were clear of hunting companions, which is seldom the case in large fields. Every horsewoman should remember that nothing is more apt to spoil a horse than allowing a brace of alternative ideas to occupy his mind at the same time. Hence, when a hunter sees a gate during a run, his thoughts should be solely occupied in doing his best to aid his rider to open, get through and shut it, or hold it open, if necessary.

Gates, as a rule, may be divided into five-barred gates (Fig. I 23) and bridle gates (Fig. I 24). Variety in gates is chiefly limited to their form of fastening, which is generally on the left-hand side of the rider when the gate opens towards her (Figs. I 25, I 26 and 127); and on her right-hand side, when it opens away from her (Fig. I 29). In Fig. I 25, we see the old-fashioned wooden latch. In Fig. I26, the spring latch has to be pulled towards the hinges of the gate; and in Fig. 127, away from them. In the double gate shown in Fig. I28, the upper fastening consists of a 
moveable $\mathrm{D}$; the lower one being a very common supplementary latch, which in Fig. I 29, is cunningly secured by a curved piece of iron that renders the gate impossible to be opened, except by a person on foot. Another form of craft that we sometimes encounter, is an arrangement by which the gate hangs so heavily on its latch, that the would-be passer-through has to lift up the gate before he or she can open it, and often at an expenditure of strength of which many women are incapable. To perform this feat, a rider would of course have to dismount, which would be very awkward, if a lady was by herself. I have met gates of this annoying description on bridle paths on which the public have a right-of-way.

A gate is opened either with the hand or hunting crop, the former being more efficient than the latter, if the latch is within reach, which would seldom be the case if the rider was on a tall horse. When the fence at the side of the fastening of a gate is low enough to allow the rider to place her horse's head over it, she usually can, by doing so, open the fastening by whip or hand, draw the gate back or push it forward, as the case may be, and pass through. If the hedge at the side of the fastening is too high for this to be done, she will have to place herself alongside the gate, with the horse's tail towards the hinges, and then open the latch, by means of the hand (with or without a whip) which is next to the latch. If the gate opens away from her, she may have to push it forward by hand or crop, unless she is on a well instructed animal, who will 


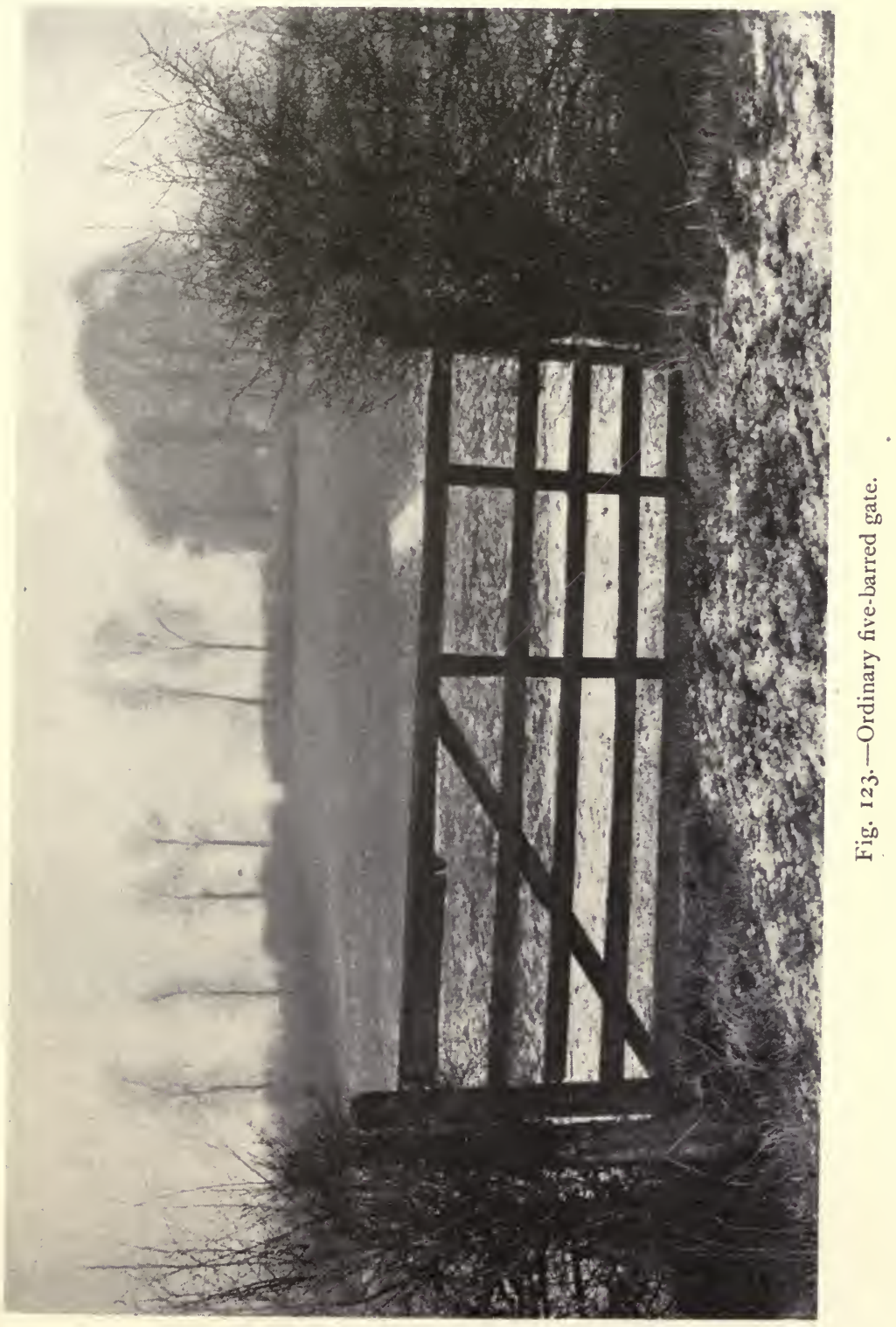





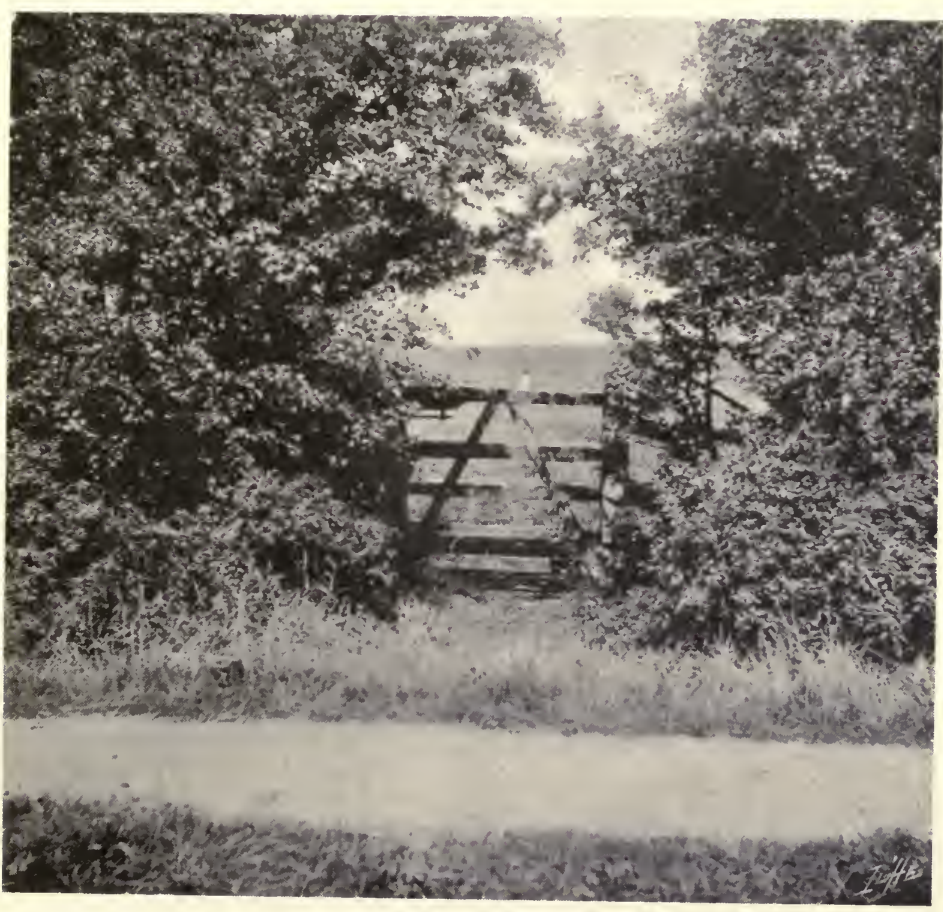

Fig. 124.-Bridle gate. 

FENCES, COUNTRY AND GATES.

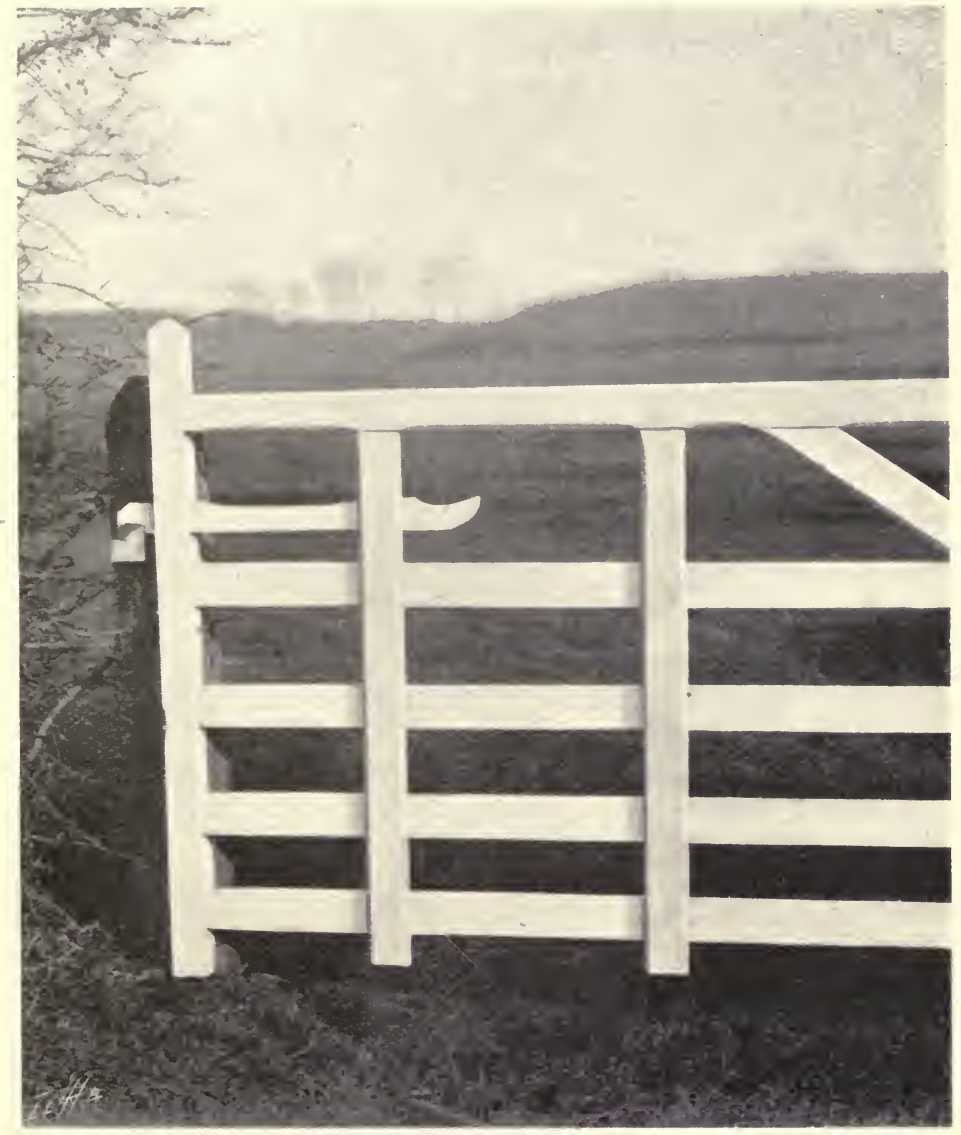

Fig. 125.-Gate with wooden latch. 



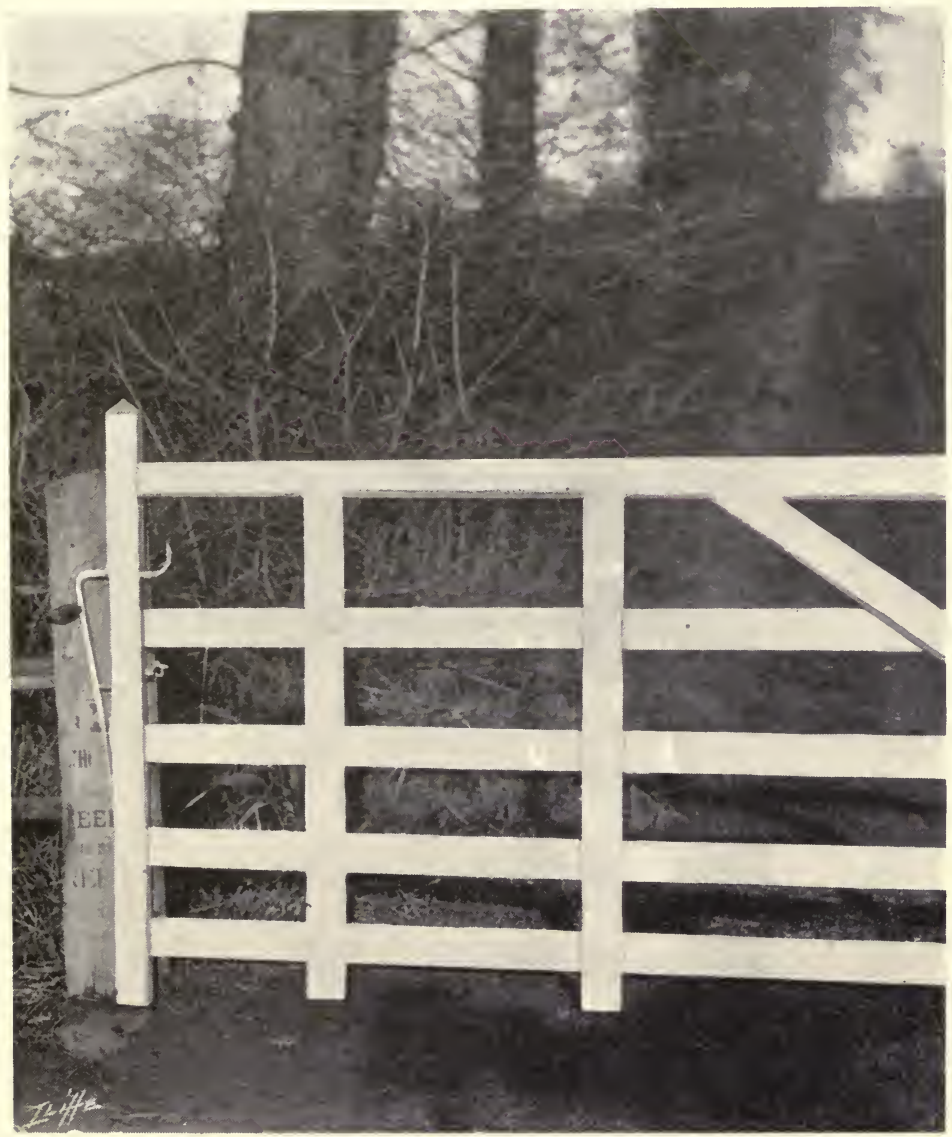

Fig. I 26. - Gate with spring latch which has to be drawn back. 



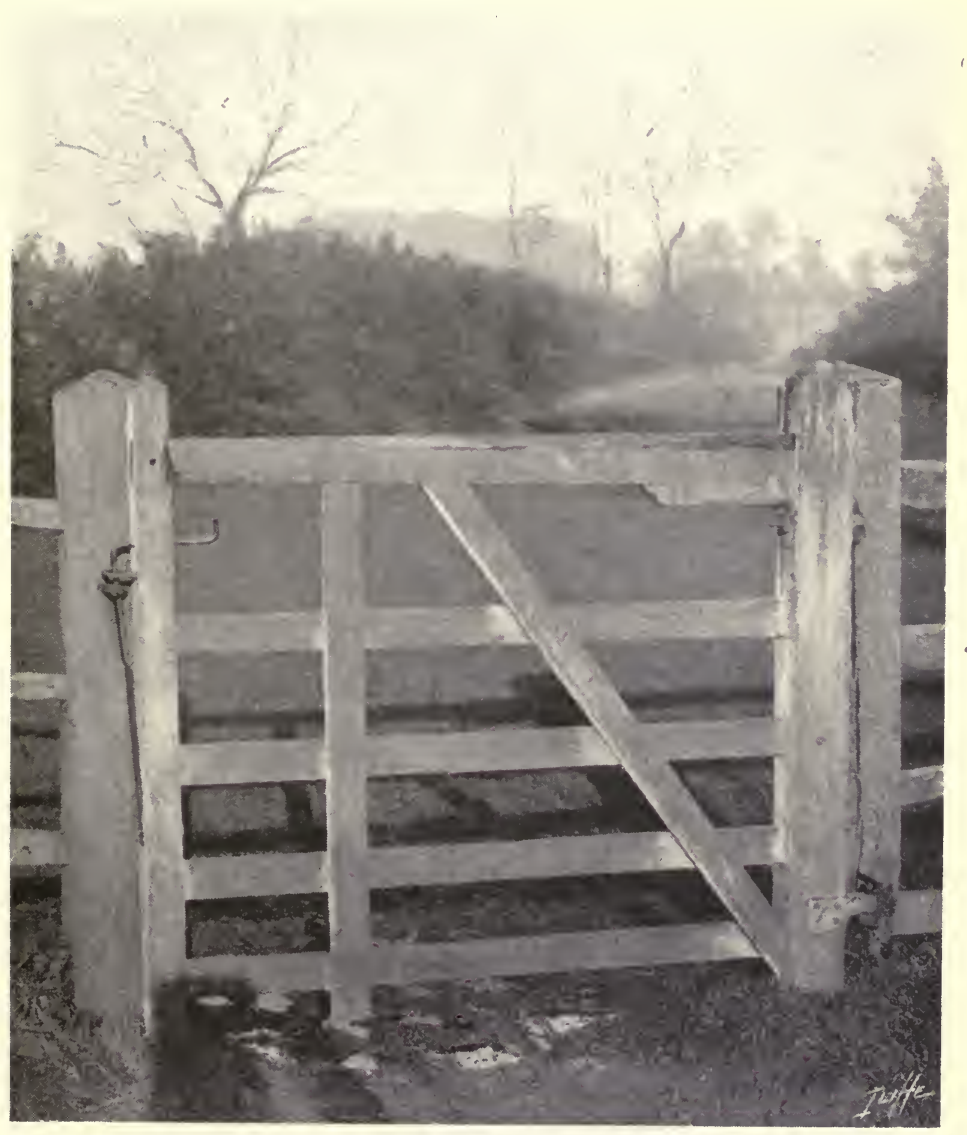

Fig. 127.-Gate with spring latch which has to be pushed forward. 



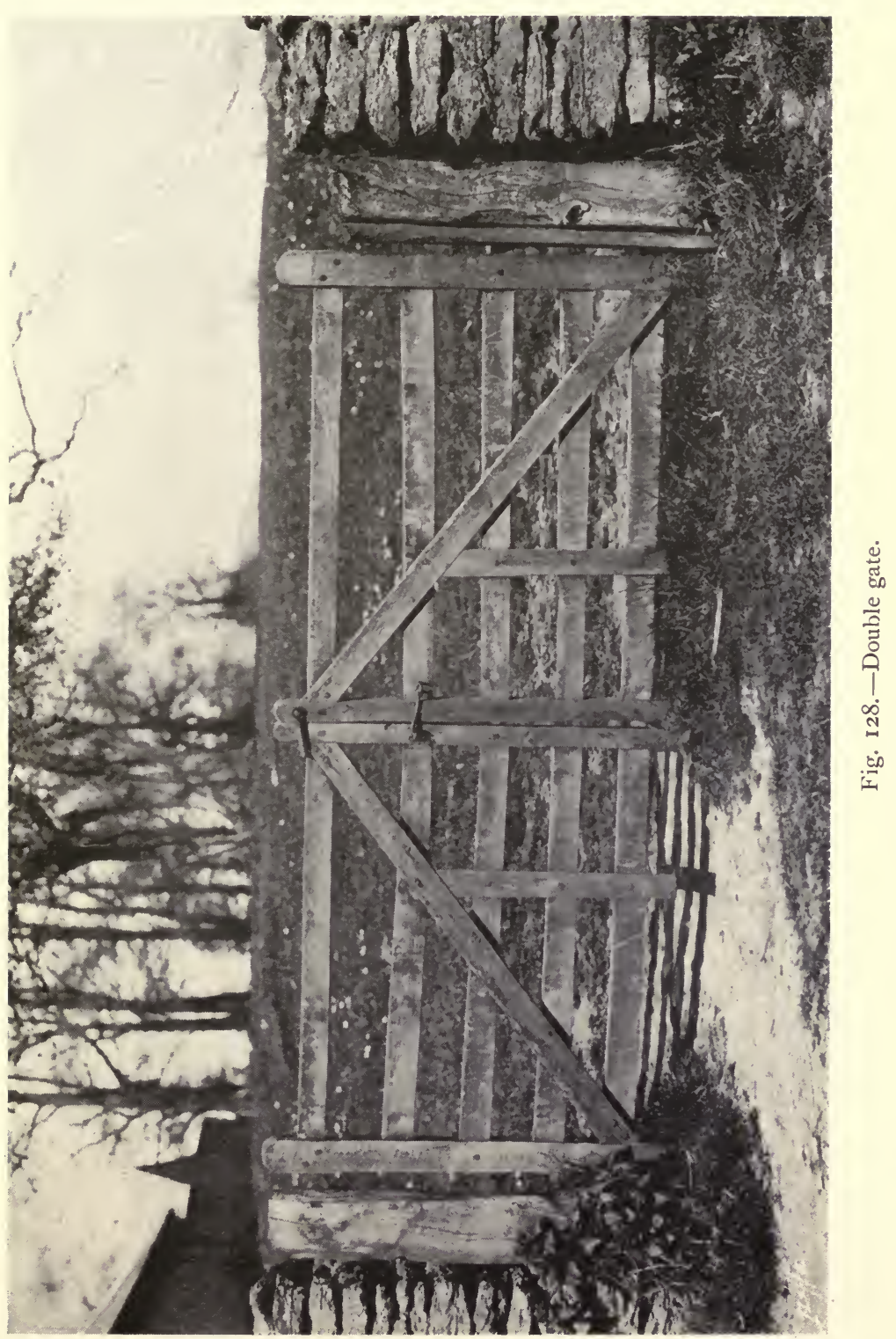



FENCES, COUNTRY AND GATES. 3OI

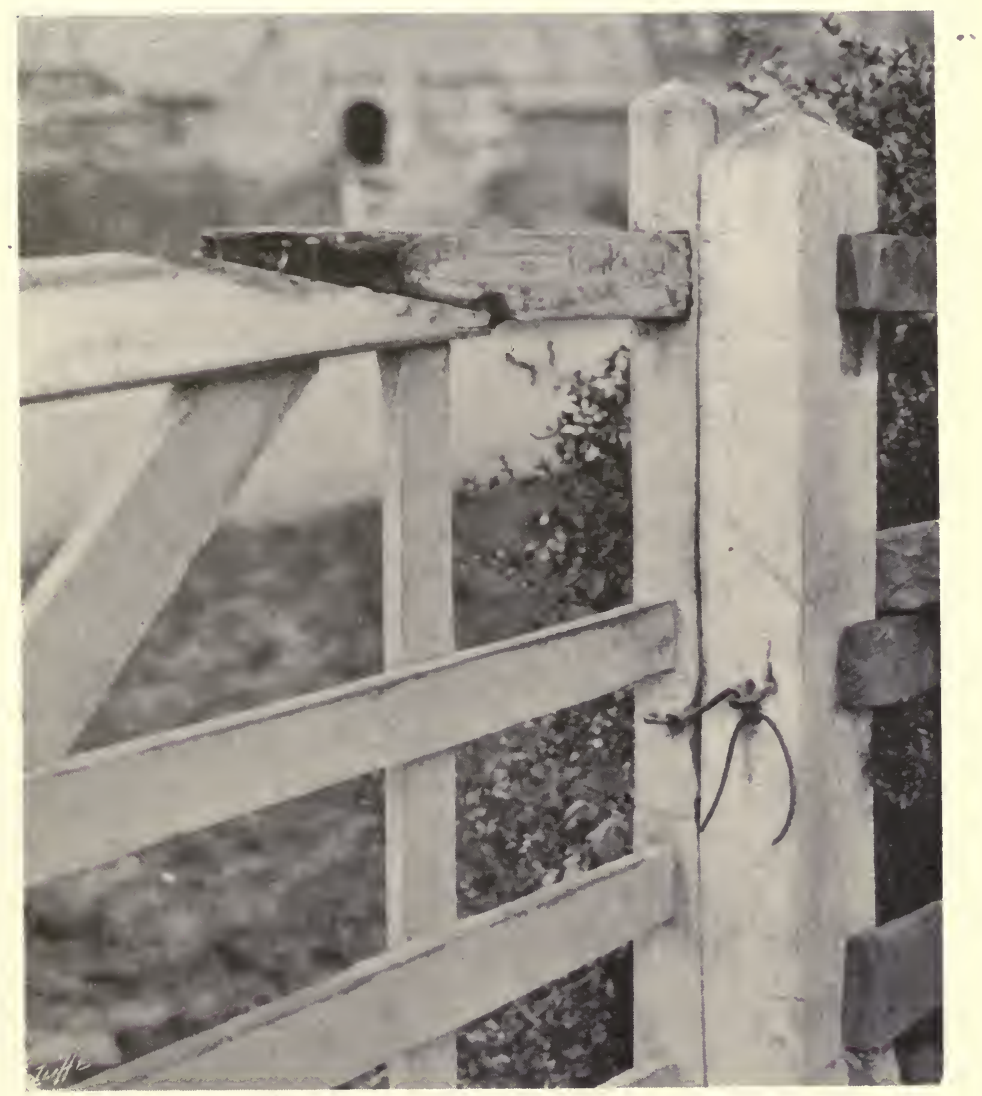

Fig. 129.-A puzzle in gate-opening. 

be always ready to save her this trouble, by pushing the gate open with his breast. If the gate opens towards her, the horse should be so trained, that when she has undone the latch, and has begun to draw the gate towards her, he will turn his hind quarters round (make a pirouette renversée, as the French call it), move his fore quarters a little to one side, so as to get them clear of the gate, and pass through, the moment he sees that his rider has opened the gate sufficiently for him to perform that final manœuvre. For instance, if a mounted lady wants to get through the gate shown in Fig. I 26, she should pull back the latch with her right hand (with or without a whip), and on drawing the gate towards her, the horse should bring his hind quarters round to the left; move his fore legs a little to the left ; and, if need be, rein back a step or two, so as to be in the proper position to move forward, as soon as he has plenty of room to do so. As a lady has not a leg on each side of her mount, to enable her to turn his hind quarters to whichever side she likes, she will have far more difficulty than a man in teaching a horse these very useful movements. At the same time, when a horse is anxious to get through a closed gateway, as he will generally be when his head is turned towards his stable, he will very quickly learn how to ably assist his rider in this process. 


\section{CHAPTER XVI.}

\section{HUNTING.}

When ladies began to hunt-Hunt subscriptions-In the field-Cub-huntingBlood-Coming home-Rider's Physical Condition-Tips and thanks-The Horn-Hirelings-Farmers and Wire-Pilots-Propriety-Falls.

\section{WHEN LADIES BEGAN TO HUNT.}

Although the hunting field is nowadays graced by the presence of many good horsewomen who ride well to hounds and are capable of taking care of themselves and their mounts, it is only within about the last seventy years that ladies have ridden across country. Mr. Elliott in his book Fifty years of Foxhunting tells us that in 1838 "Mrs. Lorraine Smith and her two daughters, with Miss Stone from Blisworth, were the only ladies who hunted then. The Misses Lorraine Smith rode in scarlet bodices and grey skirts. The improved side-saddle was not then invented to enable a lady to ride over fences." We learn from the same writer that in I84I "a lady named Miss Nellie Holmes was out, topping the fences like a bird to the admiration of all; and 
when she came to the brook, over she went. That was the first lady whom I saw go over a country. There is one certainty about ladies, what one does another will do, if it be worth the doing. Very soon others were at the game, and many have played it well since." In a pleasant little book entitled The Young Ladies' Equestrian Mamual, written by a lady and published in 18,38 , we read, "No lady of taste ever gallops on the road. Into this pace the lady's horse is never urged, or permitted to break, except in the field; and not above one among a thousand of our fair readers, it may be surmised, is likely to be endowed with sufficient ambition and boldness, to attempt the following of hounds." The saddle given in a drawing in this book has no leaping head, but the writer mentions, as I have previously noted, that movable crutches were being introduced to enable a lady to ride on either side of her horse. The leaping head (p. 33), third crutch, or third pommel, as it was first called in England, came into use in this country in the forties, and with its aid ladies felt themselves endowed with sufficient ambition and boldness to follow hounds. Captain Elmhirst, writing in 1877 , says: "It will, I think, be admitted by everyone that the number of ladies who hunt now is at least tenfold as compared with a dozen years ago," and every year since that was written, has seen a steady increase in the ranks of hunting women. 
HUNT SUBSCRIPTIONS.

Perhaps it may not be out of place to say something about what a lady should do if she desires to join a hunt and has no menkind to arrange such business matters for her. Every woman who hunts should (and usually does, I believe,) contribute her share of payment towards the sport in which she participates. If a lady is well off, and intends to hunt regularly, she would probably not give less than $£ 25$; but the Quorn and some other fashionable hunts lay down no hard and fast rule concerning the amount to be subscribed, which varies according to individual circumstances. The minimum subscription to the Pytchley is $£ 25$ for a man and $£$ Io for a lady. Lord North, who is Chairman of the Committee of the Warwickshire Hunt, states (The Field, 2oth December, 1902), in a very generous manner, that "fox-hunting must never be allowed to become the sport of the rich alone. It is a national sport, and must be open to all-to rich and poor alike." There is, however, a recognised sum which qualifies the donor for hunt membership; for instance: the Craven minimum subscription, with membership, is £ro; the Crawley and Horsham, I 5 guineas; while subscribers of $£ 25$ to the Meynell hunt are privileged to wear the hunt button. In several hunts-Lord Fitzwilliam's, Mr. Bathurst's, the Belvoir, when hunted by the Duke of Rutland, and others - the Master hunts the country at his own 
expense, subscriptions being accepted only for Covert, Wire, Poultry, or Damage Funds, as the case may be. The Vale of White Horse (Cirencester) requires a subscription from ladies of " $£_{5}$ per day, per week." Strangers who hunt occasionally with a subscription pack where capping is not practised, are expected to contribute towards the Poultry or Damage Fund. In some hunts a cap is taken from non-subscribers, from whom a certain fixed sum is expected; the Essex and Suffolk requires five shillings a day, the Burstow a sovereign, and the Pytchley and Warwickshire two pounds. The usual "field money" in Ireland is half-a-crown. The Blackmore Vale, although a subscription pack, does not fix any sum, but sensibly expects people to subscribe according to the number of horses they keep, and the amount of hunting they do. An old and sound rule is $£_{5}$ for each horse: As subscriptions vary in different hunts, the best plan for a lady who has to arrange her own business matters, is to write to the secretary of the hunt which she desires to join, and obtain from him the required information. She will find Bailey's Hunting Directory a most useful book of reference.

\section{IN THE FIELD.}

Under this heading, I shall try to give practical advice to those who are commencing their hunting career, and explain several things that I would have liked to have known myself when I first rode to hounds. As we may learn something from the failings of others 
before entering the expensive school of experience, it would be wise, before we hunt, to study certain complaints which experienced hunting men have published anent our sisters in the field. Mr. Otho Paget says : "I am not one of those who think that women are in the way out hunting, and in my experience I have always considered they do much less harm than the men, but the time when they do $\sin$ is at a check. They not only talk themselves, but they encourage men to talk as well, and I have repeatedly seen a woman lead a whole field over ground where the pack intended to cast themselves. The woman, instead of attending to what hounds are doing, enters into a conversation with a man and together they talk on without paying heed to the damage they may do. My dear sisters, forgive me for calling you to order, but if you would only keep silent when hounds are at fault, and stand quite still, you perhaps might shame your admirers into better behaviour, and thereby be the means of furthering the interests of sport." This rebuke means that when a gallop is suddenly stopped by hounds losing the scent of their fox and being obliged to puzzle out the line, the ladies of the hunt should remain silent, should pull up and not impede the huntsman who will do his best to aid his hounds in recovering the lost scent. Mr. Paget's remark about the lady who led the field over ground where the pack intended to cast themselves, means that the hounds were trying to recover the lost scent without the assistance of the huntsman, but their 
efforts had been spoiled by the people who rode over the ground and thus foiled the line. It is o'svious that to spoil the sport of others in this negligent manner is to cover ourselves with humiliation, and other unbecoming wraps.

It must be remembered that hunting, unlike other forms of sport, has no written rules of its own for the guidance of the uninitiated. Every indulgence should therefore be shown to the hunting tyro who innocently commits errors; for in nine cases out of ten it is probable she does so, from ignorance of the unwritten laws which govern the conduct of the experienced hunting man and woman. On this subject Mr. Otho Paget writes: "The lady novice comes in for her share of blame, and though she may not get sworn at, black looks will soon explain the situation. For her I would also crave indulgence, and if she becomes a regular offender, you can ask her male friends to tell her in what way she is doing wrong. In whatever way we may treat them, there is no excuse for the novice, male or female, embarking on a hunting career, without having ascertained the customs and observances which are considered necessary by those who have had considerable experience.

Anyone who comes out hunting without knowing the rules of the game, is a constant source of danger to those who are near." This is all very true of course; but the aspiring Diana may well ask "what are these said rules, and where can I obtain them?" I feel sure that all hunting novices would 
greatly appreciate and study an orthodox code of hunting laws, as it would be far pleasanter for a lady to avoid mistakes by their guidance, than to have " her male friends to tell her in what way she is doing wrong," possibly after she has received "black looks" from the whole of the field. Hunting is a science which has to be learnt, and every game of science should have its published code of regulations, or it cannot be played without grave blunders by those who have to pick it up at haphazard.

In justice to my sex it must be allowed that they do not holloa on viewing a fox, a fault that is often committed by men, especially in the Provinces. Colonel Alderson quoting from an old pamphlet on hunting which was reprinted in 1880 by Messrs. William Pollard and Co., Exeter, says: "Gentlemen, keep your mouths shut and your ears open. The fox has broken cover, you see him-gentlemen, gentlemen, do not roar out 'Tally-ho'! do not screech horribly. If you do, he will turn back, even under your horses' feet, in spite of the sad and disappointed look on your handsome or ugly faces. Do not crack your infernal whips, be silent."

Whyte Melville says: "I do not say you are never to open your mouth, but I think that if the inmates of our deaf and dumb asylums kept hounds, these would show sport above the average and would seldom go home without blood. Noise is by no means a necessary concomitant of the chase, and a hat held up, or a quiet whisper to the huntsman, is 
of more help to him than the loudest and clearest view holloa that ever wakened the dead, "from the lungs of John Peel in the morning.'

As this chapter is written with the desire to help the inexperienced huntress, she will, I feel sure, be grateful to the writers who have advised her what not to do, so we will study the next complaint which comes from that experienced sportsman Captain Elmhirst, who describes a hunting run better, I think, than any other writer on the subject. He says: "When ladies cast in their lot with the rougher sex, lay themselves out to share in all the dangers and discomforts incidental to the chase, and even compete for honours in the school of fox-hunting, they should in common fairness be prepared to accept their position on even terms, nor neglect to render in some degree mutual the assistance so freely at their command, and that men in a Leicestershire field so punctiliously afford to each other. The point on which they so prominently fail in this particular is, to speak plainly, their habitual, neglect-or incapacity -at gateways. Given the rush and crush of three hundred people starting for a run and pressing eagerly through a single way of exit-to wit, an ordinary gate swinging easily and lightly, and requiring only that each passer through should by a touch hinder its closing after him or her. Of these three hundred, in all probability thirty are ladies; and I commit myself to the statement that not more than five of that number will do their share towards preserving 
the passage for those who follow them. The bulk of them will vaguely wave what they, forsooth, term their hunting-whips towards the returning gate; while others merely give their mounts a kick in the ribs and gallop onwards, with no look behind at the mischief and mortification they have caused. The gate slams, the crowd press on to it, a precious minute or two is lost and scores of people are robbed of their chance in the forthcoming gallop. And yet these are our sisters whose arms and nerves are strong enough to steer an impetuous horse over a most difficult country and who turn away from nothing that we can dare to face. The intense annoyance entailed by a gate being dropped into its intricate fastenings through want of ability or of consideration on the part of the fair Amazon immediately preceding him, has brought into the mouth of many a chivalrous sportsman a muttered anathema of the feminine taste for hunting that scarce any other provocation would have availed to rouse. It is only quite of late that a certain number of ladies have supplied themselves with whips at all capable of supporting a gate; and not many of these can use them even now. I make bold to say that not only every lady who hunts should be armed with a sufficient hunting-crop (with of course a lash to guard against its loss in a gateway), but that no lady ought to deem herself qualified to take her place in the field until she has learned how to use it. Were such a rule adhered to, we should hear none of the sweeping 
remarks indulged in by sufferers who have over and over again writhed under disappointments, that if inflicted by our own sex, would have quickly called forth direct charges of inconsiderateness and want of courtesy.'

From this admonition the tyro may learn two things which will be of great service to her in hunting. First, the necessity of providing herself with a strong hunting crop, which should be sufficiently long and stiff to stop a gate easily, with a good handle to it capable of opening or stopping a gate, and the orthodox thong and lash attached to prevent the whip from falling on the ground if she loses her hold of it at a gateway. Provided with this serviceable crop, a lady, before she appears in the hunting field, should ride through as many different varieties of gates as she can find, and should thoroughly master the art of opening and shutting them herself, and of giving the necessary push with her crop as she passes through for the assistance of imaginary riders behind her. In Leicestershire there are so many bridle roads that a lady may obtain any amount of this practice when hacking. It would be well for her to ride the horses on which she intends to hunt, as she will be teaching them to go steadily through gates while she is perfecting herself in the art of opening and shutting them, and her hunters will also learn the important accomplishment of being able to push a gate when it opens from her. She should be careful to securely shut every gate through which she may pass, because farm stock are apt to stray through gates which 
are left open and cause great inconvenience to their owners. If a lady is the last to pass through a gate when hunting, she should always remember to shut it. Men are often far greater culprits than women at gates, apart from their holloaing propensities. Many men seem to regard the sport as provided for them alone, and look upon my sex as being in the hunting field on sufferance. Most of us have met the entirely selfish male who gallops up to a gate, rushes through it and lets it bang behind him, well knowing that a lady is making for the same means of exit, and is only a few lengths away.

Considering that women pay for their hunting and are not on the free list, it seems rather superfluous for men to assure them that they do not object to their presence in the hunting field, an announcement which appears in print so often that it sounds like protesting too much. We never hear of hunting women recording the fact that they do not object to the presence of men: even ladies who carry the horn themselves are free from prejudice in this respect. Hunting men, in assuring us of their distinguished toleration, almost appear to copy each other in their charming manner of expressing that fact. For instance, Whyte Melville says: "Far be it from me to assert that the field is no place for the fair ; on the contrary, I hold that their presence adds in every respect to its charms." Then why does he suggest such a thing? Captain Elmhirst assures us that he is "one of those who, far from cavilling selfishly 
at their presence, heartily admit the advantages direct and indirect in their participating in a pursuit in which we men are too often charged with allowing ourselves to be entirely absorbed." Mr. Otho Paget says : "I am not one of those who think that women are in the way out hunting, and in my experience I have always considered they do much less harm than the men." Nice, truthful man, and great favourite as he deserves to be. The celebrated Beckford appropriately gives as a frontispiece, in his Thoughts on Hunting, a portrait of Diana, the goddess of hunting, having her sandals girded on for the chase, and explains the picture by saying: "You will rally me perhaps on the choice of my frontispiece; but why should not hunting admit the patronage of a lady? The ancients, you know, invoked Diana at setting out on the chase, and sacrificed to her at their return; is not this enough to show the propriety of my choice?" How much nicer the ancients must have been than many moderns are! They often provoke poor Diana when setting out for the chase, and sacrifice her to their bad tempers on their return! According to Jorrocks, hunting men must be vainer than we are, for we do not wear pink. That great sportsman found that "two-thirds of the men wot come out and subscribe, wouldn't do so if they had to ride in black!"

Another admonition which should receive the serious attention of the hunting tyro comes from Whyte Mel. ville, who says: "Now I hope I am not going to express a sentiment that will offend their prejudices 
and cause young women to consider me an old one, but I do consider that in these days ladies who go out hunting ride a turn too hard. . . . Let the greatest care be taken in the selection of their horses ; let their saddles and bridles be fitted to such a nicety that sore backs and sore mouths are equally impossible, and let trustworthy servants be told off to attend them during the day. Then, with everything in their favour, over a fair country fairly fenced, why should they not ride on and take their pleasure?

"But even if their souls disdain to follow a regular pilot (and, I may observe, this office requires no little nerve, as they are pretty quick on a leader when he gets down), I would entreat them not to try 'cutting out the work, 'as it is called, but rather to wait and see at least one rider over a leap before they attempt it themselves. . . . . What said the wisest of kings concerning a fair woman without discretion? We want no Solomon to remind us that with her courage roused, her ambition excited, all the rivalry of her nature called into play, she has nowhere more need of this judicious quality than in the hunting field." Possibly the writer was thinking of two rival Dianas who ride to cut each other down, and who are a nuisance and danger to the entire field. One, if not both of them, has generally to be picked up as the result of this jealous riding.

As it is in Leicestershire that many of our finest horsewomen may be seen, I would strongly recommend the lady who has done some preliminary hunting 


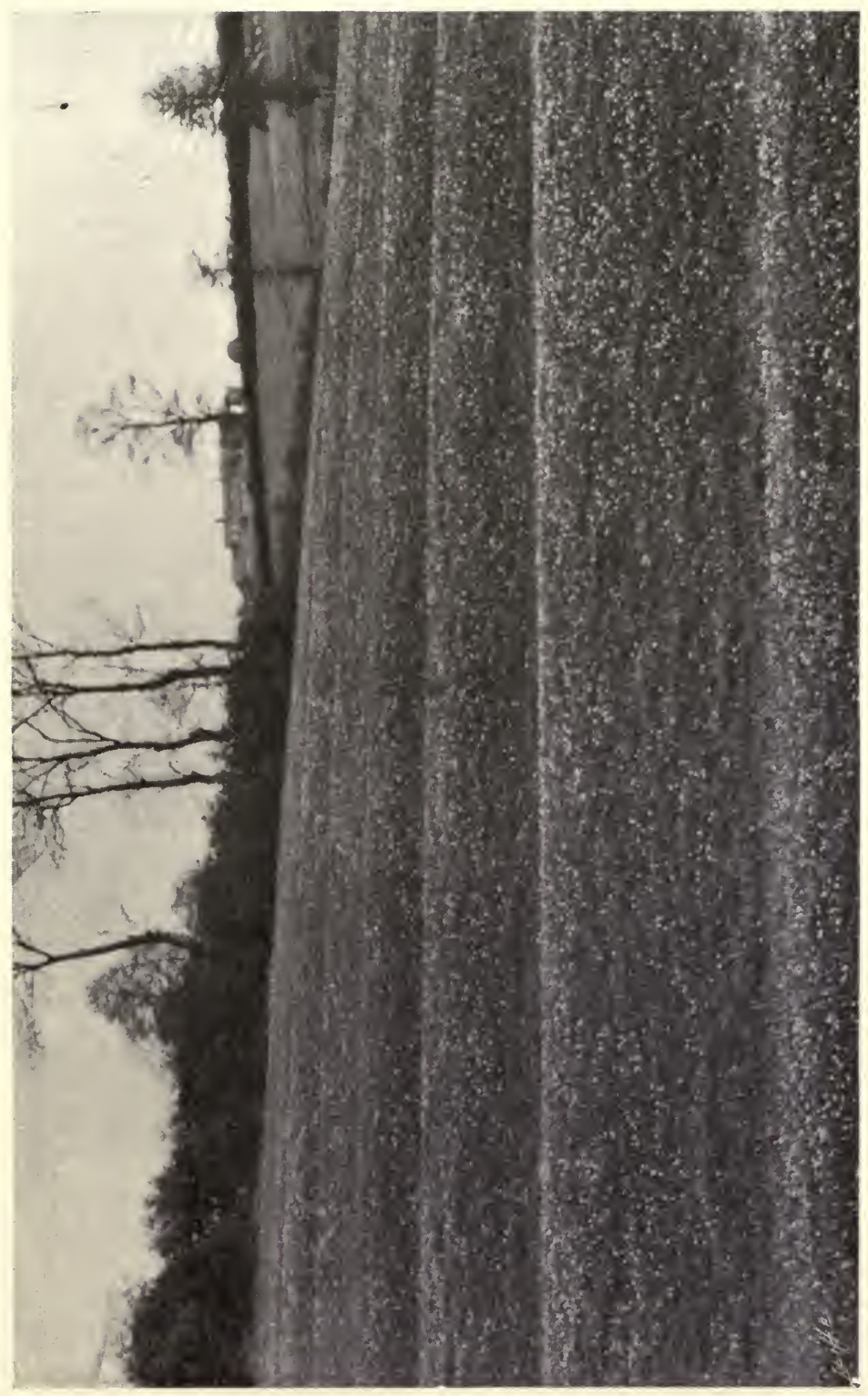

竞 

with harriers, can ride well, and who is supplied with suitable hunters which she can thoroughly control, to learn to hunt in that country. She will there get the best possible instruction in hunt discipline and see the game correctly played, which is far better for her than graduating in a country where people ride to holloas, where the Master is unable to control his field, and where hounds are interfered with in their work by ignorant or careless sportsmen. Besides, if she made her debiit. in a country which is badly hunted, she would learn a great deal that she would have to unlearn, if she should ever desire to hunt in Leicestershire. A Leicestershire field may be divided into four classes: the first flight people who show the way, ride comparatively straight and require no lead; the second flighters, who use the first flighters as their skirmishers and follow them as straight as they can; the third flighters (to which class the hunting tyro ought to belong while getting to know the country), who ride through gates and gaps and over small fences; and the fourth flighters, or macadamisers, who, like Jorrocks, "are 'ard riders, because they never leave the 'ard road."

The lady who is a capable horsewoman, which I need hardly say she ought to be before she attempts to hunt in any country, should, if she wishes to ride in Leicestershire, get as much practice as possible over ridge and furrow (Fig. I30), in order that she may be able to gallop easily and comfortably over it when hunting; for those who are unaccustomed to deep 
ridge and furrow are apt to tire themselves and their horses unnecessarily. The lines of snow in Fig. I 3 I show the presence of ridge and furrow in the distance. As it is requisite for a lady to know how to ride on the flat and over fences, it is equally important that she should obtain all the practice she can in negotiating difficult ground, so that the hunting field may have no unpleasant surprises in store for her. A very steep incline will stop many people. There is one in the North Cheshire country, near Church Minshull I think, which is like riding down the side of a house to get to the valley below. The passage from the high ground to the Belvoir Vale is also quite steep. enough to give us pause. The best and safest way to ride down such places is for the rider to lean back and take her horse very slowly and perfectly straight down the incline. He should never be taken sideways; because if he makes a mistake and his hind quarters are not under him, he will be very liable to roll over on his rider. If he is kept perfectly straight and misses his footing, he will try to save himself by putting his weight on his hind quarters, and will probably find himself sitting on his haunches until he recovers his balance. The rider, by leaning back, removes weight from his forehand and is prepared for any mistake he may make. She should remember to lower her head in passing under trees and not hurry her mount in the least, even though she may see the whole field streaming away from her in the valley below. In going up hill, if the ascent be very steep, the rider 


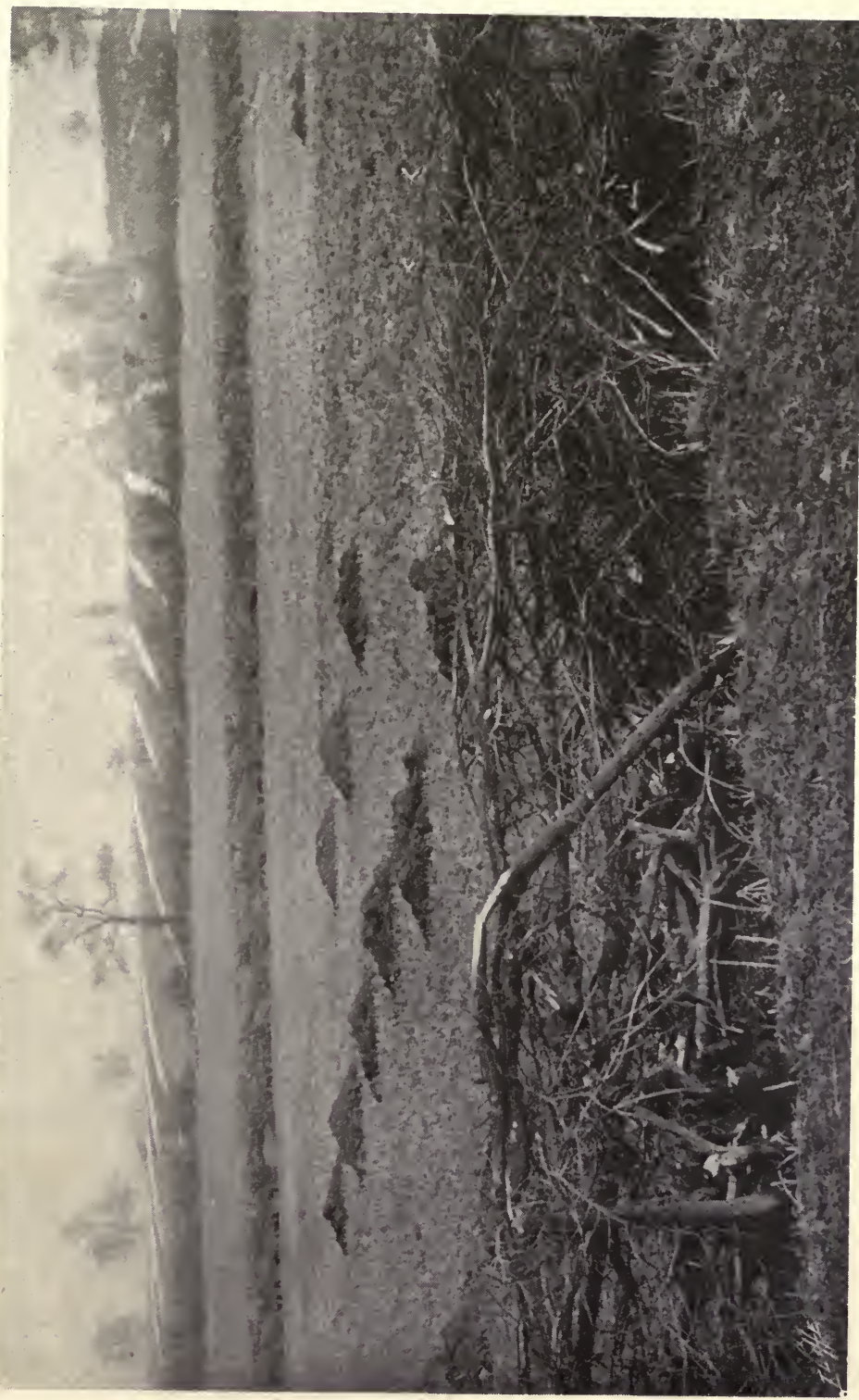

Uू. 

would do well to lean forward and catch hold of her horse's mane, if he has one, or of the breastplate, so as to avoid letting her weight make the saddle slip, and also to put her weight well forward and thus assist the horse. She should let him take a zigzag course, and should on no account interfere with his head by pulling on the reins. We may notice that a waggoner with a heavy load always takes his horse in a zigzag direction up a steep hill, as it is easier for the animal, and allows him occasional intervals for rest, if necessary. We should ride slowly and save our mount as much as possible on such occasions.

When we go a-hunting we should not forget to provide ourselves with a pocket-handkerchief of a useful size; for a dab of mud on the face is a common occurrence. Our noses and often our eyes require "mopping" on a cold day, and as the small square of lace bedecked or embroidered cambric which usually does duty as a handkerchief, is totally unable to meet the various calls made upon it, it is ridiculously out of place. If a watch is needed, it is most conveniently carried in a leather wristlet made for the purpose, as it can then be consulted at any moment, by merely raising the hand, without having to fumble for a watch-pocket.

I must not omit mention of the necessary flask and sandwich case, which are generally given into the charge of the second horseman; but if a onehorse lady goes home at the change of horses, she will not require a "snack." 
As one of the first principles of hunting is to spare both ourselves and our horses any unnecessary fatigue, a lady should, if possible, always drive to the meet, or go by rail. If she has to ride, she should undertake no distance beyond ten miles. I have ridden twelve, but I think that is too far. If she rides her hunter, she should take him quietly, alternating the pace between a walk and a slow canter on the soft side of the road, the orthodox pace being six miles an hour. She should trot as little as possible, in order to avoid the risk of giving her mount a sore back; for trotting, if she rises in the saddle, is the pace most likely to cause trouble in this respect. On arriving at the meet, she should never neglect the precaution of having her girths tightened as may be required, for her horse will have thinned down somewhat from exercise, and the girths will allow of another hole or two being taken up. One of the most fruitful causes of sore back is occasioned by thoughtlessly hunting on a horse which is slackly girthed up, as the friction of the saddle will soon irritate the back, with the result, generally, of a swelling on the off side of the withers, and on the off side of the back, near the cantle. I wish to draw particular attention to the necessity of tightening the girths of a side-saddle, even when a horse has been led to a meet; because I have found from long experience of riding young horses with tender backs, as well as hunters in hard condition, that, given the most perfectlyfitting saddle, trouble will arise sooner or later if this precaution is neglected. Some ladies are so careful 
about the fit of their saddles, that they have a separate saddle for each of their hunters. I know of a lady who has fourteen hunters so equipped.

When hounds move off to covert, a lady should be sufficiently watchful to secure a good place in the procession, as it sometimes happens that a field is kept waiting in a road or lane while a covert is being drawn, and, if she be at the tail end of it, she will get a bad start. In taking up her position she should, of course, be careful not to interfere with others. Mr. Otho Paget gives the following good advice, which we should all endeavour to follow: "When we go a-hunting, I think we should forget all the petty squabbles with our neighbours, and meet for the time on terms of cordiality. Anything approaching a quarrel will spoil the day's sport for you. Everyone should try to be genial and good-tempered, so that, even if there is only a moderate run, you return home feeling happier for the exercise and the good fellowship. There are many things to try one's temper in the hunting field, when everybody is excited, but one should control one's feelings and be invariably courteous in speech. You should apologise, even when you think you are in the right, for the other man may be equally certain he is in the right, and it would be difficult to say who was in the wrong. At the same time, when a man apologises and is evidently sorry, you ought to accept his apologies in a kindly spirit, even though he has jumped on the small of your back." It is almost superfluous, perhaps, to tender advice of this kind to my gentle sex, 
but still, sometimes-very rarely, of course-we find ourselves uttering impatient remarks in the excitement of the chase, which we feel, on mature reflection, that we would have preferred to have left unsaid.

A lady will require to keep a very clear head when the fox breaks covert and the huntsman sounds the wellknown "Gone away," which is the signal to start. In a field of three or four hundred horsemen and women all galloping off at once with a whiz like the sound of a flock of startled birds, there must be neither hesitation nor recklessness on the part of the young Diana, who should ride with discretion and judgment in order to steer clear of danger, especially at the first fence. There are generally a few left on the wrong side of it, and the chances are that there will not be so great a crowd at the next one. At the start, a judicious use of the curb will doubtless be necessary for keeping an excited hunter under control, and allowing the rider in front plenty of room to jump and get clear away from his fence. When horses have settled down to the required pace, which will be regulated by the hounds and according to scent, a lady should ride on the snaffle, keep her hands in a steady fixed position, as low down as comfortable, and should maintain a good look out in front of her, so that she may, after jumping into one field, see the shortest and best way into the next. Jorrocks speaks truly in saying " to 'unt pleasantly two things are necessary-to know your 'oss and know your own mind. . . . Howsomever, if you know your horse and can depend upon him, so as to be sure 
he will carry you over whatever you put him at, 'ave a good understanding with yourself before you ever come to a leap, whether you intend to go over it or not, for nothing looks so pusillanimous as to see a chap ride bang at a fence as though he would eat it, and then swerve off for a gate or a gap." If there is a crowd at the only practicable place in a fence, a lady must wait her turn, and should her horse refuse, she must at once give place to any rider who may be behind her, and wait until her turn comes again before having a second attempt to clear the obstacle. As precious time is lost by refusing horses, it is generally wiser if possible to find some other means of exit than to argue with a refuser. Remember that there is always a gate which can be opened, near a haystack, as the farmer places his hay where he can easily get at it (Fig. I32). A lady should save her horse as much as possible, jump only when she is obliged, for hunting is not steeplechasing, and try to keep within sight of hounds. She should remember to shut any gate she may use, and to carefully avoid riding over winter beans, wheat, clover, roots, turnips, or any crops, or ground newly sown with seed.

A lady should take a pull at her horse when going over ploughed land or down-hill in order to keep him well collected, and should always ride slowly over ground that is deep and holding, if she values her hunter's soundness.

Ladies who know every fence and covert in a country have a great advantage over strangers, because 
foxes frequently make a point from one covert to another, and experienced hunting women' will generally have a good idea where they are going. Like Surtees' Michael Hardy, they know their country and the runs of its foxes. There are people that have hunted in Leicestershire all their lives, who manage to keep comparatively near hounds and see good sport without jumping a single fence. They know the country, generally ride to points, and act as admirable pilots to the uninitiated. I owe them a deep debt of gratitude for showing me the way, when I rode young horses who were getting their first lessons in hunting. Croppers never came to me under their wise guidance, but only when tempted by the keenness and excitement of my over-sanguine youngster, I essayed lepping experiments which were not always successful.

A lady should never put her mount at a fence which she is not certain he is able to jump, for it is better to be a coward than a corpse, and even if she is pounded and loses a run, both she and her horse have plenty more good hunting days-in store. Some hunters will refuse a fence at which they see the horse in front of them come to grief, and as it is only natural that any horse with brains should feel more or less frightened at such times, his rider should sympathise with him and encourage him to make an effort, in much the same way as we would coax a child to take a dose of medicine. Few horses like jumping. Whoever saw animals at liberty larking over fences from sheer delight in leaping? It takes 


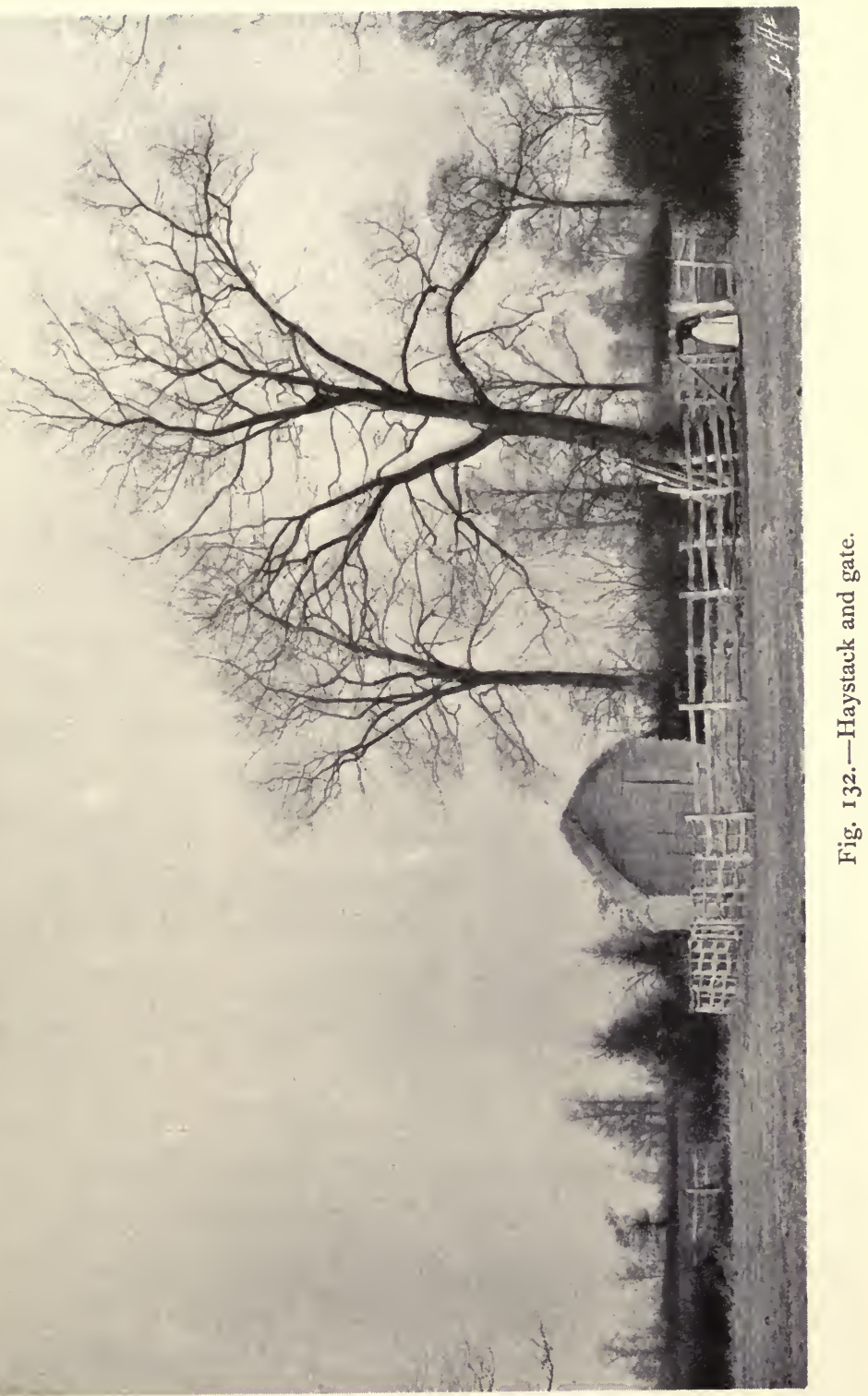



a deal of time and patience to make a good fencer, although, of course, some horses learn the art much more quickly than others. Although few horses enjoy jumping, they, luckily for us, detest falling, and I feel sure that if people would only leave their mouths alone and regard the use of the curb at fences as a death-trap, we should hear of far fewer falls in the hunting field. Captain Elmhirst truly says: "Horses are very sage at saving themselves and consequently you. They care little for the coward on their back; but for their own convenience they won't fall if they can help it." To prove this I may relate the following interesting and instructive fact: Some years ago I was giving, at Ward's Riding School, Brompton Road, London, practical demonstrations of riding over fences without reins, my husband driving on foot a horse which he had taught to jump, with the long reins. When my part of the show ended, a single pole was raised to a height of five feet, and Gustave, which was the name of this amiable grey horse, was asked to go and jump that fence by himself. He was allowed only a short run at it, as the school is not a large one, but in his desire to obey orders he would canter up to the pole, and if he considered that he had misjudged his correct distance for taking off, he would go back of his own accord and take another run at it. My husband was as much surprised as I was when we first saw the horse do this, as we had not credited him with so much intelligence. Therefore, when 'I hear people 
talking about "lifting" and "assisting" horses over their fences, I cannot help thinking that if they lifted themselves off their backs they would see how much better horses are able to jump without their assistance. Many of my readers doubtless saw the Grand National of I900, and how poor Hidden Mystery, who, after he had fallen and had unshipped his rider, jumped the fences with safety to himself and the field. Such sights must show how necessary it is for us to interfere as little as possible with our horses when riding them over fences.

If most horses dislike jumping, it is certain that they love hunting and will exert every effort to keep in touch with hounds. Those who doubt this should ride a young horse, and note how anxious he is to try and keep with hounds and how, with the fearlessness of ignorance he would charge any fence and probably kill both himself and his rider, if he were permitted to urge on his wild career. Blow a hunting horn near a stable where there are hunters, and then listen to the snorting, kicking and excitement which your action has aroused; but it is unwise to repeat the experiment, for the chances are that the excited war horses inside may do some damage in their frantic efforts to get out and follow the music. Watch farmers' horses loose in a field when hounds are in the vicinity, and you will see them careering madly up and down, as if they too would like to join in hunting the fox, although their avocation in life dooms them to the placid work of drawing a plough or heavy cart. As 
in horses so in men, and those who possess the sporting instinct will run many miles in the hope of catching a glimpse of a hunt, even though they may never be able to follow hounds on horseback. These foot people are not welcomed in any hunting field, but there is no denying that they are keen on the sport, or they would not tire themselves as they do, in their efforts to see something of it. Jorrocks says: "I often thinks, could the keen foot-folks change places with the fumigatin' yards o' leather and scarlet, wot a much better chance there would be for the chase! They, at all events, come out from a genuine inclination for the sport, and not for mere show sake, as too many do."

If a lady has the misfortune to own a hunter who, on refusing a fence, shows an inclination to rear on being brought up to it again, my advice would be to sell him, as rearing is of all equine vices the most dangerous, and a woman in a side-saddle is unable to slip off over the tail of a horse who is standing on his hind legs, a feat I have seen accomplished by men. Besides, a horse who will try to rear at a fence instead of jumping it, will be sure to revert to the same form of defence, whenever the will of his rider does not coincide with that of his own. It is very unwise to lend a hunter to anyone who is not a thoroughly good rider. I had in Calcutta a clever Australian horse which I used to ride in the paperchases that are run over a "made" course. He had never refused or made the slightest mistake with 
me until I lent him to a friend. When I again rode the horse, he refused with me at the first fence. I spoke to him, took him again at it and he jumped it, but I had a similar difficulty at another obstacle, and was entirely out of the chase. I was subsequently told by those who knew the horse that the man to whom I had lent him was very noisy, had cut the animal about with his whip, and had treated the surprised onlookers to scenes with him at every fence. The horse had a light snaffle mouth, and would quickly resent any undue interference with it. It is unwise, also, to lend a hunter to even an expert rider, if he or she is afflicted with a bad temper. I heard of a case of a brilliant hunter being lent to an accomplished horsewoman who returned him after a day's hunting with large wheals on his body, showing how cruelly she had used her whip on him. The lady to whom the animal belonged was greatly distressed on seeing the condition of her favourite hunter, who was one of the best that ever crossed Leicestershire. A whip, as I have said, should never be used with the object of inflicting pain, but as an "aid." It is a good plan to always give a hunter a touch with the whip when sending him at an exceptionally big fence, as a reminder that he must exert his best efforts; but in order that the horse may thoroughly understand its meaning, it should be used only at stiff fences; the touch should not be so severe as to hurt him, and should be given on his off flank. A horse must bring his quarters to the right before he 
can run out to the left, and a touch on the off flank will help to keep him straight.

If a lady finds herself on dangerous or difficult ground, as for instance, land intersected with rabbit holes, her best plan will be to slacken the pace into a trot or walk, if necessary, and leave the rest to her horse, who will do his best to keep a firm footing. Parts of the South African veldt are dangerous to ride over because of meerkat holes, but the horses in that country are marvellously clever in avoiding them, if they are left alone. Rabbit holes are responsible for many bad accidents in hunting. I was out one day with the Belvoir on a young mare who put her foot into one while going at a smart pace over ridge and furrow. She wrenched off a fore shoe and pecked so badly that I thought she must fall, but I had the sense to lean back and leave her mouth alone, and she appeared to save herself with a spare leg at the last moment, recovering her balance by the aid of the ridge which she had breasted. Minus a fore shoe, I had to take her home at a walk, and I smiled to myself when I saw her make a vicious stamp at a rabbit who was in the act of disappearing into another hole.

A lady should send her horse at a good pace at a brook (Fig: I33), but not at top speed, as he will not be able to collect himself to take off at a long jump if he is sent at it at full gallop. We may see in jumping competitions, especially at the Agricultural Hall, that a clever horse can clear a fair expanse of water when allowed a run of only a few lengths. The water 
jump at the Richmond Show is placed in such a position that a horse cannot be given a long run at it, and yet many horses clear it easily. It measures, I believe, about I 4 feet, and is so narrow that a horse I once rode over it showed his sense by clearing the width instead of the length, and landing near the stand. I do not think that out hunting it is usual to expect a horse to negotiate a water jump of say over I 2 feet in width. Some horses, like some men, possess a special aptitude for jumping width, although they would doubtless be poor performers at height, the style of jumping being entirely different. The hunter who is equally proficient at both styles of fencing, is as rare as he is valuable. Captain Elmhirst records an instance of "a whole Leicestershire field pounded by I 2 feet of water," and how the difficulty was at last overcome by a shallow spot being discovered, a rail broken down and the field "slink pitifully through.

How we hug ourselves as we gallop under a railway arch, to find we have bridged a bit of water that would frighten no one outside the vaunted Midlands." I believe the reason why the majority of hunting people dislike water is that they do not care to ride fast at it, for fear of being crumpled in a fall. I do not agree with the statement that a hard funker rushes at his fences. Ignorance and enthusiasm may lead people into doing that, but funk oftener than not either pilots them away from fences entirely, or incites them to pull their horses off them, and then abuse the animals for refusing! When the funky 
rider does make up his mind to take a jump, he generally lets everybody near know it by the noise he makes, ostensibly to encourage his horse, but in reality to keep his heart in the right place, and not in

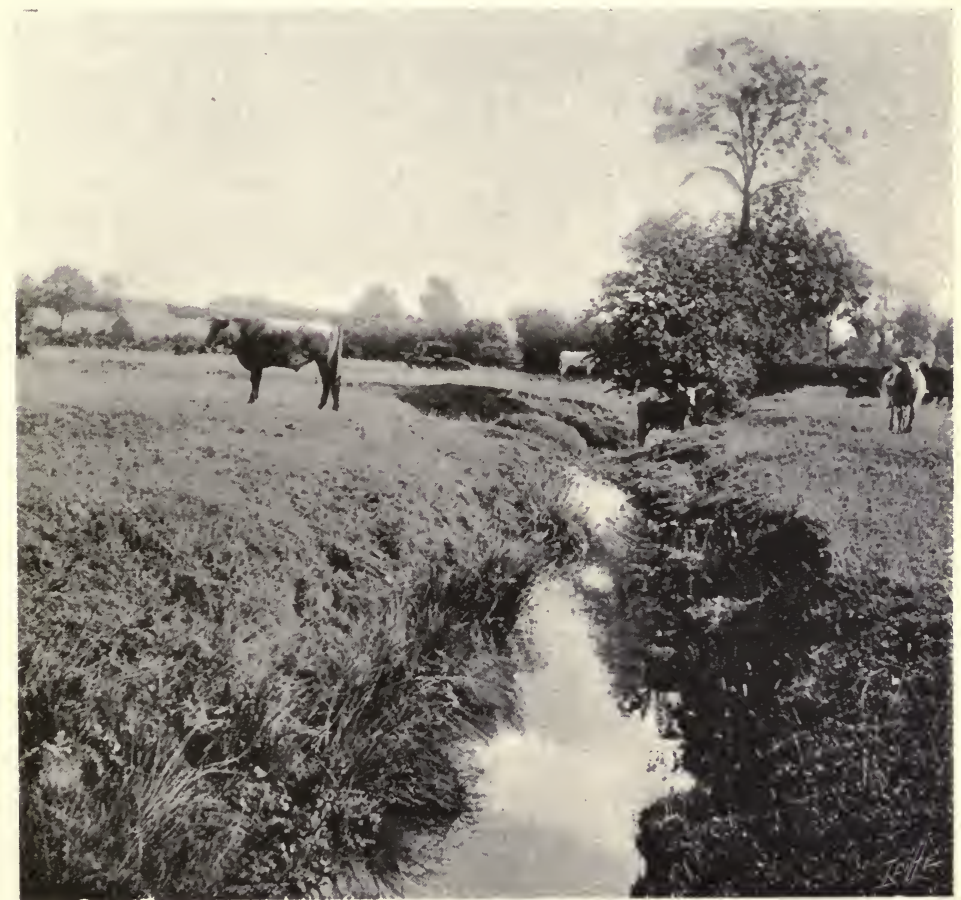

Fig. I33.-Brook.

his mouth. The ignorant horsewoman, as pointed out by the Duchess of Newcastle, rushes her horse at difficult obstacles, because she is fearless of dangers unknown to her; but a wholesome fall generally teaches her to temper valour with discretion. If a lady finds herself on a horse which is pulling too hard 
to be within perfect control, she should stop him as soon as possible and take him home, for very obvious reasons. If there is difficulty in stopping him, the best way is to try and keep him on the turn until he obeys the rein.

The presence of a line of pollard willows in the distance (Fig. I 34) is a certain sign that a brook is flowing past their roots.

In going through woodland country, a lady should be careful to lower her head in passing under trees and to ride slowly. It is essential for her to decide at once the direction which she intends to take, to keep her horse well collected, and not allow him to deviate from it by going the wrong side of a tree or opening, or to take the initiative in any other way. A good horsewoman is seen to great advantage in riding through woodland country.

CUB-HUNTING.

A lady intending to hunt should obtain as much practice in the cub-hunting season as she possibly can; for she will be helping to get both herself and her hunters into condition, and, as the season goes on, will gain experience of what fox-hunting will be like. In the early days she must not look forward to having a gallop, for hounds are being taught to hunt and kill a cub in covert, and the most useful service she can render at such times is to stand by the covert side and prevent any foxes from breaking away. I believe that only people who are really fond of hunting take part in 


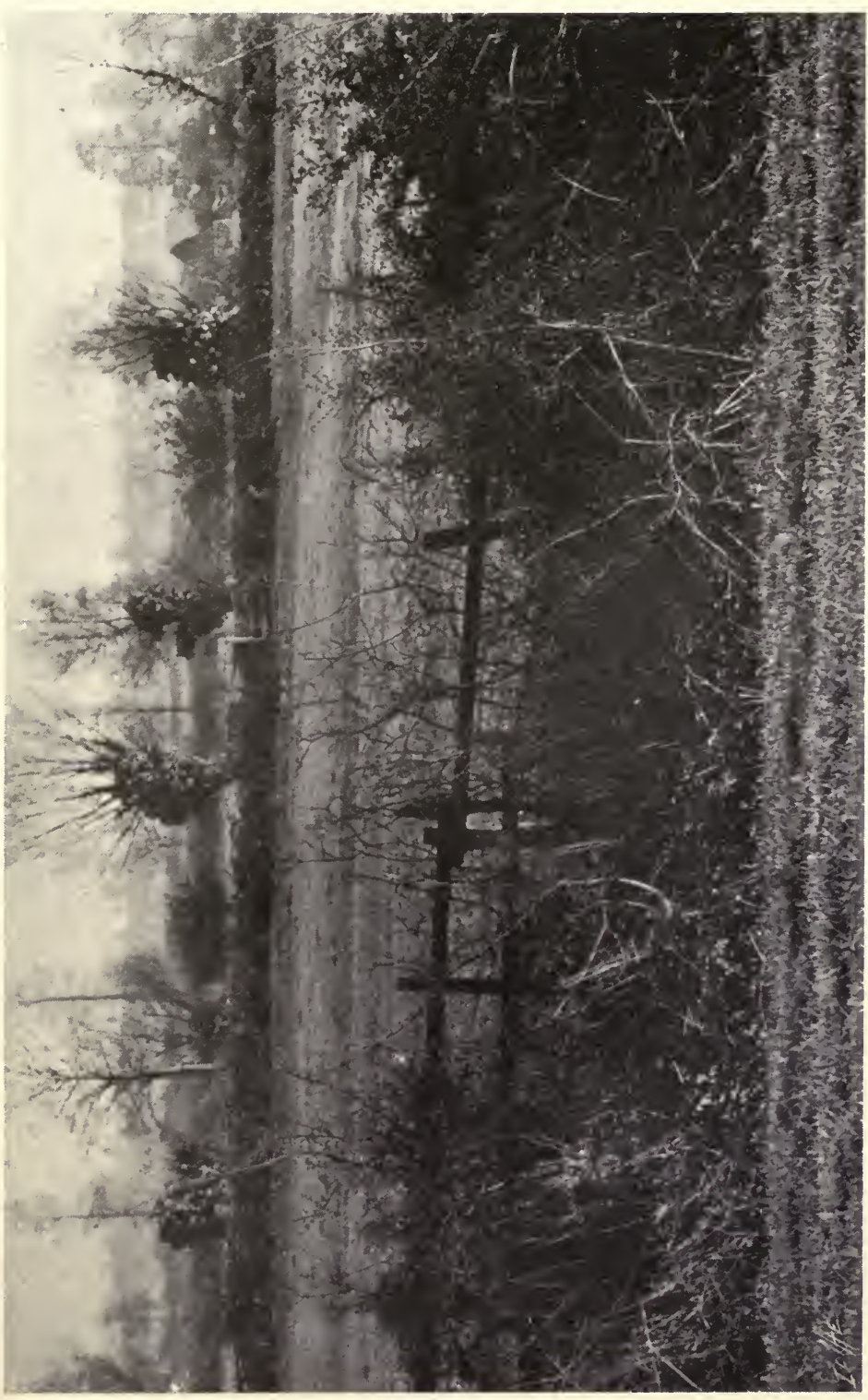

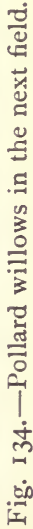



cubbing, because they must rise at, say, five o'clock in the morning and dress by candle, lamp, or gas-light. When they are ready to ride perhaps a long distance to covert, there is often only sufficient daylight to see with, rain drizzling down steadily and everything looking cheerless. A light meal, if it be only a cup of cocoatina and a slice of bread and butter, should be taken before starting, and if it is wet or threatening, a good rain coat should be worn. Towards the end of September and throughout October there will be galloping and jumping, and often the pace will be fast enough for the condition of both horse and rider, as we may see by steaming animals and flushed faces at the end of a run. I have so greatly enjoyed these cubhunting runs with their freedom from crowding and crush, that I can heartily endorse the opinion of Captain Elmhirst, who says: "Call it cub-hunting, or call it what you like, there will be few merrier mornings before Xmas than that of the Quorn on the last days of September." It seems like the breaking up of a family party when the cubbing ceases and all the pomp and circumstance of fox-hunting commences. I often wonder if people who take no interest whatever in cubhunting, but who regularly appear on the opening day of the season, really ride to hunt, or hunt to ride? Jorrocks tells us that, "Some come to see, others to be seen; some for the ride out, others for the ride 'ome; some for happetites, some for 'ealth; some to get away from their wives, and a few to 'unt." Our tyro who is enjoying her cubbing will be wise to take a 
back place on the opening day of the season, and thus avoid being jostled by the mighty crowd she will see on a Kirby Gate day. She will doubtless find her mount far more excited and difficult to manage than ever before, and will require to exert a good deal of tact and patience in restraining his ambition to catch the fox. The opening day is always the most trying one of the season. All the world and his wife seem to be at the meet. There are people in vehicles of every kind, on foot, on bicycles and tricycles, as well as about four hundred horsemen, and many things happen on this day of crowding and discomfort which must sorely tax the patience of the most angelic tempered Master.

A lady who has had a good season at cub hunting, ought to be able to take her place among the third-flight people, where she will gradually gain experience and a knowledge of the country, which will enable her to pass into the second rank, and finally into the first ; but she must work her way up by degrees, and remember that no one can ride safely over Leicestershire in the first flight who is not mounted on an accomplished performer, and is not thoroughly well acquainted with the country.

\section{KICKERS AND RED BOWS.}

Unless a lady is perfectly certain that her mount will not lash out at hounds, she should keep well away from them, and should never ride into a covert where they are. I once had a mare of this description who never kicked horses, but who would 
try to get a sly kick at even our own wow-wows during a hacking ride. We had some foxhound puppies at walk, but I never allowed her to get near them, and our own dogs got so artful that they always managed to evade her kicks. I do not believe that mare would ever have been safe with hounds, so I took good care to give her no opportunity of disgracing the pair of us in the hunting field. In every other respect she was most amiable. As there are inconsiderate people who ride kickers, a lady should carefully avoid getting near a horse whose tail is adorned with a red bow. If this is impossible, and it often is in crowds, she should try and keep to the left of the kicker, so that if he lashes out he may not be able to break her legs. Scrutator in his book on Foxhunting points out that "the risks men encounter in the chase are great enough without being subjected to the chance of having their legs broken by a bad-tempered brute at the covert side." I once had the misfortune to see a man's leg broken by a vicious kicker in Leicestershire. Another case happened while I was in Cheshire, and yet these clangerous be-ribboned animals can still be seen in almost every hunting field.

We must here draw a sharp line of distinction between horses which kick from vice, and those, especially young ones full of corn and short of work, which throw up their heels from exuberance of spirits. Many mares, particularly in springtime, are apt to kick from causes which I need not discuss. Hence, geldings are more free from this baneful habit 
than their female relations, and are consequently, as a rule, more reliable mounts. Great care should be observed in gradually accustoming a young horse to placidly bear the excitement of being surrounded by a large number of his equine companions, and he should thoroughly learn this part of his education before he is required to quit the outskirts of the field, and take his place as a hunter. This preliminary training of course comes under the heading of breaking and not of hunting. A young horse "turned out" in the open, not unfrequently gives a companion a playful kick, which very seldom inflicts any injury, because it has no "venom" in it, and the hoof that administers the tap is unshod. I have even seen mares with a foal at foot, give the young one a slight push with the hind hoof, to make him get out of the way. The motives of such taps are of course entirely different from the dangerous malevolence that prompts a confirmed kicker to "lash out" at horse or man who comes within striking distance. We should bear in mind that a touch behind is very apt to provoke a kick, whether of the vicious, playful or getout-of-the-way kind. Hence a rider should always be careful never to allow her horse's head to touch the hind quarters of an animal in front, which is a precaution that is of special application in crowds of pulled-up horses. Also, on such occasions, she should keep him straight and should prevent him from reining back. Any man or woman who knowingly rides a kicker in a large hunting field, is guilty of disgraceful conduct; because it is impossible for everyone to get 
out of reach of this bone-breaker's heels, during the frequent stoppages which occur out hunting. Some persons have a red bow put on their animal's tail, or they place a hand at the small of their back, with the palm turned to the rear, as a sly device to get more elbow-room in crowds. It is evident that such artful tricks are unworthy of imitation.

BLOOD.

With full consideration of the importance of blood for making hounds keen, I must say that the digging out of foxes is a phase of hunting that I greatly dislike to witness. I do not think that any writer has put this question more fairly than Captain Elmhirst, who says :- "We must grant that hounds are glad to get hold of their fox; but we cannot grant that it is at all necessary that they should do so. In a well-stocked country he must be a very bad huntsman who cannot find them blood enough by fair killing; while in a badly stocked one it is very certain you cannot afford wanton bloodshed. Moreover, it is almost an allowed fact that hounds well blooded in the cub-hunting season do not require it to any extent afterwards; and many authorities maintain that a good 'flare up' of triumph and excitement over the mouth of an earth is just as effectual and satisfactory to hounds as an actual worry. "And what do the field think of it? They hate and abominate it, each and every one of them. They neither sympathise with the feeling that prompts the act, nor hold with the expediency of its commission. 
To them it represents no pleasure, and certainly coincides with none of their notions of sport. They would find much greater fun in seeing rats killed in a barn, and derive from the sight a much higher sense of satisfaction. Condemned, probably, to stand about in the cold, unwilling witnesses of what they heartily detest, they spend the time in giving vent to their annoyance and contempt. . . . Finally, fox-digging, in the sense we refer to, is a crying enormity, a disgrace to a noble sport, and should be put down as rigorously as vivisection."

Tearing a poor fox to pieces is a sight which very few women would care to watch, except those manly ones who take a delight in killing wild animals themselves. Such persons would be able to look unmoved at a bullock being pole axed, without losing a particle of their appetite for a cut off his sirloin.

\section{COMING HOME.}

We are accustomed to associate hunting with pleasant runs; but there are days when covert after covert is drawn blank and a fox not found until late. Sometimes, but very rarely, we have ān entirely blank day. A lady with only one hunter out should use her own judgment about participating in a late run. A great deal would depend on the distance the animal has travelled and the length of the journey home. Some people ignorantly imagine that a hunter should be kept out until he has had a run, unless the day proves entirely blank, however tired he may be. If it is necessary for people who stay 
out all day to ride second horses, it is equally important that the one-horse lady should know when her mount has had enough. It is always a safe plan for her to retire at the "change of horses"; for there is no pleasure in continuing to hunt on a tired animal, and there is certainly danger in so doing. Old-time sportsmen were content with one horse a day. "Scrutator" tells us that in the time of Mr. Meynell " it was not the fashion to have second horses in the field." If I may express an opinion, I think that many ladies are inclined to regard horses as machines, and expect too much from them. This is probably due to that unfortunate saying "as strong as a horse," estimating the standard of mechanical power as "horse power," and so forth. I have no doubt that our domestic cat would dislike the person who said that cats have nine lives. A horse is, in reality, by no means as strong as many of us imagine, and his legs are a continual source of anxiety. Ladies who hunt should get a veterinary book, preferably Veterinary Notes for Horse-owners, and when they have read it through, they will not be likely to overtax the powers of their hunters. I once saw in an old Graphic a picture of Lady Somebody's mare which that worthy dame had ridden to death. The animal had, it was explained, gone brilliantly with her ladyship that day and had fallen dead while passing through a village. The artist had drawn the poor mare stretched out, surrounded by an inquisitive field, and the owner posed as the heroine of a great achievement, instead of 
one who had rendered herself liable to prosecution for cruelty to animals. I feel sure that no woman would knowingly commit such a heartless action. When a horse begins to show signs of distress, his rider should instantly pull up, and, if necessary, walk him quietly home. His "state of condition" should always be taken into account at such times. The hurried and distressed state of a horse's breathing, and his laboured action, are sure signs to the experienced horsewoman that the animal has had enough. To persons who know little or nothing about horses, the fact of their usually freegoing mount ceasing to go up to his bridle and to answer an encouraging shake of the reins or touch of the whip, are valuable indications that he should be pulled up, either into a trot or walk. If he is in hard condition, a respite from exertion, for ten minutes or a quarter of an hour, will make him all right for another gallop, which should be given with due circumspection. If the horse is not in thorough galloping condition he should be taken home at a quiet walk. Keeping a horse standing, especially in a cold wind, after a fatiguing run, is not an unfrequent means of giving the animal congestion of the lungs. A wise woman will take care of a good hunter, for such animals are not easy to replace, and, as Jorrocks says, "We know what we 'ave, but we don't know what we may get." If a lady intends to ride her hunter home, it would greatly conduce to his comfort, and possibly her own, especially if she has been several hours in the saddle, to dismount for, say, a quarter of an hour, have her 
horse quietly led about, and then ride him home at a walk. If she is using a second horse, it is always wise to get her second horseman to take the saddle off her first horse and rub his back well with the hand, especially at the off side of the withers and of the back, under the cantle, in order to restore the circulation of the part before taking him home. The animal ought to be given an opportunity of refreshing himself by drinking at a brook or trough on his homeward way. No harm can arise from a horse drinking cold water when at work, however hot he may be, if his exercise be continued at a slow pace for a short time.

A lady's hunter should always be examined, if possible by his mistress, or by one of the male members of her family, on his return from a day with the hounds, and his back and legs should receive special attention. The chief accidents which are liable to happen by such work, are sprains of tendons and ligaments below the knees, over-reaches, cuts, punctures from thorns, and injuries from the saddle. It is not within the province of this book to deal with such subjects, and few ladies would go through the bother of studying them. Nevertheless, there are some exceptions, as we may see by the comparatively large number of lady doctors, and by the fact that only the narrow-minded policy of the Royal College of Veterinary Surgeons prevented Miss Custance, who had studied at the Edinburgh New Veterinary College, from obtaining her diploma, to which she was fully entitled by her scientific attain- 
ments and practical experience. Those of my readers who wish to understand the treatment of horses in health and disease, cannot do better, as far as books are concerned, than to study my husband's Stable Management and Exercise, and Veterinary Notes for Horse-owners.

One point about the examination of a hard-ridden hunter which is within the comprehension of even an inexperienced girl, is the detection and proper treatment of lumps on his back which have been produced during the ride by hurtful pressure of the saddle, and which almost always appear on the off side of the withers, and on the off side of the back, near where the cantle rested. If these swellings be neglected, they will probably become developed into abscesses, which will incapacitate the animal from work for a month or longer. An admirable way of treating them, as soon as the saddle is removed, is to pour some whiskey, brandy or other spirit into the hollow of the hand, apply it to the lump, and rub the swelling briskly with the palm of the hand for at least five minutes. I have often seen a large swelling of this kind visibly decrease in size during this process, which, in the many cases I have witnessed, always caused the lump to disappear by the following morning. In applying this form of massage, no delay should occur, after removing the saddle, which should always be taken off the moment the animal returns to his stable, and his back well rubbed with the hand or with a dry whisp of straw 
or hay. When entrusting the carrying out of this treatment to the groom, care should be taken that the spirit is administered externally to the horse, and not internally to the man. If spirit be not available, careful friction with the palm of the hand will generally be sufficient to ensure the desired result. This treatment should not be applied, if the skin over the part is broken, for in that somewhat rare case the friction would irritate the wound.

\section{RIDEK'S PHYSICAL CONDITION.}

The young or old Diana, especially if she is not in hard riding condition, is very apt to get rubbed, generally by the cantle of the saddle. If the skin is cut, a dry dressing of tannoform, which is a powder that can be got from a chemist, will be found a good and speedy remedy; and is also useful for cuts in horses. It would be injudicious to ride again, or to have an injured hunter ridden again, until such an abrasion has healed.

It is essential for a lady who intends to hunt, to be able to ride a fast gallop without becoming "blown." Some hunting ladies do preparatory work cubbing or with the Devon and Somerset Staghounds. Those who are obliged to forego these pleasant methods of "getting fit," would do well to get into fairly good condition by long walks or bicycle rides. I would warn my young readers that all fast exercise should be taken gradually and in moderation, and that they should never disregard symptoms of fatigue; 
because when muscles are tired, they are unable to act with strength and precision.

TIPS AND THANKS.

We should always remember to carry some small change in our pockets to be given as tips to gateopeners and any poor persons whose services we accept.

And now, gentle ladies, let me remind you never to forget to render thanks to every person, gentle or simple, who may, by the performance of some kindly act, have helped to contribute towards your day's enjoyment. We should also try to be as useful as possible to each other; for we all admire that " nice pleasant woman" who, instead of attempting to hold us up to ridicule if our "back hair" is falling down, or anything has happened which ruffles our appearance, rides up and quietly brings the fact to our notice. I have heard female voices audibly "picking holes" in a lady's mount, which is very unkind; for their poorer sister was doubtless riding the best horse she could get, and the hearing of such rude remarks may entirely spoil her day's pleasure.

\section{THE HORN.}

Mr. J. Anstruther Thompson in his most instructive book, Hints to Huntsmen, gives the following horn notes and explanation of their meaning. Ladies who intend to hunt should study the music of the horn in order that they may understand what hounds are doing 
in covert (Fig. I35), and be ready to start off as soon as they hear the recognised signal.

"To call hounds on when drawing a covert."

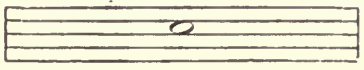

"A prolonged swelling note to call them away."

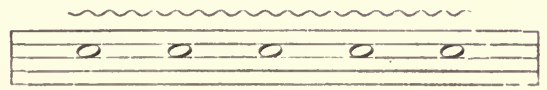

"A long single note when all are away."

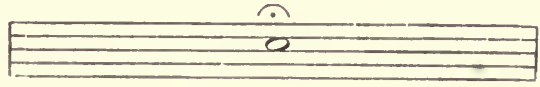

"A double note when on a scent (called doubling the horn)."

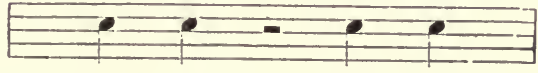

"Two short notes and a long one for 'Gone away."

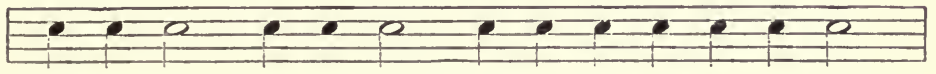

“' Tally-ho! back,' on horn and crack of whip."

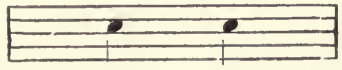

"A rattle for 'Whoo, whoop.'"

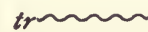

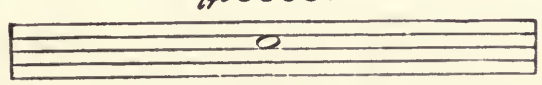

From the foregoing it will be seen that it is necessary to be on the alert for short notes, because they mean business, while the long ones denote a covert drawn blank. 


\section{HIRELINGS.}

The large majority of hunting women ride their own animals, or mounts lent them by friends; but some less fortunate ones have to content themselves with hirelings, many of which are unreliable conveyances, because they pass through so many hands, that they run a great risk of being spoiled by bad riders, and in that respect, horses have unfortunately very retentive memories. From two to three guineas is the usual charge for a day; and from $£$ I 2 to $£_{20}$ for a month. In both cases, the job-master has to bear all reasonable risks. A person who hires a horse for longer than a day, has to keep the animal and pay for his shoeing. $£_{\mathrm{I}} 5$ a month is a reasonable charge for the loan of a good hunter. When wishing to hire by the month, it is well to go to a job-master who has a large collection of hirelings, like Mr. Sam Hames of Leicester, so that the hirer may get a change of mounts, in the event of the first not being suitable.

I have ridden a few hirelings, but hunting on them gave me no pleasure; because I was entirely ignorant of their capabilities, and it is not a pleasant feeling to ride at a nasty fence with a big note of interrogation sticking in one's heart. "Scrutator" in his interesting book, Foxhunting, says he "never could find any pleasure in riding strange horses. They neither understand your way of doing business, nor you theirs, so there must of necessity be doubts 


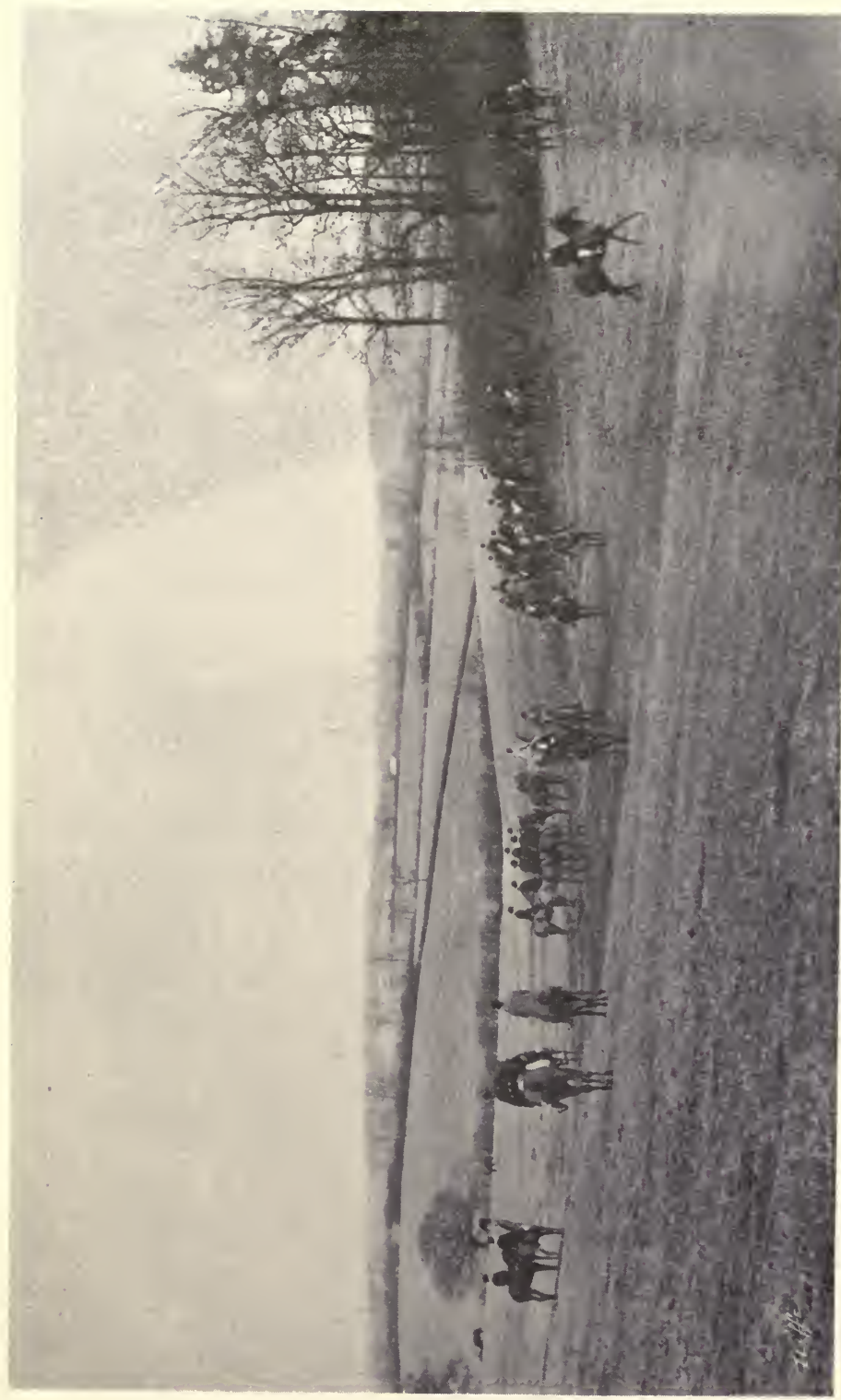

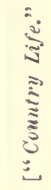

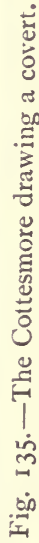

ฐัँ 

and drawbacks until both become more intimately acquainted." I have seen so many bad accidents happen to men who were riding hired hunters, that I cannot too strongly impress on my readers the necessity of letting caution mark the guarded way, by testing a strange mount at small fences to see how he shapes, before taking unwise risks. Last season, a young man who was hunting with the Pytchley on a hireling came a cropper at the first fence, staked his mount and got a kick in the head. He was greatly distressed about the poor horse which the dealer had assured him could "jump anything," a feat that no hunter in the world can perform. An accident of this kind with a hired hunter is a most unpleasant occurrence; because, if the bruised and mud-stained horseman happens to be a stranger to the dealer, the latter will naturally blame his riding, while the injured one who has to break the news as gently as possible, will consider that he has been misled concerning the animal's jumping capabilities. Jorrocks's advice, "know your horse," should be engraved in capital letters on the heart of everyone who hunts, as its observance would prevent many distressing accidents both to humans and equines.

FARMERS AND WIRE.

There is very little wire in Leicestershire, though it is far too common in other parts of the Shires. Fences where the warning red board (Fig. I 36 ) or red 
rag (Fig. I 37 ) is seen, should be avoided, as these signals denote the presence of wire. As these deathtraps bear no warning notice in some places (Fig. I 38 ), it behoves people hunting in such countries to keep a sharp look-out for unmarked wire and iron hurdles (Fig. I 39).

Some farmers appear to use wire in an unnecessary manner. For instance, placing it on the top of a gate (Fig. I40) seems to have no raison d'être, except to hurt unfortunate hunters which in breasting such a gate to push it open, are apt to get badly pricked and run suddenly back to avoid it, with the possible result of injury to both horses and riders behind them. Also, I have seen wire put up in fields in which there were no cattle, and removed after the hunting season, to duly appear again in the following one. Other tricks, such as sending sheep-dogs to head foxes, and stationing farm hands to shout "wire!" where there is none, have also come under my personal notice. Indeed it is impossible to live in the country, without observing such acts of hostility on the part of farmers towards "hunting people." I cannot help thinking that much of this tension might be removed, if every hunt secretary followed the example of Colonel Francis Henry, the Hon. Secretary of the Duke of Beaufort's Hunt, of whom we read in Baily's Magazine of March, I902:- "Colonel Henry, who, in the opinion of his numerous friends, seems to possess the secret of eternal youth, contrives to enquire personally into every complaint that is sent to him, whether relating to 


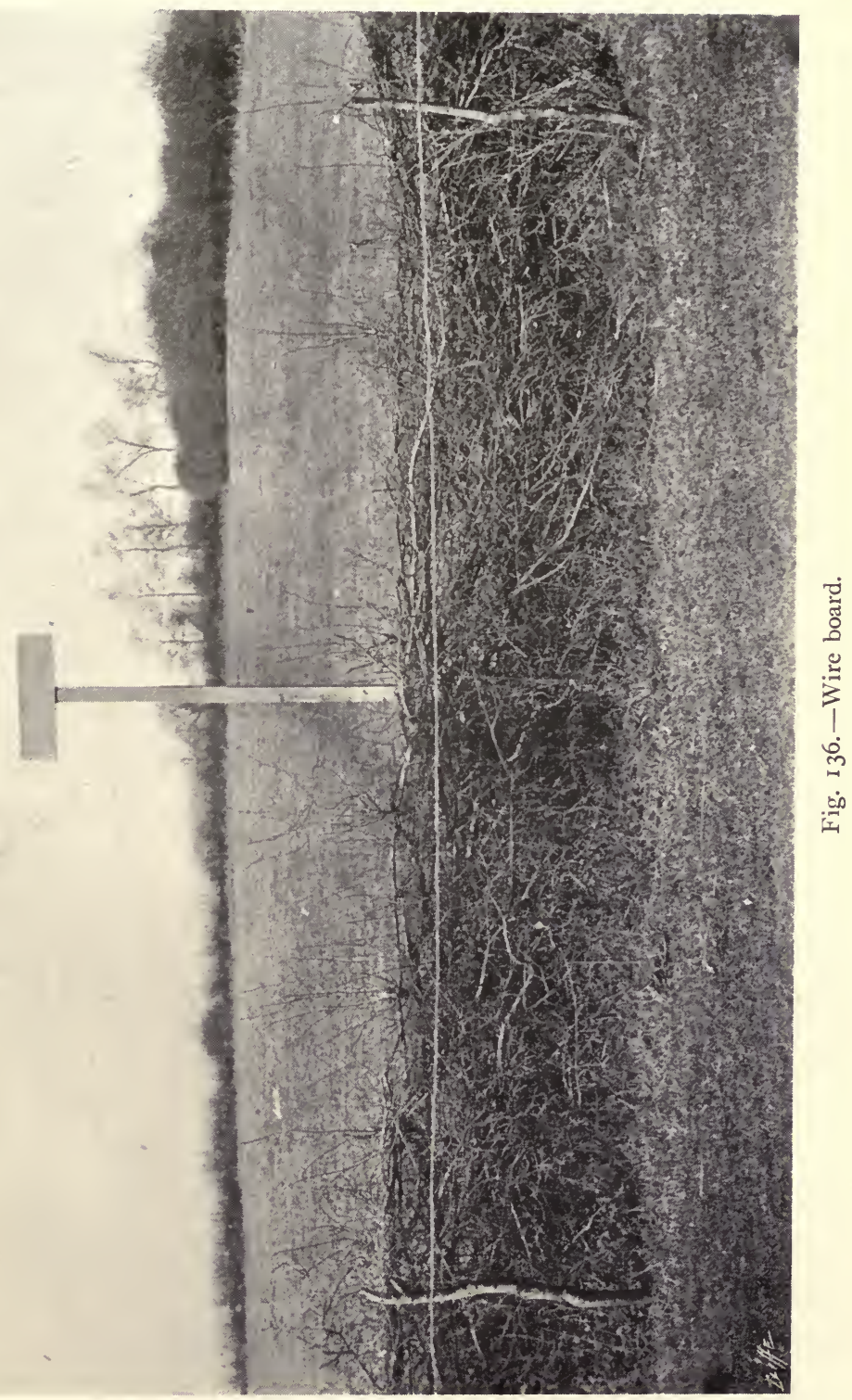



damaged tences, loss of poultry or, rarely, ' wire offences.' There is no better known figure in Gloucestershire than that of Colonel Henry on his hack, one of his own breeding by the way, which carries him on his long rides; he is wont to say that in dealing with a grievance 'one visit is worth a dozen letters.' His geniality, and the painstaking care with which he investigates every matter to which his attention is called, dissipate at their beginning many difficulties which, handled with less sympathetic diplomacy, would 'come to a head' and produce the friction which tells against sport. Landowners, farmers, and business men alike in the Badminton country are keen supporters of fox-hunting, and their attitude towards the sport is due in no small degree to the unremitting attention and care for their interests displayed by the honorary secretary both in winter and summer." The truth of Colonel Henry's remark that one visit is worth a dozen letters, was exemplified to me the other day by an old lady, a farmer's wife, who regretted the sad change in "hunting people" since her young days, when they " used to come in and chat with me as affable as could be." She mentioned the name of Mr. Wroughton, who partook of some of her "cowslip wine," and so much was she impressed with the visit that every small detail of it, even the year, month, day and hour, and also where he sat in her parlour, remains a treasured memory. He made a friend who will always speak of him in the highest terms, because he was nice and civil to her, and it seems to be a matter for regret 
that this friendly feeling is not more generally cultivated than it is in hunting districts.

Unfortunately, the old-fashioned motherly, hardworking farmer's wife is a type of woman which is rapidly dying out, and the modern specimen belongs to that large and useless brigade of "perfect ladies" who are above their position and who regard work as undignified. I recently saw an advertisement from a farmer's daughter who said in it that she had offers of plenty of mounts, but wanted some lady to give her a riding habit! Surely it would have been far better for her to have worked and earned one, instead of cadging in such a manner for her amusement? Proverbially bad as our fresh butter in the Midlands is, I fear the time is approaching when butter making will entirely cease, for, with few exceptions, farmers' daughters are not trained to do dairy work. A modern "young lady" from a farm, who had been educated in a Board school, applied to a well known lady of title for a situation as governess; but her ladyship pointed out that her educational attainments did not qualify her for such a post, and suggested that she should obtain employment as a parlourmaid. Needless to say that the farmer's daughter scorned the idea of thus "lowering" herself! Even the daughters of farm labourers nowadays ride their bicycles, instead of going out to service as their mothers and grandmothers did before them, and dress themselves ridiculously out of keeping with their position and surroundings. It seems very incongruous to see such girls living in indolence in 


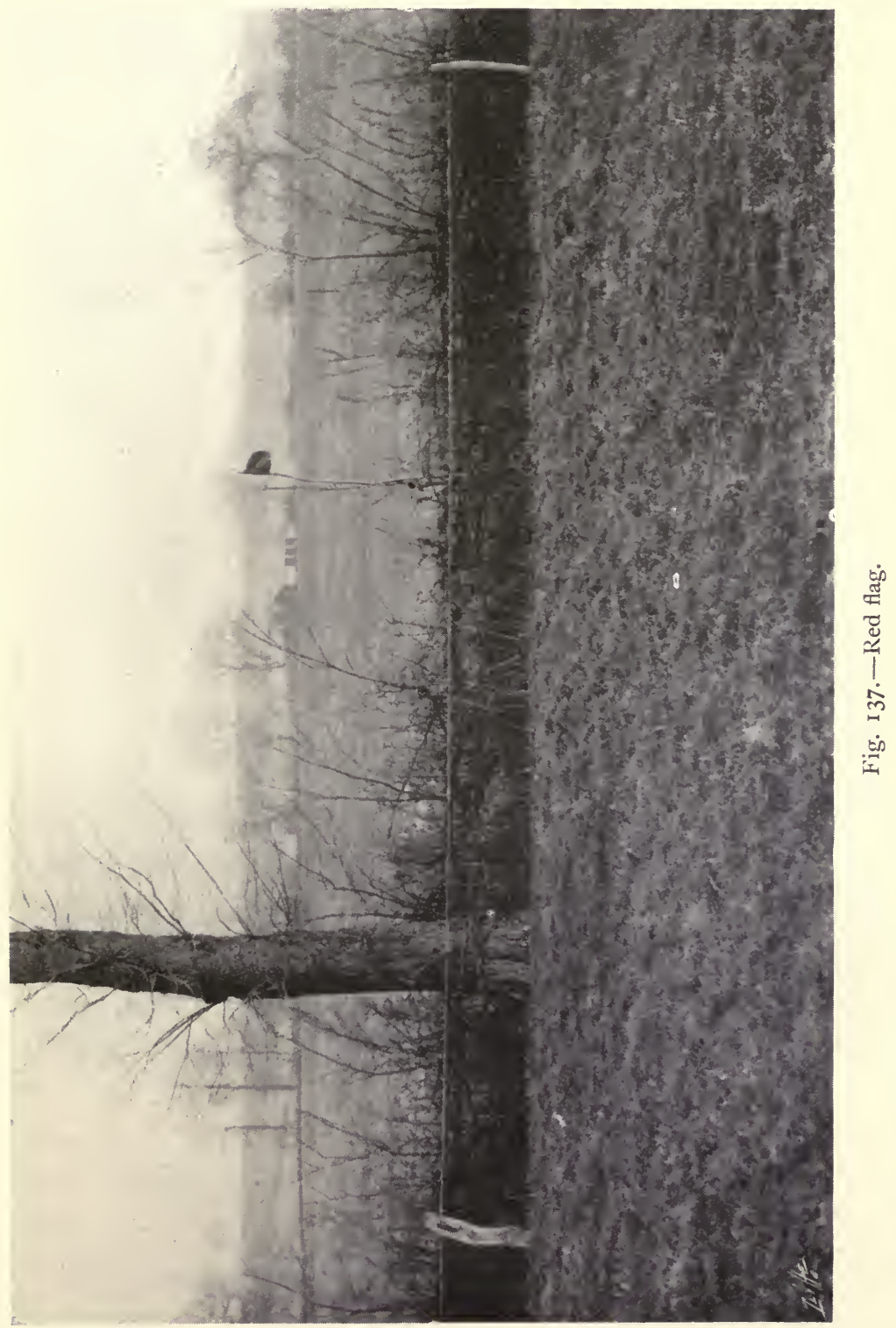



country villages, while the daughters of their parson, as frequently happens in large families, turn out and earn their own livelihood.

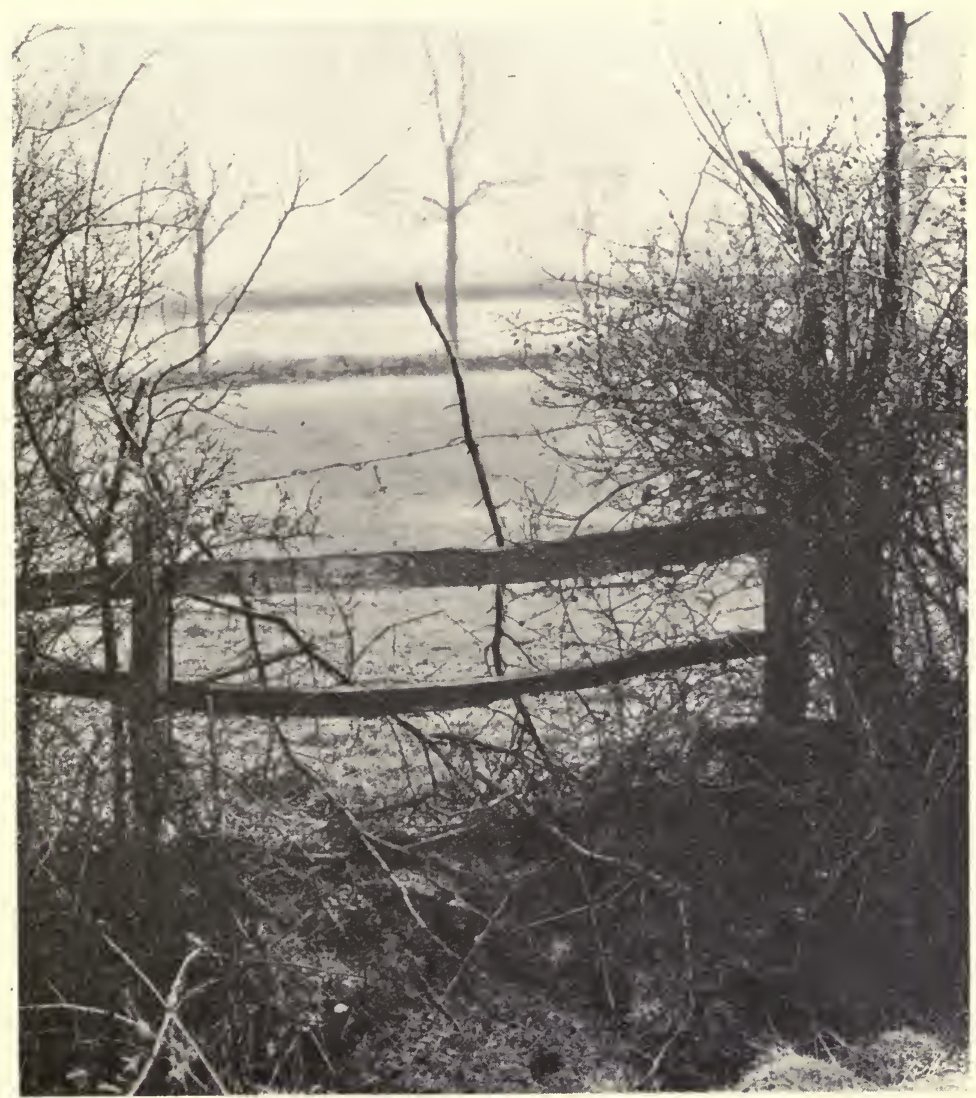

Fig. 138._"“"Ware wire."

It would cost very little to give an annual ball, say, after the Hunt ball and before the decorations were taken down, to farmers and their wives and any local residents who help towards the support of hunting, 
and I feel sure that an entertainment of this kind would be productive of beneficial results. In order to make it a success, it would have to be attended by some of the members of the local Hunt, and not in any way bear the stamp of a charity ball; for untravelled middle-class people in this country are, as a rule, very "select," and eaten up with social ambition, and many who would not think of attending a subscription dance, would be attracted by "an invitation Hunt ball." Besides, after all, even if local residents and farmers pay their guinea to be present at an annual Hunt ball, they feel themselves rather "out of it," if they are not personally acquainted with anyone in the room, and wisely avoid such dreary functions. It is recorded of $\mathrm{Mr}$. Conyers that he once presented every farmer's wife in his hunting district with a silk dress, saying that the ladies must be propitiated if hunting is to flourish.

One of the reasons why hunting is unpopular among farmers is the selfish and reckless manner in which many followers of a hunt ride over arable land; the greatest sinners in this respect being those who reside in towns, and who, knowing nothing about agriculture, err more from ignorance than indifference. Unless vegetation stares them in the face, they evidently think there is no harm in riding over ploughed land, no matter how distinctly the smoothly-harrowed surface and carefully prepared drains indicate the presence of seed underneath. In such a case, our best plan would be to skirt along, as near as possible, the 
hedge or other boundary, even if we have to go a little out of our way. Riding over cultivated "heavy" (clay) land, especially if its surface is wet, is particularly

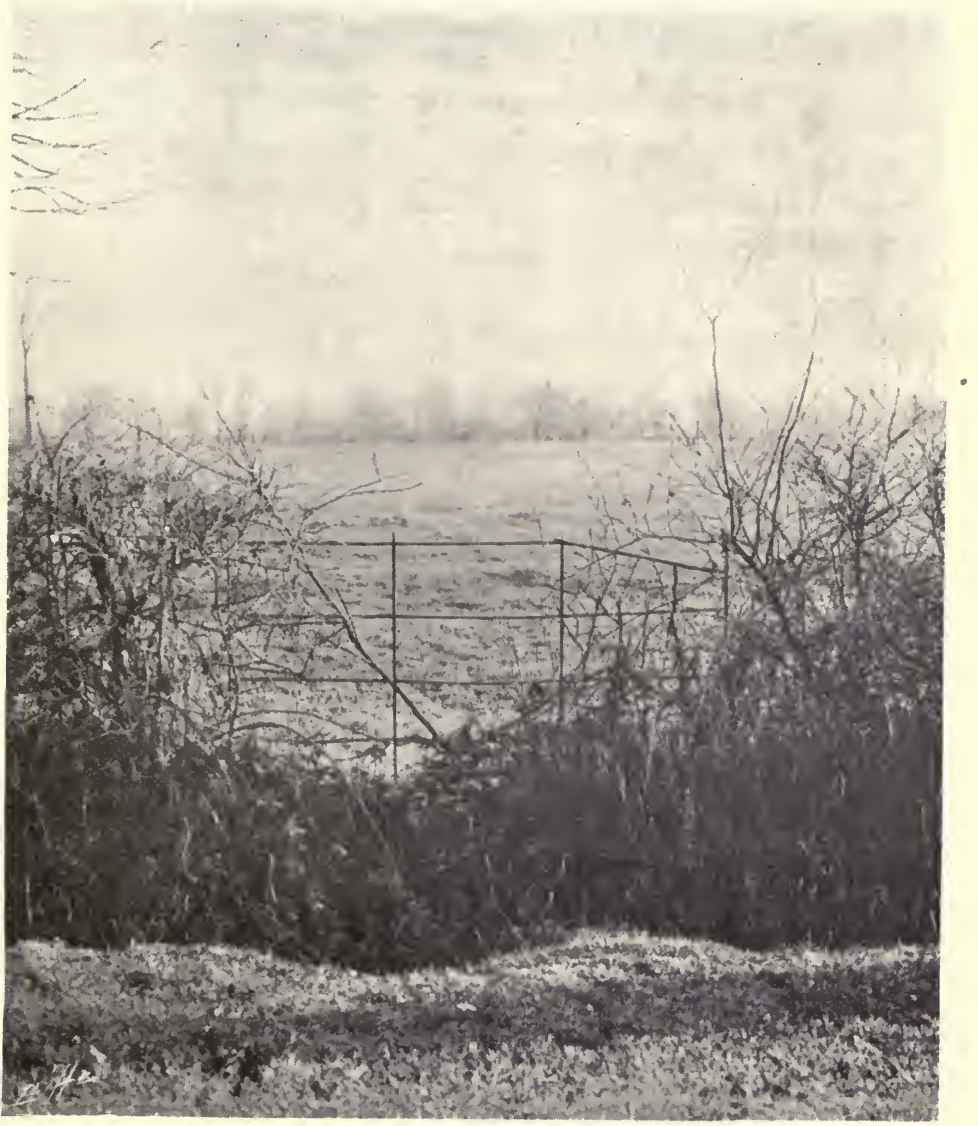

Fig. 139.-Iron hurdle.

hurtful to the crop, because each imprint of a horse's foot will form a small pool of water, which will rot the seed inside it. In "light" (sandy), land, the 
water in such holes will quickly drain off, and little or no injury will be done. While hoping that young horsewomen will not allow their enthusiasm for hunting to outweigh their sense of prudence when steering their horses over farmers' land, I would entreat them to also "hold hard" when approaching allotment ground, for this land is rented, as a rule, by the poorest of the poor, who have no gardens in which to grow vegetables, etc., for their use, and a small field of, say, a few acres may be cultivated by several villagers and their children in their "spare time of evenings." Each tenant has his own patch of allotment land on which he grows what he requires for his use. In winter we may frequently see the entire field under wheat cultivation, as many poor families grow their own grain, which the local miller grinds into flour, and in this way they save the baker's bill, as they make their own bread. To ride over and destroy their small crops is a sin which I am sure no lady would knowingly commit, and, therefore, it behoves us all to exercise due circumspection when we find ourselves on arable land.

Also, on pasture land we have need to temper valour with discretion, and especially after Christmas, when ewes and cows are heavy with young, and are not in a fit state to safely endure the dual evil of fright and violent exercise. Later on, when lambs have appeared, it is cruel to gallop so near these mothers and their young, as to cause suffering. Sheep are such stupid animals that they appear to have no idea of evading 


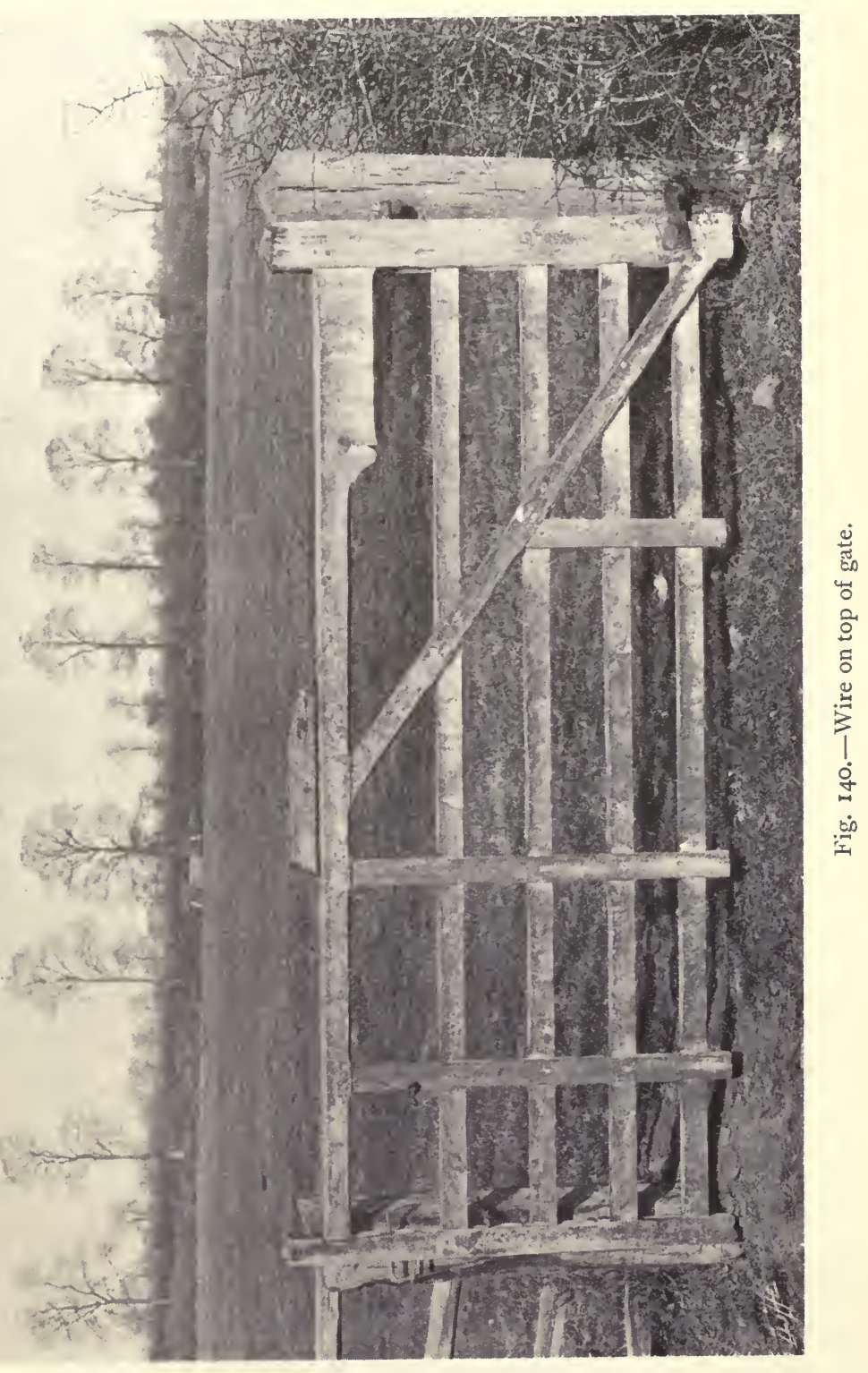



a crowd; and cattle, as a rule, lose their heads from fright, and career madly about their fields, sometimes for two or three days after the sudden passing of a hunt. When a gate is negligently left open, and the terrified animals avail themselves of this method of escape, the unfortunate farmer will generally have great trouble in finding and bringing them back, because they often go long distances, and he has seldom any means of knowing what route they have taken. Horses give him far more trouble than cattle in this respect, because they can travel faster and farther. I have seen ladies who have the interests of hunting deeply at heart-Mrs. James Hornsby, for instance-ride back and fasten gates which have been carelessly left open.

One grievance which lies very near the heart of a farmer, because I suppose it frequently touches his pocket, is the damage done to his fences, especially during a check, by people who unnecessarily potter through small gaps, which, after they have finished, resemble open spaces. The farmer who has to get them mended speaks very bitterly about fox-hunting, especially if he has to do the repairing at his own expense, as he argues that if it was necessary to work a passage in this manner through his hedge, the field might have been content with one open door instead of making several. A farmer in the North Cheshire country was so irate on this point that on one occasion when the hunt wanted to cross his land, he and his men gave us a welcome with pitchforks!

A kind of farmer whom I despise is the man that 
hunts on the free list and pretends to support foxhunting, while he keeps his land encompassed by wire during the entire season! I have known some of these men enjoy unmerited popularity with the Master, and even take charge of Hunt wire boards. Their non-hunting neighbours who take down wire and over whose land they ride with safety, are obviously the better supporters of hunting, although they may not be able to afford a nag, even if they had time to devote to the sport. The farmer who takes down his wire is naturally displeased with a Hunt which favours an individual who keeps it up; but I think if all Hunt secretaries were like Colonel Henry, such delinquents would soon be brought to book, for no Master would care to see with his hounds, a farmer who kept his land wired during the hunting season. Some of the illustrations of wired fences in this book have been photographed on the land of socalled "hunting farmers." An even worse class of man than the double-dealing farmer is the wealthy landowner who preserves his coverts, shoots foxes, lets his shooting at a big profit, and then goes off to hunt in some fashionable centre, like Melton Mowbray. In Leicestershire he would be regarded as a hunting man, while in his own district he is known as a vulpicide, for Reynard is seldom, if ever, found in his coverts. One has only to live in the country, and pretend indifference about fox-hunting, to see the tricks which some farmers perform in order to prevent people from riding over their land. I remember in the North Cheshire 
country a big covert, which was always considered a certain find, being drawn blank, much to the huntsman's surprise. As he called off his hounds, after a thorough investigation, a farmer said, with a smile: "I knew they wouldn't find a fox here, for Mr. - -'s foxhound puppy, which he is walking, has been rummaging about this covert all morning!" It appears that Mr. Blank was a farmer whose land adjoined the said covert, and who had found his foxhound puppy more useful in driving away foxes than his sheepdogs.

Instead of doling out compensation to farmers as a form of charity, it would be much better for our hunting authorities to meet them on a level footing, get them to appoint a committee of their own, and pay that official body, every year, a certain proportion of the hunt subscriptions, to be applied according to the wishes of the Farmers' Committee.

\section{PILOTS.}

I have not enlarged on the subject of hunting pilotage, because, truth to tell, I have never indulged in the luxury of a pilot, as I have preferred to know the capabilities of my mount and to see and act for myself. I believe that any woman who can ride and manage her horse with intelligent forethought, has no more need of a paid pilot than has the small boy who takes his chance on his pony. If a lady has no male companion to remain with her during the day's hunting, she should provide herself with a groom, 
whose services will be very useful to her, in the event of anything going wrong, and in helping her in various ways. It would be absurd for her to expect casual aid at every turn, in a large field composed chiefly of strangers, especially when its giver would be deprived of his place in a run.

Pilots seem to be going out of fashion, if we may judge by the large number of women who hunt safely without their assistance. The inexperienced huntress generally has her father, brother, husband, or some male friend or servant to show her the way, which is the safest and best method of learning to hunt, because they would know both the capabilities of the young lady and her mount, and could be trusted to keep her out of harm's way. If a paid pilot is engaged, his horse should not be a better fencer than that of his charge. He should also know her riding form, and over what kind of jumps she intends him to lead her.

I would strongly impress on an inexperienced lady the necessity of learning to judge pace, that is to say, to know at what speed her horse is going. The chief duty of a pilot is to set the pace for her, and to select such fences as he knows her horse is capable of jumping, the former being more important than the latter, as it is far more difficult to learn. She should see that her pilot is safely over a fence before sending her horse at it. Only practice and natural aptitude can teach a lady to judge pace: it cannot be learnt from any book. 
A lady should not deceive her pilot, any more than we should withhold the truth from our doctor or lawyer. If she feels more in skirting trim than in hard hunting nerve, she should not hesitate to say so; for we all like to take things easy at times, whether it be in hunting or in anything else, according as we feel fit or otherwise. There is no gainsaying that the human barometer is regulated to a great extent by the weather, as we may see by the big fields which greet the Master on a fine hunting morning.

The unpleasant disclosures which have been recently made in our Law Courts, concerning the free and easy conduct of a certain set of hunting men and women, may prejudice many mothers against hunting as a fitting pastime for their daughters; but the indiscretions of a few idle fast people should not be taken as a sample of the behaviour of an entire field. In the crowd and bustle of hunting, the large majority of the people are seriously engaged in the business of the day, and have no time to indulge in flirtations. Certainly no sane man would choose a meet or covert side, where he is surrounded by a crowd of people, to do his love-making. If the usual discretion is observed in the choice of a companion for a young lady going to and returning from' a hunt, she would have far less opportunity for "frivol," than in any ordinary ball room or theatre. We need only watch hunting men and women passing through a crowded gateway, to see that each one goes in turn, and that there is very little consideration for sex. 


\section{FALLS.}

Although the subject of falling is not a pleasant one to discuss, still we cannot ignore it, for even the best horsewoman occasionally gets hurt by her horse falling with her. Accidents sometimes occur over the most trivial obstacles, and when least expected; and are not confined to jumping, for some of the worst falls have happened on the flat. I remember Captain King-King breaking three ribs and a collar-bone-a pretty good dose in one gulp-by his mount coming down with him on the flat when hunting in Leicestershire. The late Whyte Melville met his death by a similar accident; and poor Archbishop Wilberforce was killed while quietly hacking, by his horse putting his foot in a hole and throwing him on his head. Unfortunately, we are unable to learn the art of falling correctly, because we have only one neck, and, if we break that, our experiments must abruptly cease. We may, however, minimise the danger of its fracture by leaning well back at our fences, and by ducking our chins into our chests when we feel ourselves coming the inevitable cropper. The worst kind of fall is when a horse breasts a stiff fence and either turns a complete somersault, or falls violently on to his head. In the former case, the accident generally means severe internal injuries, to say the least of it; in the latter, a broken collar-bone or concussion of the brain. Such bad accidents are happily rare; for, if a horse can jump, 
he will certainly do his best to clear an obstacle with his fore legs, and if he catches his hind ones and comes down, our chances of either being killed, or crippled for life, are far smaller. In Leicestershire I once saw a stranger send his mount at a posts and rails fence about five feet high, which the animal breasted and went over with a sickening fall; but I could not help thinking that the man must have been either riding a hireling, or must have imagined that his horse was a wonderful jumper to have sent him at such a forbidding thing, especially as it had been avoided by the first flight people, and what they can't jump, strangers may be perfectly certain ought to be left alone. In this case, the animal, which may have been easily able to take the jump, went at it unwillingly, for he saw it was not the line taken by other horses, and he was doubtless annoyed at being asked to incur what must have appeared to him an unnecessary risk. A similar thing occurred when a well-known Leicestershire lady broke her collar-bone. Horses were filing through the gate, and the lady, who was anxious to get forward, put her horse at a stiff posts and rails by the side of it. He apparently regarded the act as unnecessary, for he went at it in a half-hearted fashion, struck the fence, fell, and hurt his rider. It is the custom to say that the first flight people who ride safely over Leicestershire are mounted on the best horses that money can buy; but at the same time, we should remember that they seldom deceive their mounts by asking them to jump anything which is either impossible or unnecessary. 
Mr. Hedworth Barclay, who is one of the finest horsemen in Leicestershire, always rides with great judgment. If he did not, he would not have been safely carried for fourteen seasons by his brilliant hunter Freeman, and for an almost equally long time by Lord Arthur and Franciscan.

A great deal of ignorant nonsense has been written about people (and even horses!) taking "their own line," but such scribes ought to go to Leicestershire and show how that can be done! Ladies who try to follow the teaching of such people, do so at great personal risk ; for it is absurd for a stranger, however well she may ride or be mounted, to think that she can safely take her own line over an unknown country, and especially such a one as Leicestershire, which is in many parts entirely unjumpable. As it requires several seasons "to learn the "lie of the land," most people wisely prefer to hunt in a county they know. Some ladies make a great boast of their numerous falls. One recently told me that she had had fourteen croppers in a hunting season; but when I hear such talk, I cannot help thinking that there is something radically wrong with their riding, for our best horsewomen very seldom fall.

I have noticed that horses have been staked in hunting, through being taken sideways instead of straight, at their fences. It is most dangerous to ride an animal in this manner; because, if he makes a mistake and falls, he will come down on his side and may roll over on to his rider in his efforts to regain 
his feet. We may observe that when a horse is lying on his side he invariably makes a preparatory half roll in rising from that position.

The first thing to do when a horse comes down, is to try to get clear as soon as possible, and to let go the reins, unless the rider can retain them without any risk. She is so encumbered by her skirt, even if it is only an apron, that she will probably get kicked or trodden on, if she hangs on to the reins. "Scrutator" wisely remarks that "so long as there is a chance of holding him together, the pigskin should not be abandoned, but when that chance is gone, by your horse's fore-legs getting into the ditch on the other side, throw yourself clear of him to avoid a pommelling." In such times of difficulty and danger, a lady should remember to leave her horse's mouth alone, and not frighten him, at a moment when her life may depend on his remaining quiet. Whatever happens, she should never utter a startled cry, for that will do no good and may lead to disastrous results. Professor Sample, the American "Horse Tamer," once found himself underneath a cart, while breaking a horse to harness with the long reins. Enveloped as he was in his driving reins, a bad accident might have resulted if he had not kept his presence of mind, while his faithful "Jo," whom he called to his assistance as if nothing had happened, came and helped him out of his dangerous position. He then turned to the audience and calmly told them that he was showing them "how not to do it!" When a lady gets a bad fall out hunting, and we see her 
attended by men only, we should at once go to her . assistance, whether we know her or not; because it is always better for a woman to have one of her own sex to help her and, if necessary, unloosen any garments which are matters that men know nothing about. 


\section{CHAPTER XVII.}

RIDING AND HUNTING ABROAD.

I Now turn to the pleasant subject of riding and hunting abroad, with special reference to India, where almost all our fellow countrymen and women ride and own horses. Even in lonely up-country stations which contain only a few white residents, gymkhanas are often got up by officers who train and ride their own horses and ponies. Nothing seems to give these good sportsmen greater pleasure than lending their equine favourites to their lady friends. Therefore, a visitor who is fond of riding, need never be at a loss for a mount, as I found during my four years' residence in that hospitable land. I can truly say that I did not understand what real hospitality is, until I went to India, and shall always remember the great kindnesses my husband and I received from Native Princes. For instance, the late Maharajah of Vizianagram, who was devoted to horses, invited us to visit him, placed a furnished house, servants, horses, carriages, food, wines and every other comfort at our disposal, and considered our month's stay much too short. Ladies in India who ride, obtain so much practice as a rule on various kinds 
of animals, that they soon become expert horsewomen. It is the custom there to ride twice a day: In the early morning after choti haziri (little breakfast), which usually consists of a cup of tea, a boiled egg, bread and butter; and in the evening. There is no law of trespass in India, and it is delightful to canter for miles while sharing the freedom of the Son of the Desert who is carrying you. There is nothing like these lonely scampers as a cure for petty worries, for you can put. them so far behind you, that on your return you have forgotten their existence. Calcutta is an ideal riding city, with its beautiful maidan (plain), where there are miles of springy turf for galloping, a large race-course with well-kept training and hacking tracks, and hurdles for those who desire jumping practice. There is also a Red Road, which is the Rotten Row of the place, for afternoon hacking among the beauty and fashion, so what more could the heart of man or woman desire? During the misnamed "cold weather," women who are fond of cross country work, can ride once a week over made fences in the paperchases. The course is usually about three miles long, well supplied with fences, chiefly hurdles and stiff mud walls from three feet six to four feet six high. As the start takes place at about seven in the morning, and as the meets are some distance from the town, the devotees of sport have to be up at about five o'clock, dress by. lamplight, send on their chasers, and drive or hack to the trysting place. Two "hares" carry the paper in bags slung across their shoulders and receive a quarter of an hour's grace 
in which to plant their burden, where they know the coloured slips will take some finding. The hares ride over the fences, and by distributing their landmarks sparsely and in places where their pursuers can follow only in single file, they often make it difficult for the leading division to keep the line. Those who over-run the paper, of course imperil their chance of being among the first six, which is the number of "placed horses" in these paperchase records. A writer in Ladies in the Field, while discussing this form of sport, says: "Any old screw, country-bred pony or shortshouldered Arab may be brought out on these occasions." That author evidently had no experience of Calcutta paperchasing, because a horse for this work must not only be a fast galloper and clever jumper, but also must have a good mouth and temper, and be fit and well. In fact, the ideal paperchaser is a cross between a steeplechaser and a hunter, for he has to possess the speed and quick jumping qualities of the former, and the amiability and brains of the latter. Unless a lady has such a mount, it will be almost impossible for her to secure a coveted place among the first half dozen. Also, there are so many horses, say, forty or more, all galloping at the same fences, which are not broad enough for a quarter of that number to take abreast. Consequently, those behind have to see that the coast is clear, before they can proceed. Falls frequently occur, but serious accidents are happily rare. It is true that two men have been killed in these chases; but although ladies have taken part in them 
since the early days when that fine horsewoman, Mrs. " Jim" Cook, set the example, I have not heard of any woman getting badly hurt. Mrs. Cook, who was known in India as the "Mem Sahib," holds the record of being the only woman who has won the Paperchase Cup when competing against men. She won in I88I, was the only lady in about twenty starters, and her mount was appropriately named Champion. The late Lord William Beresford was second, and General Cook, her husband, was third. After I left India, Lord William gave a cup to be competed for by ladies only, which must have acted as a strong stimulant to those who had vainly tried to beat the "mere male." Mrs. Murray was a most plucky rider, and made more than one good bid for the Paperchase Cup, which she well deserved to win. I had a very good Australian horse named Terence, by Talk of the Hills, which got placed in these chases, but when I hoped to do great things with him, I got typhoid fever and exchanged my residence to the General Hospital. The first time I took Terence, who was a beautiful jumper, to a paperchase, two horses fell in front of him at the first jump. A horse ridden by that good sportswoman, Mrs. Saunders, refused a hurdle in front of us, and Terence followed suit. After I had got him sailing away again, a horse ridden by Mr. Garth, a well known horseman, fell over a big blind ditch just in front of Terence, who luckily cleared the lot. Captain Turner was walking about minus horse and hat, and that famous G.R., Captain "Ding" Macdougal, had a nasty purl. In fact, that 
chase was a chapter of accidents. Mr. "Tougal," who had helped to lay the paper, told me afterwards that two of the unbreakable mud walls were four feet three inches high, which is a very formidable height, considering that the horses had to jump out of deep mud. That chase took place on 2nd January, I 89o, and I think it was a far higher test of 'cross country cleverness, than hunters in the shires have to go through.

Mr. Clark, who lived and paperchased for several years in Calcutta, and who was a large horse dealer in Hilmorton, near Rugby, tells me that he frequently measured the mud walls which were built for these chases, and often found them full five feet high. The large majority of horses ridden in these events are well bred Australians, which, taking them all round, are the best jumpers I have ever seen. Some "countrybreds" are fine fencers, but Arabs, delightful as they are for hacking, rarely distinguish themselves across country.

The Calcutta natives were always on the look-out for squalls, like the Irish "wreckers" of olden days. It was no uncommon sight to see a black man, with nothing on but a kummerbund, running away to his lair, with a stirrup leather, hat, or even a pair of spurs belonging to some dethroned sportsman. The horse ridden by Mrs. Saunders in the paperchase I have alluded to, was a powerful "Waler" which, according to his importer, Mr. Macklin, had won nearly all the jumping prizes in Australia! He had evidently been spoiled at the competition business, like many other 
horses, for despite the careful handling of his mistress, he was useless as a paperchaser. We had, while living at Melton Mowbray, a black Irish horse which also had won prizes at show jumping, but he was a most determined refuser in the open, and had many other tricks of temper, so we soon got rid of him.

On off days, during the cold weather in Calcutta, Mr. Milton, who was a dealer and owner of large livery stables, used to invite the. riding community to hunt jackals with his "bobbery pack." The meet took place at the stables before daylight, and the " hounds" were carried to covert in a sort of watercart. They were a most ferocious lot, to judge by the scuffling, squealing and snarling that took place en route. When they were let out, they appeared to lose their heads; the greyhounds, whippets, fox-terriers, bull-terriers, pariahs and nondescripts scampering off in various directions and requiring a good deal of keeping in order. Naturally, the greyhounds and whippets did the coursing, and having sighted a jack, they soon put an end to him. Our huntsman's chief anxiety, as far as I could see, was to arrive in time to secure a bit of the prey for the small fry. It was very interesting to watch the work of these "hounds," and to note that the small terriers used their noses to advantage, and often put their speedier companions on the right track. I had many enjoyable scampers with Mr. Milton's bobbery pack, which I believe is still going strong in the City of Palaces.

At Lucknow, paperchasing was nearly allied to 
steeplechasing, for the course was flagged, and there was no paper to disturb the galloping. Few ladies took part in those functions, but I enjoyed my gallop on Mr. McAndrew's pony, Suffolk Punch, which, after floundering a bit at the double, came down at the last fence, luckily without damaging either of us. The great drawback to the paperchasing at the capital of Oudh, was the blinding dust which was raised by the leading animals, and which almost obscured the fences in front of their followers. As I was only on a pony, all I could see in front of me was flitting shadows in a brown fog, so I left everything to my game little mount, who was galloping his hardest. For the same reason, dust thrown up by the leaders, is not unfrequently the cause of accidents at steeplechasing in India.

Near Bombay and Mozufferpore, jackals are hunted during the cold season by foxhounds sent out from England. In I 889, Mr. Rowland Hudson, Master of the Mozufferpore pack, had seventeen couple of foxhounds, nine of which were supplied by himself, and eight by subscription. These hounds were selected by the late Tom Firr, from the Quorn, Cottesmore, and Pytchley, and they accounted for fifteen brace of jackals from November to March, hunting only two days a week, and after having had several good runs. Foxhounds stand the heat of India badly, and most of them out there die of liver disease, despite the precaution taken of sending them to the hills during the hot months. 
At Singapore, drag-hunting provides good sport in which ladies participate, and show their fine horsewomanship to admiring friends, when the run finishes over the fences on the racecourse. At Shanghai we can' go paperchasing on China (Mongolian) ponies, which, despite their want of pace and somewhat threecornered appearance, are very clever over bad ground. The ladies whom I had the pleasure of meeting in Shanghai, like those in India, were all devoted to riding, and I had many merry scampers across country with them. In the country round Tientsin, we had often to jump over ponderous coffins, for John Chinaman has a provoking way of omitting to bury his relations, after he has stowed them away in their long homes.

Having to stay for a month at Suez, I was greatly disappointed to find no better mounts than the very knowing Egyptian donkeys. As I had never ridden that kind of animal before, I sent my syce, Motee, to hire a couple for the day. To my surprise, the donkey owner came to tell me that I could not ride any of his animals unless he accompanied me! I assured him that I was capable of managing an ass, and would take every care of the beast entrusted to me. He smiled, apparently at my presumption, and as I saw that he would not let me have my way, I consented to the infliction of his company. At the appointed time he appeared on foot, leading two mokes and armed with a long thick stick. As he was evidently going to walk, I whispered to Motee to gallop after me as hard as he 
could, and give the stick man the slip. This I found far easier said than done, because my donkey utterly ignored my commands, even when they were backed up by force, and would take orders only from his master. I saw the man trying to conceal a smile, as I whacked my placid mount with the energy of one who meant business, so impatiently asked him if he had fulfilled the promise he had given Motee to bring me his best donkeys. He assured me that I was sitting on the back of Mrs. Langtry, who was well known as the fastest animal in Suez, and by far the handsomest. He said he had Mrs. Cornwallis West, Ellen Terry, Mary Anderson, Mrs. Kendal, and other good mounts ; but Mrs. Langtry was the pick of the basket for speed and endurance. I asked the name of Motee's moke, which he said was his next best one, and found that it was called Mr. Gladstone! The pair were excellent friends, and insisted on walking side by side, although Motee did all he could to keep Mr. Gladstone behind. Disliking this aspect of affairs, I dealt Motee's mount a couple of sharp cuts with my whip over the quarters, with the object of inducing him to set the pace. This resulted in such high kicking on the part of Mr. Gladstone, that Motee nearly fell off, and the man behind ran up yelling in such an angry tone, that $I$ almost feared he would chastise me in a similar manner. He cooled down and then patronisingly told me that when I had grown older and had gained more experience in riding, I would not be guilty of cruelty to dumb animals. Having failed in my tactics, and paid for 
my ride, I resigned all further activity in the proceedings, and submitted to having the speed of my mount regulated by the stick from behind. When pursued, Mrs. Langtry would go off with a rush, pausing at intervals to listen for footsteps behind, and assure herself that the stick man was well out of reach. Once she relapsed into a dreamy reverie, and so far forgot herself as to allow her owner to wake her up with a tremendous whack, which sent her flying with such force that I was nearly jerked out of the saddle. Our destination was the First Castle, and I was glad to turn homewards. Motee did not appear to have enjoyed his share of the joke, for he looked very angrily at the donkey man as he removed my saddle, and said: "Dis no good ponies, Mem Sahib, plenty tamasha."

That evening when I was recounting my adventures at dinner, Count Carlo Sanminiatelli, who was staying at the same hotel,' asked me in French if I was fond of riding. - On hearing my reply, he at once placed at my disposal nearly three hundred remounts which were to be shipped later on to Massowah. These horses belonged to the Italian Government, which was expecting a row with King John of Abyssinia. After that, Motee and I used to disappear for hours in the desert every day, and we wended our way back to the hotel, only when the pangs of hunger forced us to do so. We would try sometimes as many as fifteen animals in a day, and I took the numbers of those which were nice to ride. In a very short time I had 
a list of more than a dozen of the nicest horses, which I intended to keep for my own hacking. As most of them had been accustomed to the barbarous Mameluke bit, which is used in Egypt, they took very kindly to my snaffle. The desert is a grand place for trying experiments with horses; for in it there is nothing to frighten or distract their attention from their work, and if one does happen to get a spill, the falling is very soft. As soon as the news of my doings became noised abroad in Suez, the riding men mustered in great force and borrowed several of the horses I had passed as quiet. It was amusing to see some of the horsemen sending all over the place to borrow a saddle, and in a couple of days we all met for a ride. One of the ladies rode very well, but she would not try any of the remounts, as she had her own Arab. There was seldom such excitement in Suez before, the lawn tennis ground became quite deserted, and everyone seemed to have gone riding mad.

Coursing steinbok with greyhounds used to be a popular sport in South Africa, but when my husband and I were in Kimberley in I892, Mr. Fenn was establishing a pack of foxhounds. I fear the Jameson Raid and its dire results have sadly disturbed the harmony of that sporting community.

I cannot help thinking that the Germans are more devoted to riding than any other Continental nation. I have not hunted in Germany, as I was there only during the summer; but I sold a good hunter to a German Count who was a fine horseman and a Master 
of Foxhounds. He told me that a large number of ladies hunted with his pack. I was particularly struck with the immense size and beauty of the riding schools in Berlin. In the Berliner Tattersall there are three large riding schools, and I seldom went there without seeing some ladies on horseback. In the largest riding school there is a gallery, a refreshment room, reading room, several dressing rooms, a bandstand, and seating accommodation for hundreds of people. The proprietor told me that in the winter months when the weather is too bad for outside riding, ladies ride in the schools, and various entertainments are given. I saw a large number of ladies riding in the Tiergarten, although it was out of the season, and I expected to find the ride as empty as Rotten Row in the winter months. As I went there before eight in the morning, our German cousins must be early risers. On the last occasion we visited-the Tiergarten, we were on our way home from Russia, and, having a couple of hours to wait for our train, we strolled into the delightful wooded ride. It was about half-past seven on a cold March morning, and almost the first people I saw there were the Kaiser and the Kaiserin, so I no longer marvelled at German ladies' taste for early rising.

When I was in the Bois de Boulogne last season, it was greatly frequented as usual, but it struck me that fewer women ride there now than formerly, and that motor cars have absorbed their attention.

Although the riding schools of Paris are not to be 
compared to those of Berlin, the worst of them is far superior to the two miserable civilian riding schools in St. Petersburg, where riding is almost entirely a military function. Very few Russian women ride, although history tells us that Peter III. kept a pack of hounds, and that his wife, Catherine II., according to her memoirs, listened to the loving solicitations of Soltikov while they were riding together "to find the dogs." A saddle belonging to this amorous lady, which I saw at the Hermitage, was like an Australian buck-jumping saddle, with large knee rolls and a high cantle. It was covered with red velvet and decorated with cowrie shells. The side saddle appears to have been first used in Russia by the daughters of the Emperor Paul.

The Duchess of Newcastle, writing in Ladies in the Field, on "the untidy slipshod way the riders are often turned out" in Rotten Row, terms this state of things "a disgrace to a country which is considered to have the best horses and riders in the world," and wonders what foreigners must think of the sorry spectacle. This "floppy" untidyness of riding dress appears to have been introduced by the " new woman." Twenty years ago, top hats and perfectly fitting habits were de rigueur; but now neither horses nor riders are so well trained for park hacking as they were in those days. The Duchess also points out that it is as cheap to be clean as dirty, and there is no reason why the horses should not be groomed, and their bits burnished. 


\section{CHAPTER XVIII.}

\section{WALKING FOXHOUND PUPPIES.}

I BELIEVE I am correct in stating that no woman who has ever hunted, professes any other feeling than that of ardent admiration for the hounds which provide her with sport; but I would like to see this admiration take, among hunting women, the more practical form of walking hunt puppies, in whose future well-being they should have a keen personal interest. There are two maiden ladies in Ireland, who, although they have never hunted, and are long past the age at which they are likely to do so, always, from sheer love of sport, walk a couple of foxhound puppies for their district hunt. We want, I think, more of this sporting Irish feeling among our sex, for I am sure that apart from all other considerations, a hunting woman would find more to interest her in the rearing and training of a foxhound puppy, whose career she could literally follow, than in spending money and time in clothing and nursing a useless pug or toy terrier. There is no more intelligent and charming companion for a woman 
than a young foxhound, who appears to be able to do everything but speak, and even that he can do in a mute way, for when he is greatly troubled, he cries like a human being, with real tears. I am thinking as I write of a young Cottesmore pup I was walking at Melton Mowbray who, when a friend accidentally trod on his foot, came yelping up to me for sympathy with big tears rolling down his face. When I picked up this heavy lump of dog and soothed him, he at once stopped his yelping and his tears like a child.

Mr. Otho Paget in his interesting book, Hunting, says, "The whole future success of your breeding hounds rests on being able to get good walks," and in order to ensure such success, he advises generosity in the matter of prize giving at the annual puppy show and the luncheon on that occasion, to be "as smart and festive as you can make it." Mr. Paget considers that the "ideal home for a puppy" is a farmhouse; but even if this statement were correct-which I greatly doubt, seeing the poverty of many farmers and the neglected state of their own domestic animals-few farmers walk foxhound puppies even in classic Leicestershire. When a large landowner, good sportsman and lover of hunting like the late Duke of Rutland, makes an agreement with his tenantfarmers to walk puppies, the work is certain to be carried out in a give and take manner which will cement good feeling between both parties, and will promote sport; but the practice which obtains in some badly managed hunts of sending a whipper-in 
to dump down his cartload of puppies on any people who will consent to take them, is not only akin to cadging, but is also productive of many cases of neglect which ought to come before the notice of the Society for the Prevention of Cruelty to Animals. Instead of deputing servants to dispose of young hounds in this casual manner, the Master or his Secretary should approach the residents of the district, and either personally, or by writing, arrange with them to walk puppies, so that they may be prepared to receive their young charges. Also, the Master or Secretary should visit the puppies at walk occasionally, as such practical interest taken in their welfare, would tend to encourage the walker in her by no means easy task of rearing the youngsters.

Mr. Otho Paget's advice as to prize giving and a sumptuous lunch hardly, I think, meets the requirements of the case. We can dismiss the lunch, as very few of my sex care for "smart and festive" feeding, and as far as the prizes go for their trouble and expense with the animals, what is the use of judging puppies six months after they have returned from walk? The poor, neglected, half-starved animal who goes back to kennels all skin and bone may, if he be a well-shaped hound, show up better at the time of judging, than those who were returned full of good food and in hard exercise, but who may have lost in condition by fretting, or by having to live on shorter rations than before. Some puppies, as I know from experience, have either died during the six months' interval, or have 
been drafted to another pack. Therefore it would be far more satisfactory and encouraging to puppy walkers for the judging to be on a day fixed for them to take their young charges to the kennels. In bygone days when country squires lived on their land and their tenants were under contract to walk puppies, the present arrangement no doubt answered well enough, because it was to the tenant's interest to do his best to please his landlord; but times have changed since then. The large majority of people who hunt nowadays, rent hunting boxes for the season, and take so little interest in country life that they fly off to town on the first appearance of frost, and are not seen again until the land is fit to be ridden over. When the season ends, they disappear till the following one. Few of them know any of the resident farmers or inhabitants of hunting centres even by sight, or want to know them. This snobbish exclusiveness is very harmful to the interests of hunting, because the farmers are under no obligation to them-quite the reverse-and a farmer can, if he likes, refuse to allow them to ride over his land. Therefore, when hunting people show farmers no civility, the agriculturists naturally do not care to go to the trouble and expense of walking hunt puppies, as several farmers have told me, unless they are given a better inducement to do so than present arrangements offer. Then again, in judging puppies returned from walk, supposing the judging takes place at once, as it should do, only the condition of the puppies, and not their 
"points" should be taken into consideration; for the walker usually has to take any puppies that are given to him, and as he does not breed them, he cannot be held responsible for any defects which may be in their make and shape. The hunt puppy-show ought to be a function entirely apart from the walkers' show, and until this is done, the unfortunate puppies will continue to be dumped down on any stranger who will consent to take them.

I cannot help thinking that the great mortality which takes place every season among young hounds, might be considerably lessened if the various hunts were to send out with the puppies, for the benefit of inexperienced walkers, a pamphlet or card of printed instructions concerning their feeding and general management. They should also request the walker to report any case of sickness, and should at once despatch a competent veterinary surgeon to investigate such cases and prescribe for the young patients. The inexperienced puppy walker, in her anxiety to get her charges strong, often gorges them to repletion with raw meat even before they have got any permanent teeth, which is as absurd as feeding an infant on raw steak. We know not how young hounds contract distemper, but they cannot be prevented in their daily walks from eating offal, and if the germs of the disease are taken into their bodies in this way, the hound whose system has been weakened by " heating " and unsuitable food will seldom recover. I do not wish to pose as an authority on this subject and am simply giving, 
for the benefit of ladies who find themselves placed in a similar predicament, my experience, or rather, at this stage, inexperience, in walking a couple of Cottesmore pups. I tried very hard to save those pups, nursed them night and day, and had them in my room at night, but both died. One of them was slowly recovering, but was so weak that he could hardly stand, and I was recommended to give him some fresh meat cut up small. This food occasioned a relapse, and next day he was dead. I notice that Mr. Otho Paget in his book on Hunting recommends "a little raw fresh meat" for weakly pups, but possibly he would not advocate it for one getting over distemper. I attributed the death of my charges solely to improper feeding, and have since been successful in rearing others by feeding them at first on bread and milk, biscuits and gravy, scraps of cooked vegetables, and when meat has been given, I have taken care to see that it has been cooked. Even with the greatest attention to diet and exercise, that horror, distemper, has attacked them, but they have made a good recovery. At the time of writing I am walking a couple of Pytchley pups, which alas, will soon go to their permanent home. Both of them have had distemper, one in a very severe form, accompanied by an abscess in his throat, which prevented him from swallowing anything but beaten eggs and milk for several days. His portrait (Fig. I4I) shows that he has now "grown into a hound," and I am proud of him, for all of the Pytchley pups of the first, or spring batch, which were distributed in 
this village died of distemper with the exception of my couple. My pups must have contracted the disease from a neighbouring farmer's dog who died of it in great agony with an abscess in his throat. Possibly the adoption of some kind of muzzle would prevent puppies from eating diseased matter.

My belief in the necessity of giving hounds cooked meat and rigorously abjuring it in a raw state, excited ridicule here, but when the good result of such "faddy" feeding was proved by the healthy condition of the animals, the unbelievers acknowledged themselves converted. Mills, in his Life of a Foxhound, tells us that Ringwood, who appears to have been a fine hound, was brought up solely on "sweet milk, meal and broth"; but I find that pups in hard exercise want a generous supply of cooked paunch as well as bones for the development of their teeth, and that if they are blown out with sloppy food, their internal arrangements become disorganized. Besides, a hound cannot gallop on meal alone. One of the greatest difficulties with which puppy walkers in small villages have to contend, is in obtaining an adequate supply of paunches and bones, for country butchers do not kill many animals in the week, as there is little sale for meat. The average villager purchases a joint for his "Sunday's dinner," which either lasts the whole week, or is supplemented by scraps of meat, or even a "bone pie"! An ox paunch is of course dressed and sold as tripe, all sorts of pork scraps are made up into brawn, mutton ditto into "faggots," so that there is very little left for the 
foxhound puppies. During the hot summer months it is best to give pups very little cooked meat, but plenty of cooked vegetables, biscuit, house scraps of bread, \&c., and in cold weather the first meal of the day should,

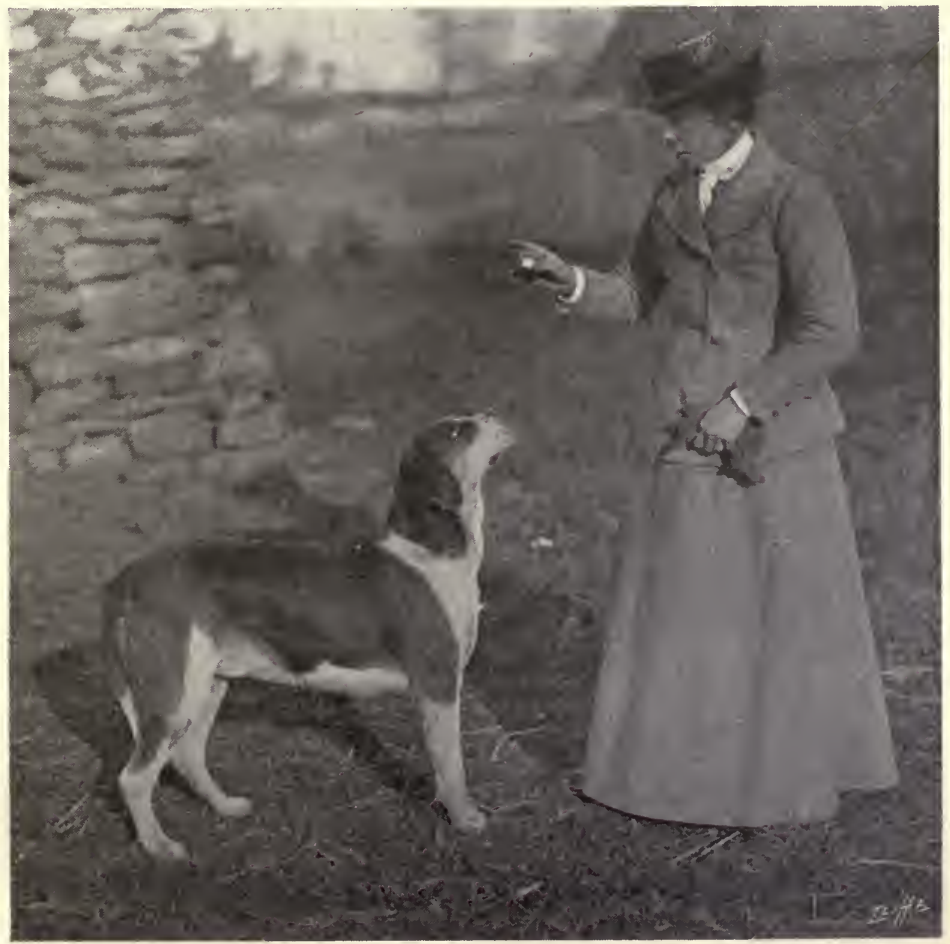

Fig. I4I.-Pytchley puppy, Mottley.

if possible, be given warm, or mixed with warm milk, for when young animals are cold and hungry, it is a good thing to warm their little insides. All meat should be given cut up. When feeding hounds on remains of fish, care should be taken to remove large 
bones, which are very apt to choke them. If puppies are shut up at night in a barn or loose box, their abode should be cleaned out every morning, and any soiled straw removed. Attention should be paid to the thawing of their drinking water during severe weather. After they have got their teeth and begin to snarl over their bones, it is best to feed them in separate tins, or the stronger and greedier of the two will get far more than his fair share, even if he allows his pal to have any at all. I have found ordinary large sized baking tins useful for feeding purposes, as crockery is liable to get smashed. It is a good plan to have a system of regular feeding morning and evening; for puppies, like children, thrive better on regular meals than when they are "picking and nipping" all day. A constant supply of fresh water should be always at hand for their use.

For ladies who attend personally to the wants of their canine friends, Messrs. D. H. Evans, of Oxford Street, have registered a kennel coat, which I think will fill a want. They have adopted my suggestions respecting its make and shape, and have made it in mud-coloured washing material, as that tint looks less unsightly when soiled than white, which is worn by kennel huntsmen. A protection of this kind for the dress is needed in tending dogs, and I have found it a very serviceable garment. Fig. I42 shows the front view of this coat ; and Fig. I43, the back view.

Another point to remember in the management of puppies is never to wash them. I believe every 
experienced hound man will bear me out in attributing many tiresome ailments to the bath tub. Hounds can be kept perfectly clean by careful brushing, and their

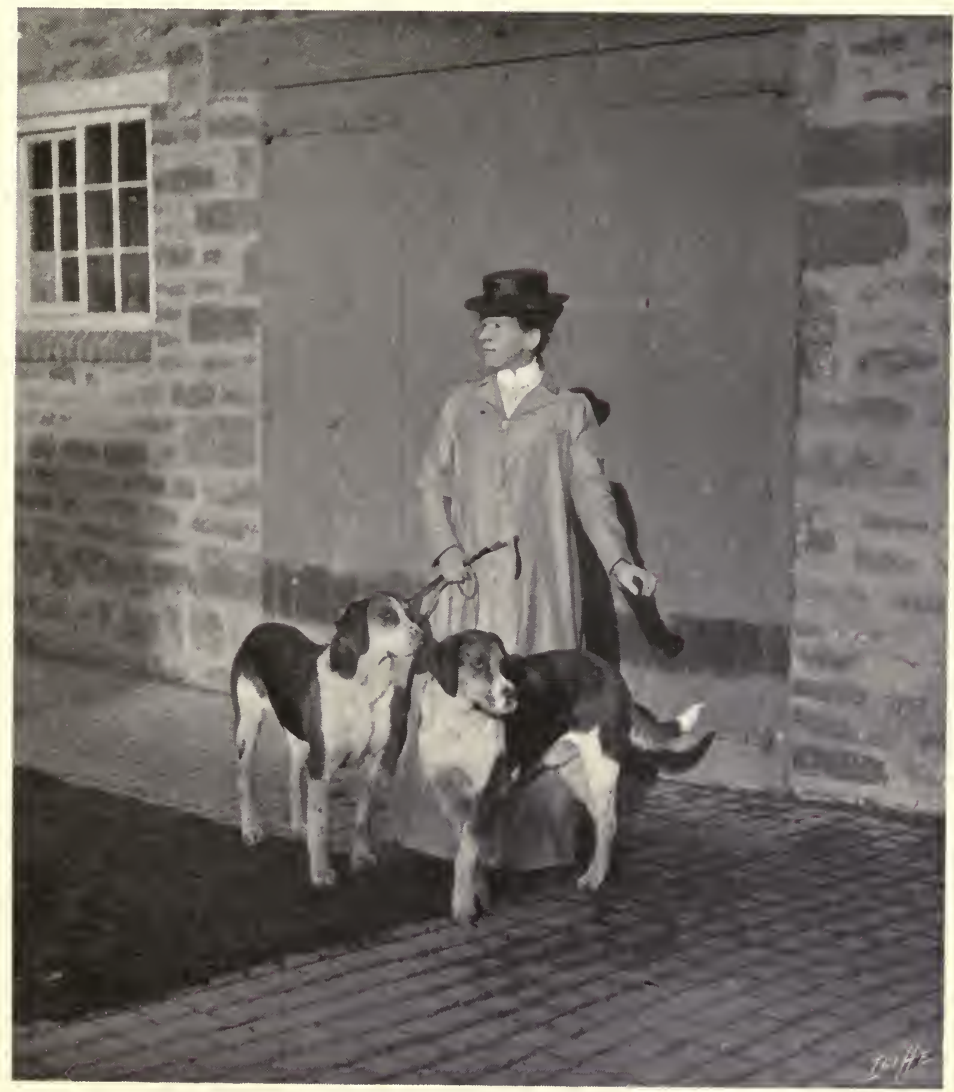

Fig. I42.-Front view of Kennel Coat.

coats will show a gloss and polish that no bathing can give. It is not unusual to find mange in pups fresh from kennel, and care should be taken that the brush is not used on the affected animal. I found that applica- 
tions of paraffin and salad oil, in equal parts of each, quickly cured mange, and that the hair on the coat grew thick and appeared to be greatly benefited by the lotion.

Although pills are supplied by some hunts to be given to pups who are off their feed, it is no easy task for a woman, or even man, to induce an animal to swallow one, and the struggles of the terrified youngster who objects to the pill, often make it do more harm than good. That safe old medicine, castor oil, is generally at hand, and a puppy will lap a spoonful or two in milk without making a fuss. My experience of dog doctoring has been practically limited to castor oil, except during distemper, when five grains of quinine have been given daily with beneficial results. The best way to give this medicine is to mix it with a small piece of butter and spread this ointment on a piece of cheese, which will be eagerly gobbled up, as all hounds appear to like cheese. The pups should have plenty of clean dry straw for their bedding, and boards are far safer and more comfortable for them to lie on than bricks, which are always more or less cold and damp. Each pup selects his own spot for his bed, which he arranges to his liking, and if plenty of straw be given, he will burrow under it in very cold weather and thus keep himself warm. There is certain to be one pup which we like best, but no favouritism should be shown outwardly, as it breeds envy, hatred and malice, and all bow-wows are afflicted with jealousy. It is best if possible to take two pups, as a lone hound is miserable 
without a playmate, and if he has no one to play with, he will be almost sure to get into mischief. One will want to boss the other, but they can generally be left to settle their own quarrels. In every pack there

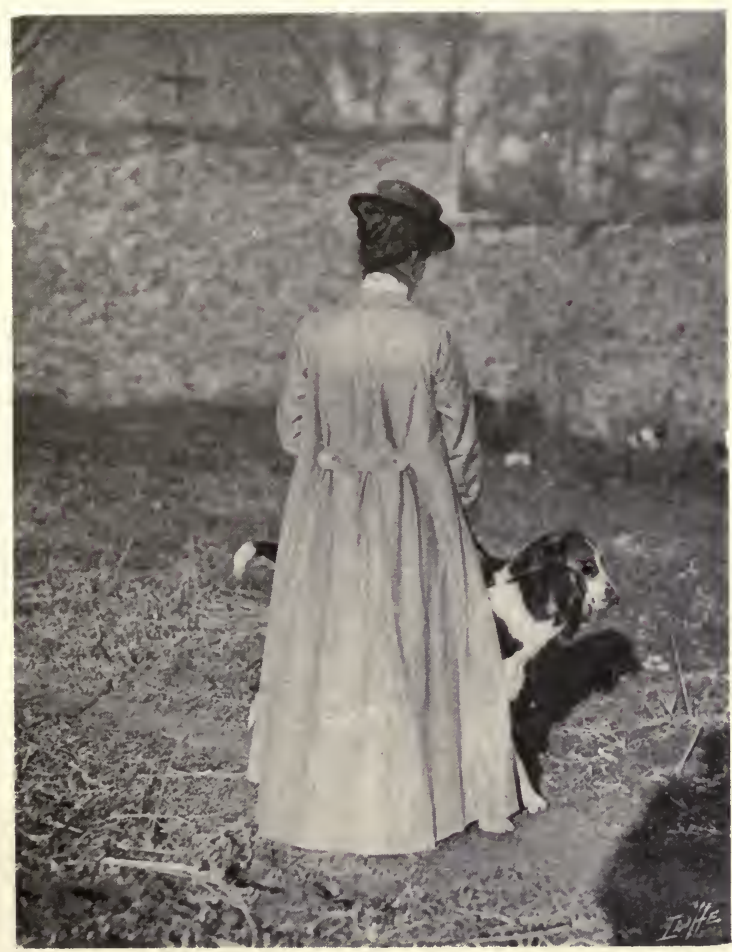

Fig. I43. - Back view of Kennel Coat.

is a master hound who rules the roost, but if he degenerates into an intolerable bully, he may, not improbably, be killed and eaten by the others, an occurrence which Mr. Mills tells us took place in Mr. Conyer's kennel at Copthall, Essex. 
Next to feeding, the most important thing in puppy walking is exercise. Foxhounds have to know how to gallop, and therefore the young hound requires training. It is both cruel and useless to keep a healthy pup shut up in a stable or yard and afford him no opportunity of learning his work. As soon as the young ones settle down in their new home, they may be taken out for short walks, in order to accustom them to pass traffic, and if possible they should have a steady old dog to lead them ; for even the placid cow coming home to be milked, will prove an object of terror to them and probably cause them to bolt home. With the exercise of patience and kindness, such fearsome journeys will soon be made with safety, and moving objects will cease to be regarded; in fact a bold hound will be likely to prove far too venturesome, and his hair-breadth escapes from being run over will occasion much anxiety. After the pups have got accustomed to getting out of the way of fast traffic, it is excellent training for them to learn to follow a bicycle, Fig. I 44; but the rider must go slowly at first and only short distances, in order not to overtax the strength of the young hounds. A good rule is to slow down when the animals lag behind, and if they show any signs of fatigue, and are not stopping merely to make investigations, it is time to go slowly home. They will soon be able to gallop as fast as any ordinary rider can safely steer her bicycle, and will sometimes show their freshness and play, by catching hold of her skirt with their teeth, as once happened to me and gave me a fall. Foxhounds are 
INTELLIGENCE OF PUPPIES.

however so intelligent that the animal who playfully caused my discomfiture, looked sorrowfully at me as I lay sprawled out with my machine on the ground,

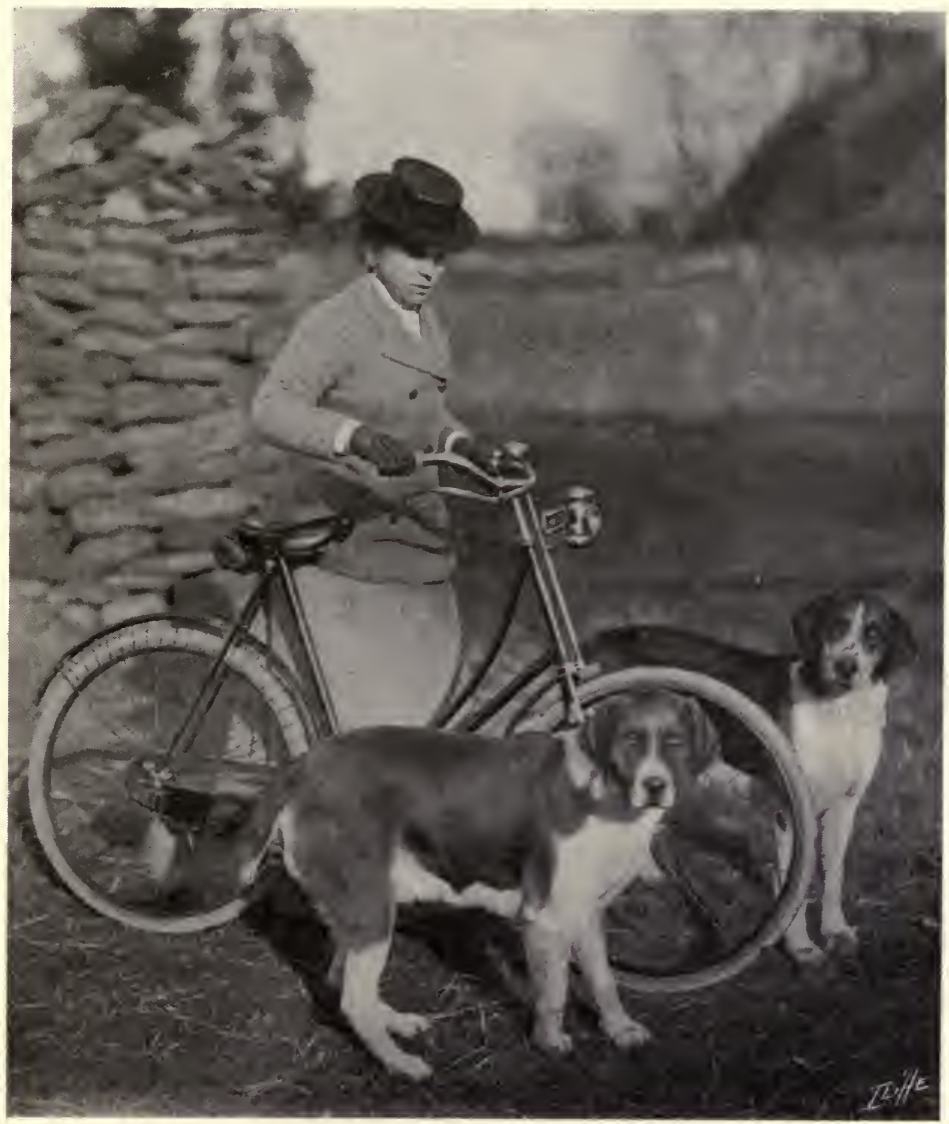

Fig. 144.-- Puppies with bicycle.

and I feel sure that when I reproached him, he understood the drift of my remarks, for he never afterwards attempted to touch my skirt, though he has often come 
bumping into me, when flying for protection from some imaginary enemy. It is impossible to be really angry with these most affectionate irresponsible beings, for they are brimful of the exuberance of youth, and if they roll over each other in the middle of the road just under the front wheel, it is advisable to try and get out of the way. A good plan when this road playing begins is to keep the break going, ready for "happenings." Riding with pups is excellent practice in bicycle control! From bicycle exercise we passed to the higher stage of taking out the pups with horses, but I regret we did not continue the bicycle training, because one day the bolder hound of the two (Fig. I45), who had several narrow escapes by reason of his insane propensity for running into the middle of the road and jumping up at the muzzle of an advancing horse, met with a serious accident, to wit, a fractured fore leg. I was not present when it occurred, but I had often ridden out with this hound, whose vagaries in the matter of jumping up at my horse's muzzle or playfully biting his hocks, frequently necessitated my riding at a walk. The animals who were ridden with these hounds were quiet, insomuch as they never attempted to kick them when all were loose in a paddock, or when ridden; but even the quietest horse in the world is apt to show annoyance if very great liberties are taken with his person by either man or hound. My experience teaches me to remember this fact and not try a horse, who is not a huntsman's mount, too highly in this respect. The more sedate pup of the two is in fine 
condition, because he takes no liberties with the horses and therefore he obtains his requisite exercise; but if I wanted a bold, generous, dashing foxhound who can use his nose, swim a river or perform in brilliant

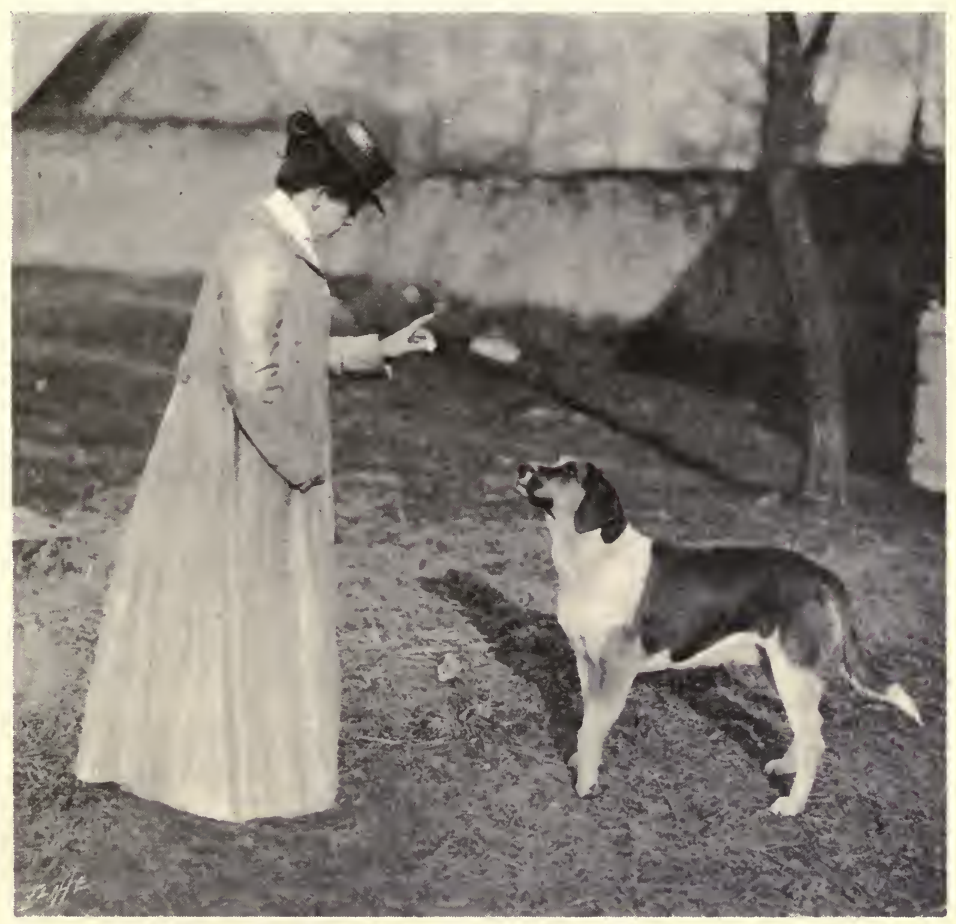

Fig. 145.-Pytchley puppy, Monarch.

style the work required in hunting, I should unhesitatingly choose the bold cripple, who I hope will get his leg right, for he would certainly perform brilliantly in any hunt, although as a show hound he would be superseded by his more sulky and indolent brother.

As the first requisites in a foxhound are pluck and 
confidence, I would, in selecting a couple of pups from the usual cartload, prefer to take from those who came and faced me boldly, as if inquiring my business, rather than to seek for "show" points among those who require to be dragged from the back of the cart for inspection. Many people are debarred from walking foxhound pups from the tales they have heard about their destructiveness, but these yarns are grossly exaggerated, for the youngsters are no worse than ordinary puppies in their desire to try their new teeth on sponges, brushes, boots or anything else they can procure. If they are taught from the first that such things are riot, and are given in their idle moments a bone on which to expend their energy, they will peacefully occupy themselves with it for hours, and after they have eaten it or as much of it as is possible to be broken off, they will solemnly proceed to inter it for resurrection on some future occasion.

A young dog who has had his necessary exercise, will prefer to sleep than to get into mischief; but if kept idle, he will naturally seek some means of working off his pent-up energy. It is as cruel to punish a young animal for gnawing and biting inanimate objects, as it is to strike a teething infant who is similarly prone to use his teeth on anything he can get hold of. We generally supply such a child with a bone ring or something equally safe to bite; and if we do not give a puppy a bone, he will quickly find something for himself. I have a sheep-dog pup who, having gnawed and buried a boot in the paddock, was brought to me 
for correction. I gave him a "good talking to" and ordered hirn to lie down near me under the table, where I believed he would be out of mischief. I went on with my work and thought he was asleep, but when I bent down and looked at him, I found him busy at a large hole he was biting in our carpet! It was all my fault - he ought to have had a bone.

We now come to the important question of corporal punishment, which I have deferred, as I hate it, but I know that it is a necessary evil. Solomon's warning about sparing the rod is more applicable, I think, to foxhounds than to children, for the spoilt hound has before him a fearful day of reckoning which a child may escape. Therefore our supposed kindness in ignoring sins of omission or commission is, in the case of a young hound, a cruel wrong which will assuredly cause him a great deal of suffering that timely correction on our part may avert. In the first place we ought to insist on implicit obedience, not by coaxing, but by the whip, for if a hound wilfully disobeys the person whom he loves as his mother, how much less will he be inclined to obey the orders of a stranger who is his whipper-in? When it is necessary to punish a glaring offence concerning which the lady walker, who is acting the part of mentor, has given an unheeded warning, the offender should be well whipped by someone told off to perform this operation, and when they fly to her for sympathy, she should remain silent as one who knows they have been justly punished. If she has to undertake these salutary thrashings herself, she should 
call the hounds to her in a tone of voice which she knows they can hear, and if, as frequently happens, they hesitate for a moment, look at her and then decide to disobey her command, she should follow them up, still calling on them to come to her, but now in a severer tone, and the disobedient ones will generally falter and take refuge in any available place. Then is the time to punish them with a few sharp cuts of whip or cane. There will be no howling, as the pups know very well that they have transgressed, and will show it on the way home by answering promptly when they are called. Pups must be punished only when they are caught in the act of disobedience; but a sin of yesterday must never be punished to-day; because foxhounds, like all dogs, have a keen sense of justice, and only, understand the meaning of punishment when it is timely administered. All attempts at hunting on their own account should be rigorously repressed, and the personal dignity of the house cats should be upheld. Even when the hounds are accorded the special favour of entering the house, our pussies must be no more disturbed by them than they would be by our house dogs who sleep near the fireside with them. I like to encourage hounds to visit me occasionally in the house, as then they are, so to speak, on their honour, and they so much appreciate these visits that they lie peacefully near the fire with the cats in perfect friendship, after having carefully examined, without touching, everything in 
the room. They may look and smell, but not touch, and as bad behaviour in this respect means instant ejection, they soon become like visitors to a museum. The worst about puppy walking is that one has to part with these delightful companions, and that parting is a time of sorrow which we feel almost as keenly as if they were our children leaving home for the first time with all life's troubles before them. 


\section{CHAPTER XIX.}

\section{KINDNESS TO HORSES.}

A GREAT deal has been said and written about badtempered horses, but hardly enough anent the riders who make them sulky or irritable. Jorrocks' remark that "the less a man knows about an 'oss, the more he expects" is perfectly true; for such persons seem to regard horses as machines, and are ever ready to slash them with the whip across the head, or any other part on which they think they can inflict most pain, and then when animals resent such cruelty, they dub them bad-tempered brutes! There are people belonging to the show-off brigade, who punish horses without the slightest provocation, in order to attract general attention to their fine' (?) horsemanship. Their method is first to job the animal in the mouth, and when he exhibits the resulting signs of irritated surprise, to "lamb" him well. Another kind of horse-spoiler is the man who, having been angered by some person, vents his pent-up rage on his unfortunate mount. Far be it from me to call down the wrath of the lords 
of creation on my thin head by denouncing them all as cruel monsters, but my experience is that, in the majority of cases, horses are rendered vicious by brutal treatment on the part of men. A horse, like a dog, has a keen sense of justice; he never forgets unmerited punishment, but is in a constant state of nervous anxiety when ridden by a man who treats him unkindly. A dog exhibits a similar feeling of distrust of a cruel master by crouching up to him when called, instead of being delighted to see him, and according him a frisky welcome. I will give an instance of what I once saw a bad-tempered man do with a bird in India. The animal was a small green parrot which the man had taught to perform a certain trick; but I don't know what it was, because the parrot did not execute it when asked to do so. The owner of the bird was a very mild private individual, who I thought was fond of animals, and who asked me to see the effect of his training on this parrot. He tried to get the little thing to perform, but as it would not, for some cause best known to itself, he actually wrung its neck in my presence! I shall never forget that incident, because it gave me one of the greatest shocks I have ever experienced. This was, of course, an exceptional case of temper, which I mention only to show to what extremities a violent burst of rage may carry a sane individual. We often hear of an uncontrollable temper, but I believe that every man can, if he likes, govern his rage, unless, of 
course, he is demented. If the vast majority of so-called vicious horses could write the story of their lives, what terrible tales of suffering and injustice they would relate! A horse, unlike a dog, bears punishment in silence, and any brutal creature may with impunity torture a horse, but if he tried to hurt a dog in like degree, the yelping of the animal would alarm the entire neighbourhood, and be almost certain to call forth a strong remonstrance from some lover of animals whose sympathy had been excited by hearing such piteous cries. People who are unacquainted with the inner life of stables, have no idea of the brutality which many grooms and strappers inflict on the animals in their charge. When we find a horse which is difficult to bridle, owing to the objection he has to allowing his muzzle or ears to be approached by the hand of man, we may be almost certain that this vice has been caused by the application of a twitch, either on his upper lip, or on one of his ears, a method of restraint which should never be employed. By laying down the law on this point of horse control, I in no way pose as an authority, but rely on what my husband, who is a veterinary surgeon, thinks on this matter. He tells me that during the two trips which he made in I9OI to South Africa in veterinary charge of remounts, he examined the mouths of over seven hundred horses and found that more than ten per cent. of them had been permanently injured, especially on the tongue, by the inhuman application of twitches. 
No one, veterinary surgeon or layman, is justified in using a twitch that will make the animal subsequently difficult to handle. If any of my readers wish to know how a twitch can be applied without this drawback, they should consult my husband's book, Illustrated Horse Breaking. Of all horses, a good hunter which passes into the hands of an incompetent master, is most to be pitied. The wretched condition of many hunters is truly pitiable. Their skins, instead of showing the glow of health, present a dried-up, kippered-herring appearance, and some of the poor things have the miserable halfstarved look of Berlin cab horses, chiefly because they live as a rule in a constant state of thirst, owing to the objection their grooms have of allowing them a sufficiency of water to drink. Such parched animals will quickly tell their mistress this secret, by loudly neighing, if, when she goes near their boxes or stalls, she takes up and rattles a stable bucket. This thirst torture is abominable cruelty.

In this country, grooms, as a rule, are given a free hand in the feeding and management of horses, with frequently disastrous results, owing to the consequent system of commissions and tips from horse dealers, corn dealers, saddlers and shoeing smiths. In India and the Colonies, horse-owners usually take a practical interest in the welfare of their equine servants, which are therefore properly fed, and have a plentiful supply of fresh water to drink. Almost all hunting grooms keep horses in loose boxes tied up 
during the day, in order to prevent them lying down, soiling themselves and disarranging the bedding, which would, of course, entail trouble on the stable attendants. To such men, the good effect of liberty on legs and health is, of course, a negligible quantity. It is evident that the benefit of a loose box is nullified, if the animal in it is tied up. When we visit horses in their stable and find that they exhibit terror at our approach, we may conclude that their fear is due to bad management, because no horse which has been kindly treated, will show the slightest fear on being approached. A class of groom whom I would not care to keep, is the funky man who is continually yelling at his animals, and thus unfits them to obey our words of command when we ride them. Every horseowner, even from a purely humane point of view, should spare a few minutes at night before turning in, to see that the animals have got plenty of hay and are not parched with thirst. I would strongly plead for our dumb friends in this matter, because, on more than one occasion, I have found my horses shut up for the night without "bite or sup," and by the welcome they always gave me, I know they were most grateful to me for my nightly visits, not only in neighing on hearing me speak, but also in dutifully obeying my voice when I rode them.. If a horse, like a dog, gets to know that his mistress is his kindest friend, he will do his best to please her, and will remain steady at her command even under 
very great provocation to "play up." Here again Jorrocks' advice to know your horse comes in, for our stable friendship with our animals establishes a bond of unity which they will always remember and appreciate. Horses are very sporting animals, and the love of competition is inherent in them all, from the hack to the steeplechaser. When it is a question of a gallop, an old nag will put his best foot foremost and try to outdistance his companion, even though his chances of so doing may be extremely small. In hunting and racing we see horses gamely struggling on, often under severe punishment. To my mind, half the pleasure of witnessing equine competitions of speed and staying power is lost by the brutality of jockeys who, possibly from rage and disappointment at losing a race, often unmercifully punish their animals with whip and spurs, even when the first three horses have passed the winning post.

One of the most fruitful causes of bad mouths is the practice which many servants adopt of jerking the reins, when a horse which they are holding becomes restless, even when the inquietude consists merely in looking at passing objects. Men who adopt this barbarous method of control, never accompany the action of their hand with the voice, and, consequently, the unfortunate animal does not know why he is punished. He naturally connects any pressure of the mouth-piece on the bars of his mouth with the idea of pain, from which he tries to escape by throwing up his head. Hence, instead of 
going freely up to his bit, and thus putting himself in touch with his rider, he will fight against it and will be unpleasant, if not dangerous, to ride.

There have been many funny books written about horsemanship! In a very incompetent book on this subject, the author states: "In riding, if a horse does not nag himself properly, take short hold of the reins with your left hand, lean back in the saddle, with a light whip or stick give him three or four strokes right and left down his shoulders, at the same time holding the reins tight so that he does not go from under you; he will soon alter his pace. That requires practice, with nerve and judgment." I think that a person who would be guilty of such a display of "nerve and judgment" deserves similar punishment with the whip. It is in the hands of such men that horses earn the reputation of being bad-tempered. This writer also tells us " not to give water before feeding, as it weakens the saliva in a horse's mouth!" Whyte Melville owed his success in horse management to the adoption of kind and humane methods. All those who have broken and ridden young horses know how thoroughly sound is his advice :- "From the day you slip a halter over his ears he should be encouraged to look to you, like a child, for all his little wants and simple pleasures. He should come cantering up from the farthest corner in the paddock when he hears your voice, should ask to have his nose rubbed, his head stroked, his neck patted, with 
those honest pleading looks which will make the confidence of a dumb creature so touching; and before a roller has been put on his back, or a snaffle in his mouth, he should be convinced that everything you do to him is right, and that it is impossible for you, his best friend, to cause him the least uneasiness or harm.

"I once owned a mare that would push her nose into my pockets in search of bread and sugar, would lick my face and hands like a dog, or suffer me to cling to any part of her limbs and body while she stood perfectly motionless. On one occasion, when I hung up in the stirrup after a fall, she never stirred on rising, till by a succession of laborious and ludicrous efforts I could swing myself back into the saddle, with my foot still fast, though hounds were running hard, and she loved hunting dearly in her heart. As a friend remarked at the time, "The little mare seems very fond of you, or there might have been a bother'! Now this affection was but the result of petting, sugar, kind and encouraging words, particularly at her fences, and a rigid abstinence from abuse of the bridle and the spur.'

Many animal lovers, especially those who have had no personal experience in studying the peculiarities of our dumb servants, consider that all horses behave well if kindly treated. This belief has a certain foundation in fact, in the case of amiable animals which appreciate good usage. There are, however, many horses, especially among the half-bred hackney class of riding animal, possessed of bitter obstinacy 
which no amount of kindness on our part can subdue. Some of these animals allow us to get on their backs and carry us quietly, so long as we permit them to proceed at their desired pace; but as soon as we attempt to assert ourselves in this matter, they display their sullen tempers in various ways, either by plunging, pulling, or setting up other defences against our authority. If we insist on our orders being obeyed, they show fight, or more usually a sullen nagging resistance that continues the whole time we remain on their backs, and they carry out the same programme every time we ride them. With such nasty tempered brutes, breaking is of no avail, for they are quiet as long as we allow them to set the pace and carry us as they like. A breaker who is a good horseman and possessed of extreme tact and patience, which of course is necessary, may continue the fight longer than an ordinary rider cares to do, but he can produce no permanent result, for he is unable to give the animal a new heart. Therefore, when we consider the important question of manners in a horse, we should first learn all we can about the disposition and temper of the animal both in and out of the stable. Given a sound foundation to work upon, that is to say, a placid generous tempered horse, we may confidently set to work in polishing up his manners as may be required, but with the sullen brutes I have described, it is a useless task. We find much the same thing in some human beings. George Moore, in his novel, Esther Waters, graphic- 
ally depicts the sullen obstinacy of a low class of person who will "neither lead nor drive." I think that this dogged obstinacy of temper is rarely met with among thoroughbred, or even well-bred horses, for I have found it to exist in its worst form only among half-breds, and especially among those which have hackney blood in their veins. As a rule, a badtempered thoroughbred does not sulk, he fights openly, says his say, like an irritated master or mistress, and, having relieved his mind, lets the matter drop, and does not nurture it up for future use, like the servants in the kitchen. My advice to any lady who is trying to win the regard of a sullen brute of this class, would be to give up the task as hopeless, get rid of him, and expend her kindness on an animal more worthy of it. No horse that will not "chum" with you, by ready obedience without asserting himself at every step he takes, is worth his keep, and it is no pleasure to either man or woman to ride such animals, however excellent both the rider's temper and horsemanship may be.

I would recommend any lady who is about to purchase a horse, to do her best to find out, not only if the animal is quiet, but if his former owner was also amiable, and on no account to buy a horse which has been spoiled by a bad-tempered man, or woman, supposing that any of my sex is sour-tempered, which I very much doubt, unless, of course, she had been spoiled by a vicious male! We should bear in mind that absolute perfection, either among humans or 
equines, is unattainable, and, as Jorrocks points out : "If his 'oss is not so good as he might be, let him cherish the reflection that he might have been far worse!"

I think that the native syces of India, like the Russian ishroshik (cabman), treat their equine charges with far greater sympathy and kindness than our English grooms and cab-drivers do. In India we ride stallions; my grey Arab, Fig. 7, was an entire, and was so kind and gentle that he was always most careful not to tread on his syce who slept in his box with him, rolled up in a corner, like a bundle of old clothes. When Gowlasher, which was the man's name, groomed him, the pony would playfully catch his arm between his teeth and make a pretence of biting it, but he never allowed his teeth to hurt the skin. Gowlasher liked to show me the funny little tricks of this animal; but if Freddie had attempted to touch the arm of an English groom, he would have been promptly struck across the muzzle, because his playfulness would have been misunderstood.

It is not the custom in this country to hunt or hack stallions, which are often led out for exercise with two men hanging on to their heads, both armed with stout sticks. Magic, a grey Arab entire, which we brought home from India and sold to Colonel Walker, of Gateacre, who won several pony races with him, carried me quietly in the Row, and his new owner found him a very clever polo pony. When passing through London on my return from a visit to Russia, we put up at an hotel in Oxford Street, where the 
night was rendered hideous to me by the brutal slashing of cab horses; for one hears nothing of that kind in Russia, and yet we English people pride ourselves on being a horse-loving nation! The speed of Orlov trotters is very great, but no whip is used in driving them; the coachmen drive with a rein in each hand, like the drivers of American trotters, and shout after the manner of firemen to clear the road, for these animals seem to require a good deal of holding. The Russian cabby uses a small whip like an ordinary dogwhip, which he tucks away somewhere under his seat, and when his horse is taking things too easy, it is only necessary for him to show it him, for he is driven without blinkers, to cause him to at once hasten his pace. Very often the man is unprovided even with this toy thing, in which case he obtains a similar result by abusing the animal's relations! During the whole time that I was in Russia, I never once saw a cabby hurt his horse with the whip. Russia is the last country to which one would go to learn anything about the treatment of human beings, knowing what we do of her past and present history; but we certainly should emulate the Russian coachmen in their kindness to horses, and not shock our neighbours by exhibitions of brutality which may be seen daily in the London streets. 


\section{CHAPTER XX.}

\section{CROSS-SADDLE RIDING FOR LADIES.}

THE question periodically arises as to whether women should adopt men's saddles in preference to their own. I have studied the art of riding astride in an ordinary man's saddle, and would give a negative answer to that query. The fact that by the adoption of the cross saddle, about seven pounds in weight would be saved, and the work for the horse would be somewhat easier, ought not to outweigh the enormous disadvantages on the other side. Whenever a lady is dragged by skirt or stirrup and killed-an accident which, happily, occurs but rarely nowadays, for we wisely adopt the best safety appliances to prevent it-up crops that evergreen question of cross-saddle riding, as if men never come to grief! Statistics would, I think, show that, considering the large number of women who hunt, the proportion of fatal accidents to them in the hunting field is extremely small as compared with the male record. Then, again, the question of sore backs from side-saddles may be urged; but with a well-fitting saddle which is properly girthed up, this trouble 
can be averted. Besides, sore backs are not confined to side saddles, for every hunting man, at some period or other, has had a sore-backed horse in his stable. My argument against the adoption of men's saddles is, in the first place, that such saddles afford us far less security of seat than we obtain in our own; for I do not think that men could ride, as we can, over fences without the aid of the reins. This statement is borne out, not only by the attempts which many good horsemen have made to do so, while my husband drove animals over obstacles with the long reins, but also by the fact that all men like a horse that goes well up to the bridle for cross-country work. Then, again, a woman's limbs are unsuited to cross-saddle riding, which requires length from hip to knee, flat muscles, and a slight inclination to "bow legs." I practised my cross-saddle riding in a school well supplied with large mirrors in which I could see my figure as I passed. It was anything but graceful, for the rotundity, which even in some men is very ugly on horseback, was far too much en évidence, and caused an outburst of laughter from the ladies who were watching my performance. I at first found it rather difficult to preserve my balance well in cantering on a circle, but that came to me far more quickly than ability to ride properly over a fence in a plain flapped saddle, such as I presume ladies would want to use if they adopted that style of riding. The directions given me were to lean back and grip with my knees; but, as in side-saddle riding, I left the reins quite 
loose, instead of hanging on to them as most men do, I lost the aid which they might have afforded me in my efforts to stick on. Besides, my grip was all wrong, and seemed to be obtainable only at the thigh, which, my husband tells me, ought, for riding purposes, to be flat and not round. My experience of this kind of riding appears to have been borne out by another lady who tried it, for " Rapier," in the Sporting and Dramatic News, Nov. 26th, I892, says: "A few weeks ago my correspondent 'Ion,' who is, I believe, an excellent horsewoman, told me how she made an essay at riding on a man's saddle, with the result that she had a very bad fall." I believe both of us would have done better if we had had no previous experience of riding, and had acquired the art of hanging on to the reins. A lady who is well known with the Devon and Somerset Staghounds asked my husband's advice about a suitable saddle, as she desired to ride astride, and he helped her to procure one with large knee pads, made on the principle of Australian buck-jumping saddles, which appears to have answered her purpose very well ; but I do not know how she would get on in Leicestershire. Mrs. Tweedie rode astride in a Mexican saddle, which, like those used by natives in India, are something after the pattern of an easy-chair. William Stokes, in an old work on riding which was published at Oxford, tells us that in Mexico "the pisana, or country lady, is often seen mounted before her cavaliero, who, seated behind his fair one, supports her with his arm thrown round her waist." This was much 
more gallant than the old English method, for the lady, after being seated sideways on the horse's croup, had to run the risk of being knocked off by her cavalier, who vaulted into the saddle in front of her. The plate illustrating this nice performance shows that the man had to stand with his left leg in the stirrup and put his weight on the saddle with his hands, while he raised his right leg over the lady's head. Having lived in the East, I am aware that Oriental women ride astride, but I have not seen any of them voluntarily go out of a walk. It is not difficult to trot and canter in a man's plain hunting saddle, but I think our conformation requires the assistance of knee rolls for jumping. We may see even fair horsemen thrown by a horse suddenly stopping dead at a fence, an accident that rarely occurs to a woman in a side saddle, as the grip afforded by her crutches gives her greater security of seat.

A large number of men's saddles have recently been purchased in London for the use of American ladies who desire to adopt cross-saddle riding. They intend wearing frock coats and breeches made exactly like men's hunting breeches, and top boots; but as the frock coats are tight-fitting and follow the contour of the figure, I do not think that the costume will enhance the elegance of the wearer. In the Tiergarten at Berlin I saw a German lady riding astride in a kind of divided skirt, and as she was rather portly, her palfrey appeared to be fully caparisoned. If the cross-saddle were to be generally adopted by women, it would be but a revival of an ancient custom which was in use 
before the side-saddle with a leaping head rendered it possible for women to ride across country. According to Audry, English ladies discarded cross-saddle riding, and began to ride with the right leg over the crutch, about the middle of the seventeenth century, which style the Countess of Newcastle is said to have been the first to adopt. In the Encyclopadia Londinensis we read that Queen Elizabeth "seems to have been the first who set the ladies the more modest fashion of riding sideways," but I think the honour of its introduction is due to Ann of Bohemia, the consort of Richard the Second. Garsault tells us that during the fourteenth, fifteenth and sixteenth centuries, ladies of the French Court usually rode astride on donkeys. Whatever may be said in favour of cross-saddle riding, we must bear in mind that it was not until the introduc tion in 1830 of the leaping head that women were able to ride over fences, and it would be a most reactionary measure to try to dispense with this valuable improve ment on the ancient and incompetent order of things. 


\section{CHAPTER XXI.}

\section{RIDING DIFFICULT HORSES.}

General Remarks-Shying-Stumbling-Dancing and Prancing-Throwing up the

Head - Habit-shy - Jibbing-Shouldering - Backing - Pulling-Refusing -Boring-Kicking-Buck-jumping-Rearing.

\section{GENERAL REMARKS.}

As ladies are not supposed to have to ride "difficult" horses, a chapter on the best means of managing such animals may appear superfluous; but even the steadiest animal is apt to go wrong at times, and as forewarned is forearmed, it is best for us to know how to act in cases of emergency. I do not think that there exists in this world an absolutely perfect horse, or faultless human being for that matter, although many members of both the human and equine race nearly approach the ideal standard, especially among our own gentle sex. A woman who rides a great variety of horses finds that each of her mounts has his or her special peculiarity of temper, which often sorely taxes her supply of patience and tact in keeping it under control. All horses, even the quietest, try to show their authority when ridden by a stranger, and still more 
so when they find themselves carrying a rider who sits in a side-saddle, which must be a most unnatural burden to a horse that has been broken and ridden by men. Apart from considerations of side-saddle gear, the extra steadiness which is required of him in standing "stock" still while a lady is being puit up on his back and her habit arranged, necessitates more patience on his part than with a male rider. On the other hand, he may be impressed with the idea that he is being asked to carry a more precious burden, and that he must prove himself worthy of the confidence reposed in him. I think this feeling of honour exists in horses, for I am reminded of a charger which an officer in India lent me, with somewhat anxious misgivings, to ride. He told me that the animal would be sure to buck at a certain spot, and, as he rode with me, he warned me when I came to this debateable ground to be ready for the usual performance. We cantered along quietly, as we had been doing, for I thought it best to pretend nothing, and my mount, to his owner's great surprise, made no attempt to buck, either then or subsequently, while I was riding him, and we remained the best of friends. A hunter mare which I had in Cheshire, gave another instance of this honourable feeling among equines. When ridden by my husband or myself, she loved to show off by shying at a white gate, a heap of stones, a piece of paper, a bird, or any imaginable thing that she could find as an excuse to dart suddenly from one side of the road to the other. When we got to the 
hunting field, with all its noise and turmoil, she was as steady as possible, and the violent shying, which was her way of showing off, seemed to be quite forgotten. She would carry my son to his school, a distance of about five miles, and bring him home without making any attempt to shy with the child, but if an adult person rode her on the same route, she would play up as usual. I can only infer from this experience that, as I have already said, many horses possess a certain sense of honour. As shying is the most common vice among horses, we may consider it first.

\section{SHYING.}

I have called this habit or trick of becoming violently startled without adequate cause a vice, because in old horses who frequently shy with the object of unseating a rider thus suddenly taken unawares, it certainly is a very bad vice, and one for which the only cure is good horsemanship - that is to say, a seat sufficiently secure in the saddle to enable us to treat such conduct with indifference. If we attach importance to it by losing our temper and hitting an artful offender of this kind, punishment may cause an unpleasant exhibition of temper on his part, besides letting him see that his object has been accomplished. In the case of young and nervous horses, shying arises from timidity and not from vice, and therefore it behoves us to exhibit patience and kindness in inspiring confidence in such animals and assuring them that there is no reason for terror. The best means of doing this is to ride on and 
take no notice, although we may see by the behaviour of our mount, as he keeps his ears pricked, snorts at the terrifying object in front of him, slackens his pace, and prepares to either stop or dart away, that he will require encouragement to induce him to go on. As long as he answers the indications of the reins and pressure (not cuts) of the whip we should keep silent; but when he falters as if his heart were failing him, it is time for us to encourage him with the voice, softly at first, and louder, in a determined tone of command, if he still hesitates. With a young horse it is well to continue speaking to and soothing him until he has falteringly passed the cause of alarm, as the sound of his rider's voice often inspires him with confidence at the critical moment by withdrawing his attention from the object of his fright. "If a lady is riding with a friend and is engaged in conversation when her horse begins to show fear at some object of alarm, she should continue her talk, because it will give him more encouragement to go on, than sudden silence on her part, which he might take as a sign that she shares his fear. If she finds it necessary to shorten her reins in anticipation of his "playing up," she should do it in an easy and gradual manner, so as not to let him know her intentions, and above all things she should refrain from speaking to him until it is absolutely necessary, which will be at the moment he is getting ready to swerve. I have at present a very amiable and steady hunter, which will invariably shy at any high vehicle, but will pass traction engines, trains and even motor 
cars quite quietly. No doubt his unsteadiness is nervousness and not vice, and is the result of an accident. It is not a good plan to wrestle with a horse until he can be induced to go up to and smell what he was shying at; for besides attaching too much importance to a trivial failing, it is not always possible to do this, in the case of moving objects, which cause animals far more terror than stationary ones. The whip should never be used on a shying horse with the object of hurting him, because it is unjust to inflict pain for an unintentional mistake, and idiotic to regard the exhibition of his fear as a personal affront, which is often done by ignorant riders. Almost all horses when they are very fresh, and especially on cold days, will shy and jump about on first being taken out, partly with the desire to keep themselves warm, and also with delight at being able to come out and enjoy a scamper. Dogs exhibit much the same skittishness; even old animals gamble like puppies when they are taken out, and the shying which results from freshness in horses should be tolerated within, of course, reasonable limits. Exercise will take away the superfluous playfulness, and it is one of the best of cures for equine failings, because even young horses which are regularly ridden, soon give up their habit of nervous shying and become steady conveyances. However terrified an inexperienced horsewoman may be on finding herself on a horse which shies badly, she should take care not to divulge her secret to him, as the animal would then try to 
usurp the reins of authority and refuse to obey her tremulous exhortations. She should always bear in mind that horses, young or old, nervous or bold, require as much keeping in their place as do domestic servants. Therefore, in all critical situations in which our ability to govern is directly challenged, we should assume the virtue of power if we have it not, and hang our banners on the outer walls, even though we may not have a shot in the locker.

\section{STUMBLING.}

Stumbling is not a vice, and therefore it would be as unjust to hit a horse for accidentally tripping, as it would be to strike a human being for making a false step and possibly spraining an ankle. Its chief causes may, I think, be traced to weakness; and, in the case of young horses, to bad shoeing and dirty stables. The subject of horse-shoeing is one which does not appeal to ordinary riders, so I may refer any lady who desires to study it, to my husband's chapter on it, in his new edition of Veterinary Notes for Horse Owners. The feet of horses should not be washed, because this practice renders horses liable to cracked heels and thrush, both of which ailments diminish the sure-footedness of an affected animal. If the feet are carefully picked out and brushed they can be kept in a hard, healthy condition, such as we find in the feet of young and unbroken horses which have never been shod. The stable should be kept clean and dry, for it is useless to expect a horse's feet to remain in a sound 
condition if he be allowed to stand in a wet and dirty stall or loose-box. The feet should always be carefully picked out after an animal has been exercised on tan, which contains matter that is injurious to the feet if it be allowed to remain in them. We have had bad cases of thrush caused by carelessness in this respect. As regards conformation, it is evident that horses with upright pasterns and heavy shoulders are far more apt to stumble than well-shaped ones, besides being rough and unpleasant to ride. Young horses which are shod for the first time, often stumble a great deal, until they get accustomed to their artificial foot-gear, and learn to go in a collected manner. Animals that are punished for stumbling by ignorant or bad-tempered riders, frequently acquire the detestable habit of dancing about every time they make a false step.

\section{DANCING AND PRANCING.}

This vice, which some badly-broken horses possess, of refusing to walk when required, and "blowing their noses " when spoken to, proceeds generally from temper, and a desire on the animal's part to show his authority. It is sometimes caused by the rider hanging on to the reins, especially if she uses a sharp curb or Pelham. I have known cases of horses which had been sold at a great sacrifice on account of this trick, become perfectly steady in a few days when properly handled. On the other hand, there are animals which prance from vice, and refuse to obey even the best horsewomen. I know of nothing more annoying to a lady, for it causes her 
to feel hot and uncomfortable, to say nothing of a possible headache and pain in the side. Such fretting and fuming brutes are not fit to ride, and should be put through a course of breaking lessons, preferably with the long reins, and be punished by being compelled to rein back, walk and halt at word of command. If it is inconvenient to have them properly broken, they should be driven in harness at a walk, and be kept standing about as much as possible to teach them obedience. A lady can offer very little defence when riding a dancing horse, but she may gain some respite by making him halt, supposing she does not desire to trot or canter. If a steady animal commences to dance without any exciting cause, such as the prospect of a hunt, his bitting and girthing up should be carefully examined, as there may be something hurting him, or the saddle may be pinching his back. Horses which are tormented by flies are apt to dance about, in which case it is best to trot or canter as much as possible. In India and other tropical countries where these pests are particularly troublesome during the hot weather, horse-hair wisps specially made for the purpose, are carried for brushing them away.

\section{THROWING UP THE HEAD.}

If a curb be used, care should be taken that its mouthpiece is not placed too high up in the mouth; that the chain is not too tight, in which case it would hurt the jaw; and that the mouthpiece of the snaffle does not press against the corners of the mouth. If 
there is nothing hurting the animal's mouth, he should be ridden by a groom in a standing martingale, at a length which will prevent him from getting his head too high. I like the Irish plan of buckling the standing martingale to the rings of the snaffle, better than that of attaching it to the noseband, because it teaches the animal to "give" to the bridle, and not to lean persistently on the noseband. The noseband method is generally adopted by polo players. The precaution of seeing how the horse behaves when he finds that he can no longer indulge in his favourite vice, should always be taken before he is ridden by a lady; because at first the checking influence of the standing martingale is sometimes resented by efforts to rear and plunge badly. If the use of the long reins is understood, it is better to have the horse circled and turned with them, but very few people are capable of using them in an efficient manner. When the animal finds himself unable to successfully resist this fixed defence and prefers to carry his head quietly, rather than to hurt his mouth by violently throwing his head up, he may be safely ridden by a lady in this martingale, and she will then be able to control him. Very few horses will fight against the martingale for any length of time, and as this most useful article of gear is considered to be indispensable to polo players for controlling their animals, its value to ladies who cannot, by reason of their perched-up position in a side-saddle, lower their hands like men, is inestimable. 
HABIT-SHY.

I use this term to designate the trick that some horses, chiefly those which are unaccustomed to the side-saddle, have of sidling away from the skirt. A good plan is to put up a groom in a side-saddle with a rug on, and get him to ride in circles to the left, kicking the rug about with his foot until the horse goes collectedly, which he will generally do in a few lessons.

JIBBING.

Jibbing, or "balking" as the Americans term it, is a detestable vice. As a rule, it is the outcome of the knowledge an animal has acquired of his own power. Some horses are foolishly allowed by their riders to jib successfully. For instance, I was once riding with a lady whose animal " planted" himself at a certain spot and refused to "budge." Instead of trying to make him go on, his mistress wearily said that that was her limit, and that she always took him home from it, because he did not want to go any farther! I suggested a change of horses, but she would not hear of it ; for she said I might upset his temper and make him worse than ever. Needless to say, the spoiled brute did precisely as he liked with her, and as she submitted to being "bossed" in this feeble manner, there was nothing to be done but go home every time he "wanted" to do so. If a horse jibs and there is nothing hurting him in the saddle or bridle, he should 
be shaken up sharply and ordered to go on. If he treats that order with silent contempt, the best thing to do is to make him turn and keep him circling until he gets tired of this performance and will go in the required direction. It is wiser not to strike an obstinate jibber, unless as a last resource, for further rousing his bad temper is productive of no good result. If punishment has to be resorted to, his rider should be able to form an idea of what defence he will be likely to offer by way of retaliation. If he is inclined to rear, the cuts should be given well behind the girth, and he should be kept on the turn to the right, in order that he may not fix his hind legs, which he would have to do in order to get up. If kicking be his speciality, they should be applied on the shoulder, while his head is held up as high as possible. If . punishment proves ineffectual, it should be discontinued at once, as no woman cares to be the centre of an admiring crowd while she is engaged in a fight which, in nine cases out of ten, does more harm than good. A man told me that he cured a bad jibber by getting off him and throwing a lighted cracker under him ; but such heroic measures had best not be undertaken by a lady, who would be wise to hand over the animal to a competent breaker if she wished to ride him again.

\section{SHOULDERING.}

This is a form of jibbing in which the horse tries to get rid of his rider by pressing her against some con- 
venient object, such as a tree or wall. As he will naturally do this on the left side, his rider should try to turn him to the left to make him bring her away from the object in question. In other respects she should act as recommended in "Jibbing."

\section{BACKING.}

This is another variety of jibbing; but it is also caused by using a severe bit which a horse is afraid to face. If the bitting and saddling are right, a touch with the whip given behind the girth will generally prove effective. Sometimes a horse will deliberately back in order to kick another. In the hunting field, mares are at times very apt to try this trick, so care should be taken to prevent it.

\section{PULLING.}

I have found from experience that the best kind of gear in which to hold a hard puller, who goes along with his mouth open and is so headstrong that he will not slacken speed when required, is an ordinary double bridle, a cavesson nose-band and a standing martingale. It is far better for ladies, especially out hunting, to ride animals in gear in which they are able to hold them, than to have them dashing about as they like, and proving a source of danger, not only to their riders, but to the rest of the field. A lady should never ride a hard puller when hunting; but as some of us have to put up with what we can get, it is well to 
fix up a difficult mount of this kind in a manner that will keep him under control.

Some clever people assert that any horse can be held with a snaffle; but I am certain that pullers can, . as a rule, be much better controlled by a curb, provided that it is properly put on. I have no faith in severe bits, because the desire to pull and tear away emanates from the brain of a horse, and if we hurt his mouth by using a severe bit, we only succeed in making him more headstrong than ever. Most, if not all, young horses make frantic efforts to get away after the hounds, when they are hunted for the first few times; and, until they settle down and learn that fences require jumping and not galloping into, it is far more difficult to hold them without a standing martingale than with one. If a horse is getting out of hand, even under the restraining influence of a curb, we can generally manage to turn him with the aid of a standing martingale, and so long as we can do that, he cannot run away, as I have found when I have been placed in somewhat critical situations, with my curb ineffective in preventing a headstrong youngster from urging on his wild career under the intense excitement of his first day with hounds. The desire which a puller has to get away would probably only occur in the early part of the day when the starting rush is made, but if it were successful he would bolt among a lot of horses and be almost certain to cause an accident. A cavesson nose-band properly put on, will shut the mouth of a 
puller which wants to keep it open, and will thus help the rider to control him. If a lady possesses doubts as to her ability to hold her horse, she should keep well away from the field, so that she may not endanger the safety of others. It is always best to put animals which are at all likely to pull, through a regular course of cub hunting from the very beginning of the season, so that they may gradually work along from the "pottering" to the galloping stage. A course of such instruction sobers them down, and they will then give their rider far less trouble than if they are dashed off into the excitement of fox-hunting without having had good preliminary training. This is a fact which ladies should bear in mind; for I have found it work very successfully.

There is nothing like plenty of regular work for taking the nonsense out of pulling horses. Mr. Caton, a well-known American trainer of match trotters, whom I met in St. Petersburg, told me that he always sent his bad pullers to do a week or two's work in one of the city tram-cars, for they always came back with a good deal of the "stuffing" taken out of them. Pulling is of course a very bad vice; for a pulling horse knows well enough what his rider is asking him, through the medium of the reins, but he shakes his head, or throws it up, if he can, as much as to say that he will not obey. A lady should not be alarmed if she finds her mount getting out of hand; but should, if possible, let him go for a short distance and then take a pull at him, at the same 
time speaking determinedly to him, and not in a frightened tone. If the brute will not obey, we must use severe measures, and in extreme cases, it is well to "saw" the bit from one side to the other, in order to hurt his mouth so much, that from very pain he must perforce yield. I believe that many bad accidents have occurred through riders becoming frightened and refraining from the use of force in stopping a hard puller, who is thus allowed to run away. I think that if people could keep their heads clear and not clutch on to the saddle and let the reins loose, or maintain a dead hold of them, which is equally ineffective, but husband their resources for determined attacks, very few horses would succeed in bolting with their riders. Of course a great deal depends on the strength of the seat of the rider; for we must sit very tight and not let our mount feel us wobbling about in the saddle. We should never forget the power of the voice as a factor in horse control, and our attempts to stop a pulling animal should always be accompanied by a sternly expressed word of command. In my travels abroad, I have ridden some extremely bad pullers which were said to bolt with men; but although I certainly had trouble with such animals, none of them succeeded in running away with me and taking me where they liked. My husband also has a similar record in this respect, so I cannot help thinking that when a rider is actually bolted with, he or she must have got frightened and confused at a critical moment 
and have allowed the animal to literally take- the reins of authority in his teeth. It requires a good deal of physical strength to control a hard puller, and I have had my gloves and hands badly cut in wrestling with particularly headstrong brutes. On the other hand, some horses which have really nice mouths, get the name of being pullers, on account of having been ridden by "mutton-fisted" men who hang on to the reins and thus irritate them beyond control. I am reminded of a big Australian horse, about seventeen hands high, which Mr. Macklin, the Australian horse-shipper, brought to Calcutta and lent me to ride in a paper-chase there. This animal carried me perfectly, although his rough rider (more "rough" than "rider") afterwards showed me an unjointed snaffle bent almost double, which he said had been caused by this "pulling devil of a horse"! There is a great deal of truth in the saying, that if you don't pull at a horse, he won't pull at you. I am sure that many horsemen, and certainly every riding member of my sex, will bear me out in stating that women manage pullers far better than do men, because they do not hang on to their mouths, in order to help them in keeping their seats. Where many women greatly err in riding confirmed pullers, is in inability to take sufficiently harsh measures which are needed for their control. I am aware that there are animals, especially race-horses, which cannot be held at all until they have gone a certain distance. The pace holds them, but such headstrong animals 
tire themselves unnecessarily, and generally have to "shut up" before the finish of a long distance race; for the steady plodding horse will almost invariably prove the better stayer of the two. In hunting, the pace will not always hold a horse, because hounds may check at any moment, the start to a "holloa" may prove a false alarm, and leaving out the uncertain behaviour of foxes, a sudden stoppage may be caused by an impossible fence, river, railway, or by a variety of causes which would amply prove the fallacy of the pace holding a hard puller in the hunting field. As pulling horses are the cause of frequent hunting accidents, I would specially caution my readers against riding animals which they are not able to keep in hand.

If a lady is riding a good old hunter who insists on going his own pace, she should interfere with him as little as possible, even in her desire to steady him over bad ground and at his fences; because the large majority of these animals have their own method of doing business, and can be safely trusted to take care of themselves. If they are unduly checked in galloping, they are apt to pull very hard, and greatly tire their riders. I am, of course, alluding to goodtempered, well-made hunters which go best with a rider who sits still on their backs and trusts to their experience and honour.

Concerning the best kind of bridle in which to hold a puller, I cannot do better than quote the following remarks from my husband's book, Riding and 
Hunting :- " As regards the bitting of a puller, I would advise that with a double bridle the curb should be put low down in the mouth. . . . . In all cases an unjointed snaffle is much the best form of bit. With a double bridle we have a choice between the two. We should bear in mind that the action of a curb is peculiarly liable to produce insensibility of the mouth on account of its pressure being distributed almost completely round the lower jaw, while that of the snaffle falls only on the upper surface of the jaw. Even the jointed snaffle and the chain snaffle leave the under surface of the jaw free from pressure, and consequently interfere comparatively little with the circulation and nervous supply of that part. Hence we should avoid riding even the worst puller continuously on the curb, the action of which we should alternate from time to time with that of the snaffle, so as to preserve the sensibility of the jaw. It is evident that the sensibility of the mouth is the means by which we are enabled to remain in touch with the forehand of the horse. I would here recommend the alternative, not the combined, employment of the curb and the snaffle." Thin bits which irritate horses' mouths often cause them to fight and pull hard; it is unfortunately no uncommon sight in the hunting field to see a tortured horse bleeding from the mouth, and yet such animals are expected to gallop and jump kindly! 


\section{REFUSING.}

To jump or not to jump, that is the question with which determined refusers have "stumped" some of the very best cross country riders. I am reminded of an instance which occurred in India, when a fine horsewoman, seeing a friend unable to make his mount jump in a paper-chase, which is nearly akin to a steeple-chase, rode him herself in the next one, with no better result, and great must have been her mortification on finding herself left on the wrong side of the first fence which the determined brute refused to look at, even when carrying this charming lady, to whom many equine bad characters had yielded obedience. This appeared to be a sheer case of equine temper and obstinacy; for the animal could jump well when he liked, but the man or woman has yet to be born who can make a horse jump when he has decided not to do so. I have a very strong belief that refusers are made, not born, for every unbroken horse which my husband had to deal with in his travels, tried his best to give satisfaction by making an effort, even if an unscientific one, to clear the obstacle, generally a heavy log of wood propped up on boxes, which was offered for his consideration. If he jumped well, and in the flippant style of a natural fencer, more boxes were produced, and sometimes these youngsters cleared quite a respectable height in one "lepping" lesson with me on their backs, and my husband at 
the end of the long reins. The abuse of the curb at fences is the cause of, I think, half the falls, and more than half of the refusals which we see in the hunting field. In Ireland, where the large majority of our hunters come from, the snaffle is the bit used in breaking and hunting, as it is in steeple-chasing; and although our Irish neighbours find the curb has its advantages, we must admit that they keep it in its proper place and do not allow it to usurp the snaffle when riding over fences. The sportsmen of Tipperary, Kildare, Cork and other parts of Ireland, who have to negotiate immense banks, would ridicule the idea of riding at such obstacles on the curb, because no sane person would think of checking a horse in such a manner; and the solid "cope and dash" stone -walls of Galway also require to be taken by an animal whose mouth is not interfered with. Here in England we see these Irish hunters frequently ridden at fences on the curb, and the poor brutes, in order to save their mouths and keep on their legs, throw up their heads and give a half buck over the obstacle, landing on all fours, and then get a cut with the whip for having jumped badly! This is how many refusers are made. Another recipe for making a refuser is to pretend to ride hard at a fence and, at the last moment, turn the animal's head from it, and then loudly rate and "lambaste" him for refusing! Still another method is to "funk" the obstacle when it is too late, and check the horse with the curb after he has made his spring, which will cause him to crash 
into the middle of the fence, and probably bring both himself and his rider to grief. My husband, being a veterinary surgeon, has had hunters brought to him in a most pitiable state of laceration, caused, I believe, in many cases, by "funk" and curb, a most disastrous combination. We have in our stable at the time of writing, a very intelligent hunter who was dreadfully injured from having, it is said, "jumped bang into a fence," but I wish that patient sufferer could tell me the real cause of his accident. It was one of those crumpling falls which seem to mean death to both horse and rider, but luckily in this case, the rider escaped with a few bruises and a smashed hat. The horse was also fortunate in a way, as no bones were broken; but the skin and flesh of his near fore-leg were torn off from almost the shoulder to the knee, and I wondered, as I looked on that gaping, bleeding wound, and the poor animal quivering with pain and hardly able to bear even placing the tip of his toe on the ground, if he would ever have the courage to face a fence again. Luckily, he is all right now.

I have heard people talk about a "good fall" being the best means for teaching horses how to jump, and there is a certain modicum of truth in this, especially with young horses, and young horsemen too for that matter; but when an old hunter gets a "bad" fall, I doubt whether he ever recovers his jumping form again, any more than we ourselves who may have come an awful "buster" after we have reached the "age of discretion." Horses frequently refuse on account of 
some physical infirmity. Unsoundness in one or both fore legs naturally makes a horse chary of jumping; because of the painful jar which he will receive on landing, when he is obliged to place his entire weight on his fore legs. Then again, if his feet are not in a hard and sound condition, he "funks" the pain of landing over a fence and tries his best to avoid jumping. Many unsound horses, generally hirelings, are hammered along out hunting, especially on roads, with most inconsiderate cruelty. I once tried to hunt on a hireling which, I soon saw, was not in a fit state to carry me without pain. Had I insisted on having my money's worth out of the animal, it would have been nothing short of gross cruelty. His fore legs were bandaged, as is usual with hired mounts, and he galloped and jumped several small fences soundly, as far as I could feel; but when he came to a rather formidable one, he stopped and tried to rear. I at once found an easier means of egress, which took me for a short distance on a road, and the hard ground of only about 20 yards seemed to tell so much on one leg, that I felt him going decidedly short, pulled him up and walked him home. When I arrived in Melton Mowbray, a lady, the last person in the world whom I would have cared to meet, hailed me with the news that Miss So-and-so had broken-her collar-bone, a fact which appeared to give her more pleasure than sorrow, "and you" she said, "have lamed your horse"! The dealer evidently expected this result; for when I rode the horse into his yard, 
so that I might personally explain things to him, he told me that the animal, which was only a four year old, had been "ridden very hard" by an officer, who, I am sorry to say, has since lost his life in South Africa. The dealer tried his best to make amends by subsequently offering me another mount for nothing; but he certainly did err in letting out this young unsound animal, and spoiling my day's sport, for which I had paid the usual guineas. My only regret in the matter is that I galloped and jumped an animal which was not in a fit state to perform such work.

Horses are frequently rendered refusers by being repeatedly jumped over the same fence, until they get so disgusted with the performance that they will have no more of it. Spurs and whip then come into play and make matters worse. Even if the animal jumps the fence after a good deal of unnecessary fighting; the memory of this unjust punishment remains in his mind, and is productive of the violent agitation which such horses exhibit on being taken near a jump. It is a wise plan to stop a "lepping" lesson immediately after the horse has cleared the jump in good style, and then make much of him (patting him on the neck and speaking kindly to him). Punishing horses at fences with whip and spur renders them afraid to face their jumps; because they think that they will be knocked about, even when they are trying their best to give satisfaction. Many faulty and bad tempered riders are unnecessarily cruel in this respect. If a horse refuses from seeing an animal fall in front of him, his natural 
prudence should not be taken as a personal affront, but he should be spoken to and encouraged to try, preferably, if possible, after another horse has got safely over the obstacle, if there is no other part of the fence negotiable. I think that by dint of patience and tactful management, many refusers may be taught to repose sufficient confidence in their riders to make an effort when required, but that can be done only by gentle means and easy tasks. Old tricky offenders cannot be cured of this or any other vice. A lady who is hunting on a doubtful jumper should be careful not to upset other horses by letting her refuser perform in front of them, but should show consideration for her companions by keeping a backward place, supposing that several horses are taking their turn at jumping the only practicable part in a fence. Refusers are detested in the hunting field, and a lady whose hunter is known to shirk his fences and stir up equine rebellion, is soon classed among the large number of those who never will be missed.

\section{BORING.}

Horses are said to bore when they carry their heads down and lean heavily on the bit or bear on it to one side. As both the curb and Pelham have a tendency to make a horse carry his head low, they should not, as a rule, be used with a borer. The rider might make the animal keep his head in proper position by playing with the snaffle, the cheekpieces of the bridle of which may be shortened, so that the mouthpiece may 
press against the corners of the mouth and thus induce him to keep up his head. The same effect can be obtained with the gag snaffle, which has the advantage that, when one's object is gained, one can ease off the gag reins and take up the other reins, which are used in the ordinary manner. When a horse bores to one side, or when he bores with his head stuck straight out, the standing martingale will often be useful for correcting this unpleasant fault. I have seen in trotting matches a bearing-rein (called in America an "over-draw checkrein") passing between the animal's ears, going down the top of his head and attached to the pommel of the saddle, effectively employed to correct this fault. It would, of course, be too unsightly to be used by a lady, but her groom might employ it advantageously in teaching a borer to carry his head in correct position.

\section{KICKING.}

If practicable, we should first of all see that the saddle does not hurt the horse in any way. If this be all right, we may "shake him up " with the snaffle " reins and make him carry his head high. If this be not effective, he should be given a few cuts with the whip on the shoulder. Making him hold up his head and touching him on the shoulder are done to "lighten" his forehand, and to put more weight on his hind quarters. Also, we may with much advantage give him some practice at reining back, within judicious limits, either when we are in the saddle, or with the 
long reins. When a horse starts kicking, the rider should take a strong grip of her crutches and lean back, as far as she is able, while holding his head up, and thus prevent herself from being thrown over his head. The most awkward kicker I ever rode was a mountain Zebra (Fig. I46), which my husband broke in at Calcutta. He kicked very neatly without lowering his head, and, as the slightest touch on his ears drove him nearly out of his mind, I had great difficulty in avoiding them, as he kicked with a sort of peculiar wriggle which complicated the performance for me, because I had had no practice on a kicking zebra, and had to pick up my knowledge as I went on. It was no use trying to rein him back; for he had a neck like a bull, with a small rudimentary dewlap, and at every kick he gave, he made a noise like a pig grunting. His skin was the best part about him, and was as lovely and soft to the touch as the finest sealskin. As I believe I am the only woman who has ridden a mountain zebra, this photograph is probably unique. It ought to be a better one, seeing the trouble I took to make my obstinate mount stand still; but he seemed to regard the camera as an infernal machine destined for his destruction, and flatly refused to pose nicely for his portrait. He was far too neck-strong to make a pleasant mount for a lady. Kickers, as I have already said, should never be taken into any hunting field. 
BUCK-JUMPING.

Under this heading I shall include the minor vices of plunging and "pig-jumping." Bucking is all but unknown among English and Eastern horses, but

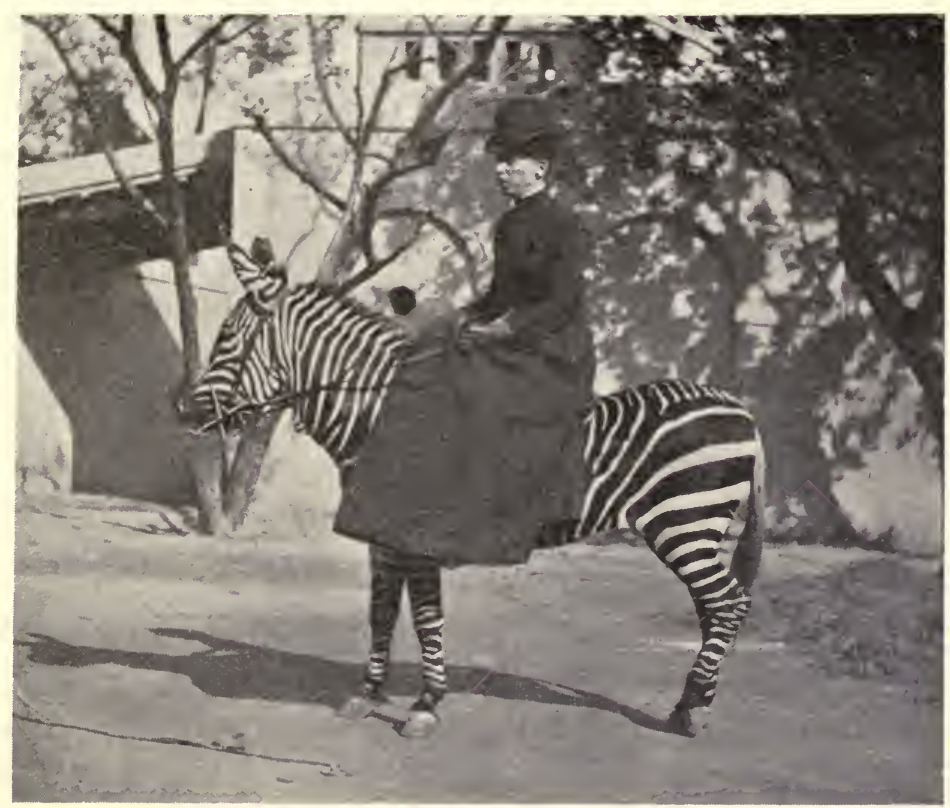

Fig. 146. - Riding mountain zebra.

is seen to its highest perfection among Australian and New Zealand animals, especially those that have been allowed their liberty up to a comparatively late period of life, say, four years old. I have ridden some buckjumping Argentine horses which were expert performers: many of the wild Russian steppe horses are very bad buck-jumpers. Some English horses, 
especially thoroughbreds, can give a very fair imitation of this foreign equine accomplishment. I remember riding a steeple-chase horse called Emigrant, which placed quite enough strain both on me and my girths when he was first called upon to carry a side-saddle. If a horse has any buck in him, the side-saddle will be almost certain to bring it out; for with it the animal requires to be girthed up extra tightly; the balance strap "tickles and revolts" him, the lady's weight is farther back than on a man's saddle, and the unusual feeling of carrying a rider whose legs are placed on one side, tends to irritate a highly sensitive horse. If an animal, on being saddled, gets his "back up," he should not be mounted until this certain indication of the buck that is in him has been removed, which may be done by either circling him with the long reins, or letting a groom run him about a little until his back goes down. A cold saddle and a chilly day will often cause a horse to come out of his stable with his back in bucking position, and, unless a lady knows her animal well, it is best to get it down before she mounts, because he may buck as she is in the act of placing her right leg over the crutch-a part of mounting which animals that are unaccustomed to it greatly dislike, as, I suppose, they think she is going to give them a kick on the head!

As I used to do the rough-riding for my husband on his horse-breaking tours in various countries, I have had to sit a good many buck-jumpers, and, am thankful to say, I never got thrown, because, from what I have seen of men being catapulted and placed on the flat of their 
backs on the ground, this kind of fall must be, as Jorrocks would say, "a hawful thing." The great difficulty in sitting a buck-jumper consists in keeping the body from being jerked forward in the saddle, and slackening the reins the moment the animal makes a vicious downward snatch at them, by ducking his head; for if the rider hangs on to his head, he will pull her forward by means of the reins, and she will be unable to sit the buck which will follow. All confirmed buck-jumpers look out for this opportunity whenever the rider draws the reins tightly. Ladies who ride with the right leg hooked back would not be able to sit a buck-jumper; for I found that the chief means which prevented me from being thrown was the ability to lean back, which the forward position of my right leg gave me. When riding bad horses at my husband's classes, I was able to see beforehand what special defence such animals offered, and was, therefore, prepared to cope with them; but I have been taken unawares when mounted on Australian horses which dealers in India have lent me, when they have wanted to sell such animals as having carried a lady. I remember one very handsome Waler, which went like a lamb with me until suddenly, when cantering quietly along, he took it into his head to try and buck me off. He did his best to accomplish his purpose, and was encouraged in his efforts by my pith hat coming off and flopping about my head. I wished the thing could have fallen, but it was held by the elastic-we wore our hair in plaits at the nape of the neck in those days-and I had 
securely pinned the elastic with hairpins under my hair. This great wobbling hat only caused the horse to buck worse than ever, until he tired of his performance and came to a sudden halt. I was greatly exhausted, and suffering from mental tension, because I was entirely unprepared for this attack, and doubted the security of my stronghold, for the girths of my saddle had seen a lot of service, and the strain on them, caused by the violent bucking of this powerful sixteen-hand animal, was very great.

The bigger a horse is, the more difficult he is to sit when he bucks badly, because he can put much more force into the performance than a small animal, and he shakes the breath out of one much sooner. It is lucky for us that a wise providence has placed a limit on a horse's bucking capabilities. I think that ten or twelve bucks, given in good style and without an interval for recuperation, is about as much as any horse can do, but possibly my Australian readers can give statistics on this point. I hope I am not offending them in saying that Australian horses are the most accomplished buck-jumpers I have met. Australian shippers send many of them over to India, and rely on the long sea voyage to quieten them down, which it does to a certain extent. Mr. Macklin, an Australian importer, told me that a horse-carrying ship was wrecked on some part of the coast, an island, I believe, between Australia and India, and that there is a big colony of wild horses to be picked up by anyone who will go and take them. I like Australian horses, 
because they are excellent jumpers, have beautiful shoulders and are remarkably sound in wind and limb. They are moreover handsome breedy looking animals, and those of them which are addicted to bucking, soon give up this vice, if ridden by capable people.

A lady who finds herself on a bucking horse should try her best to keep both her head and her seat, and not be in any way disconcerted by hearing the angry grunts which such animals often give with each buck they make to get her off. She should lean back and firmly grip her crutches as in sitting over a fence, and should try to imagine that she is jumping a line of obstacles placed close together. If she feels any forward displacement after one buck, she must hastily get into position to be ready for the next one, without pausing for a moment to think, because there will be no time for thought, and her recovery of balance must be done automatically, while the animal is doubling himself up for his next buck. If her hat, which is generally the first thing to leave the saddle, flies off, no notice must be taken, because the instant the rider devotes her attention to anything else but sticking on, she relaxes her grip and stands a good chance of being thrown. The most difficult of all bucking I have experienced was when hunting in Leicestershire on a young Argentine mare, which started to buck when we were galloping down hill over deep ridge and furrow. I knew her bucking propensities, because my husband broke her in and I had had a good deal of bucking practice with 
her, so I was able to remain, but that down hill ridge and furrow performance was extremely hard to sit. Like most young animals, she hated ridge and furrow, and her temper was upset on finding that she had to gallop down hill over this troublesome ground. The necessity of devoting careful attention to the soundness of the girth-tugs, stirrupleather, and balance-strap when riding a horse which is likely to buck is obvious, for of course if they give way under the strain, no lady would be able to retain her seat.

\section{REARING.}

Rearing is the worst of all vices in a horse which has to carry a side-saddle, because a lady, by reason of her side position and her inability to lower her hands to the same extent as a man, is utterly powerless on a rearer. I have seen men

- slip off over the animal's tail, when he was standing on his hind legs, but this is a feat which a woman is unable to accomplish, as I found when a horse reared and came over with me at Tientsin in China, and hurt my spine so much that I felt its effects for several years afterwards, especially after a hard day's hunting, or a long swim. Swimming appears to tax the soundness of the spinal bones quite as much as does riding. The best thing to do with a rearer is to prevent him from fixing his hind legs, which he would have to do before he can get up, and therefore a long whip should be used, and the animal touched with it as near the hocks 
as possible, keeping him at the same time on the turn to the right. Confirmed rearers are however so quick in getting up on their hind legs, that the rider has no time, even were she supplied with a sufficiently long whip, to get anywhere near his hocks, and all she can do is to lean well forward and leave his mouth alone. If she is still alive when he comes down, my strong advice would be to get off his back, and give him, as the late Mr. Abingdon Baird did in the case of a similar brute, to the first passer by! Rearing is no test of horsemanship, and the sickening sight of ladies in circuses mounted on rearers is one from which every good horsewoman would recoil with horror. At Rentz circus in Hamburg I saw one of these awful sights, and noticed that the ringmaster kept touching the steiger on the fore-legs with the whip in order to make him paw the air. I have been told that so long as a rearing horse keeps pawing in this manner, he will not fall over, but such horrid exhibitions ought to be prevented. There is nothing more trying to the nerves of any rider than hunting on a refuser which has a tendency to rear, and I have known ladies whose nerves have been utterly shattered in their efforts to govern such dangerous brutes. Take my advice ladies and have nothing to do with these animals; for it is far easier to get rid of a horse than it is to recover one's nerve, and the longer a lady tries to wrestle with a rearer, the more difficulty 
will she have in overcoming the strain on her nervous system. I would not take a rearing horse at a gift, for such animals can never be made sufficiently reliable for any woman to ride. Horses sometimes learn this detestable vice from others. I once had an animal in Calcutta which began rearing with me without any known cause, and I was greatly mystified about his behaviour until one day I saw my syce, who was exercising him, in company with a native on a horse which was rearing badly, while my mount was imitating him, a performance which I subsequently discovered had been going on daily for some time. If a previously quiet horse suddenly starts a new form of playing up, the riding of the groom or person who has been exercising and handling him should be carefully watched, and no animal which is known to be unsteady should be allowed to teach his bad tricks to a lady's mount, for we know that horses very quickly pick up bad habits from each other. Baron de Vaux, in his book Ecuyers et Ecuyères, tells us that Emilie Loisset, who was a brilliant high school rider, was killed by a rearer coming over with her. He says:- "Elle souffrait beaucoup, car la fourche de la selle lui avait perforé les intestins. Après deux jours de douleurs horribles, la paurve Emilie Loisset rendit le dernier soupir, surprise par la mort en pleine jeunesse et en plein succès." The animal she rode is described as d'origine irlandaise et de mauvais cœur. 


\section{CHAPTER XXII.}

\section{NAMES OF EXTERNAL PARTS OF THE HORSE.}

I sHALL here of course omit to describe parts, such as the eyes, head and tail, for instance, which are known to everyone. The figures and letters employed in the following list, have reference to those on Fig: I47, except when Fig. 148 is mentioned.

The hoof (IO) is the horny box which encloses the lower part of the leg. The front part of the hoof, near the ground surface, is called the toe; the side portions, the quarters; and the rear parts, the heels. The outer portion of the hoof is termed the wall, which is divided into a hard, fibrous outer covering, called the crust, and a soft inner layer of non-fibrous horn. The designations "wall" and "crust" are often used indiscriminately.

The frog is the triangular horny cushion which is in the centre of the ground surface of the hoof, and which, by its elasticity and strength, acts as a buffer in saving the structures inside the hoof from the injurious effects of concussion.

The cleft of the frog is the division in the middle 
line of the frog. In healthy feet, it consists of only a slight depression. In a disease, called "thrush," of the sensitive part which secretes the frog, the cleft forms a deep, damp and foul-smelling fissure, and the frog becomes more or less shrivelled up. The frog similar to the skin of the palms of our hands, requires frequent pressure to make it thick and strong. The horn of the hoof is merely a modification of the cuticle (scarf skin).

The bars of the hoof are the portions of the wall of the hoof which are turned inwards at the heels, and run more or less parallel to the sides of the frog. The sole is that portion of the ground surface of the foot which is included between the wall, bars and frog.

The pastern (9) is the short column of bones (two in number) which lies between the fetlock and hoof.

The fetlock (8) is the prominent joint which is just above the hoof.

The cannon bone ( 7 ) is the bone that extends from the fetlock to the knee (6), which, in the horse, corresponds to our wrist.

The back tendons or back sinews $(M)$ form the more or less round tendinous cord which is at the back of the leg, from the knee (or hock) to the fetlock. These tendons, which are two in number, usually appear in the form of one cord; but in horses which have a very fine skin and "clean legs," we may see that one of them is placed behind the other. The term "clean legs" signifies that the limbs are not only sound, but are also free from any fulness, which would 
more or less obscure the contour of the bones, tendons and ligaments. Muscles are the lean of meat, and their ends are connected to bones by means of tendons, which consist of hard, fibrous and inelastic material. The ligaments of the limbs are composed of the same material (white connective tissue) as tendons, and serve to connect bones together, without the inter-

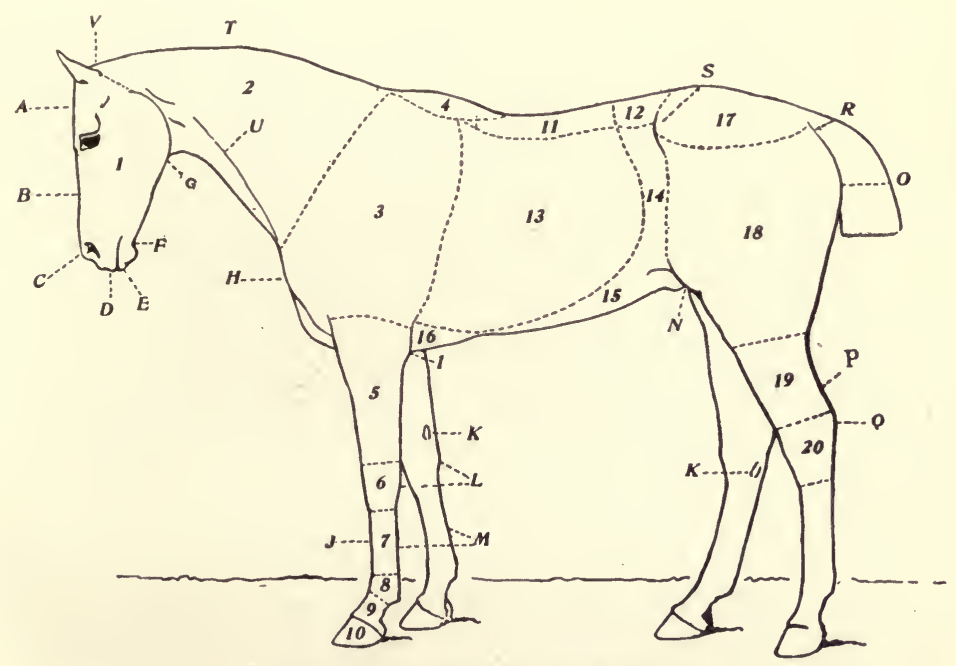

Fig. 147.-External parts of horse.

vention of muscle. The horse has practically no muscles below his knees and hocks.

The suspensory ligament is the fibrous cord which lies between the cannon bone and the back tendons. The fact that it stands sharply out between these two structures, when viewed from the side, shows that it is in a sound condition, which is a most important point as regards usefulness; because injury to it, from 
accident or overwork, is a fruitful cause of lameness, especially in saddle horses that are employed in fast work.

The fore-arm (5) is the portion of the fore leg between the knee and the elbow.

The point of the elbow $(I)$ is the bony projection which is at the top and back of the fore-arm.

The point of the shoulder $(H)$ is the prominent bony angle which lies a little below the junction of the neck and shoulder, and consists of the outer portion of the upper end of the humerus.

The forehead $(A)$ is the front part of the head which is above the eyes.

The nose $(B)$ is a continuation of the forehead, and ends opposite the nostrils $(C)$.

The muzzle is the lower end of the head, and includes the nostrils, upper and lower lips ( $D$ and $E$ ), and the bones and teeth covered by the lips.

The chin-groove $(F)$ is the depression at the back of the lower jaw, and just above the fulness of the lower lip, which, in this case, assumes the appearance of a chin.

The angles of the lower jaw $(G)$ are the bony angles between which the upper end of the wind-pipe lies.

The withers (4) are the bony ridge which is the forward end of the back.

The shoulders (3) are the bony and muscular portion of the body which is more or less included between a line drawn from the point of the shoulder 
$(H)$ to the front end of the withers, and another line drawn from the point of the elbow $(I)$ to the rear end of the withers. Anatomically speaking, the shoulders consist of the humerus (the bone which lies between the elbow and the point of the shoulder), shoulder blade, and the muscles which cover them.

The crest $(T)$ is the upper part of the neck, extending from the withers to the ears.

The jugular groove $(U)$ is the groove which is on each side of the neck, just above the wind-pipe. It marks the course of the jugular vein.

The poll $(V)$ is the part on the top of the neck, immediately behind the ears.

The breast is the front portion of the body which we see between the fore legs and below a line connecting the points of both shoulders, when looking at the animal from the front. The chest is the cavity which is covered by the ribs, and which contains the lungs, heart, etc. Therefore, instead of saying that a horse which struck a fence without rising at it, "chested" it, we should, on the contrary, say that he "breasted" it. This confusion between the terms "breast" and "chest" is not unusual.

The brisket (I6) is the part formed by the breastbone, and is the lower part of the chest.

The girth-place is that portion of the brisket which is just behind the fore legs, and which the girths pass under when the horse is saddled.

The back (4 and II) is practically the withers and that portion of the upper part of the body which is 
covered by the saddle. Strictly speaking, it is that portion of the spine which is possessed of ribs. In common parlance, the term "back" is often applied to the upper part of the horse, from the withers to the highest point of the croup (Fig. I48, H). This measurement includes the loins (12) as well as the back. The bones (six vertebræ) of the loins have no ribs, and, consequently, the flanks on each side are soft to the touch, and have a tendency to "fall in" (become depressed), especially if the abdomen, which is underneath them, be insufficiently filled with food. The croup (I7) is that part of the spine which is between the loins and tail. The hind legs are connected to the croup by means of the pelvis, which is firmly united to the croup by strong ligaments. The pelvis stands in the same relation to the hind legs as the shoulder blades do to the fore limbs, the chief difference between them being that the pelvis is a single bony structure composed of several bones, and the shoulder blades are separate bones. The front part of the pelvis is called the point of the hip $(S)$.

The stifle $(N)$ is the joint of the hind leg which is at the lower part of the flank. The thigh extends from the stifle to the hip joint.

The hock (20) is the large and freely movable joint which is immediately above the hind cannonbone. The point of the hock $(Q)$ is the bony projection at the back and top of the hock. The hamstring, or tendo Achillis $(P)$, is the tendinous cord 
which runs up the back of the leg from the point of the hock. The gaskin (I9) is the part of the leg immediately above the hock and bounded at the rear by the hamstring. The term, thigh, is usually applied to the part of the hind leg above the gaskin ; but,

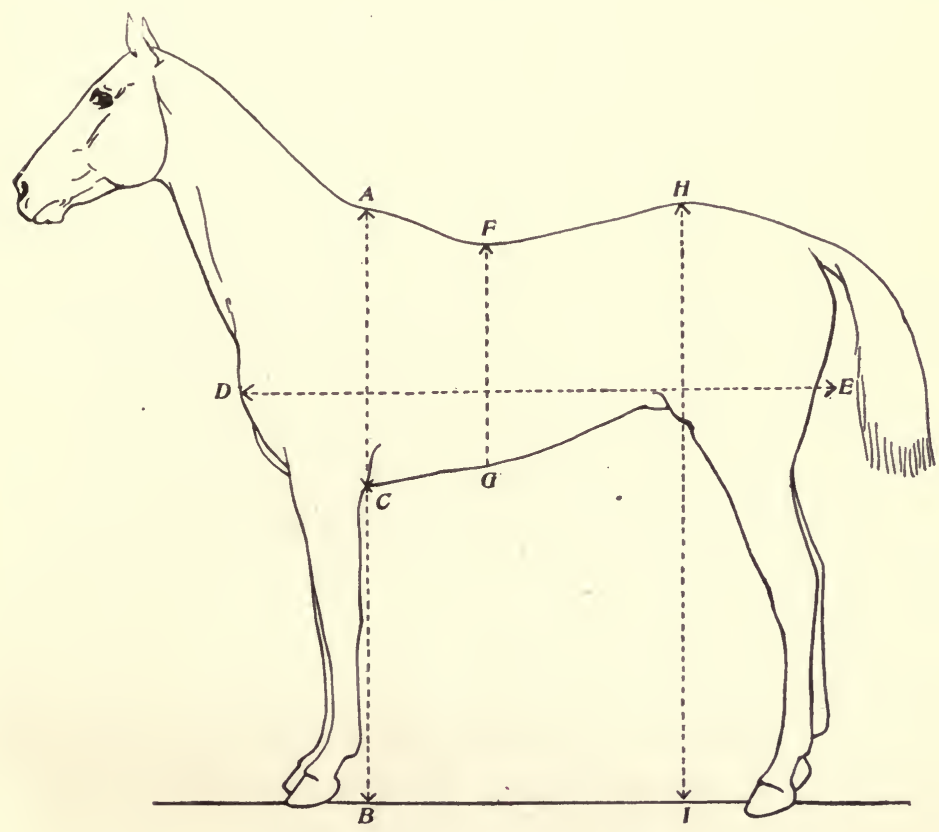

Fig. 148.-Measurements of horse.

correctly speaking, it is the part of the hind leg above the stifle.

The belly, or abdomen (15), is the underneath portion of the body of the horse which is not covered by bone.

The point of the buttock $(O)$ is the rearmost point of the pelvis. 
The dock $(R)$ is the solid part of the tail.

The height of a horse ( $A B$, Fig. I 48 ) is the vertical distance of the highest point of his withers from the ground, when he is standing with his fore legs nearly vertical and with the points of his hocks in a vertical line with the points of his buttocks. I have qualified "vertical" by "nearly" when referring to the fore legs; for when the hind legs are placed as in Fig. I47, the weight of the head and neck, which are in front of the fore legs, would cause the animal to stand somewhat "over." When a pony is being measured for polo or racing, his legs should be placed in the position I have described, although his head may be lowered until his crest is parallel with the ground.

The length of the body of a horse ( $D E$, Fig. I48), may be assumed as the horizontal distance from the front of the chest to a line dropped vertically from the point of the buttock. This measurement is a somewhat arbitrary one, but it is probably the best for the purpose. French writers generally take the length of a horse as the distance from the point of the shoulder to the point of the buttock. As this is not a horizontal measurement, I prefer to it the one just given.

The depth of the chest at the withers ( $A C, \mathrm{Fig}$. I48) is the vertical distance from the top of the withers to the bottom of the chest. This measurement being taken for convenience sake is an arbitrary one, because the chest is lower between the fore legs than behind the elbow, which is the spot I have selected. 


\section{NAMES OF EXTERNAL PARTS.}

Besides, the actual height of the withers above the roof of the chest, has no fixed relation to the depth of the chest.

Depth of the body (F G, Fig. I48). The best and most uniform point to take this is, I think, the lowest point of the back.

Height at the croup (HI, Fig. I48) is measured from the highest point of the hind quarters. 



\section{N D E X.}

ABDOMEN, 47 I.

Accidents, 5.

Across country, riding, 219.

Age to begin, 4.

Agricultural Hall, I67, 335 .

Alderson, Colonel, 3 I o.

Allen, Mr. John, 33.

Angles of lower jaw, 468 .

Ann of Bohemia, 430.

Apron skirts, 96.

Arabs, 17, I8, 424.

Argentine horses, 457.

Ash-plant, I8.

Audry, 430.

Australia, 269.

Australian horses, 457, 460 .

Ayah, 92.

\section{BACK, 469.}

$$
\text { , tendons, } 46 \overline{6} \text {. }
$$

Backing, 442.

Backs, sore, 350 .

Badminton, 36I.

Baily's Hunting Directory, 307.

Baily's Magazine, 358.

Baird, Mr. Abingdon, 463.

Balance, I48, I49.

$$
\text { ," strap, 36, } 53 \text {. }
$$

" Balking," 440.

Banks, 269, 287, 450.

Bar, stirrup, 27.

Barclay, Mr. Hedworth, 378.

Bars of the hoof, 465 .

,, of the tree, 26,28 .

,, , safety, 38-42.
Baskets, 5 .

Beckford, 3I 5 .

Beers, Frank, 246.

Belly, 47 I.

Belvoir, I4, 306, 335 .

,, Vale, 320.

Beresford, Lord William, 384 .

Berliner Tattersall, 392.

Bicycles, 6, I6.

Bit, 70.

, and Bridoon, 70, 76 .

,, , cover for, 77 .

Blackmore Vale, 307.

Blazers, 270.

"Blood," 345.

"Blowing their noses," 437.

" Bobbery pack," 386 .

Body, length of, 472.

Bois de Boulogne, I6, 392.

Bombay, 387 .

Boots, I 16.

Boring, 454 .

Brandy, 350.

Breaking and Riding, I 18.

Breaking classes, I66. ,, tours, 458 .

Breast, 469.

Breast-plate, 54 .

Breeches, I Io.

Bridle, adjustment of, 86 .

Bridles, 70.

Bridoon, 75 .

Brisket, 469.

Brooks, 335, 338.

Brow-band, 74 . 
Brutality, 4I4.4I 7 .

Buck-jumping, 457 .

Bullfinch, 248.

" Bumpy shoulders," Ioo.

Burnaby's Butterfly, Miss, 8, 9.

Butter, 362.

Butterfly, Miss Burnaby's, 8, 9.

Buttock, point of the, $47 \mathrm{I}$.

CALCUTTA, I2, I67, 333, 382, 386, 456,464 .

Camels, 168.

Cannon bone, 466.

Canter, the, 200.

Cantering, 240.

, false, 203.

Capping, 307 .

Carriages, passing, 229.

Carrots for horses, I70.

Case for extra stirrup, 42.

Catherine II., 393.

Caton, Mr., 444 .

Cattle, 248.

Ceylon, I08.

Cheek pieces, 74 .

Cheshire, 248, 343,' 432.

Chest, 469 .

,, , depth of, 472 .

Chifney, Sam, I65.

Children, side-saddles for, 59-66. ,, , teaching, 59-64.

Child's riding dress, 60, 98.

China, 108, 388, 462.

Chin-groove, 88, 468.

Church Minshull, 320.

Circus, 169. ", in Paris, I82.

Clark, Mr., 385.

"Clean legs," 466.

Cleaning a saddle, 69 .

Cloister, 287.

Cloth, 89, 90.

Coat, driving, Iog. ,, fitting riding, 100.

Coats, riding, 100-108.

Coffins, jumping, 388 .

Collars, I24.
Colonel, 244.

Colour of habit, 9o.

Coming home, 346.

Committee, Farmers', 373 .

Compensation tọ farmers, 373 .

Condition, rider's, 35I.

"Continuations," I I 2.

Conyers, Mr., 366.

Cook, Mrs. “Jim," 384.

"Cope and dash," 269.

Cottesmore, I4, 250, 395.

Country, 248.

Covert fund, 307 .

Covering of a side-saddle, 32 .

Cows, 368.

Cracked heels, 436 .

Craven, 306.

Crawley and Horsham, 306.

Creed, Mr., 92, 99.

Crest, 469.

Cross-saddle riding, 426-430.

Croup, 470.

,, , height at, 473 .

Crown-piece, 74.

Crop, 172.

Crupper, 26, 56.

Crust of hoof, 465 .

Crutch, off, 30 .

,, , upper, 29.

Crutches, movable, 305 .

, , riding the, 146.

Cub-hunting, 338.

Cuffs, 122.

Curb-chains, 88.

Curbs, 70, 78, 208, 209, 326, 438, 443, $448,450,45 \mathrm{I}$.

Custance, Miss, 349 .

"Cut-and-laid" fence, 249.

"Cut back" pommel, 28.

DAIRY-FARMING, 248.

Damage fund, 307.

"Dancing," 437.

Davis, 2, 3 .

de Vaux, Baron, 464.

Depth of chest, 472.

," , body, 473 . 
Devon and Somerset Staghounds, 35I, 428.

Diana, 3I5.

"Difficult", hor'ses, 43I-464.

Dilke, Lady, I7o.

Dismounting, I34.

Distemper, 398.

Dixon, Mr. Scarth, 245.

Dock, 472.

Docking horses, 21-24.

Donkeys, 20, 388 .

Double bridle, 75, 208.

" Dragged," 5, 50, 64-66, 98.

Dress, riding, 89-1 24 .

EAST GALWAY, 269, 270.

Ecuyers et Ecuyeres, 464 .

Elbow, point of the, 468 .

" Ellen Terry," 389.

Elliot, Mr., 246.

Elmhirst, Captain, Io, 305, 31 I, 314, $331,336,341,345$.

Emigrant, 458.

Emperor Paul, 393.

Encyclopadia Londinensis, 430.

Esa bin Curtis, 2 r.

Essex and Suffolk, 307.

Esther Waters, 422.

External parts, names of, 465-473.

FALLS, 376-380.

Fane, Lady Augusta, I 79.

Farmers, 248, 249, 357-373, 397.

, , Compensation to, 373 .

,, Committee, 373.

,, daughters, 362 .

Feet, care of the, 436.

Fence, riding up to, 24I.

Fences, 248.

," , "made," 2 I9.

,, natural, 224.

Fenn, Mr., 39I.

Fetlock, 466.

Field, in the, 307.

Field, The, 306.

Fillis, Mr. Frank, I68. ,, , Mr. James, I I 8 .
Firr, Tom, 247, $3^{87}$.

First Lessons, 3.

Flask, 323.

Fleming, Dr. G., 23, 24.

Flirting, 375 .

Flock, 32.

Foot " home," I 50.

Ford, Mr., 34, 40.

Fordham, George, I8o.

Fore-arm, 468.

Forehead, 468.

Forehead-band, 74 .

Foxhounds in India, 387 .

Foxhunting, 343, 354.

France, 16.

Franciscan, 378.

Freddie, I8, I9, 424.

Freeman, 378 .

" Frivol,"' 375.

Frog of hoof, 465 .

Front, 74.

Frost, praying for, 245 .

"'Funking," 450, 45r.

GALWAY, 269, 450.

Gallop, 206.

Garsault, 430.

Garth, Mr., 384 .

Gaskin, 47 I .

Gates, 248, 287-303, 312, 313.

Geldings, 343 .

Germans, 39I.

Germany, I6.

Girls riding, 4, 5 .

Girth place, 469 .

Girths, 5I-53.

"Give and take," I63.

Gloucestershire, 36r.

Gloves, 120.

"Gone away," 326.

Gowlasher, 424.

Grafton, 246.

Grand National, 332.

Graphic, The, 347.

Grip, I48, 149.

Gullet plate, 27.

Gustave, 3, 183, 33r. 
HABITS, 89-I Io.

Habit-shy, 440.

Hackamore, 87.

Hacking, 227.

Hacks, I6-20.

Hair, management of, I I5, I 6 .

Halt, the, r88.

I lames, Mr. Sam, 354 .

Hamstring, 470.

Hancock's bit cover, 77 .

Handkerchiefs, 323.

Hands, r6o.

,, steady, keeping, 163 .

Harding, Miss, 2 ro, 269.

Harrington, Lord, 179.

Hat-guards, Ir4.

Hats, II 3 .

, for the tropics, II 5 .

Hayes' safety skirt, 94 .

Haystacks, 329.

"Head," 70, 74.

, , near, 30 .

Head-stall, 70, 74 .

Heavy land, 367 .

Heels, 465 :

Height at croup, 473. ," of horse, 472 .

Henry, Colonel, 358, 36r, 372.

Hidden Mystery, 332.

High School Riding, r8r.

Hints to Huntsmen, 352 .

Hip, point of the, 470 .

Hirelings, 452.

Hock, 470.

Holloaing, 310.

Home, coming, 346.

Hoof, 465 .

Hooked-back seat, I 5 I, 154.

Hook for stirrup-leather, 38,39 .

Horn, the, 352.

Hornsby, Mrs., 37 I.

Horse, talking to, 229, 230.

Horse-breaking classes, 166 .

Horses for ladies, 8.

$$
\text { tours, } 45^{8} \text {. }
$$

Hot countries, jackets for, 108 .

Humerus, 469.

Hunt balls, 365, 366 .

Hunter, height of, 12.

Hunters, Australian, 8.

,, , Leicestershire, 8-r6.

Hunting, 395, 399.

,, abroad, 38I.

," ties, 122.

", whips, 312, 313.

,, women, 4,5 .

ILLUSTRATED HORSE-BREAK$I N G, 234,4$ I 7 .

India, 92, 38r, 382, 432, 449 .

,, -rubber mouth-piece cover, 77.

Ireland, 307, 394, 450.

Italian remounts, 390.

JACKEROO, MISS NEIL'S, I I. Jackets for hot countries, 108.

Jameson Raid, 391.

Japan, ro8.

Jaw, angles of lower, 468 .

Jibbing, 440.

Jorrocks, 120, 244, 31 5, 326, 333, 34I, $348,357,424$.

Jugular groove, 469 .

Junping, 209, 449-454.

, competitions, 168,183 .

, without reins, 236.

KAISER AND KAISERIN, 392.

Keeper of whip, 174 .

Kennel coat, 402.

Kent, 249.

Kickers, Io, I I, 12, 342-245.

Kicking, 455 .

Kindness to horses, 414.

Knee-pad, 99.

King-King, Captain, 376.

Kirby Gate, 342.

LADIES IN THE FIELD, 383, 393.

Laertes, 124.

Lash, 173. 
Leading fore leg, 7.

Leaning back, $150,158$.

Leaping head, 33-36.

Left leg, action of, 149 .

,, swerving to the, 146 .

Legs, position of, 3 .

Leicestershire, 95, 98, 179, 196, 219, 247, 270, 31 I, 316, 319, 328, 334, $336,342,343,357,372,377,378$, $395,428,46 \mathrm{I}$.

Length of body, 472.

Level-seated saddle, $55,56$.

Life of a Foxhound, 400.

Ligament, suspensory, 467 .

Ligaments, 467 .

Light land, 367 .

Lions, 168.

Little Pedlington, 169.

Loins, 470.

Loisset, Emilie, 464 .

Long reins, 233.

Lonsdale, Lord, 98; 247.

Lord Arthur, 378.

Lord Fitzwilliams, 306.

Lucknow, 386.

Lufra, I83.

MACDOUGAL, CAPTA I N "DING," 384 .

Macklin, Mr., 385, 446, 460.

McAndrew, Mr., 387 .

Magic, 424.

Major, 244.

Mameluke bit, 390.

Manifesto, 287.

Marengo, 2 Io.

Mares, 343 . ,, , docking, 22, 23.

Martingale, running, 82-88. ", standing, 82, I6I.

"Mary Anderson," 389.

Measuring horses, 20.

Meerkat holes, 335 .

Melton cloth, 89-92.

,, Mowbray, 386, 395, 452.

Men riding, $\mathbf{I}$.

" teaching ladies, 2,4 .
Meynell, 306. ,, , Mr., 347.

Mexico, 428.

Michael Hardy, 328.

Midlands, 248.

Midland stile, 250.

Mills, Mr., 400, 405.

Milton, Mr., 386.

Modern Riding, 33 .

Mons Meg, I67.

Moore, George, 422

, , Mr. John Hubert, 82, 163.

Motee, 388 .

Mounting, I25-I34.

Mouth-piece, cover for, 77.

Mozufferpore, 387.

Mr. Bathurst's, 306.

“Mr. Gladstone," 389.

“"Mrs. Cornwallis West," 389.

“ ", Kendal," 389.

“ , Langtry," 389 .

Murray, Mrs., 384 .

Muscles, 467.

Musician, 165 .

Muzzle, 468.

My Leper Friends, 62.

NEAR HEAD, 30.

Neckties, 124.

Neil's, Jackeroo, Miss, II.

Neilgherry cane, 18.

Newcastle, Countess of, 430.

, , Duchess of, 337, 393.

New Zealand, 269.

, , horses, 457 .

"Niggling," I63.

Ninteenth Century, 23.

North Cheshire, 14, 320, 37 I.

„, , Lord, 306.

Nose, 468.

Nose-band, cavesson, 443 .

Nose-bands, 79, 87 .

Nostrils, 468.

Numdahs, 57-59.

OFF CRUTCH, 30.

Oriental women, 429 . 
Orlov trotters, 425 .

Oxer, 250.

\section{PACE, JUDGING, 374 .}

Paget, Mr. Otho, 246, 247, 308, 309, $315,325,395,396,399$.

Panel, 32, 33, 57.

Panniers, 5 .

Paperchasing, 382-386.

Paris, 392.

Pastern, 466.

Pasture land, 368.

Pat, I7.

Patent leather, I I8.

Pelhams, 78.

Pellier, M., 33.

Pelvis, 470.

Penrhyn, Lord, 247.

Pirouette renversée, 303 .

Pilots, 373.

Pith hats, I I 5.

Ploughed land, 327.

Points of the tree, 27.

Poll, 469.

Pollard willows, 338 .

Pollok, Mr. Arthur, 269.

Pommel, 27, 28.

Polo, 144, I 79.

,, ponies, I6, I7.

Posts and rails, 249.

Poultry fund, 307.

Prancing, 437.

Pretoria, I66.

Prestonpans, 244.

Pulling, 442-448.

Puppies, exercise for, 406.

,, , feeding, 398, 402.

, , judging, 396, 397 .

,, , medicine for, 404.

,, , punishing, 4I I.

Pytchley, 209, 306, 307, 357.

, pups, 399.

QUARTERS, 465.

Queen Elizabeth, 430.

Queen, The, 60, 243.
Quorn, I4, 209, 247, 306, 341.

, Friday, II 3 .

RABBIT HOLES, 335 .

Ranelagh, I83.

" Rapier," 428.

Rearers and rearing, 333, 462.

Red board, 357.

,, bows, 342-345.

,, rag, 357, 358 .

Refusers and refusing, 327,328 , 449454.

Reining back, 2 I4.

Reins, 78-82.

,, , how to hold the, 136 .

,, , jerking the, 4I9.

,, , long, 233.

,, , military way of holding, I42.

, , riding without, 233.

,, , shortening the, 142 .

Remounts, Italian, 390.

Rentz's Circus, 463 .

Richmond Show, 336.

Ridge and Furrow, 3 rg.

Riding abroad, 381.

Riding and Flunting, 51, 57, 70, 124, I36, I 80, 208, 447 .

Riding masters, I 55 .

, without reins, 233.

Right leg, action of, I 50.

,, ,, position of, I 50.

Road, rules of the, 227 .

Roberts, Mr., 246.

Romance, 8, 55 .

Rotten Row, 16, I7, 392, 393.

Running away, 23 I.

Russia, I09, I2I.

Russian cabmen, 424, 425.

,, horses, 457.

Rutland, Duke of, 306, 395.

SADDLE, CLEANING A, 69.

$$
\begin{aligned}
& , \quad \text { cloths, } 57-59 . \\
& , \quad \text { to fit rider, } 56 .
\end{aligned}
$$

Saddling a horse, 66-68.

Saddles, riding in men's, 426-430.

"Safe," 25, 32. 
Safety bars, 38-42, 231.

," skirts, 89-1 10, 23 1.

," stirrups, 42-51, 64-66.

St. Petersburg, 393.

Salary, I4, I 5.

Sample, Professor, 379.

Sandwich case, 323 .

Sanminiatelli, Count, 390.

Saunders, Mrs., 384, 385 .

Scots Grey, 82 .

" Scrutator," 343, 354, 379.

Seats of side-saddles, 32, 55 .

Seat, the, 145 .

,, , theory of the, I45-1 56.

Second horseman, 323.

," horses, 347 .

Shanghai, 231, 388.

Sheep, 368.

Shires, 8, i 2, 91, I 76, I 79, 248, 249, 250, 269, 270, 357 .

Shoulder, point of the, 468 .

Shouldering, 44I.

Shoulders, 468.

Shying, 229, 432, 433-436.

Side-saddle, weight of, 54 .

Side-saddles, 1, 2, 6, 7, 25-69.

Sideways, jumping horses, 378 .

Singapore, 388 .

" Sit back," 214.

Skirt, accustoming horse to, 18 .

", , length of, 98 .

Slipper stirrup, 42.

Snaffles, 75, 326, 438, 443, 448, 450 .

Society for the Prevention of Cruelty to Animals, 396.

Sola topee, I I 5 .

Sole of the hoof, 465 .

Soltikov, 393.

Sore backs, 7, 68, 324, 350.

South Africa, 335, 39I.

Spinal curvature, 6.

Sporting and Dramatic News, 428.

Spur, 177.

" on whip, 182.

Square seat, I 53-I 55 .

Stable Management and Exercise, 350.

Standing jump, 24r.
Standing martingale, 439.

$$
\text { ," "over," } 472 .
$$

Stapleford Park, 250.

Staples, 54.

Stake-and-bound fence, 249.

Starting, I85.

"Steady!" I69, 204.

" Steadying" horses, 223.

Steep ground, 320.

Steiger, 463.

Steinbock, coursing, 39I.

Stifle, 470.

Stirrup bar, 27.

,, , case for extra, 42.

, leather, 36-38.

, , , length of, 156 .

,, , man's, 50.

, , position of foot in, 156 . too long, I46.

Stirrups, safety, 42-51, 64-66.

Stock, 122.

Stokes, William, 428.

Stone gaps, 269.

, walls, 269.

Strangers, 327.

Stuffing of saddle, 32, 33 .

Stumbling, 436.

Subscriptions, hunt, 306.

Suffolk Punch, 387.

Suez, 388.

Surtees, 330.

Suspensory ligament, 467 .

Swimming, 462.

Syces, 424.

TAILORS, 89, I02-I05.

Talking to horses, 229, 230.

Tan, 437.

Tannoform, 35I.

Tautz, Mr., 94, I Io.

Tendo Achillis, 470.

Tendons, 467.

Terai hat, I 15 .

Terence, 384 .

Tientsin, 388, 462.

Tiergarten, 16, 392, 429.

Tips, 352. 
Tit-bits for horses, 170.

Thanks, 352.

The Young Lady's Equestrian Manual, 305.

The Wanton Mutilation of Animals, 23.

Thigh, 470, 47 I.

Third crutch, 305.

,, pommel, 305.

Thompson, Mr. Anstruther, 352.

Thong, I73.

Throat-latch, 74, 88 .

Thrush, 436, 437, 466.

Thoughts on Hunting, 315.

Throwing up the head, 438 .

Toe, 7465 .

" Tougal," Mr., 385.

Tree, points of the, 27, 29.

,, , saddle, 25, 26-3I.

Trot, rising at the, 190-194.

,, , the, 189-200, 239.

Turner, Captain, 384 .

Turning, I87.

Tushes, 86.

Tweedie, Mrs., 428.

Twitches, 4I6, 4 I 7 .

UNDER-BODICE, 122.

Under-clothing, I 12.

Upper crutch, 29.

VALE OF WHITE HORSE, 307.

Vehicles, passing, 229.

Venus de Medici, 2 I.

Veterinary Notes for Horse-owners, 22, $347,350,436$

Vizianagram, 381 .

Voice, 165, 204, 229.

Voltaire, 24.
WALERS, 2 I.

Walk, the, 185, 239.

Walker, Colonel, 424.

Walking puppies, 394-4I3.

Wall of hoof, 465 .

Wanton Mutilation of Animals, The, 23.

Ward, Mr. Frank, I75.

Ward's Riding School, 59, 60, 167, 331.

Warwickshire Hunt, 306, 307.

Washing horses' feet, 436 .

,, puppies, 402.

Watches, 323.

Watering horses, 4I 7, 4I8.

Webs, 28.

Weight of side-saddle, 54 .

Whip, hunting, 172.

Whips, 334.

Whissendine, 250.

Whiskey, 350.

"Whoa !" I 70.

Whyte Melville, I80, I8I, 209, 310, $314,315,376,420$.

Wilberforce, Archbishop, 376.

Willows, pollard, 338 .

Wintle, Mr., 231.

Wire, 250, 357-373.

, fund, 307 .

Withers, 468.

Women riding, $\mathbf{I}$.

Woodland country, 338.

Wroughton, Mr., 36r.

YELVERTOFT CHURCH, 270.

Young horses, I5, I6, I66, 433, 434, 435,443 .

ZEBRA, RIDING A, 62, 456. 


\section{List of}

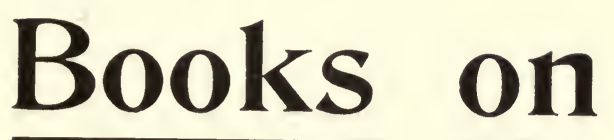

\section{Horses}

By CAPTAIN M. HORACE HAYES, F.R.C.V.S.

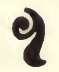

The Field. - "As trainer, owner and rider of horses on the flat and over a country, the author has had a wide experience, and when to this is added competent veterinary knowledge, it is clear that Captain Hayes is entitled to attention when he speaks." 


\section{BOOKS ON HORSES.}

\section{YETERINARY NOTES for HORSE-OWNERS.}

An Illustrated Manual of Horse Medicine and Surgery, written in simple language, with 267 Illustrations. Sixth Edition. Revised throughout, considerably enlarged, and 121 new and original Photographs added. Large crown 8vo, buckram, I5s. net.

"A necessary guide for horse-owners, especially those who are far removed from immediate professional assistance."-The Times.

"Of the many popular veterinary books which have come under our notice, this is certainly one of the most scientific and reliable."-The Field.

"This book leaves nothing to be desired on the score of lucidity and comprehensiveness." - Veterinary Journal.

"It is superfluous to commend a book that is an established success, and that has gone on from edition to edition extending its usefulness."-Army and Navy Gazette.

\section{POINTS OF THE HORSE. A Familiar Treatise}

\section{on Equine Conformation. Third Edition in the Press.}

"Oapt. Horace Hayes, the best of writers upon horses, has issued a second editionconsiderably altered and enlarged, and magnificently illustrated - of his admirable work upon the 'Points of the Horse,' which is, in fact, a complete work on horses, their races and peculiarities."-Athenoum.

"The intrinsic value of the book and the high professional reputation of the author should ensure this new edition a cordial welcome from sportsmen and all lovers of the horse."-The Times.

RIDING AND HUNTING. Fully Illustrated with upwards of 250 Reproductions of Photographs and Drawings. In I vol., demy 8vo, cloth. Price I6s. net.

"Capt. Hayes has produced a book which cannot fail to interest, if not to instruct the experienced horseman, and the beginner may learn from its pages practically all that it is necessary for him to know."-The World.

"We can imagine no more suitable present for one who is learning to ride than this book."-Pall Mall Gazette.

" $\mathrm{He}$ is no doubt the greatest authority, both on horses and horsemans hip, now living in this country. Everything which he writes is lncidly expressed, and no detail is too trivial to be explained."-The Spectator.

\section{THE HORSEWOMAN. A Practical Guide to Side-}

Saddle Riding. By Mrs. Hayes. Edited by Capt. M. H. Hayes.

Second Edition, re-written, enlarged, and with about 150 new and original Photographic Illustrations added. I vol., demy 8 vo. I I2s. net.

"This is the first occasion on which a practical horseman and a practical horsewoman have collaborated in bringing out a book on riding for ladies. The result is in every way satisfactory, and, no matter how well a lady may ride, she will gain much valuable information from a perusal of "The Horsewoman." -Field.

"A large amount of sound, practical instruction, very judiciously and pleasantly imparted."-The Times.

"We have seldom come across a brighter book than "The Horsewoman." -The Athenceum.

"With a very strong recommendation of this book as far and away the best guide to side-saddle riding we have seen."-Saturday Review. 


\section{STÁLLE MANAGEMENT AND EXERCISE}

A Book for. Horse-Owners and Students. Illustratea by numerous Reproductions of Photographs taken specially for this work. In I vol., demy 8 vo. Price I 2 s. net.

"Capt. Hayes, who may justly claim to be the first authority now living on all matters connected with the horse, is always welcome, and the more so because each successive volume is a monument of 'the reason why.' "-The County Gentleman.

"Eminently practical."-The Field.

"The work of an exceptionally competent authority, who thoroughly understands his subject, and is able to make the results of his practical knowiedge clear to readers."Badminton Magazine.

\section{ILLUSTRATED HORSEBREAKING. Second}

and Cheaper Edition. Large crown 8vo. Price I2s. net.

This Edition has been entirely rewritten, the amount of the letterpress more than doubled, and 75 reproductions of Photographs have been added.

"It is a characteristic of all Captain Hayes' books on horses that they are eminently practical, and the present one is no exception to the rule. A work which is entitied to high praise as being far and away the best reasoned-out one on breaking under a new system we have seen."-The Field.

"The work is eminently practical and reliable."-Veterinary Journal.

\section{HORSES ON BOARD SHIP. A Guide to their}

Management. By M. H. HAyes. In I vol., crown 8vo, with numerous Illustrations from Photographs taken by the Author during two voyages to South Africa with horses. Price 3s. 6d. net.

“The book altogether is like the rest of Captain Hayes' works, written on sound, practical lines, and is all the more welcome in that it deals with a subject on which we have yet a great deal to learn."-The Field.

"As he has had two voyages to South Africa in charge of large consignments, his experience is eminently practical, and his book contains much valuable information, and ought to enable the War Office to avoid in the future some of the errors of the past." -Morning Post.

"We are sure that the book will be found useful and instructive to those who are new to the work of conveying either large or small numbers of horses across the seas."County Gentleman.

\section{TRAINING AND HORSE MANAGEMENT IN}

\section{INDIA. Fifth Edition. Crown 8vo, cloth, 6s.}

"We entertain a very high opinion of Capt. Hayes' book on 'Horse Training and Management in India,' and are of opinion that no better guide could be placed in the hands of either amateur horseman or veterinary surgeon newly arrived in that important division of our Empire."-Veterinary Journal.

\section{INFECTIYE DISEASES OF ANIMALS. Being}

Part I. of the Translation of Friedberger and Froehner's Pathology of the Domestic Animals. Translated and Edited by the Author. With a Chapter on Bacteriology by Dr. G. Newman, D.P.H. Demy 8vo, IOs. 6 d. net.

"Whether considered as a work of reference for bnsy practitioners, as a text-book for students, or as a treatise on pathology in its widest significance, this rolume meets every requirement, and is an invaluabie addition to our literature."-Veterinary Record. 
AMONG HORSES IN RUSSIA. With 53 Illustrations from Photographs taken chiefly by the Author. In I vol., large crown 8vo. Price IOs. 6d. net.

"The book is exceedingly well written and illustrated."-Graphic.

"The author has made an exceedingly entertaining book of his experiences."-Baily's Magazine.

\section{AMONG HORSES IN SOUTH AFRICA. In}

I vol., crown 8vo. Price 5s.

.Capt. Hayes' book is genuinely interesting, and fully repays reading."-Black and White.

"The book is very readable."-Spectator.

"The book is written in a pleasant, chatty style, and with a broad mind."-Sportsman

\section{MODERN POLO. By Captain E. D. Miller, late}

I 7 th Lancers. Edited by Captain M. H. Hayes. Second Edition, revised and enlarged. In one vol., demy 8vo., with numerous Illustrations from Photographs and Drawings. Price I6s. net.

"Both in the matter of polo-playing and in that of choosing or breeding polo ponies, the volume is a certain authority."-The Times.

"'Modern Polo, written by F. D. Miller and edited by Capt. M. H. Hayes, will assuredly become the authoritative work concerning the game, which is rapidly growing in favour in this country. It is clear and bright in style, and it is provided with numerous illnstrations from photographs,"-Black and White.

"Mr. Miller's is by no means the only work upon the Game of Polo, but it is, at least. the most complete and comprehensive work upon the subject that has yet been issued. It has had the benefit, too, of the editorship of Capt. M. H. Hayes, one of the best authorities of the day in regard to all matters connected with horsemanship. To Capt. Bajes are also due the excellent photographs by which the book is illustrated, showing almost every turn and stroke in a rather complicated game."-Graphic. 



RETURN TO the circulation desk of any

University of California Library

or to the

NORTHERN REGIONAL LIBRARY FACILITY

Bldg. 400, Richmond Field Station

University of California

Richmond, CA 94804-4698

ALL BOOKS MAY BE RECALLED AFTER 7 DAYS

2-month loans may be renewed by calling

(415) 642-6233

1 -year loans may be recharged by bringing books to NRLF

Renewals and recharges may be made 4 days prior to due date

DUE AS STAMPED BELOW

\section{DEC 251989}

NOV 161989 \&EC']

RECEIVED 301995

AUG 151995

CRCULATION DEPT.

\section{MAY 082001}


IL CU⿺2

\section{U. C. BERKELEY LIBRARIES}

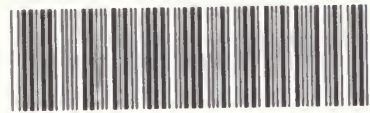

ㅁ47131552

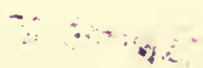


